\title{
The Interpretation of it-Clefts
}

Dissertation zur

Erlangung des philosophischen Doktorgrades an der

Philosophischen Fakultät der

Georg-August-Universität Göttingen

vorgelegt von

Anna-Christina Pavlović

aus Xanten

Göttingen 2019 


\section{Acknowledgments}

Firstly, I would like to express my sincere gratitude to my supervisor Edgar Onea for his constant professional and personal support throughout my studies, for his patience, motivation, and immense knowledge. I would also like to thank my second advisor Malte Zimmermann for his insightful comments and encouragement, but also for the hard questions which encouraged me to widen my research from various perspectives. I would further like to express my thanks to the members and associates of the XPrag.de ExCl-team for enlightening discussions and valuable comments. My sincere thanks also go to Katalin É Kiss and Balázs Surányi, as well as their teams, who welcomed me to join their research groups at the Research Institute for Linguistics of the Hungarian Academy of Sciences in Budapest, and who gave me access to their excellent research facilities. Without their precious support it would not have been possible to conduct this research. Very special gratitude goes out to the GSGG for helping with the funding for research trips and summer schools. I also want to thank all my participants for contributing in such a fundamental way to my research. Finally, I thank my parents Christa and Jürgen, and my sister Marie for always believing in me, even when I could not. Without their support and encouragement, I would have never made it here. I also want to thank my dear friend Jana for the support and advice. And, of course, I thank Edi for being my anchor and the wind in my sails, and Lana for showing me what really counts in life. 


\section{Abstract}

This dissertation addresses the interpretation of it-clefts in German, as well as that of the related focus structure of Hungarian pre-verbal focus, and presents novel answers to several research gaps. It-clefts are sentences of the form It was Sue who climbed a mountain. One of the most debated questions is whether or not this sentence structure comes with an exhaustivity inference of the form Nobody other than Sue climbed a mountain, and, if it does, whether the exhaustivity is part of the semantic structure of the it-cleft, or a pragmatic inference. This thesis presents the results of a corpus study for German which, in addition to experiments designed based on the naturally occurring corpus data, show that German it-clefts can be exhaustive, but they are not exhaustive in every case. Whether or not it-clefts receive an exhaustive reading depends largely on the context. This assumption is confirmed by a production study, which suggests that, when producing it-clefts in semi-spontaneous written dialog-situations, speakers prefer it-clefts in contexts that are exhaustive and/or contrastive. In acceptability ratings, speakers do not reject it-clefts in non-exhaustive environments. It seems that it-clefts are likely to be used and interpreted to express some kind of exhaustivity. However, the data do not support a semantic analysis of this exhaustivity inference. It-clefts are not a unified class of sentences. There are (at least) two different kinds of itclefts, namely Focus-Background and Topic-Comment Clefts, which serve different information structural purposes and differ in terms of their exhaustivity. This thesis presents experimental results for German which show that the two cleft types actually vary slightly regarding their exhaustivity judgments: TC-clefts seem to be a little less frequently exhaustive than FB-clefts. This thesis further shows that, contrary to previous theoretical assumptions, it-clefts are combinable with a large variety of focus particles, both exclusive (only) and non-exclusive (e.g. also), which can have an influence on the exhaustivity of the cleft structure. As for the case of Hungarian pre-verbal focus, this dissertation shows that this sentence structure did not show the strong exhaustivity that is frequently attributed to it. Therefore, the data support the more recent presuppositional analysis of the exhaustivity inference of Hungarian pre-verbal focus. 


\section{Contents}

1 Introduction 1

1.1 Introduction . . . . . . . . . . . . . . . . . . 1

1.2 Research Questions . . . . . . . . . . . . . . . . . . 7

1.3 Research Methods . . . . . . . . . . . . . . . . . . . . . . . 9

1.3.1 Corpus Data. . . . . . . . . . . . . . . 9

1.3.2 Judgment Experiments . . . . . . . . . . . . . . . . . . . . . 9

1.3.3 Production Experiments . . . . . . . . . . . . . . . 10

1.4 Outline of the thesis . . . . . . . . . . . . . . 11

1.4.1 State of the Art . . . . . . . . . . . . . . . 11

1.4.2 It-Cleft Exhaustivity and Focus Particles . . . . . . . . . . 11

1.4.3 Exhaustivity and the Question Under Discussion . . . . . . 12

1.4.4 It-Cleft Exhaustivity and Contrast . . . . . . . . . . . . 14

2 State of the Art 15

2.1 Introduction . . . . . . . . . . . . . . . . . . . . . . . . . . . 15

2.2 The Syntax of it-Clefts . . . . . . . . . . . . . . . 16

2.2 .1 Expletive Analysis . . . . . . . . . . . . . . . . . 17

2.2 .2 Extraposition Analysis . . . . . . . . . . . . . . . . 20

2.2 .3 Summary . . . . . . . . . . . . . . . . . . . . . 24

2.3 The Semantics of it-Clefts . . . . . . . . . . . . . . . 25

2.3.1 Background: The Notions of Focus and Topic . . . . . . . . 26

2.3.2 It-Cleft Exhaustivity . . . . . . . . . . . . . . . 34

2.3 .3 Summary . . . . . . . . . . . . . . . 57

2.3.4 Exhaustivity and the Question Under Discussion . . . . . . 59

2.3 .5 Summary . . . . . . . . . . . . . . . . 65

2.3.6 It-Cleft Exhaustivity and Focus Particles . . . . . . . . . . . 67

2.3.7 Summary . . . . . . . . . . . . . . . . 73

2.3.8 It-Cleft Exhaustivity and Contrast . . . . . . . . . . . 73

2.3 .9 Summary . . . . . . . . . . . . . . . 76 
3 It-Cleft Exhaustivity \& Focus Particles $\quad 79$

3.1 Introduction . . . . . . . . . . . . . . . . . . . . . . . 79

3.2 Background . . . . . . . . . . . . . . . . . . . . . . . 80

3.3 Corpus Study . . . . . . . . . . . . . . . . . . . . 85

3.3 .1 Introduction . . . . . . . . . . . . . . . . 85

3.3.2 Method and Objectives . . . . . . . . . . . . . . . 89

3.3 .3 Annotation . . . . . . . . . . . . . . . . . . 91

3.3.4 Analysis . . . . . . . . . . . . . . . 106

3.3.5 Discussion . . . . . . . . . . . . . . . . . . . . . 111

3.4 Judgment Experiment . . . . . . . . . . . . . . . . . . . . . . 114

3.4.1 Method and Design . . . . . . . . . . . . . . . . . 114

3.4.2 Results and Discussion . . . . . . . . . . . . . . 116

3.4 .3 Conclusion . . . . . . . . . . . . . . . . . . . . . . 118

3.5 The Scope of Focus Particles: Two Experiments . . . . . . . . . . . 119

3.5.1 Objectives . . . . . . . . . . . . . . . . . 119

3.5.2 Pilot-Study . . . . . . . . . . . . . . . . . . . . 120

3.5.3 Follow-Up . . . . . . . . . . . . . . . . . . . . . . . . . . . 129

3.5.4 Summary . . . . . . . . . . . . . . . . . . . . 132

3.6 Focus Particles and Exhaustivity: Conclusion . . . . . . . . . . 133

4 Exhaustivity \& the QUD 135

4.1 Introduction . . . . . . . . . . . . . . . . . . 135

4.2 Background . . . . . . . . . . . . . . . . . . . 135

4.2.1 Focus-Background and Topic-Comment structures in it-clefts 140

4.2.2 Hungarian pre-verbal Focus . . . . . . . . . . . . . . . 143

4.3 Experimental Study . . . . . . . . . . . . . . . . . . . . . . . 147

4.3.1 Method and Design . . . . . . . . . . . . . . . 147

4.4 Participants . . . . . . . . . . . . . . . . . . . . 151

4.5 Predictions . . . . . . . . . . . . . . . . . . . 151

4.6 Results . . . . . . . . . . . . . . . . . . . . . . . . 152

4.6.1 ExpC Hungarian: The Role of Context on Exhaustivity . . . 152

4.6.2 ExpP Hungarian: The Role of Focus Particles on Exhaustivity 156

4.6.3 ExpC German: The Role of Context on Exhaustivity . . . . 160

4.6.4 ExpP German: The Role of Focus Particles on Exhaustivity 163

4.7 Discussion . . . . . . . . . . . . . . . . . . . . . . 166

4.7.1 Hungarian . . . . . . . . . . . . . . . . . 167

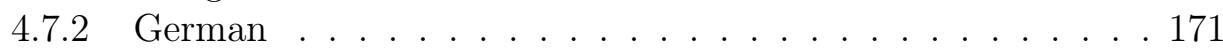

4.7.3 Acceptability Study of German Items . . . . . . . . . . . . . 175

4.8 Conclusion . . . . . . . . . . . . . . . . . . . . . . . . . . . . . 182 
5 It-Cleft Exhaustivity \& Contrast 184

5.1 Introduction . . . . . . . . . . . . . . . . . . . . 184

5.2 Background . . . . . . . . . . . . . . . . . . 185

5.2.1 Alternatives and Contrast . . . . . . . . . . . 186

5.2.2 Contrastive Discourse Relations . . . . . . . . . . . . . . 187

5.3 Pilot study on free production . . . . . . . . . . . . . . . . . . . 192

5.3.1 Method and Design . . . . . . . . . . . . . . . . 192

5.3 .2 Predictions . . . . . . . . . . . . . . . . . . 193

5.3 .3 Results . . . . . . . . . . . . . . . . . . . . 195

5.3 .4 Discussion . . . . . . . . . . . . . . . . . . . 197

5.4 Follow-Up Production Study . . . . . . . . . . . . . . . . . . . . 197

5.4.1 Method and Design . . . . . . . . . . . . . . . . . . . 198

5.4 .2 Results. . . . . . . . . . . . . . . . . . . . . 198

5.4 .3 Discussion . . . . . . . . . . . . . . . . . . . . 200

5.5 Conclusion . . . . . . . . . . . . . . . . . . . . 202

6 Conclusion 205

6.1 The main questions . . . . . . . . . . . . . . . . 205

6.2 It-Cleft Exhaustivity and Focus Particles . . . . . . . . . . . . . 206

6.3 Exhaustivity and the QUD: Hungarian pre-verbal Focus . . . . . . 209

6.4 Exhaustivity and the QUD: German it-clefts . . . . . . . . . . . . . 210

6.5 It-Cleft Exhaustivity and Contrast . . . . . . . . . . . . . . . . . 211

6.6 What did we learn about it-clefts? . . . . . . . . . . . . . . . . 212

$\begin{array}{llr}7 & \text { Appendix: Stimulus Materials } & 227\end{array}$

7.1 Chapter $3 \ldots \ldots$. . . . . . . . . . . . . . . . . . . . 227

7.1.1 Scope of Focus Particles . . . . . . . . . . . . . . . 227

7.1.2 Judgment Experiment . . . . . . . . . . . . . . . . . . 237

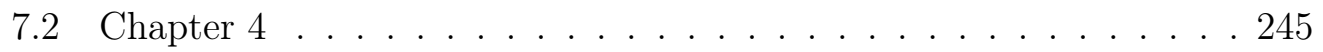

7.2 .1 Experiment $1 \ldots \ldots \ldots . \ldots . \ldots . \ldots . \ldots 245$

7.2 .2 German Stimuli . . . . . . . . . . . . . . . . . . 246

7.2 .3 Hungarian Stimuli . . . . . . . . . . . . . . . . . . . . 249

7.2.4 Follow-Up Acceptability Study German . . . . . . . . . . . . 251

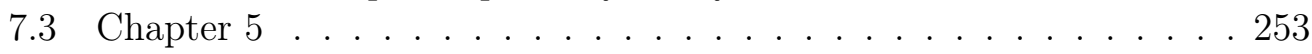

7.3.1 Free Production Pilot Study . . . . . . . . . . . . 253 


\section{List of Figures}

3.1 Example Annotation auch/also . . . . . . . . . . . . . . . . . . 92

3.2 Example Annotation nur/only . . . . . . . . . . . . . . . . . . 93

3.3 Distribution of focus particle per cleft type . . . . . . . . . . 107

3.4 Distribution of exhaustivity across cleft types . . . . . . . . . 108

3.5 Distribution of exhaustivity across cleft types: clefts without particles108

3.6 Distribution of exhaustivity among clefts with nur/only . . . . . . . 109

3.7 Distribution of exhaustivity among clefts with vor allem/especially 109

3.8 Distribution of exhaustivity among clefts with auch/also . . . . . . 110

3.9 Distribution of exhaustivity among clefts with nicht zuletzt/not least 110

3.10 Distribution of pre-mentioned particles among one exhaustive and non-exhaustive particle . . . . . . . . . . . . . . . 111

3.11 Mean results per focus particle and sentence type (cleft/canonical) . 117

3.12 Mean acceptability ratings of target sentences (all conditions, rounded) 117

3.13 Question 1 Is the sentence acceptable? Total number of judgments . 125

3.14 Question 1 Is the sentence acceptable? Total distribution: $77 \%$ yes, $23 \%$ no . . . . . . . . . . . . . . . . . . . 126

3.15 Question 2 What is the sentence about? Total number of judgments 127

3.16 Question 2 What is the sentence about? Total distribution: 41\% pivot, $59 \%$ cleft relative . . . . . . . . . . . . . . 127

3.17 Question 3 What follows from the sentence? Total number of judgments . . . . . . . . . . . . . . . . . . . . . . 128

3.18 Question 3 What follows from the sentence? Total distribution: $73 \%$ pivot non-exh, $27 \%$ cleft relative non-exh . . . . . . . . 128

3.19 Question 1 Is the sentence acceptable? Total distribution: 83\% yes, $17 \%$ no . . . . . . . . . . . . . . . . . . 130

3.20 Question 2 What is the sentence about?: Total number of judgments per answer-option pivot/relative . . . . . . . . . . . . . . 131

3.21 Question 3 What follows from the sentence?: Total number of judgments per answer-option pivot/relative . . . . . . . . . . . . 132

4.1 Experiment Context . . . . . . . . . . . . . . . 150 
4.2 Experiment Particle . . . . . . . . . . . . . . . . . . . 150

4.3 Exhaustive picture condition . . . . . . . . . . . . . . 151

4.4 Non-exhaustive picture condition . . . . . . . . . . . . . . . 151

4.5 Q-A-pair: Who is wearing a cape? - The dog is wearing a cape. . . . 153

4.6 Q-A-pair: What do you know about the dog? - The dog is wearing a cape. . . . . . . . . . . . . . . . . . 153

4.7 Average results postverbal structure . . . . . . . . . . . . . . 154

4.8 Average results preverbal focus . . . . . . . . . . . . . . . . . 154

4.9 Q-A-pair: Who is wearing a cape? - It is the dog who is wearing a cape. . . . . . . . . . . . . . . . . . . . . . . 155

4.10 Q-A-pair: What do you know about the dog? - It is the dog who is wearing a cape. . . . . . . . . . . . . . . . . . . 155

4.11 Also the dog is wearing a cape. . . . . . . . . . . . . . . . . . 156

4.12 The dog is wearing a cape. . . . . . . . . . . . . . . . . . . . 157

4.13 It is also the dog who is wearing a cape. . . . . . . . . . . . . . . . . 157

4.14 It is the dog who is wearing a cape. . . . . . . . . . . . . . . . . . . 158

4.15 Average judgments pre-verbal focus . . . . . . . . . . . . . 158

4.16 Average judgments postverbal structure . . . . . . . . . . . . . . . . 159

4.17 Q-A-pair: Who is wearing a cape? - The dog is wearing a cape. . . . 160

4.18 Q-A-pair: What do you know about the dog? - The dog is wearing a cape. . . . . . . . . . . . . . . . . . . 160

4.19 Q-A-pair: Who is wearing a cape? - It is the dog who is wearing a cape. . . . . . . . . . . . . . . . . . 161

4.20 Q-A-pair: What do you know about the dog? - It is the dog who is wearing a cape. . . . . . . . . . . . . . . . . . . . 161

4.21 Average judgments cleft structure . . . . . . . . . . . . . . . 162

4.22 Average judgments canonical structure . . . . . . . . . . . . . 162

4.23 Also the dog is wearing a cape. . . . . . . . . . . . . . . . . . 163

4.24 The dog is wearing a cape. . . . . . . . . . . . . . . . . . . . . . . . 164

4.25 It is also the dog who is wearing a cape. . . . . . . . . . . . . . . . . 164

4.26 It is the dog who is wearing a cape. . . . . . . . . . . . . . . . 165

4.27 Average judgments cleft structure with particle . . . . . . . . . . 165

4.28 Average judgments canonical structure with particle . . . . . . . . . 166

4.29 Means (median) of judgments for control condition (Hungarian) . . 167

4.30 Means (median) of judgments for control condition (German) . . . 167

4.31 It is the dog who is wearing a cape. . . . . . . . . . . . . . . . . . 167

4.32 Q-A-pair: Who is wearing a cape? - It is the dog who is wearing a cape. . . . . . . . . . . . . . . . . . . . . 168

4.33 Q-A-pair: What do you know about the dog? - It is the dog who is wearing a cape. . . . . . . . . . . . . . . . 169 
4.34 It is also the dog who is wearing a cape. . . . . . . . . . . . . . . . 170

4.35 It is the dog who is wearing a cape. . . . . . . . . . . . . . . . . . . 171

4.36 Q-A-pair: Who is wearing a cape? - It is the dog who is wearing a cape. . . . . . . . . . . . . . . . . . . . . 172

4.37 Q-A-pair: What do you know about the dog? - It is the dog who is wearing a cape. . . . . . . . . . . . . . . . . . . . . . . . . . 172

4.38 It is also the dog who is wearing a cape. . . . . . . . . . . . . . . . 173

4.39 It is the dog who is wearing a cape. . . . . . . . . . . . . . . . . . . 174

4.40 Average ratings over all conditions . . . . . . . . . . . . . . . . . . . 177

4.41 Average acceptability across conditions. . . . . . . . . . . . . . . . . 178

4.42 Average acceptability of question-answer-pairs with both answer types including also . . . . . . . . . . . . . . 180

5.1 Total numbers of produced it-clefts per condition in the pilot study 195

5.2 Raw data counts: it-clefts produced in the pilot study . . . . . . . . 195

5.3 Raw data counts: it-clefts produced in all conditions pilot study . . 197

5.4 Total numbers of produced it-clefts per condition in the follow-up study . . . . . . . . . . . . . . . . . . . . . . . . 199

5.5 Raw data counts follow-up study . . . . . . . . . . . . . . . 199

5.6 Relative Distribution of it-clefts and other sentence types produced in the pilot study . . . . . . . . . . . . . . . . . . . 201

5.7 Relative Distribution of it-clefts and other sentence types produced in the follow-up . . . . . . . . . . . . . . . . . . 201 


\section{Chapter 1}

\section{Introduction}

\subsection{Introduction}

This dissertation addresses the interpretation of it-clefts in German, as well as preverbal focus, a related focus structure in Hungarian, and presents novel answers to a number of research gaps that have not been conclusively answered yet. This dissertation aims to find new insights into the interpretation of the it-cleft sentence structure (es-clefts in German). It-clefts (or clefts, for short), are sentences that have a specific syntactic structure, and have been argued to have specific semantic restrictions, something that will be addressed later. This dissertation follows the initial definition of clefts put forward by Lambrecht (2001):

(1) A cleft construction is a complex sentence structure consisting of a matrix clause headed by a copula and a relative or relative-like clause whose relativized argument is coindexed with the predicative argument of the copula. (Lambrecht (2001), 467)

This dissertation is restricting the cases of clefts to structures that include the German copula es, which is equivalent to the English is. The cases included here are of the general form illustrated in (2):

$\left[[E s][\text { copula] [cleft pivot] }]_{\text {MatrixClause }}[\text { [relative pronoun] [predicate] }]_{\text {RelClause }}\right.$

What is described as it-clefts in this dissertation are sentence constructions that consist of a cleft pronoun (es in German), a copula, a focused element that is referred to as the cleft pivot, and a relative clause that is called cleft relative.

A copula is understood to be 
(3) an intransitivity verb that connects a subject to a noun phrase, adjective, or other kind of constituent which expresses the predicate (see e.g. Hartmann and Stork (1972), Quirk et al. (1985)).

A copula clause can be described as

(4) a minor sentence type in which the contentful predicate is not a verb, but some other category like AP, NP or PP. (Mikkelsen (2011)) ${ }^{1}$.

Copula clauses can be predicational (The hat is big./ The hat I bought for Harvey is big./ What I bought for Harvey is big.), specificational ( The director of Anatomy of a Murder is Otto Preminger. / The only person I met was Otto Preminger.), identificational (That (woman) is Sylvia.), or euqative (Sylvia Obernauer is HER./ Cicero is Tully.)(Mikkelsen (2011)).

Clefts express a simple proposition via a bi-clausal syntax. The syntactically unmarked, non-clefted version of the cleft will be referred to as canonical sentence (or canonical for short) in the following. Other than it-clefts, we can distinguish the so-called Pseudo-clefts (also referred to as WH-clefts, see e.g. Lambrecht (2001)) and Reverse Pseudo-clefts. The different sentence types are illustrated in the examples below:

(5) $[\mathrm{Sue}]_{F}$ climbed a mountain. (Canonical sentence)

Focus + clause

(6) It was $[\mathrm{Sue}]_{F}$ who climbed a mountain. (It-cleft) placeholder-it + copula + cleft pivot + relative pronoun + predicate

(7) Who climbed a mountain was $[\mathrm{Sue}]_{F}$. (Pseudo-cleft) Wh-relative + clause with copula + Focus

(8) $[\mathrm{Sue}]_{F}$ is the one who climbed a mountain. (Reverse Pseudo-cleft) Focus + copula + wh-relative clause

Note that all cleft types in the examples above are copular clauses. Only the nonclefted, syntactically unmarked version is not. Within the class of pseudo-clefts, we can further distinguish predicational (What Sue climbed was a mountain.) and specificational (Who climbed a mountain was Sue.) pseudo-clefts (see Mikkelsen (2011)). There are a number of restrictions on specificational pseudo-clefts that do

\footnotetext{
${ }^{1}$ It is important to note that there is a vast amount of cross-linguistic variation in the form and properties of copular clauses, and that some of the most important work on copular clauses has been published on languages other than English. However, since the majority of work on clefts is centered on the English it-cleft and this thesis uses the relevant terminology which refers to the English cleft, the definition of the copular clause will also be based on the English language.
} 
not hold for predicational pseudo-clefts: the focused element cannot be extracted or deleted, there is no movement allowed out of the post-copular element, the copula must be finite, tense agreement between copula and verb in the wh-clause is required, sentential adverbials are not allowed, to name just a few (for a complete list see Mikkelsen (2011), 1811). The so-called reversed pseudo-clefts, as in example (8) above, have been argued to form a special subtype of the specificational clause, as the syntactic derivations that lead to pseudo-clefts and reverse pseudo-clefts are not the same (see den Dikken et al. (2000) for complete discussion).

Another type of copular clauses that - at first sight - looks a lot like an it-clefts are sentences of the form in (9):

a. It is Joe Smith/the Mayor of Cambridge who is standing over there.

b. It is Boston that we see underneath us. (Mikkelsen (2011), 1812)

These have been called Truncated Clefts (see Hedberg (2000), 898), as they are superficially similar to it-clefts, with the crucial exception that the pronoun it is the subject of the sentence. As the it is referential in these truncated clefts, they do not meet the requirements for it-clefts where the it merely has a placeholder function but is not referential.

The position of the copula verb is can be filled with a variation of verbs that are capable of losing their lexical meaning as part of the cleft, such as verbs like be or have in English (see Lambrecht (2001)). ${ }^{2}$ For languages other than English and German, a broader variety of clefted constructions have been described. In French, for example, the predicator voilà / there is can be used (as illustrated in examples (10)-(11) below). In other languages, the position of the copula can also be filled with a bound morpheme (see examples (12)-(13) below) (see Lambrecht (2001)).

French:

(10) a. Voici / Il y a [quarante ans] (que la FDA a autorisé la pilule contraceptive).

It's been [forty years] (since the FDA authorized the birthcontrol pill).

b. La FDA a autorisé la pilule contraceptive voici / il y a quarante ans.

Forty years ago the FDA authorized the birth-control pill. (Lambrecht (2001), 500)

(11) a. Voilà [mon prof ] [qui arrive].

Here comes my professor.

b. Figurez-vous, Monsieur, qu'ils n'étaient pas mariés un an, paf! voilà

[la femme] [qui part en Espagne avec un marchand de chocolat] (Daudet).

\footnotetext{
${ }^{2}$ This thesis will however focus on such cases of (German) it-clefts with the copula verb is, as illustrated in (2) above.
} 
Can you imagine, Monsieur, they hadn't even been married a year and bang! the wife runs off to Spain with a guy who sells chocolate. (Lambrecht (2001), 509)

Mandarin, tone marking omitted:

a. Yôu [ren] [gei ni da-dianhua]. have person to you hit-telephone Someone called you. (Lambrecht (2001), 509)

Boni:

[moróor]-a, [hiléekée ki-d’ifidi ]

elephant-COP friend-my LOC-hit

An elephant hit my friend. (Lambrecht (2001), 510)

The is/es is assumed to be semantically empty in clefts (however, this view has been challenged from a syntactic point of view. For a more detailed discussion, see chapter 2 of this dissertation). The notion semantically empty is related to the theory of meaning used in this thesis. When speaking about semantics, this thesis refers to the natural language semantics is which the meaning of any kind of natural language expression is referential (as opposed to the pragmatics of a given natural language expression, which is concerned with the use of the expression). Apart from being referential, the semantic theory referred to in this thesis is also truth-conditional, which means that every natural language expression is either true or false, relative to a world (commonly the world we live in), or some other model of reality. To know when a natural language expression is true or false is the same as knowing the truth-conditions of that expression (see Speaks (2017) for detailed discussion). When arguing that an expression is semantically empty, Lambrecht (2001) says that this expression does not have a truth-value and is neither determinable as true or false. In a truth-conditional theory of semantics, this means that the given expression does not add any value to the truth-conditional meaning of the overall expression. The specific structure of the it-cleft syntactically requires the $i t$, but the pronoun itself is merely expletive and does not refer. As Lambrecht (2001) notes, this does not mean that it completely loses all meaning, just that it does not contribute any meaning to the overall meaning of the cleft sentence.

One of the most debated questions regarding it-clefts is whether or not this sentence structure comes with an exhaustivity inference. Example (14) shows the it-cleft structure, consisting of the separate parts introduced above. The sentence in example (15) illustrates the so-called exhaustivity inference. It is the inference 
that the cleft in (14) not only expresses that Sue climbed a mountain, but also that Sue was the only (contextually relevant) individual to have climbed a mountain. Therefore, Sue is the individual in the contextually relevant domain to exhaustively identify the sum of individuals who climbed a mountain (see Büring and Križ (2013)).

$$
\begin{aligned}
& \text { It was }[\mathrm{Sue}]_{F} \text { who climbed a mountain. (Cleft Sentence) } \\
& \text { Nobody other than Sue climbed a mountain. (Exhaustivity Inference) }
\end{aligned}
$$

This exhaustivity inference can also be found in sentences that express exhaustivity overtly, e.g. through an exclusive, as illustrated in (16).

Only $[\mathrm{Sue}]_{F}$ climbed a mountain. (Exclusive)

In sentences that express the exhaustivity via an exclusive, the exhaustivity is part of the asserted content of the sentence (see e.g. Horn (1981), Büring and Križ (2013)). This is not necessarily also the case for it-clefts, which becomes apparent when the exhaustivity inference is negated, as shown in (17).

a. \# She invited Fred, but it wasn't Fred she invited.

b. She invited Fred, but she didn't invite only Fred. (Büring and Križ (2013), ex. (4))

The cancellation in (17)b is felicitous, as the asserted contrast makes sense. This meaning, however, is not felicitously conveyed in (17)a.

It has not yet been conclusively answered how this exhaustivity inference is derived: as part of the semantic meaning of the structure (see e.g. Büring and Križ (2013)), or pragmatically, e.g. via a conversational implicature (see e.g. Krifka (2008)).

At this point it needs to be pointed out that this thesis assumes a binary distinction of semantic and pragmatic approaches to it-cleft exhaustivity, which is not completely in line with the most recent research developments. At this point, there are further alternatives. However, when this thesis was written, this dichotomy was still commonly used and will be assumed for this thesis.

The notion of pragmatics describes the theory of the intentional use of natural language expressions by speakers in situations. A conversational implicature is understood in terms of Grice (1975) as a non-conventional implicature. The theory of conversation presented by Grice (1975) distinguishes what a speaker says (the literal content of the utterance), and what she implicates by uttering a sen- 
tence. Implicatures are further distinguished into conventional and conversational implicatures. Conventional implicatures are part of the meaning of the uttered sentence, rather than being derived from principles of language use. All implicatures, however, are not part of the truth-conditional meaning of the expression (see e.g. Korta and Perry (2015) and Davis (2014) for further discussion).

An addressee can generally assume that a speaker is following the conversational maxims (of Quantity, Quality, Relation, and Manner) or at least the Cooperative Principle, which states that an utterance should be "such as is required, at the stage at which it occurs, by the accepted purpose or direction of the talk exchange in which you are engaged" (Grice (1975), 45). Therefore, when a speaker utters a sentence, the addressee applies the following reasoning to interpret the utterance:

(18) He has said that p; there is no reason to suppose that he is not observing the maxims, or at least the $\mathrm{CP}$; he could not be doing this unless he thought that q; he knows (and knows that I know that he knows) that I can see that the supposition that he thinks that $q$ is required; he has done nothing to stop me thinking that q; he intends me to think, or is at least willing to allow me to think, that q; and so he has implicated that q. (Grice (1975), 50)

Conversational Implicatures are further characterized as cancellable, non-detachable, and calculable.

Even within the two opposing camps of semantic and pragmatic approaches to the exhaustivity of it-clefts, the way that the semantic or pragmatic inference is reached still varies, which has lead to a large number of theoretical and experimental approaches to investigate it-cleft exhaustivity. This dissertation will provide an introduction to the discussion of it-cleft exhaustivity in chapter 2 .

Apart from the issue of exhaustivity, a number of other questions have been raised regarding the semantic properties of the cleft structure, for example:

1. If it-clefts come with a hard-wired exhaustivity inference as part of their semantics, then this would lead to certain restrictions, e.g. regarding nonexclusive focus particles, whose non-exhaustive meaning could cancel the exhaustivity of the cleft and make the sentence ungrammatical. How can natural language examples of that kind be explained?

2. On the other hand, if the exhaustivity inference is not actually part of the truth-conditional meaning of the structure, but the result of a pragmatic 
process, can it be determined what influences the exhaustivity of it-clefts, and which role the context plays in this regard?

3. When thinking about it-clefts and possibly looking at naturally occurring examples of this structure, do we find ourselves presented with a homogeneous group, or can we possibly distinguish different types of it-clefts? And if so, do these different cleft types behave differently regarding exhaustivity?

4. Given that the notions of contrast and exhaustivity are closely linked to each other, and exhaustivity is a key feature in it-cleft interpretation, then what can be said about the role of contrast regarding it-clefts? If clefts are exhaustive, are they also contrastive in every case, or is it possible to keep these two concepts separate?

These considerations lead to the following research questions, which are addressed in this dissertation.

\section{$1.2 \quad$ Research Questions}

This dissertation aims to shed new light on the four individual research questions listed below:

1. Are it-clefts exhaustive, and if yes, how should the exhaustivity be analyzed?

2. Are it-clefts combinable with focus particles and if yes, can these particles have an influence on the exhaustivity?

3. Does the cleft type (Focus-Background or Topic-Comment cleft) have an effect on the exhaustivity?

4. Does contrastivity play a role in the production of it-clefts?

Exhaustivity is by far the biggest and most debated issue regarding it-clefts. Therefore, this thesis will start by investigating this question by using a corpus-based analysis.

The detailed corpus analysis presented in chapter 3 illustrates the ways in which German native speakers use it-clefts. Additionally, it is possible to distinguish different types of it-clefts in German, which have been described for the case of English previously. Since these different types of it-clefts in English are assumed to possibly have different information-structural functions, this thesis is aimed at investigating whether this also holds for the case of German.

It-clefts can be divided into (at least) two subgroups: the Focus-Background (FB) structure, and the Topic-Comment (TC) structure. FB clefts appear in answers 
and corrective statements, with the contrast on clefted constituent. For example in this question-answer pair:

Q: Who got the highest score in the exam?

A: It was BEN who got the highest score in the exam.

In TC-clefts, on the other hand, the clefted constituent is mostly old, activated, or accessible, while the non-clefted information is new to the hearer. For the case of English, it has been argued that the main stress is on that non-clefted part, like in the example:

(20) It was just about 50 years ago that Henry Ford gave us the weekend. (Prince (1978), 898)

There is also a third class of it-clefts, the so-called all-new-clefts. In these clefts, both the cleft pivot and the cleft relative contain new information with the focus on the entire sentence (see Huber (2006)). In this case, two sub-types can be assumed: (i) maximally focused clefts that display a "topic-comment structure", and (ii) clefts without a topic which render an "all-comment structure" which is a typical feature for the so- called thetic sentences.

As part of the corpus study a large number of it-clefts which include a vast variety of different focus particles were found, not all of which were exclusives. Since the possibility of the occurrence of non-exclusive focus particles in it-clefts has been debated within the theoretical literature, this thesis aims at taking a closer and systematic look at what types of focus particles can and do appear in it-clefts and whether or not these non-exclusive particles can have an influence on the assumed exhaustivity inference.

This thesis investigates experimentally whether the type of it-cleft or the insertion of an additive focus particle can have an influence on the exhaustivity. As part of a cross-linguistic comparison this thesis also provides results for Hungarian preverbal focus, a structure which has been analyzed in close proximity to the it-cleft. Since the notion of contrast is very closely connected to that of exhaustivity, it has been addressed in the literature whether these two concepts can be kept strictly separate when it comes to it-clefts. This is especially interesting when it comes to the question of what types of contexts it-clefts are most frequently produced in, and whether exhaustivity and contrast play a role in triggering it-cleft production. The notion of contrast can be defined pre-theoretically as a relation between sentences, where $\mathrm{s}_{1}$ contains an element $\alpha$ that can be construed as an alternative to an element $\beta$ in $\mathrm{s}_{2}$, as illustrated below:

$$
[\text { Pete }]_{\text {Contr } 1} \text { went to }[\text { Rome }]_{\text {Contr } 2} \text {. }[\text { Marc }]_{\text {Contr } 1} \text { went to }[\text { London }]_{\text {Contr } 2} \text {. }
$$


(Repp (2016), 2)

For contrast to appear in a sentence or group of sentences, the following two aspects need to be taken into consideration: (a) the existence of an alternativeness of the elements, and (b) the role of discourse relations between two sentences which includes the concept that contrast is not either present or absent, but can vary in degrees (see Repp (2016)).

\subsection{Research Methods}

In this thesis, a variety of different research methods are used. These methods are described below.

\subsubsection{Corpus Data}

Regarding the question of exhaustivity, a corpus-based approach is implemented, in addition to specifically designed experiments which make immediate use of the naturally occurring examples found in the corpus. As the question whether itclefts come with an exhaustivity inference of some sort has been debated for quite some time from both theoretical and experimental perspectives, but has not as of yet been conclusively answered, the new approach presented in this thesis provides a fresh perspective and novel data. The view that is applied to it-cleft exhaustivity is usage-based and focuses on the it-clefts within their respective context environments. Considering naturally occurring examples in combination with the contexts they are produced in has the additional benefit of enabling us to later use these examples in experimental design and build our theories from them. Getting to know more about the contextual effects that might have an influence on the production of it-clefts, and under which circumstances those clefts are to be interpreted as exhaustive or non-exhaustive, can help us design experimental material closer to naturally occurring examples and thereby achieve better experimental results.

\subsubsection{Judgment Experiments}

Throughout this thesis a variety of individual experimental designs is used to answer the various experimental questions described above. On the most general level, these experimental designs can be divided into perception and production experiments. As part of the perception experiments, participants are presented with experimental material and then asked to answer questions about the material. 
This experimental input material is either presented in written text-form on a screen in front of the participants, or is given via audio-recordings. Both text-based and audio-based designs are used, which provides a wider range of experimental insights to draw conclusions from. One benefit of using spoken material is that, when investigating naturally occurring examples, it is more natural and closer to an actual conversational environment than written language. There might also always be constraints on written material, as speakers might tend to use and interpret written language differently (e.g. more formal) than spoken language, which can have effects on their judgments. However, it is common linguistic practice to use written input material in experiments to achieve reliable data.

In addition to the linguistic input material, pictures are also used for some of the experimental designs. These pictures have to be matched to the linguistic input by the participants. A variety of different rating systems is used within the discussed perception experiments. On a 7-point Likert scale, participants are asked to judge the acceptability of a given item from 1 (unacceptable) to 7 (completely acceptable). In addition to that, a binary forced choice responding system is used, in which participants are given the choice between two answer option (e.g. Question: Is the sentence acceptable? Answer options: yes/no). The motivation to use each individual experimental method in the specific circumstances is explained in the respective chapters of this dissertation.

\subsubsection{Production Experiments}

Apart from perception-based tasks, a production experiment is used to investigate the way in which speakers produce it-clefts and in what way this might be dependent on the specific linguistic context. Here a semi-spontaneous written production is used, in which participants are first presented with written descriptions of everyday conversational situations in which they should picture themselves. Participants are then asked a direct overt question by their fictitious conversation partner (also introduced previously), and receive a hint. This hint should make the content of their response. Using this hint, their task is to answer the question in a way that seems most natural to them in the given situation. Ideally, production experiments are done in a spoken environment, in which the experimenter can engage in actual direct spoken conversation with the participants. If that is not an option, however, using semi-spontaneous written conversation is also an effective method of eliciting language production data for naturally occurring examples. 


\subsection{Outline of the thesis}

We now proceed to outline the topic and give a brief description of each of the chapters of this thesis.

\subsubsection{State of the Art}

Chapter 2 gives a brief introduction to the most important notions of syntactical analyses that have been put forward in order to analyze the structure of it-clefts. This is followed by a thorough overview of the vast number of both theoretical and experimental approaches towards an analysis of the semantic and pragmatic properties of it-clefts. This introduction follows the overall structure of this thesis by presenting the relevant literature in relation to the key notions of exhaustivity, the role of focus particles in it-clefts, contrastivity, and information structure.

\subsubsection{It-Cleft Exhaustivity and Focus Particles}

This chapter presents a detailed analysis of a large variety of naturally occurring examples extracted from corpus data for German, after first giving a thorough introduction to the semantic-pragmatic debate on the exhaustivity effect of itclefts. The focus here lies mainly on the specific role that certain focus particles may play in these it-clefts. Previous studies which use corpus data for an analysis of it-clefts have argued in favor of a pragmatic approach to the exhaustivity inference, while theoretical approaches tend to suggest a semantic analysis. When it comes to whether or not focus particles can be part of it-clefts, theoretical approaches also vary. As part of the corpus analysis, this chapter presents novel data that show that this is not only possible, but, in fact, fairly frequent. Additionally, the fact that the cleft structure, which is rather uncommon in (spoken) German actually appears quite frequently in the corpus of newspapers and Wikipedia-forum discussions is in itself an interesting result.

In addition to showing that (both exclusive and non-exclusive) focus particles can and do appear in it-clefts, this chapter also introduces and discusses the two kinds of it-clefts, Focus-Background and Topic-Comment Clefts, the latter of which can be characterized as non-prototypical (compared to the more common FB-clefts). The corpus analysis also allows us to see whether all it-clefts appear to be exhaustive, when considering their respective contexts. We see that, when considering naturally occurring examples, the exhaustivity inference is not as strong as has been assumed by the theoretical literature, but that there can in fact be nonexhaustive it-clefts.

Following the corpus analysis, this chapter discusses the scope the focus particles may take in the two cleft-types. This is further investigated using two judgment 
studies, which show that in German it-clefts with an additive focus particle that appears directly in front of the cleft pivot, the focus particle can modify the VP of the cleft relative. If these clefts are exhaustive, this can then be explained by the focus particle, despite its syntactical position, actually modifying the VP.

In addition to that, this chapter presents the results of a rating experiment that is designed in line with the naturally occurring examples from the corpus, and shows that certain it-clefts in combination with focus particles are judged as acceptable by native speakers. We see that German it-clefts combined with particles that carry a non-exclusive meaning receive a overall acceptable rating (above 5 on a 7-point scale). Therefore, this experiment provides evidence to argue against the theoretical approach that it-clefts carry an exhaustivity inference that is hardwired into the semantics of the structure. If that was indeed the case, it should not be possible to cancel a semantic inference by the insertion of a particle which takes scope over the focused element.

\subsubsection{Exhaustivity and the Question Under Discussion}

This chapter first introduces the Hungarian pre-verbal focus structure, a sentence structure that has been analyzed in close connection to it-clefts and has been described as semantically exhaustive in the way that exclusives such as only are. The structural properties of it-clefts and their influence on the two types of it-clefts that we can distinguish (in German), Topic-Comment (TC) and Focus-Background (FB) clefts, are further discussed. The question whether the two different cleft types vary with regard to their respective exhaustivity (as a possible result of their different information structural functions) are investigated in an experiment for German and Hungarian, in which pre-verbal and post-verbal focus in Hungarian, as well as (both FB and TC) it-clefts and canonical sentences in German are tested against each other for exhaustivity judgments, both with and without a non-exhaustive particle. The experimental design presented in this chapter brings together findings from previous chapters to find a conclusive answer to the issue of it-cleft exhaustivity, context, and information structure.

The experiment answers the question whether different kinds of overt context questions have an influence on the exhaustivity judgment of it-clefts and Hungarian pre-verbal focus. In addition to that, this chapter also shows the results of a second experiment, which investigates the possible effect that non-exclusive focus particles may have on the exhaustivity judgment of the two focus constructions.

The design uses overt wh-questions, which are answered by the different structures. The question-answer pairs are presented in spoken language and are combined with context pictures.

The experimental results show that Hungarian pre-verbal focus is exhaustive in 
some way, as non-exhaustive pictures are rejected in combination with the preverbal focus. Regarding the two different question types that were used to trigger narrow and wide focus respectively, we can see that pre-verbal wide focus receives strongly exhaustive judgments. Pre-verbal narrow focus also receives strongly exhaustive judgments. In a non-exhaustive context, the narrow focus is mostly judged low. However, it is not necessarily exhaustive, as there are a number of higher judgments. Based on the results it can be suggested that in Hungarian, preverbal focus constructions can be used in more contexts than previously assumed by the literature.

The fact that both sentence structures receive similar exhaustivity judgments is taken to mean that the kind of focus question (narrow/wide) preceding the sentence has more influence on the exhaustivity than the syntactical construction (preverbal/post-verbal focus for Hungarian).

As an answer to questions conveying wide focus, pre-verbal focus is accepted in exhaustive as well as non-exhaustive contexts, while this is not the case with narrow focus. When assumed to be answering a narrow focus question, speakers reject pre-verbal focus in non-exhaustive contexts, while this structure is accepted when it answers a wide-focus questions.

Generally, the experiment shows that Hungarian pre-verbal focus is exhaustive in some way, as non-exhaustive contexts are rejected in combination with the preverbal focus. As the patterns for both narrow and wide question types are not parallel, it can be said that Hungarian pre-verbal focus is not semantically exhaustive.

The results for German show that the two cleft types actually vary slightly with regard to their exhaustivity judgments: TC-clefts seem to be a little less exhaustive than FB-clefts. This provides experimental evidence against a semantic approach to it-cleft exhaustivity, as in that case, both cleft types should receive the same exhaustivity judgment. Thus, it is concluded that these two clefts types are not to be treated completely equally, even though they can actually both serve as answers to overt wh-questions. We see that FB-clefts can be used to mark focus in a more narrow sense, while TC-clefts can also be used for other information structural purposes, e.g. shift of discourse direction or introduction of a new topic. The experimental data presented in this chapter contribute to the empirical evidence that supports a pragmatic approach to the exhaustivity inference in Hungarian preverbal focus and it-clefts. This thesis does not provide a detailed formal analysis of the exhaustivity, however, the approaches presented by Horn (1981), Horn (2014), or Onea and Beaver (2009) seem to best fit the results presented in this thesis. 


\subsubsection{It-Cleft Exhaustivity and Contrast}

It-clefts have been described as a way to mark contrast morphosyntactically, as the contrastive constituent moves to the left periphery of the sentence into the cleft pivot. This chapter first gives a detailed overview of the literature on contrast in relation to it-clefts and to the notion of exhaustivity, and introduces previous experimental studies done on the subject. It is further investigated whether specific properties of the context can influence the production of it-clefts. As shown by the corpus analysis in chapter 3, it-clefts are actually fairly frequent in written German, yet it is still not clear how frequent (and, therefore, how accessible) they are in spoken German. This production experiment provides a first step into the direction of investigating whether and when speakers of German actually produce it-clefts. This chapter then presents results that show that it-clefts are actually produced by speakers in the semi-spontaneous setting of the experiment. The results indicate that there is a tendency for a higher production of it-clefts in exhaustive and/or contrastive contexts as opposed to contexts that have neither of those two characteristics. 


\section{Chapter 2}

\section{It-Clefts across Languages: State of the Art}

\subsection{Introduction}

This chapter gives an overview of the main syntactic and semantic approaches regarding it-clefts. The focus is on the theoretical and experimental work that has been done on the semantics of it-clefts. This dissertation deals with cleft structures across languages. The majority of the theoretical work on it-clefts has been done regarding English language examples, like illustrated below. (22)a shows an it-cleft construction, while (22)b shows the corresponding canonical sentence:

a. It is CHAMPAGNE (that) I like.

b. I like CHAMPAGNE. (Lambrecht (2001), 467)

The objective of this thesis are naturally occurring examples of es-clefts in German, which translate into English it-cleft structures:

(23) Es war Charles Darwin, der den Menschen ihre natürliche Herkunft erklärte.

It was Charles Darwin who the people their natural heritage explained It was Charles Darwin who explained their natural heritage to the people. (Z09/JAN.00109 Die Zeit (Online-Ausgabe), 08.01.2009; Danke, Darwin!)

(24) Es ist frisches, natürliches Bier, unfiltriert und nicht pasteurisiert, das wir ausschenken.

It is fresh natural beer unfiltered and not pasteurized that we serve It is fresh, natural beer, unfiltered and not pasteurized that we serve. (A97/JUL.15772 St. Galler Tagblatt, 24.07.1997, Ressort: TB-ARB (Abk.) ; Tafeln neben Braumeister) 
Apart from German it-clefts, this thesis deals with Hungarian pre-verbal focus, a syntactical structure that has been analyzed on par with it-clefts. Pre-verbal focus can be accurately translated into English using a cleft structure. It also stands in contrast to a non-focused sentence structure:

(25) Péter szét tépte a levelet.

Peter apart tore the letter

Peter tore the letter apart.

(26) Péter A LEVELET tépte szét.

Peter the letter-ACC tore apart

It was the letter that Peter tore apart. (É. Kiss (2006), 2)

(27) Mari ki nézett magának EGY KALAPOT.

Mary out picked herself A HAT

Mary picked for herself A HAT.

(28) Mari egy kalapot nézett ki magának.

Mary a hat-ACC picked out herself-ACC

It was A HAT that Mary picked for herself. (É. Kiss (1998), 249)

The first part of this chapter introduces the two main syntactical analyses of itclefts, the extraposition analysis and the expletive analysis. The second part of the chapter then moves on to the various approaches that have been proposed on the semantics of it-clefts. The different theoretical and experimental approaches are discussed under the key questions regarding exhaustivity, focus particles, contrastivity, and taxonomy/information structure.

\subsection{The Syntax of it-Clefts}

There are two competing analyses to the syntax of cleft sentences among the literature: clausal extraposition vs. expletive analysis (see Hedberg (2000) for discussion), which both have been argued for in various ways. The expletive analysis treats the cleft clause as being directly connected to the cleft pivot, while the cleft pronoun is treated as an expletive pronoun which is unrelated to the cleft pivot. In what Hedberg (2000) calls the extraposition analyses, the cleft pronoun and cleft clause are treated as forming one syntactic constituent, while the cleft clause only bears an indirect relation to the cleft pivot via the copula.

This distinction was first introduced by Jespersen who first mentioned the extraposition analysis of clefts in Jespersen (1927) and later rejected it with the expletive analysis in Jespersen (1937). The cleft relative is analyzed as a subject clause with the cleft pronoun as the subject. Therefore it does not modify the immediately preceding cleft pivot, but the cleft pronoun at the beginning of the sentence. 


\subsubsection{Expletive Analysis}

In this approach, the cleft pronoun, copula, and relative pronoun are treated as expletive items that are not directly related to the sentence. What makes out the main parts of the sentence are cleft pivot and cleft relative (minus the relative pronoun). This analysis has been adapted (in slightly different ways) by a large number of later analyses of cleft structures (e.g. Hedberg (2000), É. Kiss (1998), Chomsky (1977), Delin (1989)).

\section{(29) It was $[\text { Sue }]_{F}$ who climbed a mountain.}

As Hedberg (2000) points out, this analysis has become dominant. The later adaptions of the expletive analysis mostly keep Jespersen (1937)'s general structure. They mostly agree on treating both the cleft pronoun and the copula as semantically inert, thereby contributing no semantic meaning to the sentence.

Interestingly, this analysis was brought forward by Jespersen (1937) to reject his initial extraposition analysis of it-clefts from Jespersen (1927). Both the cleft pronoun and the copula are treated as semantically empty, simply being a dummy element and playing no semantic role in the construction.

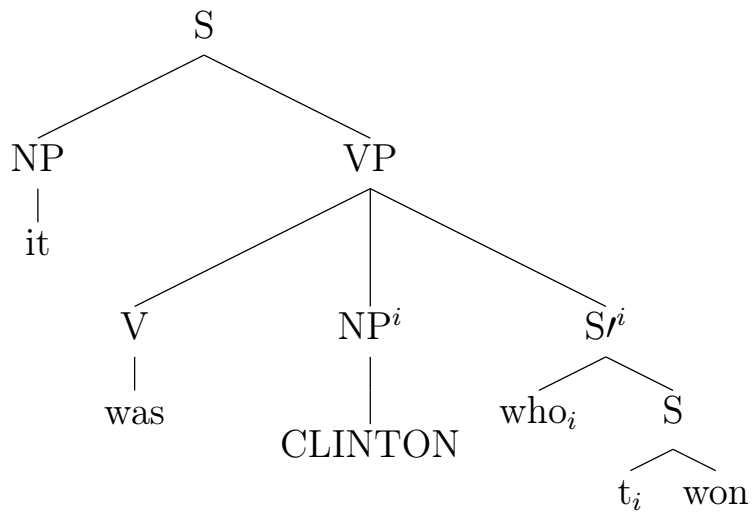

(Delin (1989), as cited in Hedberg (2000), 910)

In this analysis for NP-clefts (see Delin (1989)), the cleft clause is a relative clause which bears no further than the default relation to its head. In it-clefts other than NP clefts, the cleft clause is introduced via the complementizer that as a sentential constituent. The cleft clause in these cases includes a dependent gap, which is then filled by the cleft pivot (which is the XP).

The analysis suggested by É. Kiss (1998) marks an exception, as she treats the copula as the syntactic head of the focus phrase (FP) which assigns identificational 
focus to the pivot (Spec). The cleft relative is the complement of F. There are two options for the cleft pivot: (a) the pivot can be moved out of the CP and into SPEC of FP via spec-CP, or (b) it can be base-generated im the spec of FP, while being co-indexed with the WH-operator in spec of $\mathrm{CP}$ at $\mathrm{LF}$.

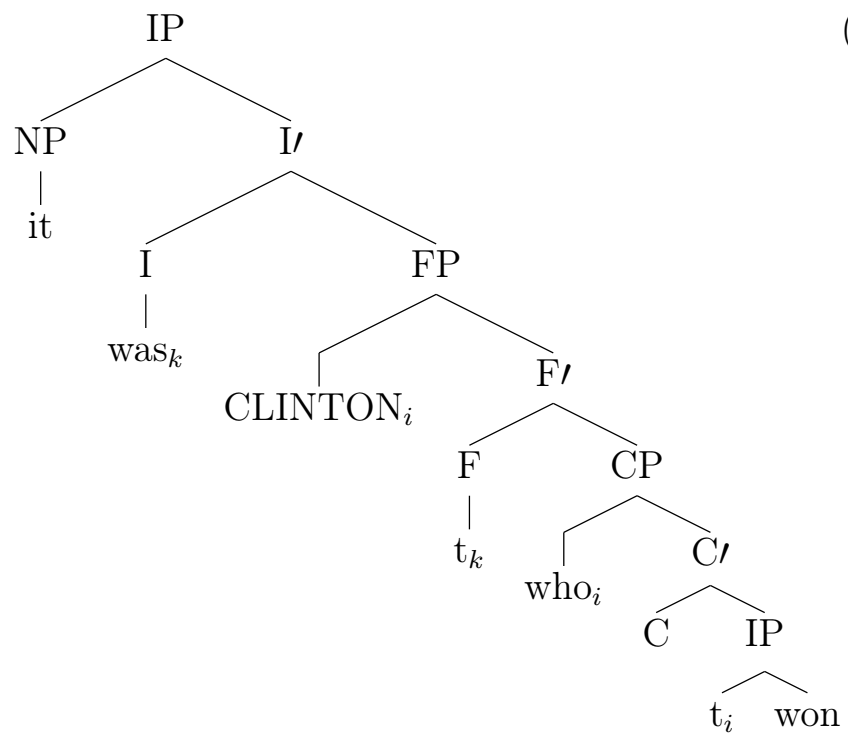

(Hedberg (2000), 911)

The expletive analysis aims to relate the cleft relative directly to the cleft pivot. All theories reach this by rendering one or more elements (the cleft pronoun it and/or the copula) of the it-cleft as semantically empty, thereby giving it an expletive status.

Hedberg (2000) herself offers a third analysis, which is a combination of extraposition and expletive analysis. She moves on from a solely syntactic analysis and unites syntactic, semantic, and pragmatic elements: The cleft relative modifies the pivot syntactically, but semantically and pragmatically, it is directly related to the cleft pronoun. The copula is also not semantically inert, but is the linking verb for either a indentificational or predicational interpretation. 


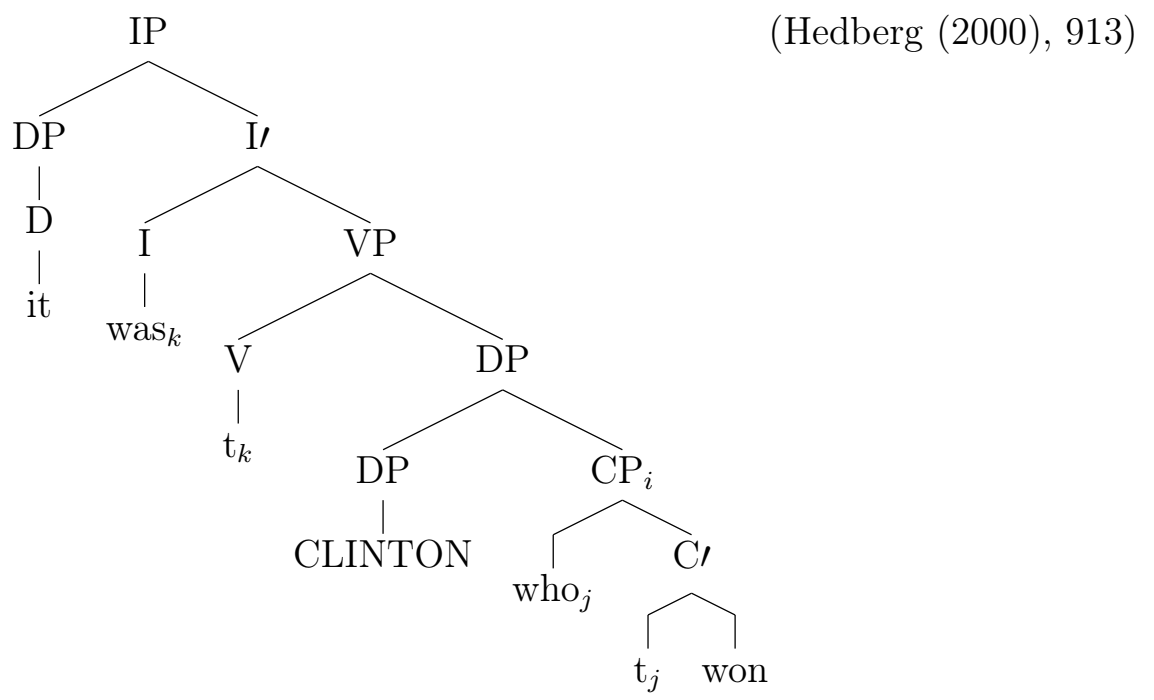

In the case of ambiguity, the syntactic structure of it-clefts has semantic effects. Apart from ambiguity, it has been observed that it-clefts carry an existence presupposition (see e.g. Percus (1997)), which leads to the fact that nobody cannot stand in the cleft pivot, as the existence presupposition is violated by the negative quantifier:

Q: Who kissed Mary?

A1: $[\text { NObody }]_{F}$ kissed Mary.

A2: *It was $[\text { NObody }]_{F}$ who kissed Mary.

Another semantic effect that will be discussed in further detail throughout this thesis is the exhaustivity of it-clefts.

According to Krifka (2008), the following example says that nobody stole a cookie but John and Bill.

$$
\text { It's [JOHN AND BILL }]_{F} \text { that stole a cookie. }
$$

In a test first introduced by Szabolcsi (1981) and later discussed by É. Kiss (1998), it can be shown that it-clefts provide some kind of exhaustivity inference, as illustrated below

a. Mary picked a hat and a coat for herself.

b. Mary picked a hat for herself.

a. It was a hat and a coat that Mary picked for herself.

b. \#It was a hat that Mary picked for herself. (see É. Kiss (1998), 250) 
While in (35), the sentence in (b) is a logical consequence of (a), this is not the case for (36). According to É. Kiss (1998), an identificational focus, such as a cleft, represents a subset of the set of elements accessible in the context for which the predicate in the cleft relative can potentially hold. This subset is identifiable as the exhaustive subset of this set for which the predicate actually holds. Syntactically, this is represented by $\mathrm{F}_{I D E N T}$ which is assigned by $\mathrm{F}$ to the constituent in Spec, FP.

\subsubsection{Extraposition Analysis}

Even though Jespersen (1937) rejected this analysis later, it has been used in a number of theories since then (see e.g. Akmajian (1970), Gundel (1977), Percus (1997), Hedberg (2000)). In this analysis, the cleft pronoun and the cleft relative form a definite DP as part of a specificational copula clause. The cleft relative is extraposed to the right and adjoined to IP, while the cleft pronoun is the phonological spell-out of $\left[D P \mathrm{D}_{\text {def }}\left[{ }_{N P} \varnothing\right]\right]$.

$$
\text { It was }[\text { Sue }]_{F}\left[_{C P}\right. \text { who climbed a mountain]. }
$$

Under this analysis, it-clefts have the same properties as specificational copula sentences (or pseudo-cleft sentences). The two examples below are therefore interchangeable:

a. It was Sue who climbed a mountain.

b. The one who climbed a mountain was Sue.

As pointed out by Akmajian (1970), clefts and pseudo-clefts share a lot of features, apart from being synonymous: they have the same presuppositions, can be used as answers to the same questions, share the same stress pattern, and neither provides any additional information to the other. Additionally, the two structures put the same element in focus. This observable phenomenon can be explained by looking at the underlying syntactic structure of the two sentences. Akmajian (1970) argues that clefts are syntactically derivable from pseudo-cleft sentences via an extraposition rule. The two sentences are completely synonymous. In this framework, if clefts are analyzed as extraposed pseudo-clefts, one can account for complicated formal properties of the structures such as verbal agreement patterns. Cleft sentences have a specific and complex agreement pattern, which can actually be predicted from their pseudo-clefted counterparts. The verb in a cleft does not agree with the pivot, but it does have number agreement with the focus noun. The verb is always in third person, no matter what the cleft pivot is:

a. It is me who is responsible. 
b. It is us who are responsible.

c. It is you who does this job.

but: You do this job.

d. It is us that always get the tough breaks.

e. It is me that always gets the tough breaks.

but: I always get the tough breaks. (Akmajian (1970), 150-151)

To explain why there is number agreement but not person agreement, Akmajian (1970) derives the cleft forms from their respective pseudo-cleft versions:

a. The one who is responsible is me.

b. The ones who are responsible are us.

c. I am the one who does this job.

d. We are the ones that always get the tough breaks.

e. I am the one that always gets the tough breaks. (Akmajian (1970), 151)

The example sets illustrate that there is a systematic agreement pattern for plural marking, but the third person in the head noun stays constant. Akmajian (1970) assumes the Cleft Extraposition Rule, which operates on pseudo-clefts with noun phrases with heads and prepositional phrases in the focus position. The rule extraposes the cleft relative to the end of the matrix clause.

a.

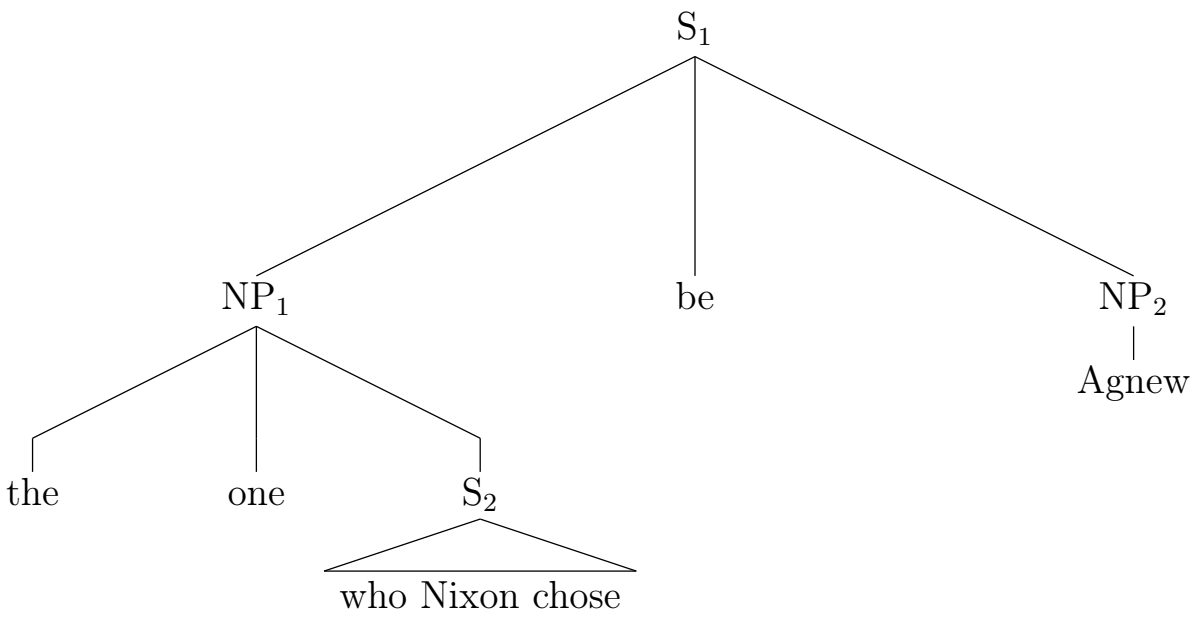


b.

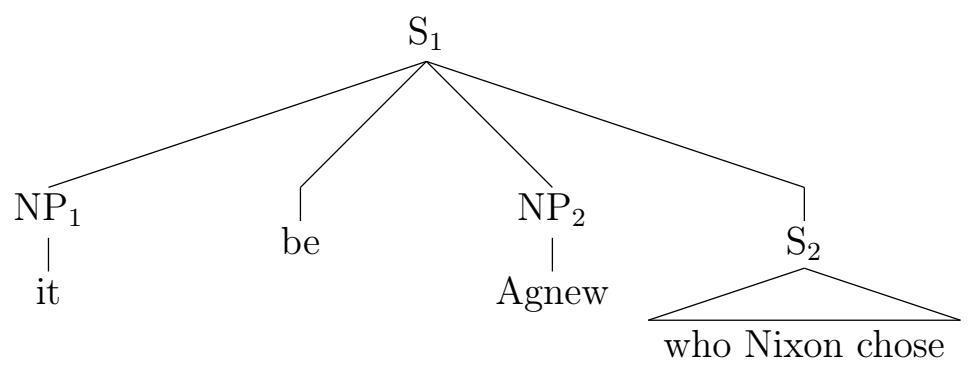

(Akmajian (1970), 149)

This analysis serves to account for a lot of problematic formal properties of verbal and pronominal agreement patterns within the cleft structures, which is why it has been widely recognized.

As Gundel (1977) argues, clefts are "reduced forms of structures underlying rightdislocated pseudo-clefts" (Gundel (1977), 543). This is illustrated in the example below.

a. What you heard was an explosion.

b. It was an explosion that you heard. (Gundel (1977), 543)

Gundel $(1977)^{1}$ notes an ambiguity that comes with pseudo-clefts such as in (42)a above. The sentence "What you heard was an explosion" can receive two readings: (i) a "true pseudo-cleft reading" that, via the phrase right of the copula, identifies what is being described by the left-located relative clause, or (ii) a reading in which the described property is simply being attributed. Gundel (1977) therefore distinguishes an ID (identifying) interpretation and an AT (attributive) interpretation of pseudo-clefts. This distinction is further illustrated by the example below. In the AT-reading, the speaker bought two dogs, one being a German Shepherd and the other being a St. Bernard. In the ID-reading, however, he bought one mixed-breed dog.

(43) What I bought is a German Shepherd and a St. Bernard. (Gundel (1977), $544)$

This semantic ambiguity is possible because pseudo-clefts actually stem from two different syntactic structures, shown in the figures below:

${ }^{1}$ Also see Gundel (2008), Gundel (2006) 

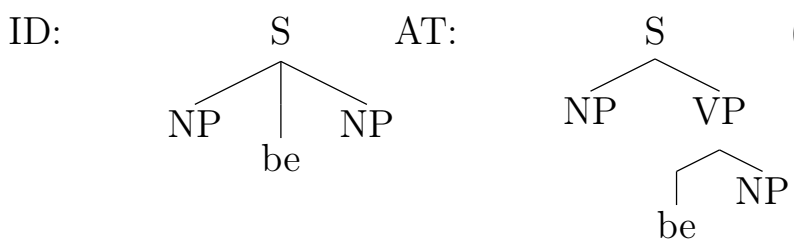

(Gundel (1977), 546)

It-clefts are only derivable from those pseudo-clefts that stem from an ID-structure. This becomes clear when changing the example above into a cleft. Here, only the ID interpretation is available:

(45) It was a German Shepherd and a St. Bernard that he bought. (Gundel (1977), 548)

This derivation of clefts from right-dislocated pseudo-clefts applied by Gundel (1977) is similar to the approach proposed by Akmajian (1970): The cleft pronoun it is understood to be a pronominal reference to the sentence-final topic. There is a variety of evidence brought forward to explain why the cleft pronoun is not semantically empty. Gundel (1977) shows that e.g. for the case of Russian, where dummy-subjects do not exists and sentences without subjects are possible. The fact that Russian èto-clefts have to begin with a pronoun which cannot be deleted is taken as evidence that the cleft pronoun is an ordinary anaphoric pronoun which carries meaning. The cleft pronoun is actually the subject of the cleft sentence, as a result of pronominalization of the subject in the corresponding pseudo-cleft.

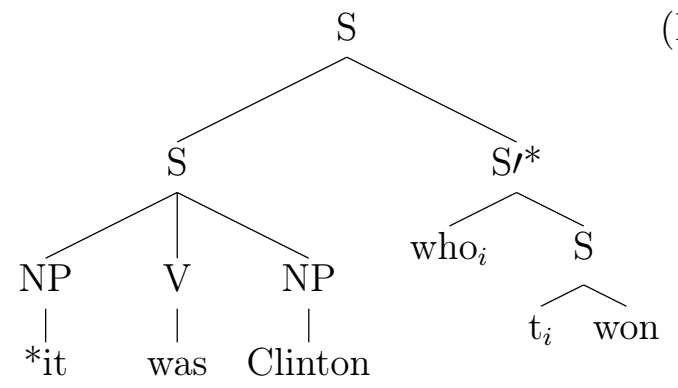

(Hedberg (2000), 908)

Both Gundel (1977) and Akmajian (1970) thereby stand in opposition to the argument that cleft sentences can be analyzed by assuming that the subject it is semantically empty.

Percus (1997) provides a slightly different approach to the extraposition analysis of cleft sentences. In this framework, a cleft sentence includes a copula clause whose subject is a description with a definite determiner and a null head. The cleft relative is extraposed and the cleft pronoun is a morphological spell-out of the DP which contains the definite determiner as the CP trace. 
a. It is $[\alpha]_{F}$ that has property $\Pi$

b. $\left[_{I P}\left[D P \text { the } 0\left[{ }_{C P} \mathrm{OP}_{i} \text { that } \mathrm{i}_{i} \text { has property } \Pi\right]\right]_{j}\left[{ }_{V P} \mathrm{t}_{j}\right.\right.$ is $\left.\left.\alpha\right]\right]$

c. Extraposition: $\left[\left[_{I P}\left[{ }_{D P} \text { the } \mathbf{0} \mathbf{t}_{k}\right]_{j}\left[{ }_{V P} \mathrm{t}_{j}\right.\right.\right.$ is $\left.\left.\alpha\right]\right]\left[{ }_{C P} \mathrm{OP}_{i}\right.$ that $\mathrm{t}_{i}$ has property $\Pi]_{k}$

d. The one that has property $\Pi$ is $\alpha$.

e.

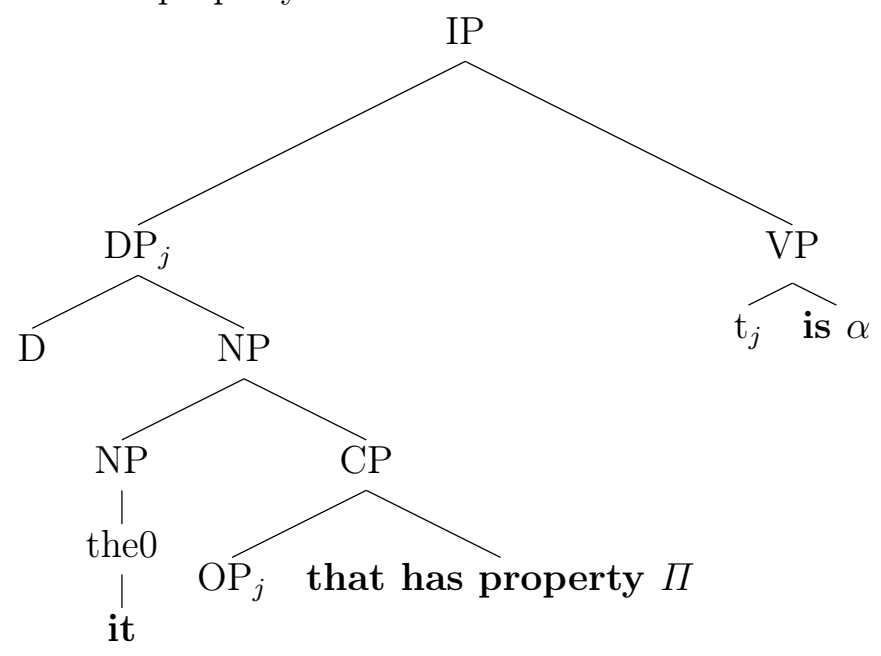

(Percus (1997), 337-338)

Percus (1997) follows Akmajian (1970) and Gundel (1977) in their analysis of clefts as structurally indistinguishable from definite descriptions, like in (47)d above. The null head has the same interpretation as the one, meaning that it serves as a predicate for any kind of entity. "The $0 t_{k}$ " gets spelled out as the cleft pronoun it and the CP moves to the extraposed right location of the cleft relative.

\subsubsection{Summary}

As discussed above, there are two main approaches when trying to analyze the syntactic structure of the it-cleft.

In the expletive analysis, the cleft clause is treated as being directly connected to the cleft pivot, while the cleft pronoun is an expletive pronoun unrelated to the cleft pivot. This analysis treats both the cleft pronoun and the copula as semantically inert. All theories reach this by rendering one or more elements (the cleft pronoun it and/or the copula) of the it-cleft as semantically empty, thereby giving it an expletive status. As Hedberg (2000) points out, the expletive analysis of it-cleft syntax has become dominant. It also stands in line with the definition given for it-clefts in chapter 1 of this thesis and the analysis of it-clefts proposed here. 
According to the extraposition analysis, cleft pronoun and cleft clause form one syntactic constituent, while the cleft clause only bears an indirect relation to the cleft pivot via the copula. Under this analysis, it-clefts have the same properties as specificational copular sentences (or pseudo-cleft sentences). This analysis (see e.g. Gundel (1977), Akmajian (1970)) does not support the prediction that cleft sentences can be analyzed by assuming that the subject it is semantically empty. This assumption goes against the initial definition of it-clefts given in this dissertation (see Lambrecht (2001)). It-clefts are distinguished from so-called truncated clefts by the fact that in truncated clefts, the sentence-initial it has referential status, while it bears no meaning in it-clefts.

Looking back at the definition of it-clefts given in chapter 1 of this thesis, reiterated below in a slightly extended version, it can be seen that the expletive approach fits rather well with the definition that this thesis follows.

A cleft construction is a complex sentence structure consisting of a matrix clause headed by a copula and a relative or relative-like clause whose relativized argument is co-indexed with the predicative argument of the copula. Taken together, the matrix and the relative express a logically simple proposition, which can also be expressed in the form of a single clause without a change in truth conditions. (Lambrecht (2001), 467)

The following section will take a closer look at the semantics of it-clefts and the different theories that have been proposed in the past.

\subsection{The Semantics of it-Clefts}

The meaning contribution of it-clefts has been under constant debate. There are a variety of theoretical and experimental approaches that use various means to describe and analyze the semantics of it-clefts. In the past, the most debated question has been whether or not it-clefts are exhaustive. There have been both theoretical and experimental approaches to answer this question. This chapter reviews the most important approaches. Both theoretical and experimental approaches are introduced under the aspects of what they have to say concerning it-cleft exhaustivity, the role of focus particles in it-clefts, contrastivity, and information structure. The goal is to gain a broad and insightful overview of the analyses on it-cleft semantics so far. Before looking into the different approaches in more detail, the notions of focus and topic are introduced to provide the necessary background. 


\subsubsection{Background: The Notions of Focus and Topic}

\subsubsection{The Notion of Focus}

In general, the notion of focus can be understood as a universal category of information structure. Information structure has been described as a phenomenon of information packaging regarding the communicative needs of interlocutors in a discourse (see Chafe (1976)). Information Structure ${ }^{2}$ is held as a universal of human discourse. It is independent of specific syntactic structures or other conventions of given languages. Discourse is taken to be organized by rational speakers around a series of conversational goals and the specific strategies these speakers develop to achieve their goals. Speakers aim at sharing information about the world with other speakers within a discourse. The Common Ground (CG) is a way to model the information that is mutually known to be shared and continuously modified by all interlocutors in communication (see Krifka (2008)). Information structure, thereby, belongs to the field of common ground management, as opposed to common ground content (see Zimmermann and Onea (2011)).

Focus can be defined as follows ${ }^{3}$.

(49) Focus indicates the presence of alternatives that are relevant for the interpretation of linguistic expressions. (Krifka (2008), 247)

This definition is in line with Alternative Semantics (see Rooth (1985) Rooth (1992)). Focus can be marked in different ways, e.g. by a pitch accent or via a specific sentence structure like an it-cleft. The definition above does not say anything specific about the mentioned alternatives, which is why it can be further specified:

A property $\mathrm{F}$ of an expression $\alpha$ is a Focus property iff $\mathrm{F}$ signals (a) that alternatives of (parts of) the expression $\alpha$ or (b) alternatives of the denotation of (parts of) $\alpha$ are relevant for the interpretation of $\alpha$. (Krifka (2008), 248)

The case of focus described in (a) above is called expression focus, the one in (b) denotation focus. The sentences below illustrate cases of expression focus, which is typically used for corrections and marked in-situ.

\footnotetext{
${ }^{2}$ Also see Zimmermann and Féry (2010).

${ }^{3}$ This thesis follows the theory of focus presented by Krifka (2008). While the favored approach to focus in this thesis follows the assumptions of Alternative Semantics (see e.g. Rooth (1985), Rooth (2016), Rooth (1992)), there have been several analyses of the phenomenon of focus. Focus can for instance be treated as expressing new information (see e.g. Halliday (1966), Selkirk (1984)), as highlighting or expressing a greater level of informativeness (see e.g. Bolinger (1985)), or as identifying a presupposition (see e.g. Jackendoff (1972))
} 
(51) Grandpa didn't $[\text { kick the BUcket }]_{F}$, he $[\text { passed aWAY }]_{F}$. (Krifka (2008), 248)

A: They live in BERlin.

B: They live in $[\text { BerLIN }]_{F}$ ! (Krifka $\left.(2008), 248\right)$

In (51), the possible alternatives are the expressions themselves (of which one is more appropriate than the other), not the denotations, as both expressions refer to the same property, namely dying. In (52), the two alternatives are the different ways in which the word Berlin can be pronounced, one of which is correct.

In the case of denotation focus, on the other hand, the relevant alternatives are located on the level of denotations. It can be defined as follows

(53) Denotation focus on an expression $\alpha$ with a meaning [ $\alpha$ ] leads to the assumption of a set of alternative meanings that play a role in the interpretation of the constituent in which $\alpha$ occurs. (Krifka (2008), 249)

Within the field of denotation focus, Krifka (2008) further distinguishes semantic and pragmatic uses of focus. Focus can be used pragmatically to highlight the part of an answer that corresponds to the WH-phrase of a related question, as illustrated below.

A: Who won the bake off?

B: $[\text { PEter }]_{F}$ won the bake off.

Another pragmatic use of focus is to indicate covert questions that are available in the context, as illustrated below for the questions What happened?, What was there?, and What did she do?:

And then something strange happened. [A MEteorite fell down. $]_{F}$

Once upon a time, there was [a PRINcess $]_{F}$

Mary sat down at her desk. She [took out a pile of NOTes] $]_{F}$ (Krifka (2008), ex 13)

This position assumes a correlation between questions and the position of focus in answers (see e.g. Rooth (1992)) $)^{4}$ A question in a given discourse determines a set of potential answers. The focus in the uttered sentence then has the function of signaling other propositions which are potential answers in the context of the question. Therefore, focus in an answer is an expression of contrast between the asserted answer and other potential answers (see Rooth (1992)).

\footnotetext{
${ }^{4}$ Hamblin (1973) states that the meaning of a question is the set of alternative answers. (thus: propositions)
} 
According to Roberts (1996), speakers follow two types of rules, (a) language internal or conventional rules, i.e. syntactic, compositional, semantic, etc., and (b) conversational rules, following the Gricean Maxims (see Grice (1975)). Within the rules, speakers make two kinds of moves (or speech acts) when communicating: they make either set-up moves, i.e. ask questions, or payoff moves, i.e. assert answers to questions. It should be mentioned that the questions in a discourse do not always have to be uttered explicitly, while a discourse is still organized and structured by question-answer-relations. One way of stating an implicit question is prosodic focus (Roberts (1996) looks at English), which presupposes a certain Question Under Discussion (QUD) for the current discourse ${ }^{5}$. This enables the speaker to reconstruct the implicit question and therefore the direction in which the discourse is being moved by the assertion. Since intonational focus in English is presuppositional, the information that interlocutors can gain from intonational focus is redundant. When an utterance has a presupposition ${ }^{6}$, this presupposition is already at least entailed by the context, or explicitly part of the CG. This redundancy can be used by interlocutors to indirectly convey information. This, however, is not a semantic operation, but a pragmatic derivation of certain focus effects, and it does not assume any direct focus sensitivity for focus particles like only or even.

When defining her notion of QUD ${ }^{7}$, Roberts (1996) refers to Stalnaker (1974) and the notion of The Big Question (What is the way things are?) as the goal of a discourse $^{8}$. A question which is uttered in the discourse sets up a partition on the context set.

The context set itself represents the ultimate set of alternatives. The context set is the selection of a unique, or actual world, which is the goal of a discourse. Assertions by speakers are choices among alternatives. If accepted by all interlocutors, they are added to the CG and thereby shrink the context set. Answers to the Big Question stand in an entailment relation to answers to a set of all sub-questions. For example, the question "What do you like?" entails "What drinks do you like?". As a result, if interlocutors can answer enough sub-questions, they have an answer to the superquestion. Another result of this entailment relation of questions and answers is that inquiries in discourse have a hierarchical structure. The set of questions that are at stake at a given point in the discourse is thought of as a push-down store, which Roberts (1996) calls the QUD-stack. When a question

\footnotetext{
${ }^{5}$ For further discussion of the notion of QUD also see Zondervan (2009), Zondervan et al. (2008), Beaver and Clark (2008), Beaver et al. (2017), Simons et al. (2017), Roberts (1998).

${ }^{6}$ For further discussion of the notion of presuppositions also see Beaver (1997), Beaver (1992), Beaver (2001), Delin (1995), Horn (1969).

${ }^{7}$ For further discussion on the semantics of questions also see Onea (2016), Karttunen (1977), Krifka (2001), Groenendijk and Roelofsen (2009)

${ }^{8}$ Also see Stalnaker (2002).
} 
is accepted into the CG by all interlocutors, it is added on the top of the stack. When a question is answered (or determined to be unanswerable), it is moved from the stack, making way to the ones below it. The question on top of the stack is the (immediate) QUD at any point in discourse.

\subsubsection{Focus Sensitive Particles}

Krifka (2008) notes that semantic operators whose interpretational effects depend on focus are associated with focus. This association with focus can be of different kinds (see Beaver and Clark (2008)). One example are focus sensitive particles such as even, also, and only. Generally, Krifka (2008) describes the case of exclusives such that the focus denotation is the only one among the alternatives that results in a true assertion. For the case of additive particles such as also he notes that they express the presupposition that the assertion holds for other alternatives. For the case of scalar particles such as even he states that they presuppose that the denotation of the focus constituent is extreme when compared to other alternatives (see also König (1991)). All focus sensitive operators have in common that they are required to stand in a position within any given sentence which allows them to scope over their focus. For the example (58) below, this means that only may associate with the painting, Alan, with showed or with the entire VP, but not with Tom (see Krifka (2008)).

(58) Tom only showed the painting to Alan.

Roberts (1996) assumes that exclusives and other focus sensitive particles do not have a conventionalized dependency on focus, but associate freely with focus. As described in more detail above, Velleman et al. (2012) argue that the main difference between it-clefts and exclusives can be found in the discourse-status of the exhaustivity inference that is assumed to come with both. Exclusives make the exhaustiveness inference at-issue, while it-clefts make the same inference not-atissue (see, e.g. Horn (1981), Velleman et al. (2012), Büring and Križ (2013), Horn (2014), Destruel et al. (2015). This is illustrated in the example below:

a. \# Bob knew she invited Fred, but he didn't know it was Fred she invited. (not-at-issue exhaustivity)

b. Bob knew she invited Fred, but he didn't know she only invited Fred. (at-issue exhaustivity) (Büring and Križ (2013), 2, adapted from Horn (2014))

In the framework of Roberts (1996), the exhaustivity inference is described as being at-issue if it addresses the question under discussion (QUD). Presuppositions and conventional implicatures are said to be not-at-issue inferences (see Simons et al. 
(2010), Tonhauser et al. (2013), Potts (2005)). The distinction between at-issue and non-at-issue exhaustivity has been the objective of several publications on it-clefts (see e.g. Drenhaus et al. (2011), DeVeaugh-Geiss et al. (2015), Destruel (2012), Destruel et al. (2015)).

From a cross-linguistic perspective, it has been noted that exclusives such as only (and possibly also scalar particles such as even) are the only focus sensitive expressions that need to conventionally associate with focus and require focus alternatives (see Zimmermann and Onea (2011) for a detailed discussion). This does not hold for other focus sensitive expression such as additive particles (also). For the case of Chadic languages, the conclusion has been drawn that these focus expressions are not as closely related to focus and do not conventionally associate with focus (Zimmermann and Onea (2011)). However, note that for the case of English, both exclusives and additives have been analyzed as belonging to the same class of conventionally associating particles (see Beaver and Clark (2008)), because these particles function as operators that have an effect on every sentence they appear in. We can generally distinguish three classes of focus sensitive expressions, which are listed and briefly summarized below (see Beaver and Clark (2008) for a full discussion).

1. Quasi Association with focus:

The focus sensitive operators that bear a quasi-association with focus result in a pragmatic inference, which can be canceled. The expressions that fall under this class are non-veridical, propositional operators, e.g. negation, either and perhaps. The negation of a proposition does not entail the proposition itself, which is why it is non-veridical. The negation applies only to the focused part of the utterance, while the remaining elements of the sentence are not negated, like in the examples below:

a. Kim doesn't study [linguistics] $]_{F}$ at Northwestern.

b. Kim doesn't study linguistics at [Northwestern $]_{F}$.

In these examples, what determines the QUD is the position of the focus, resulting in a pragmatic effect.

2. Free Association with focus:

When a focus-sensitive operator freely associates with focus, a free variable needs to be resolved. This is the case for pronouns or ellipsis, quantificational determiners, like every, superlatives, counterfactuals, because-clauses, modals, emotive factive verbs, verbs of desire, as well as quantificational adverbs such as always, usually and mostly. 
3. Conventional Association with focus:

Particles that conventionally associate with focus bear a grammatical dependency on the CQ, which is also lexically encoded. Therefore, these operators should have an effect on the focus on every sentence they appear in, independent of context or other pragmatic constraints (e.g. CG). Beaver and Clark (2008) name the following operators as belonging to this class: exclusives: only, just, merely, additives: too, also, scalar additives: even, intensifiers: really, totally, downtoners: kind of, barely, hardly, at the least, scarcely, at most, at best, and particularizers: in particular, for example.

Beaver and Clark (2008) note that, while these operators are all supposed to conventionally associate with focus, they may serve different purposes: the function of exclusives is to say that the strongest true answer to the Current Question (CQ) is weaker than some expected answer, and the function of scalar additives like even is to say that the strongest true answer is stronger than expected. An additive like too says that its argument parallels a previous answer to the CQ.

To sum up, focus can be described as a universal category of information structure. The focusing of a sentential element facilitates information updates by indicating which contextually relevant alternatives are available for the evaluation of a given assertion in the context of utterance (see Zimmermann and Onea (2011)).

\subsubsection{The Notion of Topic}

This thesis follows the following definition of topicality:

The topic of a book, a conversation, a sentence, a piece of research, or a movie is taken, in ordinary use, to be what the book or the conversation, etc., are about. (Reinhart (1981), 54)

A topic is therefore what a sentence is about. ${ }^{9}$ Since the notion of topic is used to describe a relation between different elements of a sentence, it is called a relational term. However, it does not behave like other relational terms. It can, for instance, not be defined on syntactic structures alone, because it is possible for various expressions of a sentence to be the topic of that sentence. The actual sentence topic depends on the context of utterance. Reinhart (1981) shows that the question test can be used to determine the topic of a sentence. Like in the example below, what is the topic of a sentence depends on the discourse question it is being used to answer (with alternations of intonation in the sentence):

\footnotetext{
${ }^{9}$ Another word for what is here called topic (in the Anglo-Saxon tradition, as Reinhart (1981) points out) is the term theme, which has been introduced by the Prague School of functional linguistics (see e.g. Sgall et al. (1973)).
} 
Max saw Rosa yesterday.

a. Who did Max see yesterday? Topic: Max

b. Has anybody seen Rosa yesterday? Topic: Rosa (Reinhart (1981), 56)

Because the notion of topic is sensitive to context, it is a pragmatic phenomenon. The notion of topic put forward by Reinhart (1981) can also be called aboutness, and defines topicality as a relation between an argument and a proposition relative to a context. Previous notions of topic highlight information status as the only relevant factor for topicality (see Chafe (1976)). This leads to a definition of topic as the old ${ }^{10}$ or given information, and defines topicality as a property of the referents denoted by the linguistic expressions in a given context.

Krifka (2008) agrees with the description of topicality presented by Reinhart (1981), namely as the element that the sentence is about, while the rest of the sentence, the comment, provides the information about the topical element.

a. [Aristotle Onassis $]_{\text {topic }}[\text { married Jacky Kennedy }]_{\text {comment }}$

b. [Jacky Kennedy $]_{\text {topic }}[\text { married Aristotle Onassis }]_{\text {comment }}$

Both sentences in (63) express the same proposition, but (63)a provides information about Aristotle Onassis (namely, that he married Jacky Kennedy), while (63)b tells us something about Jacky Kennedy (namely, that she married Aristotle Onassis).

Reinhart (1981) integrates this notion of topic into a theory that uses the notion of the CG. New information, in this framework, is not just added to the CG content unordered, but is immediately associated with entities. She uses the image of files that are stored: Every information in a file card system is linked to file cards with certain headings. For the example in (63), this means that (63)a is saved as information about Aristotle Onassis, and (63)b is saved as information about Jacky Kennedy, even though both sentences express the same proposition. Krifka (2008) defines topicality in relation to this file-like structure assumed by Reinhart (1981) as follows ${ }^{11}$ :

\footnotetext{
${ }^{10}$ The word old here is equivalent to the notion fo shared knowledge of interlocutors in a discourse (see Clark and Haviland (1977) A piece of information is old in those cases where it is assumed to be generally known by or accessible to all participants of a given discourse, without having to be made explicit.)

${ }^{11}$ By including sets of entities in this definition, Krifka (2008) accounts for the way that quantified sentences are usually interpreted. In the examples below, the quantifiers have the function of expressing to what extent the comment holds for the elements of the set.
}

(i) Every zebra in the zoo was sick. (Krifka (2008), ex. 42)

(ii) Most zebras in the zoo were sick. (Krifka (2008), ex. 42) 
(64) The topic constituent identifies the entity or set of entities under which the information expressed in the comment constituent should be stored in the CG content. (Krifka (2008), ex. 39)

The file-card metaphor used by Reinhart (1981) explains why sentences typically have one single topic (while it is however possible to have sentences with multiple topics). The easiest way to add information is to add it on one single file card.

A special class of topics are the contrastive topics, which have a rising accent, as illustrated below:

A: What do your siblings do?

B: $\left[\mathrm{My}[\mathrm{SISter}]_{\text {focus }}\right]_{\text {topic }}[\text { studies MEDicine }]_{\text {focus }}$, and $\left[\mathrm{my}[\mathrm{BROther}]_{\text {focus }}\right]_{\text {topic }}$ is [working on a FREIGHT ship] focus

This class is special because contrastive topics are not means of informationpackaging, but rather represent combinations of topic and focus. As illustrated by the sentence in (65), contrastive topics consist of an aboutness topic that contains a focus. The focus has the same function as any focus usually does, namely indicating an alternative. In the case of the example in (65), it indicates an alternative aboutness topic: the focus on the topic my sister indicates the alternative topic my brother. The function of these contrastive topics is most commonly to highlight that the present sentence fails to deliver all the information that is expected by the hearer.

Both Reinhart (1981) and Krifka (2008) suggest that one should not model the notion of topic as simply referring to old information, as this disregards important aspects of what a topic can be (e.g. new information).

In the example below, a new entity is introduced into the discourse, while at the same time being used as the denotation of a topic constituent, which means that a new file card is being introduced into the CG content.

$$
[\text { A good friend of mine }]_{\text {topic }}[\text { married Britney Spears last year }]_{\text {comment }}
$$

To sum up, topic can be described in terms of aboutness as what a given conversation, sentence, etc. is about. The topic constituent identifies the entity under which the information that is expressed in the comment constituent should be stored in the CG content. Typically, sentences have one topic ${ }^{12}$.

\footnotetext{
${ }^{12}$ For further discussion on the notions of topic and focus also see Gundel and Fretheim (2003), Zimmermann and Onea (2011).
} 


\subsubsection{It-Cleft Exhaustivity}

In general, it is taken as a robust intuition that cleft structures like in (67) come with an exhaustivity inference as shown in (68). Therefore, most theories of it-cleft semantics argue that the cleft comes with an exhaustivity inference, which is often taken to be similar to the assertion in exclusive sentences like (69).

(67) It was $[\text { Sue }]_{F}$ who climbed a mountain. (Cleft Sentence)

(68) Nobody other than Sue climbed a mountain. (Exhaustivity Inference)

(69) Only $[\text { Sue }]_{F}$ climbed a mountain.

A central question that is yet to be conclusively answered is, whether this exhaustivity effect is conventionally coded in the structure of the cleft and therefore semantic (see e.g. Büring and Križ (2013)), or can be derived pragmatically as a conversational implicature (see e.g. Horn (1981)). In what follows, different approaches to this exhaustivity question will be described.

\subsubsection{Exhaustivity via Presuppositions}

Percus (1997) identifies it-clefts as definite descriptions. It-clefts carry the same presuppositions (existence and uniqueness) as their corresponding definite description. This means that the two sentences in (70)a and (70)b below do not differ in their presuppositions. The presuppositions do not hold for the corresponding non-clefted version in $(70) \mathrm{c}$ :

a. It is Sue who dances.

b. The individual that dances is Sue.

c. Sue dances.

Percus (1997) tests whether a sentence comes with an existence presupposition by using the insertion of nobody into the cleft pivot. This leads to an infelicitous sentence as it clashes with the existence presupposition:
A: Who saw John?
B: $[\text { NObody }]_{F}$ saw John.
$\mathrm{B}^{\prime}$ : *It is $[\text { NObody }]_{F}$ who saw John. (Percus $\left.(1997), 339\right)$

The existence presupposition (there is someone who saw John) in the it-cleft is contradicted by the utterance that nobody saw John.

The existence presupposition also holds up under negation:

a. Since nobody saw John, it follows that Bill didn't see John.

b. \# Since nobody saw John, it follows that it isn't Bill who saw John. 
Because of the uniqueness-presupposition, it-clefts are incompatible with particles like even and also, and redundant (yet, possible) with exclusive particles such as only. Since these particles can usually associate with focus, as in (73), Percus (1997) argues that, in the case of it-clefts, the uniqueness-presupposition of the cleft and the semantics of the particles clash. This clash leads to unacceptable sentences, as illustrated below (74)a-c:

(73) It was even/also/only the case that $[\mathrm{JOHN}]_{F}$ saw Mary. (Percus (1997), 341)

(74) a. ?It was even/also/only the case that it was $[\mathrm{JOHN}]_{F}$ who saw Mary.

b. ??It was even $[\mathrm{JOHN}]_{F}$ who saw Mary.

c. ??It was also $[\mathrm{JOHN}]_{F}$ who saw Mary. (Percus $\left.(1997), 341\right)$

The exclusive, however, does not carry the same presuppositions as the two other particles and does therefore not clash with the uniqueness-presupposition of the it-cleft. Only does therefore not lead to an unacceptability of the sentence:

It was only $[\mathrm{JOHN}]_{F}$ who saw Mary.

While exclusives can felicitously appear in it-clefts (as illustrated in (73)), Percus (1997) notes that they are redundant in the it-clefts. He assumes that "the requirement is something special about the cleft" (Percus (1997), 340). The issue is further addressed by Velleman et al. (2012), who agree with Percus (1997) that it-clefts and exclusives have the same meaning component. Velleman et al. (2012) suggest that it-clefts and exclusives differ in the at-issueness ${ }^{13}$ of the meaning component: while the exhaustivity in asserted with exclusives and presupposed or conventionally implicated with it-clefts (see Velleman et al. (2012), 442)

Büring and Križ (2013) observe that the account proposed by Percus (1997) can not account for are examples such as (76) below. Here, (76) a and b do not presuppose (76)c:
a. It wasn't Fred she invited.
b. Was it Fred she invited?
c. She invited Fred an no-one else. (Büring and Križ (2013), 3)

A possible line of defense for Percus (1997) is that the presupposition could be that she invited exactly one individual (and therefore a cleft of the form it was $x$ that $P$ presupposes that $P$ denotes a singleton set). But this approach falsely predicts that the following example should be bad, as the second sentence contradicts the

\footnotetext{
${ }^{13}$ For a more detailed discussion of the notion of at-issueness also see chapter 4 of this thesis.
} 
presupposition that it is exactly one individual ${ }^{14}$ :

It wasn't Fred she invited. She invited Bob and Gord. (Büring and Križ (2013), 3)

The new analysis proposed by Büring and Križ (2013) suggests the following: The presupposition of an it-cleft is that the cleft pivot is not a proper part of the maximal members that fulfill the cleft relative. This is illustrated in the example below:

It was Fred she invited. (It is $x$ that $P$ )

Assertion: She invited Fred.

Presupposition: Fred is not a proper part of the sum of all people invited by her. (Büring and Križ (2013), 4)

It is important to note that invite is a distributive predicate, which requires that if $x$ is in $P$, it is the maximal $P$, the sum of all elements in $P$. When the assertion and presupposition of the example above are combined, the exhaustivity inference (She invited Fred an no-one else) is satisfied. A continuation that does not satisfy the exhaustivity, as illustrated below, is predicted to lead to a presupposition failure

\footnotetext{
${ }^{14}$ On a historical note, Halvorsen (1978) also uses uniqueness to account for it-cleft exhaustivity. Halvorsen (1978) identifies uniqueness as the source of it-cleft exhaustivity. He does not use a uniqueness operator to derive the inference, but proposes that the cleft pivot is identical to the relative pronoun. Additionally, in his framework, the cardinality of the relative pronoun is fixed to be identical with the cardinality of the cleft pivot as the result of a conventional implicature.

(i) It was Mary who climbed a mountain.

Conventional Implicature: At most $n$ people climbed a mountain and $n=\mid$ Mary $\mid$

Exhaustivity is not seen as a truth-conditional property of the cleft, but a uniqueness requirement reached via a Conventional Implicature that depends on cardinality.

Atlas and Levinson (1981) observe that questions do not preserve this Conventional Implicature. Therefore, they argue against using a fixed cardinality to reach uniqueness.

(ii) A: Was it John and Rick that Mary kissed?

Conventional Implicature: Mary kissed only two persons

B: No, she kissed John, Rick, and Mart. (Atlas and Levinson (1981), 25)

The example illustrates that the cardinality is not fixed in question-answer-pairs, as it is possible to deny the implicature and violate it with a direct answer. Instead of cardinality, Atlas and Levinson (1981) suggest that it-cleft exhaustivity is reached via an identity operator. The identity operator states that if anything is true of the cleft relative, then that thing must be identical to the cleft pivot. Identity determines it-cleft exhaustivity. For the question-answer-pair in (ii) above, this means that what the question is asking is whether the $\mathrm{x}$ that kissed Mary is identical to John and Rick.
} 
for the cleft. The reason for this is that an addition to the cleft relative would mean that Fred is a proper part of the sum of all invitees.

She invited Fred and Gord.

The way exhaustivity is described as a presupposition by Büring and Križ (2013) is via the notion of uniformity, which is closely connected to definites. A definite description of the form "The individuals she invited" maps a property $Q$ to true if there is an individual $x$ she invited which has property $Q$ and presupposes that every individual $x$ she invited is part of $x$. The negation of the cleft as stated above, i.e. "The individual she invited is not Fred" is therefore true if the maximal individual she invited is not Fred, which is also valid for cases in which she invited a sum of individuals, e.g. Fred and Gord. Exhaustivity, therefore, is not taken to be part of the presupposition, which Büring and Križ (2013) take to mean that the exhaustivity in it-clefts is not part of the asserted meaning of the it-cleft. The uniformity presupposition of definites states that a sentence of the form "[The $P$ ]

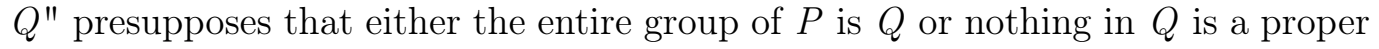
part of the maximal $P$. Büring and Križ (2013) further argue that, for the case of it-clefts, distributive and collective predicates show the same behavior, namely that if $a$ is a proper part of those who $Q$, a sentence of the form "It was $a$ that Qed" is undefined rather than false.

To sum up, Büring and Križ (2013) propose an analysis of the exhaustivity in it-clefts that states that the exhaustivity is a presupposition such that any individual in the domain of the function denoted by the structure "It was $x$ that $P$ " is not a proper part of the extension of $P$, with the important entailment that if the individual is in $P$, then it is the maximal $P$.

To describe the exhaustivity in it-clefts via presuppositions has certain advantages. It for example explains why some elements (i.e. non-exclusive focus particles such as even and also) cannot appear in the cleft pivot. When looking at naturally occurring examples, it can be asked if that prediction meets the data. Consider the following corpus examples:

(80) Es ist auch ihre Perspektivlosigkeit, die viele Jugendliche zur Flasche greifen lässt.

It is also their lack of perspective that makes many teenagers reach for the bottle.

(RHZ04/APR.20135 Rhein-Zeitung, 23.04.2004 ; Jugend braucht mehr Chancen)

(81) Es ist vor allem das Nahrungsangebot, das die Halden für Möwen attraktiv macht. 
It is especially the range of food that makes the dumps attractive for seagulls.

(K00/MAI.35512 Kleine Zeitung, 04.05.2000, Ressort: Lokal ; Möwenforscher lauert den Vögeln in Müllhalden auf)

The examples illustrate that the predicted clash of the meaning component of the particle and the exhaustivity inference of the it-cleft does not occur. This will be addressed further in chapter 3 of this thesis.

\subsubsection{Exhaustivity as a Semantic Property of Focus}

The exhaustivity inference in it-clefts has been derived as a semantic property of this focus construction. É. Kiss (1998) argues that identificational focus (expressing exhaustive identification) must be distinguished from information focus (conveying new information $)^{15}$. The function of identificational focus is defined as follows:

(82) An identificational focus represents a subset of the set of contextually or situationally given elements for which the predicate phrase can potentially hold; it is identified as the exhaustive subset of this set for which the predicate phrase actually holds. (É. Kiss (1998), 245)

In contrast, information focus is described as follows:

(83) If a sentence part conveys new, non-presupposed information marked by one or more pitch accents-without expressing exhaustive identification performed on a set of contextually or situationally given entities, it is not an identificational focus but a mere information focus. Information focus is not associated with movement. An information focus is present in every sentence, but not every sentence contains an identificational focus. (É. Kiss (1998), 246)

Focused expressions that appear in the immediately pre-verbal position in Hungarian are cases of identificational focus, as illustrated below. When the focused element appears in any other position in the sentence, this exhaustivity inference is not available (cf. Szabolcsi (1981), Onea and Beaver (2009)). In these cases, the focus is merely marked prosodically. ${ }^{16}$

\footnotetext{
${ }^{15}$ Note that both kinds of focus described here are identificational in some way, as mentioned by Kenesei (1986).

${ }^{16}$ The examples below include the verbal modifier meg. Verbal modifiers can appear before the verb in a 'neutral' sentence (the sentence then is unmarked), but postpose in the presence of a focused expression in the pre-verbal focus construction (see e.g. Wedgwood (2005)).
} 
Péter MARIT csókolta meg.

Peter Mary.ACC kissed PRF

Peter kissed Mary (and no one else).

Péter meg-csókolta MARIT.

Peter PRF-kissed Mary.ACC

Peter kissed Mary (and possibly someone else as well). (Onea and Beaver (2009), 342)

The following two examples illustrate the two kinds of focus for the case of Hungarian:

Immediate pre-verbal (ex situ) focus, expresses exhaustive identification ${ }^{17}$ :

Tegnap este $[\text { Marinak }]_{F}$ mutattam be Pétert. last night Mary.DAT introduced.I PERF Peter.ACC

It was [to Mary] $]_{F}$ that I introduced Peter last night. (É. Kiss (1998), 247)

Postverbal (in situ) focus, does not express exhaustivity:

Tegnap este be mutattam Pétert [MARINAK $]_{F}$.

Last night I introduced Peter [TO MARY] . (É. Kiss (1998), 247)

As illustrated in (86), the pre-verbal position has some characteristics that distinguish it from postverbal focus, which is illustrated by (87). First of all, the pre-verbal position can only be filled with one element per sentence (see Wedgwood (2005), Zimmermann and Onea (2011)). This is due to the fact that the pre-verbal position is strictly adjacent to the verb. Secondly, the pre-verbal focus is prosodically marked by a pitch accent on the focused element which precedes the prosodically unmarked verb. All other elements following the focus are not stressed. A third feature of the pre-verbal focus construction is the presence of a so-called verbal modifier. Verbal modifiers are a group of items that appear unmarked in front of the verb in unmarked sentence constructions, but postpose when appearing in a pre-verbal construction in combination with a focused expression or negation (see Wedgwood (2005)). This is illustrated in the examples below:

(88) Kati megevett egy almát.

$$
\text { Kati VM-ate an apple-ACC }
$$

\footnotetext{
${ }^{17}$ As noted by Zimmermann and Onea (2011), the exhaustivity that comes with pre-verbal ex situ focus in Hungarian does not affect the asserted content, but may possibly be reached via a presupposition.
} 
Kati ate an apple (up).

(89) Kati evett meg egy almát.

Kati ate VM an apple-ACC

It's Kati who ate an apple (up).

(90) Kati (*meg)evett egy almát.

Kati VM-ate an apple-ACC

Intended: It's Kati who ate an apple (up). (Wedgwood (2005))

Another example for identificational focus are exclusives, such as only, which are analyzed as identificational foci carrying an evaluative presupposition. The constituent bearing the identificational focus stands for the value of the variable that is bound by an abstract operator which expresses exhaustive identification.

Certain types of constituents (e.g. universal quantifier, also/ even-phrases, as well as something/somebody) cannot function as identificational focus. However, there is no restriction on the type of constituents that can function as information focus. Since the pre-verbal focus construction in Hungarian has often been translated as a cleft construction in English, É. Kiss (1998) uses this construction to illustrate her position on it-cleft exhaustivity. ${ }^{18}$ É. Kiss (1998) argues that for the case of English, identificational focus is realized in clefts, while in situ foci with a pitch accent fail to express exhaustive identification. The intuition that non-clefted sentences with a pitch accent do not express exhaustivity can be confirmed by tests. One test was introduced by Szabolcsi (1981). This particular test consists of a pair of sentences, where the first sentence contains a focus with two coordinate DPs and the second sentence still has one of the two DPs, while the second DP has been dropped. Usually, it can be assumed that two coordinate constituents have a logical relationship, meaning that the second DP can be assumed to logically follow from the first DP. This is illustrated below. If the sentence in (b) is not among the logical consequences of the preceding sentence in (a), the focus can be said to express exhaustive identification (see É. Kiss (1998), 250). The examples in (91) illustrate this for the Hungarian pre-verbal focus and the English it-cleft, while the example in (92) illustrate this for the case of Hungarian post-verbal information focus and English in situ focus.

a. Mari egy kalapot és egy kabátot nézett ki magának.

a. Mary a hat.ACC and a coat.ACC picked out herself.to

It was [a hat and a coat) $]_{F}$ that Mary picked for herself.

b. Mari egy kalapot nézett ki magának.

b. Mary a hat.ACC picked out herself.to

It was [a hat] $]_{F}$ that Mary picked for herself. (É. Kiss (1998), 250)

\footnotetext{
${ }^{18}$ For a more detailed discussion of Hungarian pre-verbal focus see chapter 4 of this thesis.
} 
a. Mari ki nézett magának EGY KALAPOT ÉS EGY KABÁTOT.

a. Mary out picked herself.DAT a hat.ACC and a coat.ACC

Mary picked A HAT AND A COAT for herself.

b. Mari ki nézett magának EGY KALAPOT.

b. Mary out picked herself.DAT a hat.ACC

Mary picked A HAT for herself. (É. Kiss (1998), 250)

As É. Kiss (1998) argues, (91)b is not a logical consequence of (91)a, but actually a contradiction. It was /a hat $]_{F}$ that Mary picked for herself does not follow from It was [a hat and a coat $]_{F}$ that Mary picked for herself.

(92)b, however, is a logical consequence of (92)a. Mary picked A HAT for herself does follow from Mary picked A HAT AND A COAT for herself.

Therefore, both the Hungarian pre-verbal identificational focus and the English it-cleft in (91) pass this exhaustivity test, but the post-verbal and plain focus do not.

To sum up, É. Kiss (1998) defines identificational focus as a semantic operator expressing exhaustive identification, while information focus is the carrier of new information.

The assumption that Hungarian pre-verbal focus comes with a strong structural exhaustivity much like that found with exclusives (see e.g. Szabolcsi (1981), Kenesei (1986), É. Kiss (1987), Szabolcsi (1994)) has been challenged in the literature (see e.g. Wedgwood et al. (2006), Szendrối (2003)).

Rather, similar to the case of it-clefts, the meaning of ex situ pre-verbal focus in Hungarian has been described (see e.g. Zimmermann and Onea (2011)) as being not identical to that of sentences expressing exhaustivity via an exclusive such as only in English or csak in Hungarian, as illustrated in the examples below:

(93) A tanár sajnálja, hogy csak [Johnnak $]_{F}$ sikerült a teszt.

The teacher regrets the fact that only John passed the test. (Zimmermann and Onea (2011), 1667)

(94) A tanár sajnálja, hogy $[\text { Johnnak }]_{F}$ sikerült a teszt.

The teacher regrets the fact that it is John that passed the test. (Zimmermann and Onea (2011), 1667)

The sentence in (94) is true in a situation where more than one student passed the test (among them John), but the teacher would have preferred for John not to pass. The sentence in (93) is true in a situation when no other students apart from John passed the test, but the teacher does not have any particular attitude towards John's passing the test.

The first experimental study which shows that the intuition that exhaustivity in 
pre-verbal focus and it-clefts is not as strong as previously assumed is provided by Onea and Beaver (2009). Onea and Beaver (2009) ${ }^{19}$ present a text-completion task with multiple choice for answers for Hungarian focus which shows that the exhaustivity effect found in Hungarian pre-verbal focus is not as strong as the effect which can be observed with the exclusive focus particle csak/only. They argue against the common analysis of pre-verbal focus as semantically exhaustive, i.e. that the exhaustivity is part of the truth-conditional content of the construction. Onea and Beaver (2009) propose a pragmatic account of pre-verbal focus exhaustivity. Their experimental design, the so-called "Yes, but"-test, aims at measuring the way participants react to sentences in which the exhaustivity inference in Hungarian pre-verbal focus was violated in relation to visual stimuli. For the case of pre-verbal focus as illustrated in (95), matched with a picture that contradicts the exhaustivity inference, participants were asked to choose from the possible answers in (96) below:

$$
\begin{aligned}
& \text { MARCI fogott meg egy lepkét. } \\
& \text { Marci caught PRT a butterfly } \\
& \text { It was Marci who caught a butterfly. (Onea and Beaver (2009), ex. (14)) } \\
& \text { a. Yes, and Peter caught a butterfly, too. } \\
& \text { b. Yes, but Peter caught a butterfly, too. } \\
& \text { c. No, Peter caught a butterfly, too. }
\end{aligned}
$$

The hypothesis was that if Hungarian pre-verbal focus comes with a strong exhaustivity effect, participants would chose the answer in (c) as their reaction to an overt violation of the exhaustivity. If, on the other hand, the exhaustivity inference is weak, participants would react by choosing (a) or (b). The results show that for the case of exclusives, as illustrated in (97), speakers rejected the violation of exhaustivity by choosing the answer in (c). However, in the case of the pre-verbal focus, less participants chose the (c) answer.

$$
\begin{aligned}
& \text { Csak MARCI fogott meg egy lepkét. } \\
& \text { Only Marci caught PRT a butterfly } \\
& \text { Only Marci caught a butterfly. (Onea and Beaver (2009), ex. (15)) }
\end{aligned}
$$

Given these results, Onea and Beaver (2009) draw the conclusion that the exhaustivity effect that comes with Hungarian pre-verbal focus is a pragmatic effect. The analysis they present assumes that pre-verbal focus leads to exhaustivity as a pragmatic implicature. This implicature arises because the pre-verbal focus indicates that the corresponding sentence is an answer to a wh-question. Speakers have a pragmatic tendency to interpret answers to questions as complete (or: exhaustive)

\footnotetext{
${ }^{19}$ For a more detailed discussion of this approach, see chapter 4 of this thesis.
} 
answers in a cooperative discourse, which explains the (weak but present) exhaustivity inference.

Destruel $(2012)^{20}$ replicates the findings of Onea and Beaver (2009) for the case of French. She presents an empirical study on the exhaustivity effect in French it-clefts. As for the case of English and German, French it-clefts have been argued to come with an exhaustivity inference that is part of the semantic meaning of the cleft (see e.g. Clech-Darbon et al. (1999)).

(98) C'est $[\text { Batman }]_{F}$ qui a pour mission d'attraper les cambrioleurs.

It is Batman who has the mission of catching thieves.

Exhaustivity Inference: No one else than Batman has the mission of catching thieves (Destruel (2012), 95)

Seul $[\text { Batman }]_{F}$ a pour mission d'attraper les cambrioleurs.

Only Batman has for mission to catch thieves.

Exhaustivity Inference: No one else than Batman has the mission of catching thieves (Destruel (2012), 95)

Destruel (2012) challenges this assumption, and argues that, while both structures are similar, the acceptability of these structures when exhaustivity is violated diverges. In an experiment which uses the experimental design of the "Yes, but"test introduced by Onea and Beaver (2009), the degree of exhaustivity of French it-clefts were tested. Participants were presented with a questions-answer-pair and three possible continuations of which they were asked to choose the most natural.

(100) Q: Qu'est-ce que le fermier a brossé?

What is it that the farmer has brushed?

'What is it that the farmer brushed?'

(101) A: C'est le cheval que le fermier a brossé.

'It's the horse that the farmer brushed.'

(102) C1: Oui, et le fermier a aussi brossé la chèvre.

'Yes, and the farmer also brushed the goat.'

C2: Oui, mais le fermier a aussi brossé la chèvre.

'Yes, but the farmer also brushed the goat.'

C3: Non. Le fermier a aussi brossé la chèvre.

'No. The farmer also brushed the goat.' (Destruel (2012), 101)

The results indicate that the exhaustivity effect associated with a c'est-cleft is not as strong as the one that comes with an exclusive, but much stronger than that

${ }^{20}$ For further studies on French it-clefts also see Destruel (2017), Destruel (2013) 
of a canonical. The results further support the prediction that native speakers of French are more likely to overtly contradict sentences that are semantically exhaustive (as in the case of exclusives such as only) than in structures where exhaustivity is somewhat weaker. Destruel (2012) concludes that the French c'est-cleft does not semantically contribute exhaustivity to the meaning fo a sentence, and the exhaustivity inference is part of the non-at-issue meaning ${ }^{21}$ of the French it-cleft. ${ }^{22}$

As the results found by by Onea and Beaver (2009) and Destruel (2012) suggest, there are differences in the exhaustivity inference that comes with exclusives and it-clefts or the pre-verbal focus construction. The studies discussed above only test for conscious behavior of participants. Drenhaus et al. (2011) present an empirical study that tests for subconscious behavior to close this research gap. Drenhaus et al. (2011) provide two experiments (for German) in which they work with violation and cancellation of the exhaustivity inference in different structures to show that it-clefts and exclusives do not have the same processing costs. This means that the two structures are processed in different ways, and the exhaustivity that comes with it-clefts is processed with a higher cognitive cost than the exhaustivity of exclusives. In their first experiment, Drenhaus et al. (2011) compare ERP (event related potential) patterns ${ }^{23}$ of non-exhaustive it-clefts versus their exhaustive counterparts, as well as violations of the exhaustivity in sentences with exclusives.

Drenhaus et al. (2011) first replicate the experiment designed by Onea and Beaver (2009). They conduct an acceptability rating study in which participants judge the acceptability of sentences including exhaustivity violations on a six-point scale. The results show that native speakers are less accepting of exhaustivity violations in only sentences than in it-clefts. These results suggest that the exhaustivity (or the violation of exhaustivity) in the two structures may be different.

In the following, novel ERP study, participants are presented with written input material on a screen, with a unit-by-unit presentation of the material. After the end of each trial, a single noun is presented on screen and participants are asked to say whether or not this noun had been part of the previous trial.

The measured effect was a globally distributed negativity as a reaction to exhaus-

\footnotetext{
${ }^{21}$ For a more detailed discussion of the notion of at-issueness also see chapter 4 of this thesis.

${ }^{22}$ In light of this approach, the results of Onea and Beaver (2009) were reconsidered by Destruel et al. (2015) to show that the "Yes, but"-test does not actually diagnose the source of the exhaustivity inference (semantic or pragmatic), but its status (at-issue or non at-issue). For the tested languages Hungarian, German, French and English, the authors conclude that the exhaustivity inference of cleft sentences is not at-issue. This is further discussed in the following section.

${ }^{23}$ The use of ERP patterns is a method that has been proven useful to investigate language processing and linguistic theories, and has been used to investigate the notion of focus, see e.g. Bornkessel et al. (2003) Cowles et al. (2007)
} 
tivity violations in it-clefts. Drenhaus et al. (2011) conclude that the exhaustivity effect in it-clefts is a semantic or pragmatic phenomenon, rather than syntactic. A syntactic violation should have triggered a positivity effect rather than a negativity effect. Drenhaus et al. (2011) conclude the following: when presented with an exhaustivity violation in it-clefts, speakers react with post-hoc canceling of the exhaustivity inference they have initially processed. Speakers thereby pragmatically adapt to the new information. Drenhaus et al. (2011) moderately argue that the question whether exhaustivity is a conventional meaning component of it-clefts or the result of pragmatic strengthening still remains open at this point. However, when taking all of the studies discussed above into consideration, it is possible to make stronger predictions. Most of the studies that have challenged the assumption that the exhaustivity inference in it-clefts is semantic in nature presented results that indicate that this assumption is no longer valid. At this point of the research it can be assumed that either the assumption that the exhaustivity inference is semantic is false, or that studies which support this assumption do not correctly interpret the data.

\subsubsection{Exhaustivity as a Termination of Inquiry: At-issueness in it- Clefts and Exclusives}

While the previously discussed approaches have found that there are some similarities between it-clefts and exclusives, but the exhaustivity inference found in the two structures is not identical, Velleman et al. (2012) attempt to explain those findings with a novel approach ${ }^{24}$. They classify it-clefts and exclusives as inquiry terminating (IT) constructions. IT constructions have the following characteristics: they are focus-sensitive, have closely related semantics, and have the discourse function of marking an utterance to give a complete answer to the Current Question $(\mathrm{CQ})^{25}$. In this framework, it-clefts are treated as exhaustive. The exhaustivity is derived via two semantic operators, which are introduced into the logical form of the cleft. The crucial difference between the exclusive and the it-cleft is that in exclusives, exhaustivity is directly asserted and therefore at-issue, while in it-clefts, it is presupposed or conventionally implicated and therefore non at-issue.

Velleman et al. (2012) assume the following two semantic operators, $\mathrm{MIN}_{S}$ (presupposed, requirement: there is a true answer to the CQ above a certain lower bound) and $\mathrm{MAX}_{S}$ (asserted/at-issue, requirement: there is no true answer to the CQ above a certain upper bound). Exhaustivity in clefts and sentences with exclusives is treated as a pragmatic discourse function introduced via the two semantic operators $\mathrm{MIN}_{S}$ and $\mathrm{MAX}_{S}$ (S here stands for sentence). These IT-constructions

\footnotetext{
${ }^{24}$ Also see Velleman and Beaver (2016) for further discussion.

${ }^{25}$ For a more detailed discussion of the notion of the Current Question, see section 2.3.3 of this thesis.
} 
thereby assign to a sentence the function of being the maximal (or: complete/ exhaustive) answer to the CQ and terminating the line of inquiry.

In general, the part of an utterance that is at-issue is described as directly asserted (see Potts (2005)) or the "ordinary content" (see Beaver and Clark (2008)) of that utterance. ${ }^{26}$ At-issueness is often defined (see e.g. Potts (2005), Simons et al. (2010)) in opposition to Conventional Implicatures (CIs) (see Grice (1975)). CIs are secondary entailments rarely used by cooperative speakers to express propositions where speaker and hearer might disagree, or carry the main themes of a discourse. They can help the hearer to gain a better understanding of why the at-issue content is particularly relevant at that moment of discourse, as illustrated below:

(103) Ed's claim, which is based on extensive research, is controversial. at-issue: Ed's claim is controversial.

not-at-issue: Ed's claim is based on extensive research. (Potts (2005), 3)

The different at-issueness status of exclusives and it-clefts can, according to Velleman et al. (2012), also help explain the proposed asymmetry in the two constructions regarding informativeness, as illustrated by Horn (1981) using the following examples:

(104) I know Mary ate a pizza...

a. ?? but I've just heard it was a pizza she ate.

b. but I've just heard she only ate a pizza. (Horn (1981), 130)

The sentence in (b) bears the at-issue content and is therefore informative in itself (Mary ate a pizza and ONLY a pizza). While (b) can serve as an extension of the statement, this is not the case for (a). The cleft in (a) is redundant. The $\mathrm{MIN}_{S}$ (Mary ate at least a pizza), which is made at-issue by the cleft, is already in the Common Ground, and is therefore not informative.

While arguing that the exhaustivity in it-clefts is a discourse function, Velleman et al. (2012) still hold onto the idea that it is conventionally coded and cannot be canceled. In case speakers wish to close a line of inquiry but leave open the option of adding more information, other constructions are available (e.g. in situ focus):

A: Who laughed?

a. B: MARY laughed. So did JOHN.

b. B: \# It was MARY who laughed. And so did JOHN. (Velleman et al. (2012), 457)

\footnotetext{
${ }^{26}$ For a more detailed discussion of the notion of at-issueness also see chapter 4 of this thesis.
} 
As mentioned above, Destruel et al. (2015) take a new look at the data elicited by Onea and Beaver (2009) and present new data on it-clefts in English and French. The arguments are built directly on the results of Velleman et al. (2012) in terms of the non-at-issueness of it-cleft exhaustivity. Regarding the notion of at-issueness, they show that the "Yes, but"-test actually targets the at-issueness status of the exhaustivity, and not, as previously assumed, the source of the exhaustivity inference (semantic or pragmatic). The authors come to the conclusion that the exhaustivity in English and French it-clefts is non-at-issue. Destruel et al. (2015) adapt the experimental design of Onea and Beaver (2009) and add the following factors: relevance implicature, scalar implicature, appositives, and non-restrictive relative clauses. All these constructions have been argued to trigger presuppositions, implicatures, or other non-entailment inferences. These inferences all behave differently when it comes to at-issueness: Scalar Implicatures are at-issue, relevance implicatures may or may not be at-issue, while appositives and non-restrictive relative clauses are non-at-issue.

The experimental categories are illustrated in the examples below (see Destruel et al. (2015), ex. 23-26):

Relevance Implicature:

(106) There is a bank just a few steps further.

Inference to be contradicted: The bank will let you carry out whatever sort of business you need.

Possible Continuations: Yes, and / Yes, but / No, the ATM is broken.

Scalar Implicature:

(107) The soup is warm.

Inference to be contradicted: The soup is not hot.

Possible Continuations: Yes, and / Yes, but / No, the soup is hot.

Appositive:

(108) Paula, Peter's sister, had a baby.

Inference to be contradicted: Paula is Peter's sister.

Possible Continuations: Yes, and / Yes, but / No, Paula is not really Peter's sister.

Non-restrictive relative clause:

(109) Paul, who is very diligent, sits at his desk all day long.

Inference to be contradicted: Paul is very diligent.

Possible Continuations: Yes, and / Yes, but / No, Paul is not at all 
diligent.

Participants were asked to choose a continuation of the discourse which seemed most natural to them. The results show to be incompatible with the previous prediction that the "Yes, but"-test targets the source of the exhaustivity inference. Appositives, non-restrictive relative clauses, and relevance implicatures received mostly "Yes, but"-answers, while scalar implicatures received mainly "No"responses. The data elicited in Onea and Beaver (2009) are therefore re-interpreted to indicate that the exhaustivity in German es-clefts and Hungarian pre-verbal focus is not-at-issue.

In addition to re-evaluating this previous experiment, Destruel et al. (2015) present new experimental data on English and French it-clefts which also support the prediction that the exhaustivity inference is not-at-issue. The design used by Onea and Beaver (2009) is adapted again. The assumption is that at-issue inferences are to be contradicted with the "No"-response, while non-at-issue inferences trigger a weaker response ("Yes, but" or "Yes, and"). This time, there was no visual stimulus, but an audio-dialog of the form illustrated in (98):

(110) What did Phillip buy for his sister?

a: Phillip bought his sister A NECKLACE.

b. It was a necklace that Phillip bought his sister.

c. Phillip only bought his sister a necklace.

Once again, participants were asked to choose from three answer options, illustrated below for the given example:

a. Yes, and Phillip also bought his sister a bracelet.

b. Yes, but Phillip also bought his sister a bracelet.

c. No, but Phillip also bought his sister a bracelet.

For the case of English, participants mostly contradicted the answer with "No" in the cases of sentences with exclusives, significantly more often than in the case of it-clefts. Canonicals and it-clefts pattern similarly. In the case of French, in clefts and canonicals, the two weaker answer options are preferred, while exclusives trigger an overt contradiction with "No". Therefore, Destruel et al. (2015) see their hypotheses verified and conclude that it-clefts (like Hungarian pre-verbal focus) carry a non-at-issue exhaustivity inference.

Horn (2014) agrees that at-issueness plays a key role in it-cleft exhaustivity. For him, the question is whether the exhaustivity is entailed or implicated ${ }^{27}$. Horn (2014) presents three counterarguments to the view that it-clefts (and other related

\footnotetext{
${ }^{27}$ Presupposition is ruled out by Horn (2014) because its projection properties are not satisfied
} 
focus constructions) assert and entail exhaustivity:

Firstly, it-clefts do not license negative polarity items (NPIs) in cases where there is no overt exhaustivity marker like an exclusive, which is illustrated below:

a. \# It is $[\mathrm{BUSH}]_{F}$ who ever proposed any tax cuts in wartime.

b. Only $[\mathrm{BUSH}]_{F}$ ever proposed any tax cuts in wartime.

c. It is only $[\mathrm{BUSH}]_{F}$ who ever proposed any tax cuts in wartime. (Horn (2014), 14)

Note that the cleft with the NPI becomes acceptable when combined with the exclusive only. Only makes the exhaustivity at-issue, while this is not the case in the cleft in (a). The plain cleft is not combinable with NPIs, which indicates that the exhaustivity in it-clefts is non-at-issue.

Secondly, clefts are uninformative when the corresponding un-marked proposition has already been established in the Common Ground. This is not the case for sentences with only.

I know Mary ate a pizza...

a. \# but I've just heard it was a pizza she ate.

b. but I've just heard she only ate a pizza.

c. but I've just heard it was only a pizza that she ate. (Horn (1981), 130)

When inserting only into the cleft construction, the exhaustivity becomes at-issue, and the statement in the cleft is no longer uninformative.

Thirdly, the exhaustivity in clefts can be canceled or overridden, such as illustrated below:

It's the ideas that count, not just the way we write them. (Horn (2014), 16)

The "Yes-but" task, introduced by Onea and Beaver (2009), is slightly altered to illustrate that it-cleft and Hungarian pre-verbal focus exhaustivity is a result of the interaction between focus and the Question Under Discussion ${ }^{28}$ and therefore a pragmatic phenomenon. Horn (2014) supports this argument further by introducing the "Bullshit-diagnostic" which is modeled after the "Yes-but" test and uses the refutation maker bullshit.

A: It's you I love.

$\mathrm{B}_{1}$ : \# Bullshit - you love Rosalin, too.

$\mathrm{B}_{2}$ : Yes, but you love Rosalin, too. (Horn (2014), 22)

\footnotetext{
${ }^{28}$ For a detailed discussion on the notion of the Question Under Discussion see section 2.3.3.2 of this thesis.
} 
A: It's only you I love.

$\mathrm{B}_{1}$ : Bullshit - you love Rosalin, too.

$\mathrm{B}_{2}$ : \# Yes, but you love Rosalin, too. (Horn (2014), 23)

As illustrated by the two different answers $B_{1}$ and $B_{2}$, the exhaustivity inference can be refused with the bullshit-marker when the exhaustivity is stated overtly via the exclusive. When only is not present in the cleft, the exhaustivity is not targeted by the refutation maker and the answer is not felicitous. Horn (2014) concludes that exhaustivity in clefts is - unlike in exclusives - not truth-functional. Citing Wedgwood (2005), Horn (2014) argues that exhaustivity is not part of the truth-functional meaning of neither identificational nor information focus. Instead, it is derived pragmatically via the discourse structure and the alternative sets present in the discourse. Overall, the conclusion is that it-cleft exhaustivity is non-at-issue and might be due to a conversational implicature. Furthermore, Horn (2014) suggests that it-cleft exhaustivity might be a matter of degree that can vary depending on the discourse function.

While Horn (2014) presents a theoretical account of the non-at-issueness of itcleft exhaustivity, DeVeaugh-Geiss et al. (2015) present an empirical study on the exhaustivity of German es-clefts that has its main focus on its at-issueness status. They work with the assumption that the exhaustivity in it-clefts is nonat-issue inference, directly opposed to the behavior of sentences with exclusives such as only, where the exhaustivity is an at-issue part of the asserted content, as illustrated below:

Only Sabine visited the zoo.

At-issue, semantic: Nobody other than Sabine visited the Zoo.

Not-at-issue, semantic: Sabine visited the zoo.

It was Sabine who visited the zoo.

At-issue, semantic: Sabine visited the zoo.

Not-at-issue, semantic/pragmatic?: Nobody other than Sabine visited the zoo.

As a third category, definite descriptions are tested, because clefts and definite descriptions have been described as similar (cf. Büring and Križ (2013)):

The one who visited the zoo is Sabine.

At-issue, semantic: Person who visited the zoo $=$ Sabine

Not-at-issue, semantic: Unique person that visited the zoo $=$ Sabine (i.e. Nobody other than Sabine visited the zoo)

The hypothesis of this experimental design is that it-clefts will show weaker ex- 
haustivity than sentences with exclusives. The experiment consists of a felicity judgment task with acceptability under contradiction. Participants judge the felicity of two conjoined sentences (of the three sentence types listed above) on a 7-point Likert scale. The second conjunct contradicts the meaning components, as illustrated below:

a. Only Philip fed the cat and Lars fed the cat. (at-issue contradiction) b. Only Philip fed the cat and he didn't feed the cat. (non-at-issue contradiction)

c. It's Philip who fed the cat and he didn't feed the cat. (at-issue contradiction)

d. It's Philip who fed the cat and Lars fed the cat. (non-at-issue contradiction)

The results do not support the hypothesis that it-cleft exhaustivity and exhaustivity in exclusives are different in terms of at-issueness. The results show no improvement in acceptability for exclusives between the at-issue and non-at-issue conditions, and they observe a highly significant improvement for clefts in the nonat-issue condition. However, the results are still compatible with exhaustivity in it-clefts being pragmatic. Based on these results, a follow-up experiment was run to test a possible presupposition failure of exclusives to that found with definite descriptions. This was done because it is possible that the results of the first experiment were due to the prejacent of exclusives being different from other at-issue inferences. Unlike in the first experiment, DeVeaugh-Geiss et al. (2015) did not find a significant interaction of sentence type and contradiction type. While in the first experiment, exclusives were judged equally unacceptable across the atissue and non-at-issue conditions, the second experiment showed a slight increase in acceptability in the non-at-issue condition. Their results show similar patterns for exclusives and definite descriptions, as participants judge the contradiction of at-issue content slightly worse than the presupposition failure for exclusives and definite descriptions.

In general, DeVeaugh-Geiss et al. (2015) argue that the hypothesis that the exhaustivity in it-clefts is weaker than the one found with exclusives as a result of the at-issueness was not supported. DeVeaugh-Geiss et al. (2015) compared (not)at-issue inferences with other (not-)at-issue inferences. Specifically, they tested the strong presupposition failures of exclusives to violations of exhaustivity in itclefts and pseudo-clefts with definite descriptions. What their results do support, however, is the prediction that the exhaustivity effect in clefts is weaker than the one found with exclusives as the result of a pragmatic phenomenon.

They propose an analysis of it-cleft exhaustivity as a scalar implicature triggered by focus, loosely following Horn (1981), and Horn (2014). The focal alternatives to the 
cleft pivot (in the clear-cut case of focus-background clefts) draw out scales. With the Maxim of Quantity (Grice (1975)) conversationally implicating the exclusion of alternatives higher on the scale, exhaustivity in it-clefts is reached via a pragmatic principle as the result of information enrichment.

\subsubsection{Exhaustivity as Conversational Implicature}

As discussed above ${ }^{29}$, the view that the exhaustivity found in it-clefts is a structural (or semantic) phenomenon has been challenged in the literature. The approaches to explain it-cleft exhaustivity that have been discussed above had one thing in common: they all generally assumed (at least as the starting point for their studies) that cleft structures are exhaustive in some way. Most of the studies discussed above cite the work of Horn (1981), who, on the other hand, challenges the view that the exhaustivity inference generally comes with it-clefts.

Horn (1981) lists three problems that come with structural approaches to it-cleft exhaustivity: First, it clefts can not be felicitously used in all contexts in which sentences with exclusives such as only can.

a. \# I know that Mary ate a pizza, but I've just discovered that it was a pizza that she ate!

b. I know that Mary ate a pizza, but I've just discovered that it was only a pizza that she ate!

(Horn (1981), 130)

This addresses the point that clefts have been described as being structurally similar to only, either via a definiteness operator (cf. Atlas and Levinson (1981), Chomsky (1977), Percus (1997)), or via an exhaustive focus feature (cf. É. Kiss (1998)).

Second, Horn (1981) presents four other structures that come with an exhaustivity inference, not in virtue of structural similarity but by having the same meaning as the it-cleft:

a. What Mary ate was a pizza. (Pseudo-cleft)

\footnotetext{
${ }^{29}$ This section discusses the approach to it-cleft exhaustivity presented by Horn (1981). It is discussed at this point of the thesis for argumentative reasons only, even though his work has been cited by the approaches discussed above. Historically, the approach of Horn (1981) was presented much earlier than some of the studies discussed above. It is presented isolated at this point in this thesis to highlight the fact that it argues for a pragmatic approach to it-cleft exhaustivity, which seems to be the general conclusion of the state of research up top this point. Therefore, even though Horn (1981) presented his approach very early on in the discussion on it-cleft exhaustivity, the theoretical and experimental debate following his paper culminates in the same line of conclusions that Horn (1981) proposed: that it-cleft exhaustivity is reached via a pragmatic process rather than semantically encoded into the structure of the cleft.
} 
b. The thing that Mary ate was a pizza. (Th-cleft)

c. A pizza, Mary ate. (Y-movement or focus shift)

d. Mary ate A PIZZA. (Contrastive or focus intonation) (Horn (1981), 132)

Exhaustivity is non-detachable, which means that expressions with identical meaning raise the same exhaustiveness premise (see Horn (1981)).

Third, Horn (1981) points out that exhaustivity does not project and does not hold for negated it-clefts or it-clefts in question form, not even in cases where the simple clefted counterpart is exhaustive. This argument is build on the work of Halvorsen (1978), who assumes that not only lexical items, but complex syntactical constructions (e.g. clefts) can have conventional implicatures (i.e. an exhaustivity implicature). In this framework, a cleft of the form in (123)a entails or asserts (123)b, and conventionally implicates (as well as entails) (123)c.

a. It was a pizza that Mary ate.

b. Mary ate a pizza.

c. Mary ate something.

d. Mary ate only a pizza. (Horn (1981), 129)

The existential premise, as Horn (1981) calls it, does hold for it-clefts. However, the exhaustiveness premise, as illustrated in (123)d, is merely suggested by (123)a, but does not survive the test for projection properties ${ }^{30}$.

a. It wasn't a pizza that Mary ate.

\footnotetext{
${ }^{30}$ Conventional implicatures (in the framework of Horn (1981)), need to have a well-defined set of projection properties, which make it possible for the implicatures of complex constructions (e.g. clefts) to be created from the implicatures of their parts. Normally, these complex conventional implicatures will survive under negation and in yes-no-question environments. This is illustrated in the following examples.

(i) a. The teacher is strict, but he is fair.

b. Even Sue passed the exam.

c. Sue managed to pass the exam.

According to Grice (1975), the sentences in (i) above are classical examples of conventional implicatures carried by lexical items (but, even, manage to). (i)a holds the same truth conditions as the corresponding simple conjunction and is true iff the teacher is strict and he is fair. (i)c and $\mathrm{d}$ as the same truth conditions as the sentence in (ii) below, while (i)c comes with a conventional implicature that other students also passed the test and Sue was the least likely among them to pass. (i)d carries the conventional implicature that passing the exam was difficult for Sue.
}

(ii) Sue passed the exam. 
b. Was it a pizza that Mary ate? (Horn (1981), 128)

Neither the negation nor the question form commit the speaker to the exhaustive premise of (123)d, while both of them do commit the speaker to the existential premise of (123)c. Assuming that conventional implicatures are maintained in complex structures, this can be used as a test for cleft exhaustivity:

While the larger part of the syntactic and semantic structure of the cleft is maintained when changing it into a question or negating it, what changes is the conversational purpose of the utterance (e.g. regarding entailments). If a meaning is part of the structure of a sentence, it should be preserved under negation and in question environments. This is not the case for cleft exhaustivity.

Instead, Horn (1981) proposes to analyze it as a generalized conversational implicature that arises from the conventional implicature of existence that comes as a property of the it-cleft. His definition is restated below:

The utterance in context $\mathrm{C}$ of any sentence which entails $\mathrm{F} \alpha$ and conventionally implicates $\exists \mathrm{xFx}$ will induce a generalized conversational implicature to the effect that $\sim \exists \mathrm{x}(\mathrm{x} \neq \alpha$ \& $\mathrm{Fx})$, where the variable $\mathrm{x}$ ranges over entities in a set determined by the context C. (Horn (1981), 132)

While the approach presented by Horn (1981) is theoretical in nature, ByramWashburn et al. (2013) present an empirical study which follows Hedberg (1990) ${ }^{31}$ in splitting it-clefts into two groups ${ }^{32}$ : stress-focus-clefts (topic-clause-cleft), which are structurally exhaustive, and informative-presupposition-clefts (comment-clauseclefts), which are not exhaustive ${ }^{33}$.

Byram-Washburn et al. (2013) conduct a psycholinguistic experiment that aims at speakers judgments of English it-clefts in different contexts. The main focus is to see whether non-exhaustive it-clefts are less acceptable than their exhaustive counterparts. Contexts are presented in written form and target items (it-clefts) as audio material to control for proper focus intonation. A pre-test indicates that speakers find it-clefts more acceptable in confrontational situations, which is why the background story introduces a tension between the characters. The it-clefts are uttered in direct response to overt questions. The design includes four factors:

1. +/- exhaustive

2. + /- contrast

\footnotetext{
${ }^{31}$ For a more detailed discussion of Hedberg (2000)'s syntactical approach see section 2.2 of this thesis.

${ }^{32}$ Byram-Washburn et al. (2013) argue that, if stress-focus-clefts were also not to be structurally exhaustive, this division into two cleft types would be unnecessary. In that case, the differences would not be structural, but mainly information structural.

${ }^{33}$ For a more detailed discussion of different types of it-clefts, see chapter 4 of this thesis.
} 
3. +/- Premise three (relevance): hearer has reason to believe that a more informative statement is not relevant

4. +/- explicitly named alternatives to the cleft pivot in the context

The experimental conditions are listed below:

Condition 1: Exhaustive, Contrastive, Prediction: Acceptable (Baseline for acceptability)

(126) Jane and Tom painted furniture. Tom painted a chair.

Later, Kevin remarks: I bet Tom painted only lamps again, didn't he?

Jane responds: He doesn't always paint lamps. Yesterday, it was a chair that he painted.

Condition 2: Exhaustive, Non-contrastive, Prediction: Unacceptable (Baseline for unacceptability)

(127) Jane and Tom painted furniture. Tom painted a chair.

Later, Kevin remarks: I bet Tom painted only a chair again, didn't he? Jane responds: Yes. Yesterday, it was a chair that he painted.

Condition 3: Non-Exhaustive, Explicit, Irrelevant, , Prediction: Acceptable

(128) Jane and Tom painted furniture. Tom painted a chair, a desk, and a table.

Later, Kevin remarks: I bet Tom painted only lamps again, didn't he?

Jane responds: He doesn't always paint lamps. Yesterday, it was a chair that he painted.

Condition 4: Nonexhaustive, Explicit, Relevant, Prediction: Unacceptable

(129) Jane and Tom painted furniture. Tom painted a chair, a desk, and a table.

Later, Kevin remarks: I bet Tom painted lamps again, didn't he?

Jane responds: No, he didn't. Yesterday, it was a chair that he painted.

Condition 5: Nonexhaustive, Implicit, Irrelevant, Prediction: Acceptable

(130) Jane and Tom painted furniture. Tom painted a variety of furniture.

Later, Kevin remarks: I bet Tom painted only lamps again, didn't he?

Jane responds: He doesn't always paint lamps. Yesterday, it was a chair that he painted.

Condition 6: Nonexhaustive, Implicit, Relevant, Prediction: Unacceptable 
Jane and Tom painted furniture. Tom painted a variety od furniture. Later, Kevin remarks: I bet Tom painted lamps again, didn't he? Jane responds: No, he didn't. Yesterday, it was a chair that he painted.

Participants are asked to rate the naturalness of the target items on a 6-point Likert scale.

The main finding of this study is that speakers do not judge non-exhaustive clefts as unnatural. Instead, the non-exhaustive clefts patterned with the exhaustive it-clefts. If exhaustivity in it-clefts is a presupposition, it should always be present and violations should be rejected by native speakers. If, however, exhaustivity in it-clefts is a conversational implicature, it is expected that there are cases in which the implicature does not arise.

Another finding is that speakers do not judge a violation of exhaustivity to be as unnatural as a violation of the presupposition of contrast (see Drenhaus et al. (2011) for similar findings for German).

A second experiment was designed using the same input material with one difference: the it-clefts were swapped for in-situ contrastive focus. In-situ contrastive focus can be used in the same contexts as it-clefts and it also presupposes contrast. However, unlike it-clefts, it is almost exclusively considered to be non-exhaustive. If it is the case that it-clefts are not exhaustive, then this follow-up experiment was predicted to produce the same results as the previous experiment, because in-situ focus is not exhaustive. The prediction was met with the experimental results. In both experiments, the non-exhaustive conditions were more natural than the unacceptable non-contrastive condition (Condition 2), but not significantly less natural than the acceptable exhaustive and contrastive condition (Condition 1). Since it-clefts patterned similar to in-situ foci, which are generally not taken to be structurally exhaustive, Byram-Washburn et al. (2013) take these findings to suggest that it-cleft exhaustivity is also non-structural.

Byram-Washburn et al. (2013) conclude that sometimes, it-clefts are exhaustive and sometimes they are not. Consequentially, they conclude that the exhaustivity in it-clefts is reached via a conversational implicature, more specifically, a scalar implicature, that is reached via the interaction between the Gricean maxims of Quantity and Quality (also see Grice (1975)) and the following additional premises:

1. S asserts $\alpha$ correctly.

2. Opinionated speaker: $\mathrm{S}$ believes that either $\beta$ or $\beta^{\prime}$.

3. Relevance: $\mathrm{S}$ believes that $\beta^{\prime}$ is relevant.

When all three premises and the two maxims hold, a given utterance will be interpreted exhaustively. 


\subsubsection{Summary}

As the overview over the various approaches to it-cleft exhaustivity illustrates, there are a number of ways in which the exhaustivity inference of the it-cleft can be described and analyzed.

When exhaustivity is derived via presuppositions (see Percus (1997), Büring and Križ (2013)), it-clefts are said to carry the same presuppositions as the corresponding definite description, namely an existence and uniqueness presupposition. Additionally, Büring and Križ (2013) introduce the notion of a uniformitypresupposition, which states that any individual in the domain of the function denoted by the structure "It was $x$ that $P$ " is not a proper part of the extension of $P$, given that if the individual is in $P$, then it is the maximal $P$. The uniquenesspresuppositon predicts that clefts are incompatible with certain additive particles (such as even and also). This is challenged by naturally occurring examples and will be addressed further in chapter 3 of this thesis for the case of German.

When treating exhaustivity as a semantic property of focus, É. Kiss (1998) first distinguishes identificational and informational focus. Identificational focus is analyzed parallel to the pre-verbal focus in Hungarian, as well as exclusives, such as only. Since the pre-verbal Hungarian focus is the translation of the English it-cleft, these two structures are treated on a par. While there is no restriction on the type of constituents that can function as information focus, certain types of constituents (e.g. universal quantifier, also/ even-phrases, as well as something/somebody) cannot function as identificational focus. The exhaustivity in this analysis is part of the semantics of the focus structure, pre-verbal focus as well as it-cleft. Empirical evidence indicates, however, that the exhaustivity inference that comes with exclusives and it-clefts cannot be analyzed on a par. For the case of Hungarian pre-verbal focus, Onea and Beaver (2009) show that the exhaustivity effect in this focus construction is pragmatic. Speakers react with disagreement to a violation of exhaustivity in pre-verbal focus, while they openly contradict it with exclusives. These results can be supported for the case of German and Hungarian with the empirical data presented in chapter 4 of this thesis. For the case of French, Destruel (2012) shows that the exhaustivity effect associated with a c'est-cleft is not as strong as the one that comes with an exclusive, but much stronger than a canonical. It can be concluded that the French c'est-cleft is not semantically exhaustive, and the exhaustivity inference is part of the non-at-issue meaning.

Some of the aforementioned approaches put it-cleft exhaustivity in close relation to the exhaustivity that can be found in sentences that contain exclusives such as only. Empirical data (see Drenhaus et al. (2011)) show that it-clefts and exclusives do not have the same processing costs. Native speakers are less accepting of 
exhaustivity violations in only sentences than in it-clefts. This suggests that these two structures do not have the same source for their exhaustivity. In this empirical approach, the exhaustivity inference is analyzed as a pragmatic phenomenon. Speakers react with post-hoc canceling of the exhaustivity inference they have initially processed when presented with an exhaustivity violation in it-clefts.

When analyzing exhaustivity as uniqueness, exhaustivity is not seen as a truthconditional property of the cleft, but a uniqueness requirement reached via a conventional implicature that depends on cardinality (see Halvorsen (1978)). However, cardinality is not preserved in questions. To solve this, a uniqueness operator can be assumed, which expresses that if anything is true of the cleft relative, the relative must be identical to the cleft pivot (see Atlas and Levinson (1981)).

In analyzing exhaustivity as a termination of inquiry, Velleman et al. (2012) analyze clefts in very close connection with exclusives. Exhaustivity is a combination of the pragmatic requirement to give a complete answer to the Current Question (CQ), and a semantic operator that is part of the logical form of the it-cleft. While exhaustivity in exclusives is directly asserted and therefore at-issue, it is presupposed or conventionally implicated and therefore non at-issue in it-clefts. Taking at-issueness into consideration is highly relevant when it comes to it-cleft exhaustivity. This can also be seen in the experiments presented in this thesis (see chapter 4). However, while arguing that the exhaustivity in it-clefts is a discourse function, Velleman et al. (2012) still hold onto the idea that it is conventionally coded and cannot be canceled.

When deriving exhaustivity via discourse structure (see Horn (2014)), the notion of at-issueness plays a crucial role. Using the NPI-test and the "Bullshit"-test, it can be shown that the status of the exhaustivity is not-at-issue in it-clefts. Exhaustivity can be derived pragmatically via the discourse structure as a conversational implicature.

Theoretical as well as empirical evidence point into the direction of a pragmatic phenomenon as the explanation for it-cleft exhaustivity. A possible approach is to analyze exhaustivity as a conversational implicature. This generalized conversational implicature arises from the conventional implicature of existence that comes as a property of the it-cleft (see Horn (1981)). This approach is convincing as it eliminates the problems of the exhaustivity inference in the cleft not being equivalent with that in only-sentences and not holding up under negation. This would be required, however, if one wanted to analyze it-cleft exhaustivity as a semantic phenomenon. Furthermore, it can be backed by empirical evidence. It is possible to split it-clefts into two groups: stress-focus-clefts (topic-clause-cleft), which are 
exhaustive, and informative-presupposition-clefts (comment-clause-clefts), which are not exhaustive (see Byram-Washburn et al. (2013)). Clefts reach exhaustivity via a conversational implicature appearing from the interaction between the Gricean maxims of quantity and quality (see Grice (1975)).

The experimental results (see Byram-Washburn et al. (2013)) show that speakers do not judge non-exhaustive clefts as unnatural. Exhaustivity can be derived from it-clefts, but it is not necessarily the case. Combined with the theoretical assumptions proposed by Horn (1981), the approach to derive exhaustivity in it-clefts via a conversational implicature is highly convincing as it is able to explain the naturally occurring data that this thesis presents.

This thesis takes a different approach to investigate the exhaustivity question. So far, research has mainly been looking at isolated generic examples of it-clefts. In this dissertation, it-clefts are investigated using naturally occurring examples extracted from a corpus. This allows to take the context of a naturally occurring example of a cleft into consideration. Chapter 3 of this dissertation presents the results of a detailed corpus study as well as experimental data which show that it-clefts are not exhaustive in every case. The significant majority of those es-clefts is, however, exhaustive. The results suggest that the context needs to be taken into consideration when judging the exhaustivity of an it-cleft. The context plays an especially important role when the it-cleft includes a focus particle positioned directly in front of the cleft pivot.

\subsubsection{Exhaustivity and the Question Under Discussion}

What kinds of it-clefts can be distinguished is part of the notion of information structure. The following section will take a closer look at the information structural properties of it-clefts.

As mentioned earlier (see chapter 1 of this thesis), the following types of it-clefts can be distinguished on a syntactic level (re-stated below):

(132) $\quad[\mathrm{Sue}]_{F}$ climbed a mountain. (Canonical sentence)

Focus + clause

(133) It was $[\text { Sue }]_{F}$ who climbed a mountain. (It-cleft) placeholder-it + copula + cleft pivot + relative pronoun predicate

(134) Who climbed a mountain was $[\mathrm{Sue}]_{F}$. (Pseudo-cleft or Wh-cleft)

Wh-relative + clause with copula + Focus

(135) $\quad[\mathrm{Sue}]_{F}$ is the one who climbed a mountain. (Reverse Pseudo-cleft)

Focus + copula + wh-relative clause 
According to Prince (1978), the difference between it-clefts and wh-clefts lies in their respective presuppositions: in wh-clefts, the presupposed wh-clause is known information to both speaker and hearer and both interlocutors are actively thinking about it at the time of utterance. As for it-clefts, there are: (i) it-clefts in which the presupposed part (the cleft relative) is known information to both speaker and hearer, but the hearer is not actively thinking about at the time of utterance, and (ii) it-clefts in which the presupposed information is known to the speaker, but not known the hearer. The former are called stressed-focus clefts, while the latter are informative-presupposition clefts.

In stressed-focus clefts (or what in the terminology of this thesis is called FocusBackground clefts ${ }^{34}$ ), only the pivot with the focused element receives strong intonational stress. It is used in discourse situations where the focus in the pivot expresses new (and often also contrastive) information.

... So I learned to sew books. They're really good books. I's just the covers that are rotten. (Prince (1978), 896)

The presupposed cleft relative (the that-clause as Prince (1978) calls it) bears old or accessible information. Both speaker and hearer are assumed to be familiar with the presupposed information or have access to it through the context, as illustrated by the example below:

(137) The leaders of the militant homophile movement in America generally have been young people. It was they who fought back during a violent police raid on a Greenwich Village bar in 1969, an incident from which many gays date the birth of the modern crusade for homosexual rights. (Prince (1978), 898)

(138) It was also during these centuries that a vast internal migration (mostly by the Galla) from the south northwards took place, a process no less momentous than the Amhara expansion southwards during the last part of the nineteenth century and the beginning of the twentieth century. (Prince (1978), 898)

Additionally, Prince (1978) argues that the cleft relative is so non-informative in these clefts that it can actually be omitted.

Regarding intonation, Prince (1978) notes that stressed-focus clefts have weakly intonated/stressed cleft relatives, while informative-presupposition clefts have normally stressed that-clauses.

The informative-presupposition clefts are used to inform the hearer about the information given in the cleft relative. The hearer is assumed to be oblivious about the

\footnotetext{
${ }^{34}$ For a detailed introduction to the terminology used in this thesis, see chapter 1 of this thesis.
} 
presupposed information. Considering the example below, Prince (1978) explains a common function of informative-presupposition clefts as so-called "newspaper fillers". These are sentences that typically stand at the beginning of a newspaper article and express well known information or information that can be assumed to be common knowledge:

It was just about 50 years ago that Henry Ford gave us the weekend. On September 25, 1926, in a somewhat shocking move for that time, he decided to establish a 40-hour work week, giving his employees two days off instead of one. (Prince (1978), 898)

It was 10 years ago this month that young Irwin Vamplew was bopped on the head by a nightstick while smashing windows in Berkeley in order to end the war in Vietnam. So you can imagine the elation of his parents when he finally emerged this week from his decade-long coma. His first words, naturally, were: "Down with the Establishment!" (Prince (1978), 901)

The newspaper article actually starts with this cleft, and the cleft structure is a very conscious choice here. If the author had used a different structure, it would look like the newspaper had actually discovered (...) the information in the cleft relative. However, the it-cleft marks it as a generally known fact that might not be part of the active knowledge of every single reader. (see Prince (1978), 898). The informative-presupposition clefts do therefore not only mark the presupposed information as old or accessible, but as an actual fact that neither speaker nor hearer came up with. Prince (1978) calls this a sub-function of informative-presupposition clefts. These clefts bring the reader of the newspaper up to date in order to then being able to receive the actual news that the article conveys.

According to Delin (1992), to merely show that it-cleft presuppositions mark information as known facts (see e.g. Prince (1978)) does not go far enough. Instead, it-cleft presuppositions ${ }^{35}$ are taken to mark information as, first of all, anaphoric, which does not depend on any information structural properties. Secondly, information is marked as non-negotiable in it-clefts. This property arises from the anaphoricity, as anaphora implies that there be prior references to the same piece of information in the discourse.

Generally, it is assumed here that it-clefts are frequently used to convey new information which has not been previously introduced into the Common Ground.

\footnotetext{
${ }^{35}$ Delin (1992) uses the following notion of presupposition: A presupposition of a given utterance consists of background believes or information that is mutually assumed by the speaker and hearer of that utterance in order to be rendered appropriate and meaningful in the given context (cf. e.g. Levinson (1983))
} 
Delin (1992) points out that a possible reason as to why it-clefts have been so frequently assumed to convey information that is already present in the discourse might be the fact that they have been studied using isolated examples with generalized assumptions of prosody and the placement of focus. Instead, Delin (1992) proposes the following arguments for the anaphoricity of cleft presuppositions:

1. Elements that are ambiguous between an anaphoric and an emphatic use take on their anaphoric reading when placed within an it-cleft presupposition;

2. It-cleft presuppositions enable the anaphoric relation upon which contrast depends to be established, in contexts where information that is simply Given does not have the same effect; and

3. Information placed within an it-cleft presupposition appears to remind rather than inform, regardless of its objective status in the discourse. (Delin (1992), 8)

Corpus examples are provided to strengthen these points which show that, when there is no antecedent available in the discourse, they are interpreted as emphatic in non-clefted sentence environments, while they are interpreted as anaphoric in clefts, as in this case, they are presuppositional.

Regarding the point of contrast, it is noted that the cleft presupposition serves the function of "pulling out" a proposition to establish it as the basis for the contrast relation. While this can also be achieved via the notion of given information, itcleft contrast is unique as it also can be established via the presupposition when the presupposed information is not overtly present, as illustrated by the two corpus examples in (141)a and (141)b below. In this case, only the cleft serves to assert a contrast.

(141) a. Doubling the selling space to 700 square feet was not to be the greatest expense. It was the new fixtures and fittings to fill this space that would be costly.

b. ?Doubling the selling space to 700 square feet was not to be the greatest expense. The new fixtures and fittings to fill this space would be costly. (Delin (1992), 10)

Therefore, Delin (1992) concludes that it-cleft presuppositions establish coherence relations (such as anaphoricity and contrast) that are not available outside of this structure.

Regarding the third argument stated above, it-clefts function as a reminder of a fact rather than an information-giving structure, which is illustrated by the corpus examples below: 
a. B: To be frank, I've heard from a number of sources that when you were interviewed for a job here that you think that you didn't get the job because of me

A: Oh no, I never said that... I went to great pains to tell people that you were the one supporting me. In fact, it was VERY shortly AFTER that INTERVIEW that I sent my circular letter AROUND to various scholars and I sent YOU a copy.

b. In fact, VERY shortly AFTER that INTERVIEW I sent my circular letter AROUND to various scholars and I sent YOU a copy. (Delin (1992), 11)

The de-clefted version seems to much more clearly convey the characteristics of a new information than the clefted version, which is taken to mean that it-cleft presupposition serves the purpose of marking an utterance as a reminder of already known information rather than a way of presenting new information.

In terms of the non-negotiability property of it-cleft presupposition, Delin (1992) argues that speakers use the cleft construction to mark something as presuppositional and thereby not open for discussion. In the corpus example below, the speaker wants to limit the scope of the negation to what he is fascinated by, not to the fact that he is, in fact, fascinated:

(143) Another Spring flower, the Iris, is sometimes called "the Poor Man's Orchid". It is not the colour nor the texture of the iris petals that fascinate me, but the fine detail of their exquisite shape. (Delin (1992), 12)

It-clefts are therefore used to express information that is treated as a fact by the speaker. What distinguishes this factual information from simply asserted information is, according to this framework, the anaphoricity of the it-cleft presupposition. Delin (1992) cites Prince (1978)'s notion of the speaker wanting to say "I didn't invent this" when using a cleft and extents it to "I didn't invent this now". Prince (1978)'s notion does not reach far enough as it is possible for speakers to refer back to an antecedent they have introduced into the discourse themselves at an earlier point:

A: John's finished all the coffee.

B: Well, why don't you make some more?

A: Because it's him who finished it, and I don't see why I should make it all the time. (Delin (1992), 13)

Therefore, Delin (1992) notes that it is not relevant for speakers to point out where the presupposed information comes from. She concludes that it-cleft presuppositions are non-negotiable as they are marked as "un-original", which means that 
the speaker uses them to refer back to a prior mentioning of the same information, no matter whether it is available to all interlocutors.

Taken the framework proposed by Delin (1992) into consideration, Delin and Oberlander (1995) systematically distinguish two kinds of it-clefts, the stressed-focus (SF) or topic-clause cleft on the one hand, and the informative-presupposition (IP) or comment-clause cleft on the other hand. In general, Delin and Oberlander (1995) propose the idea that clefts are not all to be treated the same, as there are different cleft types that can have various discourse effects.

As a group, clefts are described as presuppositional, and functioning as a way to mark the cleft pivot as a somehow unique or exhaustive listing of the elements that satisfy the predicate stated in the cleft relative.

The Stressed Focus clefts are characterized by having a nuclear stress on the cleft pivot, while the cleft relative is weakly stressed. The cleft pivot conveys new and frequently also contrastive information, while the information in the cleft relative is accessible, known, or old information ${ }^{36}$. These clefts support contrastive statements as answers to direct questions.

Informative Presupposition clefts, on the other hand, have the new and important information in the cleft relative, with the cleft pivot being old or anaphoric. The IP-clefts are described as functioning as backgrounding devices that convey known or accessible information. The main function of the IP-clefts is temporal: the backgrounded information in the pivot is presented as being prior in time to the new information on the predicate presented in the cleft relative. This is not possible using a non-clefted version of the same clause. IP-clefts therefore are interpreted as having a temporal discourse function. Another specialty of the IP-clefts is that the speaker can introduce new information in the cleft relative, while treating it as having been there all along in the discourse, as usually, the information in the cleft relative is understood to be presupposed.

This distinction is motivated by the assumption that clefts are not only described as asserted and presupposed content or focus, but can also be framed using the notions of known-fact effect or backgrounding. Delin and Oberlander (1995) call clefts stativising devices, which highlights the feature that it-clefts convey their content as a stative eventuality description as a result of the copula. The use of the copula not only creates a stative sentence environment, but marks a contrast. By using a cleft construction, a speaker presents the event described in the sentence as a state.

a. I saw Mary at the mall today.

\footnotetext{
${ }^{36}$ Delin and Oberlander (1995) go as far as stating that the cleft relative may, in fact, be deleted without loosing any necessary information
} 
b. It was Mary who I saw at the mall today.

The two sentences in (145) above have the same content. But in the cleft in (145)b does not only denote the event that is stated in the cleft relative as well as in the canonical sentence in (145)a (the speaker seeing Mary at the mall), but, additionally, it creates a state (of the speaker seeing someone at the mall). The state that is created by the cleft construction is the state of someone being the agent of the reported action, which is an increase in information compared to the non-clefted version which only reports the stated event. These states ares described as being existential, and are, therefore, comparable to the existential presupposition that is generally said to come with a cleft construction.

\subsubsection{Summary}

When trying to determine how many kinds of it-clefts can be distinguished, there are different approaches to be considered.

1. Focus-Background clefts

- also called: stressed-focus clefts (Prince (1978)); Stressed-focus cleft (Delin and Oberlander (1995)); Topic-Clause cleft (Delin and Oberlander (1995))

- only the pivot with the focused element receives strong intonational stress

- weakly intonated/stressed cleft relatives

- pivot expresses new (and often also contrastive) information

- the presupposed cleft relative (the that-clause as Prince (1978) calls it) bears old or accessible information

- cleft relative is so non-informative in these clefts that it can be omitted (see Prince (1978))

- used as answers to direct questions

2. Topic-Comment clefts

- also called: informative-presupposition clefts (Prince (1978); Delin and Oberlander (1995)), comment-clause cleft (Delin and Oberlander (1995))

- used to inform the hearer about the information given in the cleft relative

- hearer is assumed to be oblivious about the presupposed information 
- mark the presupposed information in the cleft relative as an actual fact that neither speaker nor hearer came up with

- speaker can introduce new information in the cleft relative, while treating it as having been there all along in the discourse

- normally stressed that-clauses

- main function of the IP-clefts is a temporal discourse function: the backgrounded information in the pivot is presented as being prior in time to the new information on the predicate presented in the cleft relative (not possible using a non-clefted version of the same clause) (Delin and Oberlander (1995))

When looking at the informational structural properties of it-clefts, two subgroups can be distinguished: the very frequent Focus-Background structure, and the less common Topic-Comment structure.

Focus-Background (FB) clefts appear mostly in answers and corrective statements, with the contrast on clefted constituent, as illustrated below:

Q: Who drank most at the party?

A: It was Max who drank most at the party.

In Topic-Comment clefts (TC), also called Informative-Presupposition Clefts (see Hedberg (2013)), the cleft pivot is mostly old, activated, or accessible, while the cleft relative is new to the hearer. The main stress, at least in the case of English clefts, is on non-clefted part, like in example (116):

It was in 1879 when Edison invented the electric lightbulp.

It might be the case that FB and TC-clefts have different information structural functions: the FB-clefts might be means of focus marking (see Roberts (1996)), which is why they can be introduced by an explicit question. TC-clefts, on the other hand, rather shift the direction of discourse. TC-clefts can also appear at the very beginning of a discourse, which is not the case for FB-clefts (see Prince (1978), Hedberg (2013)). TC-clefts can be described as being presuppositional in every case, as the cleft construction is used to add redundant information in the pivot.

For the case of German, the corpus analysis presented in this thesis shows that FB-clefts are overall significantly more common than TC-clefts, which leads to the conclusion that the FB-clefts can be classified as the default case for German it-clefts and the TC-clefts as non-prototypical. 


\subsubsection{It-Cleft Exhaustivity and Focus Particles}

The question whether additive focus particles can be part of an it-cleft has mostly been rejected in the literature (see e.g. Altmann (1976), Büring and Križ (2013), Percus (1997)). A possible reason to argue that non-exclusive focus particles cannot be part of an it-cleft is that the meaning contributions of the particle and the cleft clash (see Percus (1997)). The non-exclusive particle is used to express non-exclusivity, while the cleft structure expresses exhaustivity. This combination leads to infelicitous or unacceptable sentences. In cases where the focus particle has an exclusive reading, like the particle only, as illustrated in (148), the combination of these particles and the cleft structure is possible.

$$
\text { It was only John who came late. }
$$

When a non-exclusive particle is used in a non-exclusive context, like in sentences with a scalar interpretation of even, as illustrated in (149) below, the combination of particle and cleft structure is a little surprising, albeit intuitively possible.

It was even John who came late (and he is always on time).

The particle auch/also, however, is said to not be possible in a cleft sentence because it carries a non-exclusive meaning in form of a non-uniqueness presupposition. (see Altmann (1976)).

Generally, for the case of German, focus particles take up the syntactical position adjacent to the focused element. In (150) below, the indirect object the girl receives narrow focus. The particle even is adjacent to the object position. When this is not the case, as in (151)a, where the subject is moved between the indirect object and the particle, the positioning results in inacceptability (see Büring and Hartmann (2001)).

Gestern hat Rufus sogar [dem MÄDCHEN] ${ }_{F}$ Blumen geschenkt. yesterday has Rufus even the-DAT GIRL flowers given Yesterday, Rufus even gave flowers to the girl.

a. ${ }^{*}$ Gestern hat sogar Rufus [dem MÄDCHEN] ${ }_{F}$ Blumen geschenkt.

b. Gestern hat sogar $[\text { RUFUS }]_{F}$ dem Mädchen Blumen geschenkt.

Yesterday, Rufus even gave flowers to the girl. (Büring and Hartmann (2001), ex. 3)

Regarding the meaning contribution that the focus particle makes to the overall meaning of a sentence, we will look at exclusives and additives.

The meaning contribution of also to the overall meaning of a given sentence can be illustrated by replacing a focus $\beta$ by an existential quantifier like somebody/ 
something other than $\beta$ in that part of the sentence that corresponds to its semantic scope. (König (1991), 32) This is illustrated below:

a. FRED also bought a new car.

b. Fred bought a new car. (entailment)

c. Somebody other than Fred bought a new car. (meaning contribution) ${ }^{37}$ (König (1991), 32)

For the case of the exclusive only, a negated existential quantifier (nobody/nothing other than $\beta$ ) can be replaced for a focus $\beta$ in the relevant sentence part. The entailment relation described for the case of also holds here as well.

a. Only FRED bought a new car.

b. Fred bought a new car. (entailment)

c. Nobody other than Fred bought a new car. (meaning contribution) (König (1991), 33)

As opposed to only, which is often referred to as an exclusive particle, additives such as also can be called inclusive particles. This classification is due to fact that exclusives exclude possible alternatives found in the discourse, while additives include possible alternatives for the open value in their scope (i.e. the focused element in the given sentence) (see e.g. König (1991), Beaver and Clark (2008)). Sentences with an inclusive particle such as also entail the corresponding sentence without the particle. Additionally, they presuppose that at least one of the alternative values available in a given context satisfies the predicate (see König (1991), as illustrated in (153) above). Furthermore, while exclusives clearly make a contribution to the truth conditions of a sentence, this is not the case for additives (see König (1991)). What is asserted in a sentence with also is presupposed with only, and what is asserted with only is presupposed with also.

When looking at the discourse function rather than the truth conditions of the exclusive, Beaver and Clark (2008) note that exclusives come with two meaning components, the universal (or exclusive) and the prejacent.

(154) Only Mary smokes.

a. prejacent: Jane smokes (positive component)

b. universal: Nobody else smokes. (negative component) (Beaver and Clark (2008), 214)

(155) Mary only smokes [Luckies $]_{F}$.

a. prejacent: Mary smokes Luckies.

\footnotetext{
${ }^{37}$ What König (1991) calls meaning contribution is a presupposition.
} 
b. universal: Mary smokes no brand apart from Luckies. (Beaver and Clark (2008), 214)

Within the framework of the Prejacent Presupposition Theory, Beaver and Clark (2008) assume that the prejacent is presupposed, whereas the universal is entailed, leading to an asymmetry of the inferences of an exclusive. This becomes clear when embedding the exclusive under negation, which is a commonly used test for presupposition (see Horn (1969), Roberts (2006)):

Not only Mary smokes.

a. prejacent, presupposed: Mary smokes.

b. universal, not entailed: \# Nobody other than Mary smokes. (Beaver and Clark (2008), 216)

Beaver and Clark (2008) develop a discourse functional account of the exclusive ${ }^{38}$. Exclusives are grammatically constrained to pick up the CQ and have the direct effect of containing the CQ and its expected answer. Exclusives are described as challenging an overly strong expectation of the interlocutors. The meaning of exclusives is defined as follows (see Beaver and Clark (2008), 251): Exclusives have the discourse function of commenting on the CQ in a way that the salient or natural expectations are weakened. Therefore, the prejacent must be weaker than the expected answer to the CQ. Additionally, the strongest true alternatives in the CQ must be at least as strong as the prejacent to make the sentence with an exclusive felicitous. When it comes to descriptive content, the strongest true alternatives in the CQ must be at most as strong as the prejacent.

Along the lines of Roberts (1996) ${ }^{39}$, Beaver and Clark (2008) assume a hierarchical order of potential answers to the CQ, going from weak to strong. In the case of an utterance with an exclusive, the prejacent is one potential answer to the CQ. The speaker uttering a sentence with an exclusive must assume the hearer to take some answer stronger than the prejacent to be true (this is the discourse function of the

\footnotetext{
${ }^{38}$ Furthermore, it should be noted that exclusives can be used in direct answers to wh-questions (see Geurts and van der Sandt (2004)).

(i) Q: Which one of them smokes?

A: Only Mary.

Beaver and Clark (2008) point out that naturally occurring examples of exclusives that are used to answer direct wh-questions can only be found with some difficulty. However, it is imaginable that it could be shown in a questionnaire study that this is at least acceptable to native speakers. In examples like the one above, the prejacent is not presupposed. Therefore it is not part of the CG between the interlocutors, as there is no direct preceding context. This is discussed and experimentally tested in more detail in chapter 4 of this thesis.

${ }^{39}$ See section 2.3 .3 .2 of this thesis for a more detailed description of the theory of information structure presented by Roberts (1996).
} 
exclusive), and the speaker himself believes that something at least as strong as the prejacent (mostly, the prejacent itself) is true (this is the descriptive content of the exclusive).

The remains of this section discuss the different answers that have been given to the question whether certain focus particles can or cannot occur as parts of cleft sentences.

Altmann (1976) describes the function of a cleft to be the emphasized identification combined with uniqueness. Particles, with this background, are only combinable with (German) it-clefts in those cases that carry a scalar interpretation, and are not used to express non-exclusivity (like nicht nur/ not only), or presuppose nonexclusivity (like sogar/ even). Therefore it is possible for the exclusive nur/only to appear in cleft sentences. The scalar particle sogar/even can also occur in it-clefts, but only in contexts which do not carry a non-exclusive reading. The additive particle auch/also, however, should not be occurring in cleft sentences because it carries a non-exclusive meaning in form of a non-uniqueness presupposition.

Furthermore, Percus (1997) argues that, since clefts carry a presupposition that only the focused element in the pivot has the property denoted by the relative clause, ${ }^{40}$ they are incompatible with particles like even and also, and redundant with exclusive particles such as only. Since these particles can usually associate with focus, Percus (1997) argues that, in the case of it-clefts, the uniquenesspresupposition of the cleft and the semantics of the particles clash, resulting in unacceptable sentences.

As noted by Krifka (2008), an additive focus particle like also or even can trigger a conflicting presupposition if the exhaustivity inference in clefts is taken to be a presupposition as the effect of an identificational focus. Exhaustive focus should not be described as compatible with additive particles. Krifka (2008) proposes a presuppositional or pragmatic analysis of exhaustivity as opposed to a truthfunctional approach.

Büring and Križ (2013) mention that in the case of (the possible, yet peculiar combination of) it-clefts with only, the exhaustivity presupposition of the cleft is tautologous. This resluts in it-clefts with only being equivalent to ordinary predication with only. They account for this by providing an analysis of it-cleft pivots of the form only DP as quantifiers.

\footnotetext{
${ }^{40}$ Percus (1997) notes that the presupposition is not as simple as this formula suggests. For further discussion, see Halvorsen (1978).
} 
Horn (1981) presents examples which he takes to illustrate that the insertion of exclusives into a cleft does have a truth-functional effect, as illustrated in (139), while this is not the case for clefts without a more explicit way of stating the exhaustivity inference through the exclusive particle, as can be seen in (140).

(157) I know Mary ate a pizza, but I've just discovered that it was only a pizza that she ate.

(158) ??I know Mary ate a pizza, but I've just discovered that it was a pizza that she ate. (Horn Horn (1981), 130)

Exclusives are taken to semantically assert exhaustivity, whereas the exhaustivity inference is taken to be a conversational implicature in the case of plain focus (see Beaver and Clark Beaver and Clark (2008)).

Lambrecht (2001) argues that also and even presuppose the existence of other members of the set that is introduced by the focused element in the pivot. The cleft, however, requires (via its focus function) that this set is closed. Clefts with also and even are regarded unacceptable.

Following É. Kiss (1998) in assuming that it-clefts are to be analyzed on par with Hungarian pre-verbal focus, this means that the following constituents need to be ruled out as being able to be in the cleft pivot: universal quantifiers, also/ even-phrases, as well as something/somebody: Sentences that are modified by the additive particles is/also and még ... is/ even, as well as vala-/ some presumably cannot be preposed into the position of identificational focus. This is due to their meaning being incompatible with the $[+$ exhaustive] feature of identificational focus. (É. Kiss (1998), 267). This also holds for the English translations of the Hungarian pre-verbal focus sentences. English it-clefts are similarly restricted, which means that universal quantifiers, sentences with even, also (except for certain contexts), and something/ somebody cannot occur as cleft constituents (see É. Kiss (1998), 252). Presumably, these expressions carry a feature that characterizes them as distributive and (following Szabolcsi (1994)) can only accommodate group-denoting quantifiers.

(159) Mari [egy kalapot $]_{F}$ nézett ki magának. It was [a hat $]_{F}$ that Mary picked for herself.

*Mari [minden kalapot] $]_{F}$ nézett ki magának. * It was [every hat $]_{F}$ that Mary picked for herself.

*Mari [egy kalapot is] $]_{F}$ nézett ki magának.

? It was also [a hat $]_{F}$ that Mary picked for herself. 
*Mari [még egy kalapot $]_{F}$ is nézett ki magának.

* It was [even a hat] $F_{F}$ that Mary picked for herself.

*Mari [valamit $]_{F}$ nézett ki magának.

*It was [something] $]_{F}$ that Mary picked for herself. (É. Kiss (1998), 251252)

There are, however, also reasons to assume that certain focus (for example the non-exclusive particles also and even) particles can be part of it-clefts. While É. Kiss (1998) argues that this, in general, is not possible, this position does allow for some exceptions. É. Kiss (1998) cites the framework presented by Kenesei (1986) where identificational focus is described as exclusion by identification. This has the advantage that universal quantifiers and the particles also and even can be part of the pivot constituent, as the quantifier (or particle) performs identification without exclusion. It does so by operating on a set that is specified by its restrictor. In case of a cleft with also, it can be rendered acceptable when it is interpreted as identifying a member of the relevant set in addition to one or more members of that same set (which have to have been previously identified as such in the discourse) for which the cleft relative holds. The rest of the set remains excluded from holding the cleft relative. If taking the members of a group that participated in a hiking tour the previous weekend, all sentences of the discourse in the English language example below are acceptable ${ }^{41}$ :

A: Jill climbed all the way to the top of the mountain.

B: No, it was John that made it to the top.

C: It was also Sue that reached the top of the mountain. (cf. É. Kiss (1998), 252)

As É. Kiss (2016) points out, it is also possible to cancel ${ }^{42}$ the exhaustivity of the pre-verbal focus with the insertion of a non-exclusive focus particle:

János TÖBBEK KÖZÖTT ÉVÁT hítva fel. It was Eve, among others, that John called up. (É. Kiss (2016), 681)

\footnotetext{
${ }^{41}$ It should be noted that this is not the case for Hungarian, as illustrated in examples (161) and (162) above.

${ }^{42}$ It might be somewhat strong to speak of a cancellation in this case, as the presence of among others merely marks that other individuals present in the discourse are irrelevant for the given sentence. The exhaustivity of the pre-verbal focus construction as such is not canceled.

It is not possible to include an exclusive into the sentence, as illustrated below:

(i) *It was only Eve, among others, that John called up.

This will be discussed in more detail in chapter 4 of this thesis.
} 


\subsubsection{Summary}

This section has shown that exclusives come with two meaning components, the universal (or exclusive) and the prejacent. They are defined as having the discourse function of commenting on the CQ in a way that the salient or natural expectations are weakened (see Beaver and Clark (2008)).

The question whether certain focus particles are combinable with the cleft structure has lead to a variety of different answers. Some focus particles are rejected as part of a cleft sentence mostly due to the fact that the assumed exhaustivity inference of the cleft structure and the non-exclusive meaning contribution of the focus particle are not combinable and lead to inacceptabilty of the resulting sentence (see Altmann (1976), Percus (1997), É. Kiss (1998), Krifka (2008), Büring and Križ (2013), Lambrecht (2001)).

This thesis presents corpus data and experimental data that show that it-clefts are in fact combinable with certain (non-exclusive) focus particles in German. German it-clefts are actually quite frequent in combination with various focus particles, and they are judged as acceptable by native speakers. Chapter 3 presents the results of corpus and experimental studies which show that the following focus sensitive particles appear frequently in German es-clefts: only, especially, also, not least. In combination with only, the clefts are interpreted as exhaustive by speakers, while clefts are regarded as non-exhaustive with especially, thereby following the presupposition and/or meaning contribution of the respective particle.

In the cases of the particles also and not least, the picture is not as clear. There are it-clefts that receive an exhaustive interpretation, which is rather unexpected given the semantic of the particle. These non-prototypical cases are then addressed by showing that the additive particle and the cleft pivot do not form a constituent, which is a way to explain why these sentences can carry an exhaustivity implicature in spite of the presupposition of the non-exclusive particle.

\subsubsection{It-Cleft Exhaustivity and Contrast}

The third research question that this thesis is concerned with is whether the notion of contrast plays a role in the production of it-clefts. The notion of contrast was first mentioned in relation to it-clefts by Jespersen (1927), who proposed the following:

(166) A cleaving of a sentence by means of it is (often followed by a relative pronoun or connective) serves to single out one particular element of the sentence and very often, by directing attention to it and bringing it, as it were, into focus, to mark a contrast. (Jespersen (1927), 147f.) 
Additionally, previous studies have shown that such a connection between contrast and it-cleft production might exist. Destruel and Velleman (2014) show in a production task for English that speakers are more likely to use a cleft structure when they are correcting a previous statement, thereby making a contrastive statement. On the other hand, when just giving an informative answer, speakers of English are more likely to use a simple informational sentence structure. Destruel and Velleman (2014) conclude that the use of it-clefts in English is restricted to certain pragmatic uses of focus, namely to offer a correction to a presupposition made in the previous context. In a psycholinguistic experiment, Byram-Washburn et al. (2013) found that speakers judge it-clefts as more acceptable in confrontational situations.

We can observe two main ways in which the notion of contrast is defined: contrast regarding alternatives (see e.g. Rooth (1985), Rooth (1992), É. Kiss (1998), Krifka (2008)), and contrast regarding discourse relations (see e.g. Kenesei (2006)).

Following É. Kiss $(1987)^{43}$, Destruel and Velleman (2014) distinguish two main kinds of focus: information focus and identificational focus, as discussed in more detail in section 2.3.2.2 above. Information focus marks new, non-presupposed information, while identificational focus operates via semantic identificational predication, thereby exhaustively identifying the set of individuals of which the predicate holds. Exhaustivity is part of its meaning and, therefore, semantically encoded. Destruel and Velleman (2014) propose that identificational focus is (always) exhaustive and (sometimes) contrastive.

Destruel and Velleman (2014) develop a gradient understanding of contrast (also see Repp (2016)), where contrast is defined as as a conflict of hearer expectations (cf. Zimmermann (2011)). Contrastive focus is used in situations where the speaker can reasonably suspect that the hearer does not expect the assertion of the focused constituent as likely to be included into the Common Ground. This notion of contrast is anaphoric, and it-clefts are only felicitous in contexts where there is an antecedent available in the previous discourse as an alternative to the focused element. Clefts are assumed to mark contrastive focus, which operates from a closed set of alternatives and stands in opposition to informational focus (É. Kiss (1998)).

The following examples illustrate contrastive and non-contrastive, as well as both contrastive and exhaustive contexts.
A: Who cooked the beans?
B: $[\text { John }]_{F}$ cooked the beans. (not contrastive)

\footnotetext{
${ }^{43}$ For a more detailed discussion of É. Kiss (1987), see section 2.3.1.2 of this thesis.
} 
$\mathrm{A}^{\prime}$ : Who cooked the beans, John or his brother Fred?

$\mathrm{B}^{\prime}$ : $[\mathrm{John}]_{F}$ cooked the beans. (contrastive)

$\mathrm{B}^{\prime \prime}$ : It was $[\mathrm{John}]_{F}$ who cooked the beans. (contrastive and exhaustive) (Destruel and Velleman (2014), 200-201)

According to Destruel and Velleman (2014), the following context should be thought of for the sentence in (167):

(170) An open set of individuals - all the friends invited to the party Saturday night - were supposed to bring a dish and someone cooked beans, namely John. In this case, there is no need to know the exact number of friends who have been invited or who these friends are (the alternatives can remain implicit or contextually available), in which case the focus element is simply interpreted as introducing new information into the discourse, answering the wh-question. (Destruel and Velleman (2014), 200)

However, if the alternatives are explicitly mentioned in the discourse, as in the sentence in (168), the focus constituent receives a contrastive interpretation ${ }^{44}$.

Destruel and Velleman (2014) present experimental data that show that speakers are more likely to produce a cleft sentence (as opposed to a canonical sentence) in context that are contrastive. It-clefts, therefore, are taken to be the preferred way of expressing a contrast.

Contrast does also appear in corrective statements. It-clefts, however, are not restricted to corrective contexts. To account for that, Destruel et al. (2016), who build on the results of Destruel and Velleman (2014), introduce the notion of contrariness. Contrariness is defined as the product of commitment (of the speaker to his or her own utterance) and contradiction (whether or not the information in a second speaker's sentence contradicts the information stated in the last sentence uttered by the first speaker). Their conduct a rating study in which they show that it-clefts are rated as more natural by native speakers in context environments that have a strong degree of contrariness. Destruel et al. (2016) conclude that, while the presence of an explicitly stated alternative to the focused element makes clefts more felicitous, this is a necessary, but not a sufficient condition. When there is a metalinguistic contrast (i.e. when the antecedent is not expected by the interlocutor) in the discourse, clefts are more natural.

This thesis presents experimental data from production experiments which suggest

\footnotetext{
${ }^{44}$ Destruel and Velleman (2014) point out that Krifka (2008) has argued that this type of question is not contrastive. It should also be noted that this answer can be thought of as exhaustive, as the answer exhaustively lists the contextually relevant individual that cooked the beans.
} 
that there is a tendency for a higher production of it-clefts in exhaustive and/or contrastive contexts as opposed to contexts that have neither of those two characteristics. The interpretation of the data then follows the conclusions of Destruel and Velleman (2014) in that the use of it-clefts in (spoken) German is (while not restricted, as in the case of English, though possibly) favored by particular pragmatic uses of focus, i.e. to either correct a presupposition of the statement made in the previous context, or to provide an exhaustive listing of the members named in previous context that satisfy the property denoted by the cleft relative.

\subsubsection{Summary}

This chapter provided an overview over the main theoretical and empirical approaches to the syntax and semantic of it-clefts across languages.

Regarding the syntactical structure of the it-cleft, this thesis follows the expletive analysis. In the expletive framework, the cleft clause is said to bear a direct connection to the cleft pivot and the cleft pronoun is treated as an expletive pronoun which is unrelated to the pivot. The cleft pronoun and the copula are treated as semantically empty as well as making no meaning contribution to the overall meaning of the cleft.

Regarding the semantic of the it-cleft, this chapter has looked at what previous research has taught us about the four research questions this thesis is concerned with.

The exhaustivity question asks if it-clefts are exhaustive and if they were, how this exhaustivity should be analyzed. There are theories which argue that it-clefts come with a hard-wired semantic exhaustivity inference, albeit providing several ways as to how this semantic exhaustivity is to be analyzed. Exhaustivity can be analyzed as uniqueness while being reached via a conventional implicature that depends on cardinality (see Halvorsen (1978)), or semantically via a uniqueness operator which expresses that if anything is true of the cleft relative, the relative must be identical to the cleft pivot (see Atlas and Levinson (1981)). The method of analyzing exhaustivity as a presupposition (existence and uniqueness) (see Percus (1997)) has shown to not be able to account for the corpus based and experimental evidence provided in chapter 3 of this thesis, which shows that the exhaustivity effect in it-clefts can be canceled. When analyzed as a semantic property of focus, the exhaustivity is seen as part of the semantics of the it-cleft (see É. Kiss (1998)), parallel to the case of exclusives and Hungarian pre-verbal focus. This analysis strictly rules out certain types of constituents (e.g. universal quantifier, also/ even-phrases, as well as something/somebody) that cannot func- 
tion as identificational focus or be in the cleft pivot. This approach is challenged by empirical data which show that not all of these limitations can stand up to speaker behavior in experiments (see e.g. Onea and Beaver (2009)). Speakers react with disagreement to a violation of the exhaustivity in pre-verbal focus, while they openly contradict such a violation with exclusives. As native speakers are less accepting of exhaustivity violations in only sentences than in it-clefts, the empirical data suggest that these two structures do not have the same source for their exhaustivity. These results can be supported for the case of German and Hungarian with further empirical data presented in chapter 4 of this thesis. Exhaustivity can also be analyzed as a pragmatic requirement to give a complete answer to the Current Question (CQ) and a semantic operator that is part of the logical form of the it-cleft Velleman et al. (2012). While exhaustivity in exclusives is directly asserted and at-issue, it is presupposed or conventionally implicated and non at-issue in it-clefts. Since there have been counter arguments to the main points of the semantic approaches to it-cleft exhaustivity, the alternative way is to analyze exhaustivity pragmatically as a Conversational Implicature arising from the conventional implicature of existence that comes as a property of the it-cleft (see Horn (1981)), or appearing from the interaction between the Gricean maxims of quantity and quality (see Byram-Washburn et al. (2013)). Empirical evidence shows that exhaustivity may be derived from it-clefts, but it is not necessarily the case. Various tests provide evidence that it-cleft exhaustivity is reached pragmatically via the discourse structure as a conversational implicature. It is non-at-issue.

The taxonomy questions asks how many kinds of it-clefts can be distinguished. Generally, one can distinguish two types of it-clefts from a information-structural perspective: stressed-focus clefts and informative-presupposition clefts (see Prince (1978), Delin and Oberlander (1995)). Stressed-focus clefts (in this thesis they are referred to as Focus-Background Clefts) are used when the focus in the pivot expresses new (and often also contrastive) information. The presupposed information in the cleft relative is old or accessible. The informative-presupposition clefts (in this thesis called Topic-Comment Clefts), on the other hand, are used to inform the hearer about the information given in the cleft relative.

The focus particle questions asks whether it-clefts are combinable with certain focus particles and whether or not these particles have an effect on the meaning of the it-cleft.

The notion of focus is a universal category of information structure. The focusing of a sentential element leads to updating of the information in a discourse by indicating which contextually relevant alternatives are available for the evaluation of a given assertion in the context of utterance (see Zimmermann and Onea (2011)). 
Focus describes a close relation between questions and the position of focus in answers (see eg.Rooth (1992)).

Regarding the notion of topic, it can be summarized as follows: When information status is seen as the only relevant factor for topicality (see Chafe (1976)), this leads to a definition of topic as the old or given information of a sentence. Another possibility is to understand topicality as aboutness (see Reinhart (1981), Krifka (2008)). The topic is then what the sentence is about, while the backgrounded information is called the comment.

The question whether certain focus particles are combinable with the cleft structure has often been rejected mostly due to the fact that the assumed exhaustivity inference of the cleft structure and the non-exclusive meaning contribution of the focus particle are not combinable and lead to inacceptabilty of the resulting sentence (see Altmann (1976), Percus (1997), É. Kiss (1998), Krifka (2008), Büring and Križ (2013), Lambrecht (2001)).

However, there are some theoretical and empirical arguments for the combinability of it-clefts and additive focus particles. Assuming that the meaning contribution of the particle is not truth-functional, but presuppositional, the particle that associates with the focus adds presupposed information to the focused element. Additionally, ERP results show different effects for exhaustivity violations in only-sentences and it-clefts. This suggests that the exhaustiveness violations in German it-clefts and sentences with exclusives involve different processing mechanisms. While these arguments are only secondary, as they do not directly show the possibility of non-exclusive focus particles being acceptable in an it-cleft sentence environment, it will become clear in chapter 3 of this thesis that this is in fact the case.

The contrastivity questions asks whether contrast plays a role in the production of it-clefts. The connection of contrast and it-clefts was first made by Jespersen (1927) and were demonstrated empirically in previous studies. Speakers are more likely to use a cleft structure when expressing a contrast (see Destruel and Velleman (2014)), and judge them as more acceptable in confrontational situations (see Byram-Washburn et al. (2013)). Chapter 5 of this thesis replicates the experiment for German and presents results that suggest that speakers have a higher tendency to produce it-clefts in contexts that are contrastive. 


\section{Chapter 3}

\section{It-Cleft Exhaustivity and Focus Particles}

\subsection{Introduction}

This chapter discusses the exhaustivity question (are it-clefts exhaustive, and if yes, how should the exhaustivity be analyzed?) and the focus particle question (are it-clefts combinable with focus particles and if yes, can these particles have an influence on the exhaustivity?). First, this chapter provides an introduction to the semantic-pragmatic debate on the exhaustivity effect of it-clefts, before showing a variety of naturally occurring examples extracted from corpus data for German. Special attention is payed to the role of focus particles in these it-clefts. Previous studies which analyze corpus data for it-clefts (see e.g. Wedgwood et al. (2006)) have argued in favor of a pragmatic approach to analyze the exhaustivity inference, while theoretical approaches (see e.g. Büring and Križ (2013), Percus (1997)) tend to suggest a semantic analysis. Within this debate, there are empirical findings regarding the special case of it-clefts which include focus particles, that are surprising: While some semantic approaches (see e.g. É. Kiss (1998), Percus (1997), Altmann (1976)) argue that certain focus particles can (or should) not appear in it-clefts, this chapter presents corpus data that show that this is not only possible, but, in fact, fairly frequent. Taking the corpus data to indicate that focus particles are not at all bad or unacceptable in German it-clefts, this chapter then discusses the difference between Focus-Background (FB) and Topic-Comment (TC) clefts, two types of it-clefts that have been introduced earlier (see chapter 2 of this thesis). While FB-clefts are most frequent, TC-clefts can be characterized as non-prototypical. There are naturally occurring corpus examples of both cleft types which include different focus particles. The question of the effect of these focus particle on the exhaustivity inference in both types of it-clefts is investigated 
in two experiments. This chapter then moves on to presenting the results of a rating experiment that was designed in line with the naturally occurring examples from the corpus, and shows that certain it-clefts in combination with focus particles are judged as acceptable by native speakers.

\subsection{Background}

In Chapter 2 of this thesis, some of the main points in the discussion regarding the exhaustivity of the it-cleft structure have been introduced. We can distinguish a number of ways in which the exhaustivity inference of the it-cleft can be described and analyzed.

Despite a majority of the literature supporting the position that the exhaustivity inference can be derived from a cleft-structure, there is an ongoing debate on whether this exhaustivity inference is semantic (i.e. conventionally coded in the structure; cf. Percus (1997), Velleman et al. (2012), Büring and Križ (2013), Halvorsen (1978)) or pragmatic ${ }^{1}$ (i.e. a Conversational Implicature; cf. Horn (1981), Horn (2014)). There are several positions as to how the semantic exhaustivity is derived. Some theories hold that the effect is a conventional implicature (cf. Halvorsen (1978)), while others analyze it as a uniqueness or maximality presupposition, parallel to definite descriptions (cf. Percus (1997)), while still others take the effect as truth-functional, like the meaning of exclusive particles like only (cf. Atlas and Levinson (1981), É. Kiss (1998)), or as an exhaustiveness presupposition (cf. Büring and Križ (2013)).

While the theoretical background on it-cleft exhaustivity has already been discussed in some detail in chapter 2 of this thesis, the following section will briefly reiterate the most relevant points regarding the special case of exhaustivity and focus particles.

É. Kiss (1998) argues from a theoretical point of view that structural focus expresses exhaustive identification. On the syntactic level, structural focus is realized e.g. in the case of pre-verbal focus in Hungarian and clefts in languages such as English and German. Her analysis of focus particles in such constructions follows Kenesei (1986), arguing that the semantic operation performed by the identificational focus is characterized as exclusion by identification. The particles also and even, however, perform identification without exclusion:

\footnotetext{
${ }^{1}$ It should be noted here (as already pointed out in chapter 1 of this thesis), that this distinction reflects the state of the art at the time this thesis was written. In the meantime, the research has moved from this dichotomy. For the sake of the argument of this thesis, I however assume this distinction.
} 
Even John laughed.

The example with the focus particle even above identifies one member of the relevant set of individuals for which the predicate holds (here: John) without excluding any members that it does not hold for.

A cleft with also seems to be acceptable only in those contexts where it can be taken to identify a member of a relevant set in addition to one or more members identified previously as such for which the predicate holds, with the rest of the set still excluded, as illustrated below:

A: Bill danced with Mary.

B: No, it was Sam that danced with Mary.

C: It was also John that danced with her. (É. Kiss (1998), 252)

When combining identificational foci and exclusives, only is taken to introduce an evaluative presupposition into the meaning of the sentence. It expresses that the elements of the set on which exhaustive identification is performed are ordered along a scale, and the element identified as that for which the predicate exclusively holds represents a low value on this scale.

$$
\begin{aligned}
& \text { Mari csak Jánost szereti. } \\
& \text { Mary only John.ACC loves } \\
& \text { Mary loves only John. (É. Kiss (1998), 266) }
\end{aligned}
$$

The set of individuals that Mary could potentially love is ordered along a scale such that the total set of all individuals represents the highest value, and a single individual the lowest value. Identificational focus then quantifies over sets of individuals. The difference between identificational focus and exclusives is understood to be that exclusives cannot be combined with a once only predicate, a predicate that cannot be simultaneously true of more than one individual(e.g. a superlative):

*Csak Mari volt a legszebb. only Mary was the mostbeautiful

Only Mary was the most beautiful.

*Csak Mari erkezett elsonek. only Mary arrived first Only Mary arrived first.

*Csak Mari János anyja. only Mary John's mother

Only Mary is John's mother. (É. Kiss (1998), 267)

Furthermore, it is possible to include non-exclusive focus particles in the pre-verbal 
focus structure:

János TÖBBEK KÖZÖTT ÉVÁT hítva fel.

It was Eve, among others, that John called up. (É. Kiss (2016), 681)

As mentioned previously (see chapter 2 of this thesis), certain focus particles have been said not to be acceptable in cleft sentences if their meaning contradicts the exhaustivity inference either via uttering it (e.g. not only) or presupposing it (e.g. even) (see e.g. Altmann (1976), Percus (1997)). However, the data presented in this chapter show that it-clefts which include non-exclusive focus particles do, in fact, appear in naturally occurring examples, as illustrated below:

Es ist auch ihre Perspektivlosigkeit, die viele Jugendliche zur It is also their lack-of-perspective, RelPron many teenagers to-the Flasche greifen lässt.

bottle reach lets

It is also their lack of perspective that makes many teenagers reach for the bottle.

(RHZ04/APR.20135 Rhein-Zeitung, 23.04.2004; Jugend braucht mehr Chancen)

Es ist vor allem das Wetter, das uns bis jetzt einen Strich

It is especially the weather, RelPron us until now a line

durch die Rechnung macht.

through the equation makes

It is especially the weather that has messed up our plans so far.

(NUZ06/JUN.00081 Nürnberger Zeitung, 01.06.2006; Umsatzrückgang beim Einzelhandel im April - Wetter verregnete das Geschäft)

This study is focused on German it-clefts that include focus particles (e.g. exclusives like only/nur, additives like too/auch, iteratives like again/wieder, particularizers like for example/beispielsweise), of the kind illustrated above.

Previous studies have shown the importance of considering corpus data in the context of the semantic-pragmatic debate on it-clefts and similar focus constructions (e.g. Wedgwood et al. (2006) for Hungarian, Hedberg (1988) for English). Naturally occurring examples seem to clash with primarily theoretical assumptions regarding the exhaustivity inference.

The corpus examples suggest that the focused element in the cleft pivot is not the only item having the property denoted by the cleft relative, hence (in some way) canceling the exhaustivity inference. This becomes clear when we look at the naturally occurring example in (180) below, where the conflict between exhaustivity 
inference in (180)a and the meaning contribution of the particle in (180)b can be clearly seen.

A newspaper article first introduces Jette, a female Beagle, who did very well at a dog show, in which 18 dogs participated. The article then specifies why Jette did so well:

Es ist vor allem Jettes Intelligenz, die verblüfft.

It is especially Jette's intelligence that is surprising.

a. Expected exhaustivity inference of it-cleft: Nothing besides Jette's intelligence is surprising.

b. Presupposition of particle: Something besides Jette's intelligence is (also) surprising.

Examples like this strongly suggest non-exhaustivity, which is incompatible with a semantic analysis of exhaustivity in it-clefts, and clash with the argument that clefts cannot include particles contradicting the exhaustivity inference (cf. Altmann (1976), Percus (1997)).

Returning to the example given in (180) above, recited below, another argument against a semantic analysis of it-cleft exhaustivity presents itself when looking at the sentence that follows the cleft.

(180) Aus 18 Hunden stach die zweieinhalbjährige Beagledame hervor, und das nicht nur aufgrund ihres ungewöhnlichen Charmes oder wegen ihrer bezaubernden sherryfarbenen Augen.

Out of 18 dogs, the 2,5 year-old beagle lady was particularly noteworthy, and not just because of her exceptional charme or her lovely sherrycoloured eyes.

Es ist vor allem Jettes Intelligenz, die verblüfft.

It is especially Jette's intelligence that surprises.

Und ihre schnelle Auffassungsgabe.

And her fast understanding.

(BRZ11/ MAI.01452 Braunschweiger Zeitung, 04.05.2011; Jette ist ein Superstar auf vier Pfoten)

The focused element that is positioned in the cleft pivot (Jettes Intelligenz/ Jette's intelligence), is not intended to be the unique element which satisfies the property denoted by the relative clause. The following sentence states, on the contrary, another item that fulfills the cleft relative, thereby explicitly expressing non-exhaustivity.

One argument against the combinability of it-clefts and certain focus particles is 
a clash of the different presuppositions: the cleft structure comes with an exhaustivity (or uniqueness) presupposition, while non-exclusive focus particles carry an opposing presupposition. Altmann $(1976)^{2}$ argues that focus particles are only combinable with German it-clefts when they carry a scalar interpretation, and are not used to express non-exclusivity (like nicht nur/ not only), or presuppose non-exclusivity (like sogar/ even). Therefore, the particle nur/ only can occur in cleft sentences, and sogar/ even can occur in it-clefts in contexts which do not carry a non-exclusive reading. The particle auch/ also, however, cannot occur in a cleft sentence because it carries a non-exclusive meaning in form of a nonuniqueness presupposition. Percus (1997) argues that, since clefts of the form "It is $[\alpha]$ that $\varphi s$ " carry the presupposition that only $\alpha$ has the property $\varphi$ (also called the uniqueness presupposition $)^{3}$, they are incompatible with particles like even and also, and redundant (yet, possible, as in (183)) with exclusive particles such as only. Since these particles can usually associate with focus, as in (181), (Percus (1997)) argues that, in the case of it-clefts, the uniqueness-presupposition of the cleft and the semantics of the particles clash. This leads to unacceptable sentences, as illustrated in (182)a-c below:

(181) a. It was even/also/only the case that $[\mathrm{JOHN}]_{F}$ saw Mary. (Percus (1997), 341)

(182) a. ?It was even/also/only the case that it was $[\mathrm{JOHN}]_{F}$ who saw Mary.

b. ??It was even $[\mathrm{JOHN}]_{F}$ who saw Mary.

c. ??It was also $[\mathrm{JOHN}]_{F}$ who saw Mary. (Percus $\left.(1997), 341\right)$

Looking at (183), however, (Percus (1997)) notes that this structure with only does not lead to an unacceptability of the sentence, while the same construction and position of the particle lead to the mentioned unacceptability with even and also, as illustrated in (182)b-c:

It was only $[\mathrm{JOHN}]_{F}$ who saw Mary.

Büring and Križ (2013) note that in the case of (the possible, yet peculiar combination of) it-clefts with only, the exhaustivity presupposition of the cleft is tautologous. This results in it-clefts with only being equivalent to ordinary predication with only ${ }^{4}$.

If the exhaustivity inference in clefts is taken to be a presupposition as the effect

\footnotetext{
${ }^{2}$ These theories have already been discussed in chapter 2 of this thesis. The arguments are reiterated here for the reader's convenience.

${ }^{3}$ Percus notes that the presupposition is not as simple as this description suggests. For further discussion, see Halvorsen (1978).

${ }^{4}$ Büring and Križ (2013) account for this by providing an analysis of it-cleft pivots of the form only $D P$ as quantifiers.
} 
of an identificational focus, an additive focus particle like also or even triggers a conflicting presupposition (see Krifka (2008)). Exhaustive focus is then not compatible with additive particles.

Horn (1981) presents examples which he takes to illustrate that the insertion of exclusives into a cleft has a truth-functional effect, as illustrated in (184), while this is not the case for clefts without a more explicit way of stating the exhaustivity inference through the exclusive particle, as can be seen in (185).

(184) I know Mary ate a pizza, but I've just discovered that it was only a pizza that she ate.

(185) ??I know Mary ate a pizza, but I've just discovered that it was a pizza that she ate. (Horn Horn (1981), 130)

In this example, it is the exclusive that makes the cleft acceptable in the context. Without the exclusive, the it-cleft is not informative and, therefore, less accept-

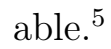

To sum up, it can be said that whether non-exclusive focus particles can be part of it-clefts has mostly been rejected in the literature. The argument here is that the exhaustivity inference of the cleft structure and the non-exclusive meaning component (commonly analyzed as a presupposition) of the focus particle clash. This leads to unacceptable sentences. This does not hold for exclusive particles such as only. Here, there is no clash of presuppositions, but rather a strengthening of the exhaustivity effect. This theoretical assumption has been challenged by experimental data as well as naturally occurring corpus examples, and will be challenged further by the data presented in the following sections of this chapter.

\subsection{Corpus Study}

\subsubsection{Introduction}

A variety of examples for German it-clefts that include focus particles were be found in a corpus study of several corpora including newspapers from German-

\footnotetext{
${ }^{5}$ As mentioned earlier (see chapter 2), recent experimental studies support the argument that the exhaustivity effect in clefts is not truth-functional in the way that only-sentences are. Drenhaus et al. (2011) provide data from questionnaire and on-line experiments which show that a violation of the exhaustivity effect in German only-sentences is less acceptable than in it-clefts. They conclude that the exhaustivity effect may have a different truth-functional status. This is supported by the results of a related ERP study, which shows different effects for exhaustivity violations in only-sentences and it-clefts, suggesting that the exhaustiveness violations in German it-clefts and only-sentences involve different processing mechanisms.
} 
speaking countries (Germany, Austria, and Switzerland) and Wikipedia entries, as well as Wikipedia forum discussions. The random data collection amounts to nearly 400 German clefts which include focus particles. The examples with particles were found during a data collection for regular cleft structures, and were then collected and annotated separately to allow for further systematic research. Particular attention was payed to (i) naturally occurring examples in which the exhaustivity inference is canceled or violated through the occurrence of a focus particle which has the clefted element in its scope, and to (ii) examples where the exhaustivity inference is strengthened through an exclusive.

The following focus particles were frequent in the corpus: erneut, auch, beispielsweise, vor allem, nicht zuletzt, nur (again, also, for example, especially, not least, only). Examples (186)-(192) illustrate the kinds of natural sentences that appear in the corpus. Sometimes, the German examples include a combination of particles, as illustrated in (191) and (192).

(186) Es ist nicht zuletzt der strenge Rahmen aus Stein und Asphalt, der dem Central Park seinen einzigartigen Charakter verleiht.

It is not least the rigid frame of rocks and asphalt that gives Central Park its unique character.

(NZZ12/FEB.00616 Neue Zürcher Zeitung, 04.02.2012, S. 53; Geometrie der Gier Prisma der Welt)

(187) Es ist vor allem das Nahrungsangebot, das die Halden für Möwen attraktiv macht.

It is especially the range of food that makes the dumps attractive for seagulls.

(K00/MAI.35512 Kleine Zeitung, 04.05.2000, Ressort: Lokal; Möwenforscher lauert den Vögeln in Müllhalden auf)

(188) Es ist nur die in Udine gebotene Leistung, die momentan so nachdenklich stimmt.

It is only the performance presented in Udine that makes one thoughtful right now.

(A98/OKT.64464 St. Galler Tagblatt, 13.10.1998, Ressort: TB-SPO (Abk.); «Spiritus retour»)

(189) Es ist auch der Reiz des Neuen, der viele hierher treibt.

It is also the appeal of the new that brings many here.

(BRZ06/MAI.10876 Braunschweiger Zeitung, 20.05.2006; Jobs im Ausland immer attraktiver)

(190) Es ist zum Beispiel der Ensemblespieler Alexander Seibt, der seine Karikatur eines menschlichen Aschenbechers in heftigst alkoholisiertem Zustand zu einem der Höhepunkte des Abends macht. 
It is for example the ensemble member Alexander Seibt who turns his version of a heavily drunk human ashtray into a highlight of the evening. (NZS12/MAR.00217 NZZ am Sonntag, 11.03.2012, S. 63; Existenzialistische Flaschenpost)

(191) Es ist zum Beispiel auch Werner Langen, der die Sache im Europäischen Parlament als Berichterstatter massiv angeschoben hat.

It is for example also Werner Langen that pushed the matter forward massively in the European Parliament as a messenger.

(L98/DEZ.24042 Berliner Morgenpost, 05.12.1998, S. 6, Ressort: POLITIK; Über CDU pur und neue SPD)

(192) Es ist vor allem auch der politische Stil, der die Regierungsgegner erregt.

It is especially also the political style that upsets the opposition.

(K00/APR.32693 Kleine Zeitung, 22.04.2000, Ressort: Landespolitik; VP-Klubchef sorgt sich um "soziale Defizite" der Partei)

Contrary to the existing approaches, the presented data show that there are, in fact, naturally occurring examples of it-clefts in combination with focus particles that have a non-exclusive meaning in German.

There are compatible studies that look at corpus evidence in the case of it-clefts (e.g. Hedberg (1988)). Wedgwood et al. (2006) present a corpus study of Hungarian pe-verbal focus in which they show that, when looking at naturally occurring examples from corpus data, the pre-verbal focus does not in fact show the robust exhaustivity inference that has been ascribed to it (see e.g. É. Kiss (1998)). Instead, the Hungarian examples show a great variety of focus adverbials which have the effect of explicitly de-exhaustifying the focused element. This is illustrated in the two examples below for the cases of legkevésbé/least of all, elsósorban/ primarily, and többek közótt/ among others:
A Zöld Párt 1980-as megalakulása
a legkevésbé the Green Party 1980-in formation-POSS3SG the least [ökológiai problémákhoz] volt köthető - annak ellenére ecological problems-to was connectable - that-DAT notwithstanding - hogy az atomerómúvek s a nukleáris átmeneti tárolók - that the atomic.power.plants and the nuclear transitory stores [...] ellen alakult polgári kezdeményezésekból [...] szerveződött [...] against formed civil infantry-from [...] was.organized párttá. party-into 
The formation of the Green Party in 1980 had least to do /with ecological problems], notwithstanding that it became a party out of civil initiatives against nuclear power plants and nuclear intermediate storage sites. (Wedgwood et al. (2006), ex. 11)

A kulturális bizottságban azonban elsősorban [szakmai the cultural commission-in however primarily professional szempontokból] vizsgálták ezt a kérdést, és perspectives-from examined-3PL this-ACC the question-ACC and kerestek politikai jellegú kompromisszumot, politikailag felvetett sought.3PL political type compromise-ACC politically raised vitás kérdésekben. disputed questions-in

But in the cultural commission this question was mainly examined /from professional perspectives], and they were looking for a political compromise for the disputed questions that were raised by politics. (Wedgwood et al. (2006), ex. 12)

(195) A küldöttségben Chris Patten, az unió külügyi the delegation-in Chris Patten the union foreign biztosa mellett helyet kap Javier Solana, akiket commissioner-POSS3SG beside place gets Javier Solana whom útjukra többek között [Anna Lindh svéd külügyminiszter] way-on others among Anna Lindh Swedish foreign-minister kísér majd el. accompany FUTURE VM

In the delegation, Javier Solana will be included in addition to Chris Patten, the foreign commissioner of the EU, and they will also be accompanied by among others [the Swedish foreign minister Anna Lindh]. (Wedgwood et al. (2006), ex. 13)

Therefore, if we want to answer the question which focus particles can occur in German it-clefts and find possible correlations between the various focus particles, as well as take a closer look at the contextual environment of the cleft structure, further corpus research is needed.

The first part of this chapter presents the results of the corpus study which separately accounts for Focus-Background (FB) and Topic-Comment (TC) clefts ${ }^{6}$ in German. The data allow insights on three aspects:

1. distinction of FB and (non-prototypical) TC-clefts,

\footnotetext{
${ }^{6}$ For a more detailed discussion of the different cleft types, see chapters 2 and 5 of this thesis.
} 
2. exhaustivity status of the it-clefts, and

3. kinds of focus particles that appear within clefts.

Previous theoretical work (Altmann (1976), Percus (1997)) suggests that focus particles cannot appear in clefts if their meaning contradicts the exhaustivity inference. This corpus analysis of over 400 clefts shows that it-clefts which include nonexclusive focus particles (auch/also, nicht zuletzt/not least, vor allem/especially) do, in fact, appear in naturally occurring examples, as illustrated in the examples above.

The second part of this chapter accounts for such cases of it-clefts with additive focus particles that appear to be exhaustive in spite of the non-exclusive presupposition of the focus particle. Cases like these raise the question, namely whether the particle always modifies the focused NP or DP in the cleft pivot, or might take a wider scope over the entire sentence, or modify the VP in the cleft relative. To shed light on this issue, a number of constituency tests are performed on selected corpus examples. Additionally, the results of a pilot experiment with follow-up are presented which aim at the exhaustivity and the scope of the focus particle. In addition to that, the results of a rating experiment that tests the acceptability of it-clefts with focus particles (of the kind found in the corpus) are presented.

\subsubsection{Method and Objectives}

A corpus study was conducted ${ }^{7}$ using the online corpus COSMAS II, which allows to search several corpora, including newspapers from German-speaking countries (Germany, Austria, and Switzerland) and Wikipedia entries, as well as Wikipedia forum discussions. COSMAS II is an online text collection which provides access to a total of 374 text corpora of over 30 billion words (as of September 2016) for German that are provided by the Mannheim German reference Corpus (DeReKo) ${ }^{8}$. In searching for it-clefts in the corpus, a few basic search methods were used to produce the output of the form "Es ist/war [x], der/ die /das"... / It is/was [x] that/which....

The reason why we are looking at examples in which the focus particle is positioned directly in front of the cleft pivot is that these are the examples we searched for and analyzed in the corpus study. It is, however, also possible for a focus particle to appear in another position in an it-cleft, as illustrated below. However, they may not all be equally acceptable in English.

\footnotetext{
${ }^{7}$ Parts of this chapter have been previously published in Boell (2016).

${ }^{8}$ For a complete list of the corpora, see http://www.idsmannheim.de/cosmas2/projekt/referenz/korpora.html (last accessed Oct 6th, 2017).
} 
a. It is also Peter who danced with Mary.

b. It is Peter who also danced with Mary.

c. It is Peter who danced also with Mary.

d. ?It also is Peter who danced with Mary.

e. ??Also, it is Peter who danced with Mary.

Several options were tested before concluding that a search using mostly the regular natural language items produced a larger outcome of the desired structures than a narrower morphological search. The distance operator $+w 1$ was used.

A string of the following form was entered into the search engine:

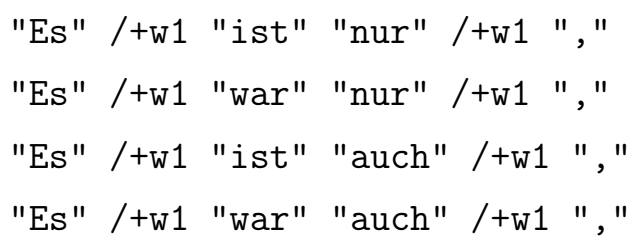

The copula was alternated between is and was, and the focus particles were individually entered. Each focus particle was searched for separately, which is why this corpus study cannot serve to compare frequencies of the different focus particles within the corpus. The corpus was searched for the following focus particles: nur/ only, also/auch, especially/vor allem, not least/ nicht zuletzt, for example/ beispielsweise. This resulted in a very large output with a large amount of items that were not actually it-clefts. The critical items were then extracted manually and collected separately. To produce a comparable body of critical items, we extracted 100 items for each focus particle.

The main objectives of the corpus search were to (a) provide an overview over the ways in which it-clefts are used by German speakers in the different media provided by the COSMAS text collection, to (b) gain insights on the frequencies of the different types of it-cleft used in German, and to (c) collect naturally occurring examples of it-clefts in their communicative contexts.

Objective (a) is of interest as the it-cleft structure is rather uncommon in (spoken) German, and for a conclusive analysis of the semantics and pragmatics of this structure, it is viable to investigate how and when speakers use it-clefts. As the contexts of the it-clefts are important to determine whether the cleft is used to express exhaustivity, the data was collected including a number of sentences preceding the it-clefts.

Objective (b) is of interest in order to gain a better understanding of which focus particles can and do occur in which types of it-clefts (Focus-Background and TopicComment clefts).

Objective (c) is of interest from a methodological point of view. Analyzing it-clefts 
based on their use in naturally occurring examples has been done in previous studies (e.g. Wedgwood et al. (2006) for Hungarian, Hedberg (1988) for English). The corpus study presented in this chapter is aimed at providing the necessary data material for further research of the use of it-clefts in German.

The data collection is random and amounts to more than 400 German clefts which include different focus particles, plus 100 clefts without particles. To have a direct comparison regarding the specific use of the focus particles in syntactically unmarked sentences, the corpus was additionally searched for non-clefted sentences with the same focus particles.

Particular attention was payed to naturally occurring examples in which the exhaustivity inference is canceled through the occurrence of a focus particle which takes the syntactic position right before the focused element in the sentence. In the case of German, this position makes it likely for the particle to modify the focused element (see e.g. König (1991)). Attention was also payed to examples where the exhaustivity inference is strengthened through an exclusive.

\subsubsection{Annotation}

The cleft sentences were extracted from the corpus including some of their preceding contexts. This allows to look for the possible effects of contextual surroundings on the exhaustivity inference that is said to come with cleft constructions. The cleft sentences were then annotated in the following categories ${ }^{9}$ :

1. \pm Focus particle

2. Cleft type (Focus-Background or Topic-Comment)

3. \pm Exhaustivity

4. \pm Contrast

5. Is the cleft pivot pre-mentioned in the preceding context? (yes/no/partially/by related concept)

6. Distance of pre-mentioned pivot from it-cleft (by sentence number)

7. Grammatical role of pre-mentioned pivot in preceding sentence (subject, object, or topic)

8. Is the predicate pre-mentioned? (yes/no/ partially/ by related concept)

\footnotetext{
${ }^{9}$ For the completely annotated version of this corpus, please see the following link: https: //www.researchgate.net/publication/331328106_it-CleftCorpusGerman
} 
9. Distance of pre-mentioned predicate from cleft (by sentence number)

10. Intonation: Pivot and/or particle stressed

Additionally, the annotation also includes the non-clefted version to account for the intuitive scope of particle. In the case of the collected data for the particle only/nur, the intended meaning of the particle was also annotated. The German nur can be used to express a meaning close to the English only (which can also be translated into the German ausschließlich) as well as a meaning close to the English just (which can also be translated into the German lediglich). All examples were annotated by the same person (the author of this thesis). On the one hand, this makes the annotation very consistent, while on the other hand, it leaves room for discussion and difference of judgment.

The following figures illustrate the annotation with the example of one data point each. The annotation was done in Excel using a classic table structure.

Figure 3.1: Example Annotation auch/also

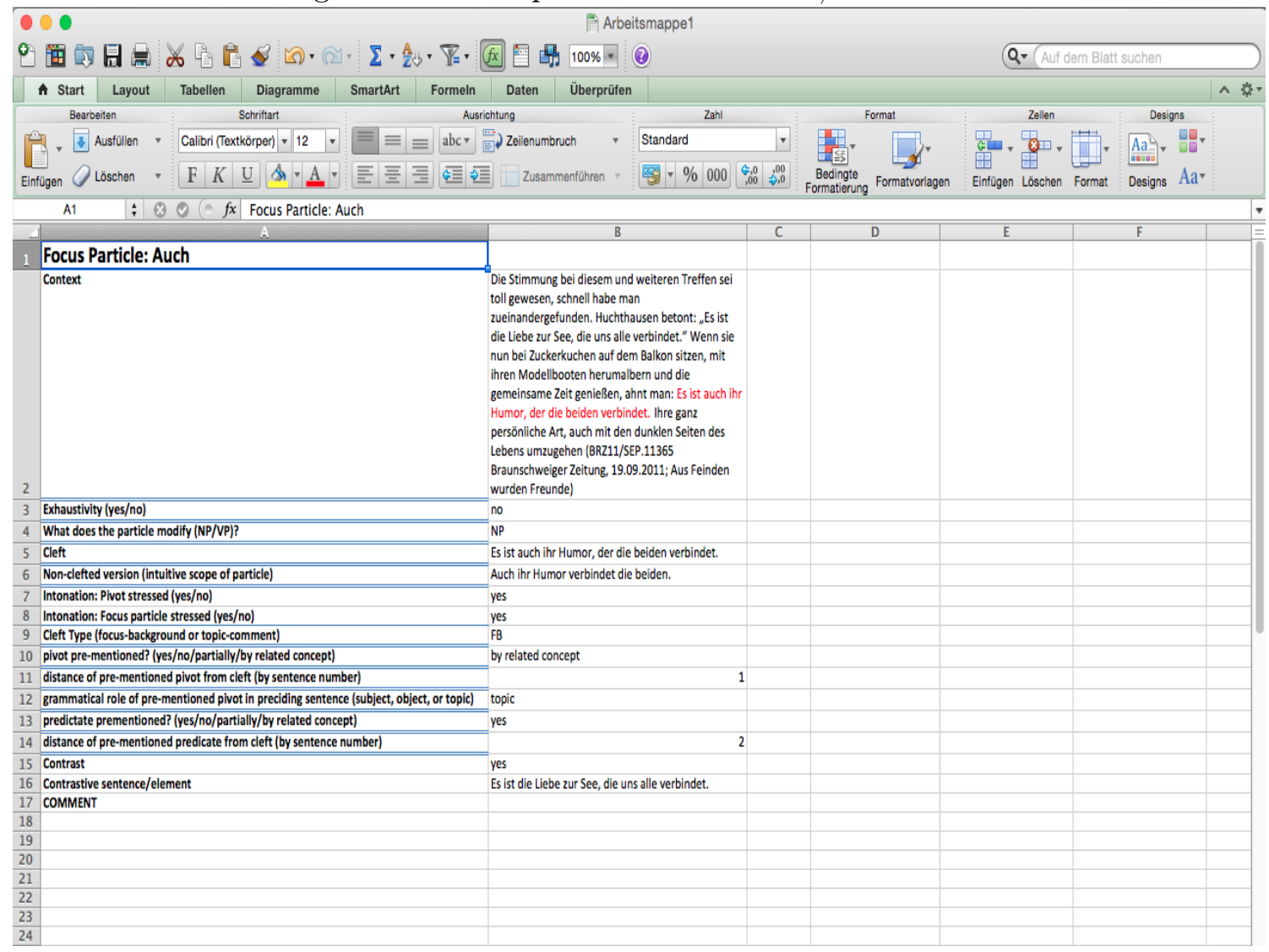


Figure 3.2: Example Annotation nur/only

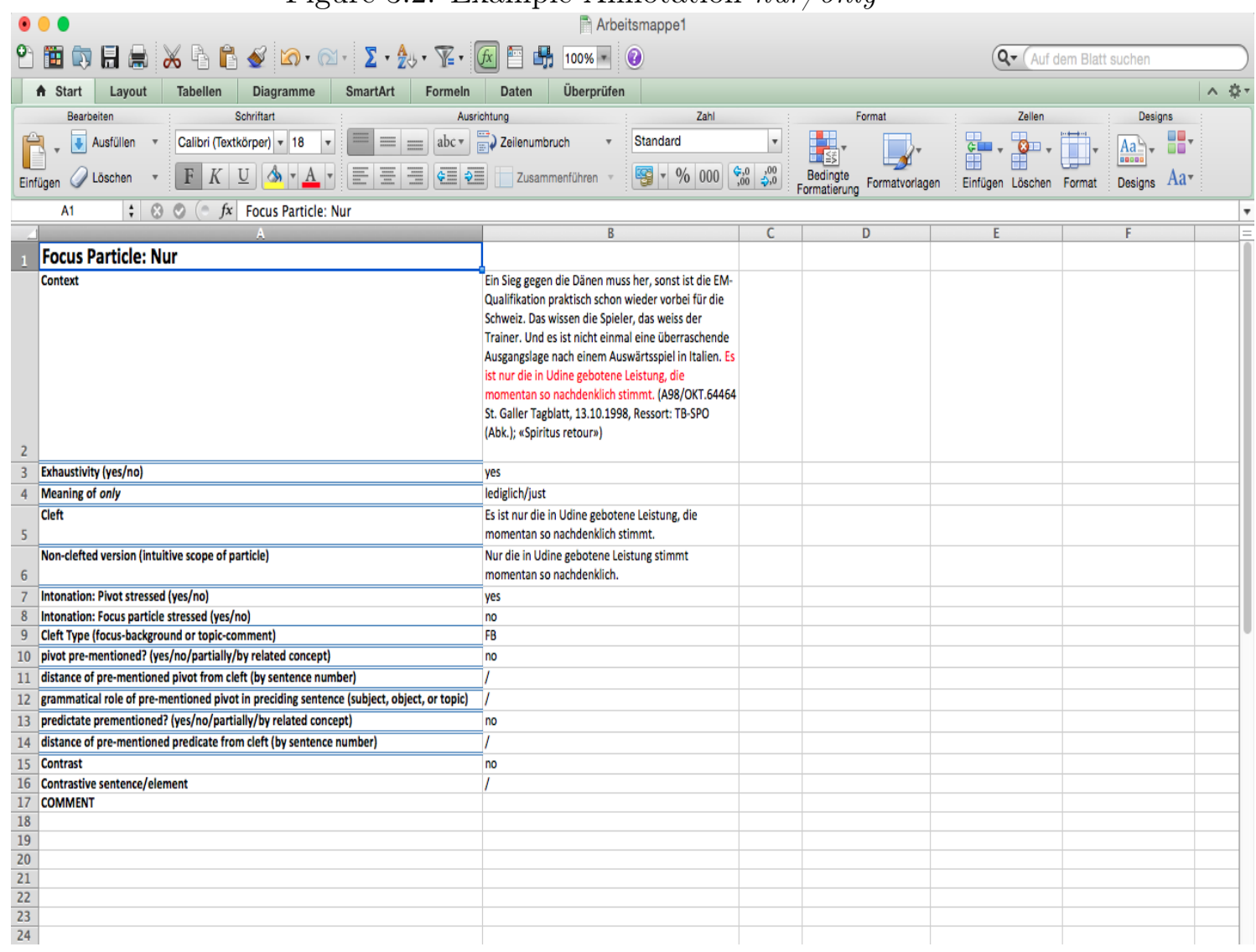

In the following, we take a closer look at the aforementioned categories.

\subsubsection{Focus Particle}

As mentioned previously, the corpus search for it-clefts that include focus particles was motivated by an earlier corpus search which did not explicitly include any particles. As the results produced several it-clefts with different focus particles, it was then decided to specifically search for it-clefts with certain focus particles. The decision which particles to include in the search was motivated by previous studies and their remarks on the combinability of it-clefts and focus particles. Since exclusives like only are said to generally be unproblematic in combination with it-clefts, we wanted to see whether this could be supported by corpus data for the case of German. The additives also and even have been argued not to be possible in it-clefts (see e.g. Percus (1997), Büring and Križ (2013)), which is why there were included in this corpus search. In addition to these, the focus particles 
nicht zuletzt/ not least, vor allem/ especially and beispielsweise/for example were included as they were found among the examples in the previous corpus search. To produce a comparable body of critical items for each focus particle, this thesis only compares those categories for which approximately 100 items were found.

While the particles sogar/even and beispielsweise/for example were not included in the analysis because the search did not produce enough examples, it is still worth mentioning that there were in fact corpus examples with these two particles. Specifically, we found 9 examples with beispielsweise/zum Beispiel and 4 examples with sogar. One example for each of these particles is listed below for illustration:

(201) Schaut man Dimitar Rangelow zu, so möchte man nicht sein

Looks one Dimitar Rangelow at, so wants one not his

Manndecker sein. Nicht nur, weil der Stürmer des FC Luzern

marker be. Not only, because the striker of-the FC Luzern

einen schnellen Antritt besitzt, weil er wendig, robust und

a fast acceleration owns, because he agile, robust and

torgefährlich ist. (...) Am Sonntagmorgen ist am Telefon

deadly-dangerous is. (...) On sunday-morning is on-the telephone

nichts von dieser Härte zu spüren. Rangelow nimmt sich

nothing of this toughness to feel. Rangelow takes RefPron

Zeit, hört zu, antwortet überlegt und souverän. Es ist sogar

time, listens to, answers deliberate and confident. It is even

Sanftmut, die durchdrückt, als im Hintergrund das gentleness, RelPron carry-through, when in-the background the Töchterchen zu weinen beginnt und Rangelow tröstend eingreift. little-daughter to cry starts and Rangelow soothing step-in

When one observes Dimitar Rangelow, one does not want to be his marker. Not only because the striker of FC Luzern has a fast acceleration, because he is agile, robust and deadly. (...) Sunday morning on the phone, none of that toughness is noticeable. Rangelow takes his time, listens carefully, answers deliberate and confident. It is even gentleness that carries through when the little daughter starts to cry in the background and Rangelow steps in soothingly. (NZZ13/DEZ.02104 Neue Zürcher Zeitung, 16.12.2013, S. 33; Dank Vertrauen anders)

(202) Es ist schwer zu verstehen, dass Kritik am Staat Israel oder It is difficult to understand, that criticism on-the state Israel or seiner Regierung, sei sie nun berechtigt oder nicht, mit RelPron government, be RelPron PART justified or not, with 
dem Vorwurf des Antisemitismus belegt wird. Es ist beispielsweise the accusation of antisemitism proven FUT. It is for-example der Journalist Michel Friedman, der zu Recht immer wieder the journalist Michel Friedman, RelPron with justice always again heftigst darauf hinweist, dass Judentum und Israel nicht most-strongly thereon indicates, that Judaism and Israel not gleichzusetzen sind.

equal are

It is difficult to understand that criticism of the state of Israel or its government, may they be justified or not, are faced with the accusation of antisemitism. It is for example the journalist Michel Friedman who keeps on correctly pointing out that Judaism and Israel are not equal. (RHZ12/APR.05460 Rhein-Zeitung, 07.04.2012, S. 2;)

\subsubsection{Cleft Type}

Focus-Background $(\mathrm{FB})^{10}$ clefts appear mostly in answers and corrective statements, with the contrast on clefted constituent. For example in this questionanswer pair:

(203) Q: Who drank most at the party?

A: It was Max who drank most at the party.

In Topic-Comment clefts (TC), also called Informative-Presupposition Clefts (cf. Hedberg (2013)), on the other hand, the clefted constituent is mostly old, activated, or accessible, while the non-clefted information is new to the hearer.

(204) It was in 1879 when Edison invented the electric lightbulp.

It is important to keep these two kinds of clefts distinct, because they might have different information structural functions: It is possible that the FB-clefts are means of focus marking (as introduced by Roberts (1996)) and that is why they can be introduced by an explicit question. TC-clefts, on the other hand, do not have the same information structural function. These it-clefts rather shift the direction of discourse towards the topic, providing further information on the topic instead of the focused element. TC-clefts can also appear at the very beginning of a discourse, which is not the case for FB-clefts (cf. Prince (1978), Hedberg (2013)).

Therefore, TC-clefts can be described as being presuppositional in every case, as the use of the cleft construction as a kind of focus marking is in fact used to add

\footnotetext{
${ }^{10}$ The distinction between FB and TC-clefts has already been discussed in chapter 2 of this thesis and is repeated here for the benefit of the reader.
} 
redundant information in the pivot. Roberts (1996) argues that focal alternatives are calculated on the basis of the placement of prosodic focus in the utterance, along the lines of those developed in the theories of Rooth (1985), Rooth (1992) and von Stechow (1989).

This category was rather clear to decide and it is very unlikely that it includes a lot of mistakes.

The following examples extracted from the corpus illustrate the two different cleft types. (205) is an example of a FB-cleft with also/ auch. (206) presents an example of a FB-cleft with especially/vor allem. (207) is an example of a TC-cleft with only/nur, where the element that appears in the cleft pivot is mentioned in the preceding sentence. (208) is an example of a TC-cleft with not least/nicht zuletzt, in which the cleft pivot is also mentioned in the preceding sentence.

(205) Huchthausen betont: „Es ist die Liebe zur See, die uns alle Huchthausen emphasizes: "It is the love to-the sea, which us all verbindet." Wenn sie nun bei Zuckerkuchen auf dem Balkon sitzen, connects." When they now with cake on the balcony sit, mit ihren Modellbooten herumalbern und die gemeinsame Zeit with their model-boats joke-around and the together time genießen, ahnt man: Es ist auch ihr Humor, der die beiden enjoy, guess one: It is also their humor, RelPron the two verbindet.

connects.

Huchthausen emphasizes: "It is the love for the sea that connects us". When they sit on the balcony eating cake and joking around with their model-boats one can sense: It is also their sense of humor that connects them. (BRZ11/SEP.11365 Braunschweiger Zeitung, 19.09.2011; Aus Feinden wurden Freunde)

(206) Mit drei Verhandlungstagen kalkuliert die Schwurgerichtskammer With three days-of-trial calculates the jury-court

am Landgericht Nürnberg-Fürth derzeit, Zeugen der at-the district-court Nürnberg-Fürth presently, witnesses of-the

Bluttat und Sachverständige sind gefragt. Es ist vor-allem das bloody-deed and experts are asked. It is especially the

Motiv der Tat, das Rätsel aufgibt. motive of-the crime, RelPron riddles raises.

Presently the court at the district court in Nürnberg-Fürth plans to have three days for the trial, witnesses of the crime and experts are in demand. It is especially the motive of the crime that raises questions. (NUN12/JUL.01966 Nürnberger Nachrichten, 19.07.2012, S. 9; 
Messerangriff auf Taxifahrer - Nürnberger ab heute wegen Mordversuchs vor Gericht)

(207) Die Einwohner aus Mitte-West haben gesprochen. Zugegeben: Es ist The citizens from Mid-west have spoken. Admittedly: it is nur ein kleiner Teil der Mitte-Westler, der bei der only a small part of-the mid-wests, RelPron with the Bürgerbefragung zu Wort kam.

citizens-poll to word came.

The citizens of Mid-West have spoken. Admittedly: it is only a small part of the Mid-Westians, that had a say in the poll. (BRZ06/ JAN. 07999 Braunschweiger Zeitung, 17.01.2006; Subjektiv)

(208) Heute ist er neben Ziegelbrücke die wichtigste

Today is PRONmasc next-to Ziegelbrücke the most-important

Drehscheibe des öffentlichen Verkehrs im Unterland, denn von turntable of-the public transport in-the Unterland, as from hier aus ist jede Bus- oder Eisenbahnhaltestelle im verzweigten here on is every bus or train-stop in-the branched-out Glarus Nord ohne Umsteigen erreichbar. Es ist nicht zuletzt diese Glarus Nord without layover reachable. It is not least this gute Erreichbarkeit, die das so genannte Zschokke-Areal östlich good accessibility, RelPron the so called Zschokke-Areal east-of des Bahnhofs in den Augen des Gemeindepräsidenten zu einer the train-station in the eyes of-the community-president to a weiteren Perle macht.

further pearl makes.

Apart from Ziegelbrücke, it is today the most important public transport turntable in the Unterland area, as one can reach every bus or train station in the far reaching Glarus Nord from here without layover. It is not least this good accessibility, that makes the so-called ZschokkeAreal east of the train station to a real gem in the eyes of the community president. (SOZ10/APR.03327 Die Südostschweiz, 20.04.2010; Näfels soll nicht weiterschlafen)

\subsubsection{Exhaustivity}

The exhaustivity was annotated on the basis of the preceding context of the cleft sentence. This category is of particular interest, as this thesis is aimed at investigating whether TC-clefts or FB-clefts are more likely to be exhaustive. While this category is clearly one of the most interesting in light of this thesis, it was also rather difficult to annotate. Due to the fact that the author of this thesis was the 
only person who annotated the corpus data, especially this category is prone to include mistakes or unclear cases. Whenever it was not possible to determine the exhaustivity of an it-cleft, the item was marked as unclear and excluded from the statistical analysis.

The sentence in (205) is an example of a non-exhaustive it-cleft. In this case, the annotation as [+exhaustive] is clear, as the preceding context overtly names alternatives to the cleft pivot.

The sentence in (207) is an example of an exhaustive it-cleft with only.

A small number of unclear cases was not included in the statistical analysis. These cases were unclear as it can not be decided whether the sentences were exhaustive or not in their respective contexts. The relevant cases are listed in the examples below:

Es ist nicht das „Moment der Agape“, das in den Eros „eintritt", It is NEG ART "moment of Agape" RelPron in the Eros "steps-in" wie Ratzinger schreibt.

how Ratzinger writes.

It is not the "Moment of Agape" that "enters" the Eros, as Ratzinger writes.

(WDD11/A02.03031: Diskussion: Agape, In: Wikipedia-URL: http:// de.wikipedia.org/wiki/Diskussion: Agape: Wikipedia, 2011)

Es ist nicht der Neoklassizismus, der so inhuman daherkommt. It is NEG ART neoclassicism RelPron so inhumane comes-along It is not neoclassicism that comes across so inhumane.

(WDD11/A16.93824: Diskussion:Architektur im Nationalsozialismus, In: Wikipedia-URL:

http:// de.wikipedia.org/wiki/ Diskussion: Architekturim Nationalsozialismus: Wikipedia, 2011)

(211) Es ist ja nicht die Musik, die bei ASP „gotisch“ wirkt. It is yes NEG ART music RelPron with ASP "gothic" seems It is after all not the music that seems "gothic" when it comes to ASP. (WDD11/A25.86939: Diskussion:ASP (Band)/Archiv 1, In: WikipediaURL:

http:// de.wikipedia.org/wiki/ Diskussion:ASP(Band)/ Archiv1: Wikipedia, 2011)

(212) Es ist aber definitiv (und glücklicherweise) kein Regelwerk, das It is but definitely (and luckily) no rulebook RelPron 
in jedem Einzelfall prinzipiell das beste Vorgehen in every single-case as-a-matter-of-principle the best procedure prophezeit.

predicts

But it is definitely (and luckily) not a rulebook that necessarily predicts the best procedure in every case.

(WDD11/A28.04907: Diskussion: Adalbertkirche, In: Wikipedia-URL: http:// de.wikipedia.org/wiki/ Diskussion:Adalbertkirche: Wikipedia, 2011)

Es ist also keineswegs das "irdische Fleisch", welches It is after-all by-no-means ART "material flesh" RelPron auferstehen wird (nach Paulus). resurrect will (after Paulus)

It is by no means the "material flesh" that will resurrect (according to Paulus.)

(WDD11/A29.61163: Diskussion: Auferstehung/ Archiv2, In: WikipediaURL: http:// de.wikipedia.org /wiki/Diskussion: Auferstehung/Archiv2: Wikipedia, 2011)

(214) Es ist nie Steiner, der sich geirrt oder schlecht It is never Steiner RelPron ReflPron mistakenPERF or bad ausgedrückt hat. expressed has It is never Steiner who was mistaken or expressed himself badly. (WDD11/A36.99695: Diskussion: Anthroposophie/ Archiv/ 2008, In: Wikipedia- URL: http:// de. wikipedia.org/ wiki/ Diskussion: Anthroposophie/ Archiv/2008: Wikipedia, 2011)

The examples above are unclear and therefore not included in the statistical analysis of the distribution of exhaustivity across cleft types due to the negation elements found in each cleft. As it is not entirely clear whether negation has an effect on the exhaustivity of the it-clefts, the question whether these examples are exhaustive could not be answered.

The following two examples were excluded from the statistical analysis as they include the German discourse particle doch, which in these examples can be translated as yet/ however/ but. As it cannot be determined what effect this particle has on the two examples above and whether it might influence the exhaustivity inference, these examples were excluded from the analysis.

Es wird jetzt doch niemand behaupten, dass Oswald es war, der It will now yet nobody claim that Oswald it was RelPron 
Ruby erpresst hat. Ruby blackmailed has Nobody will now actually claim that it was Oswald who blackmailed Ruby. (WDD11/A36.59457: Diskussion: Attentat auf John F. Kennedy/Archiv/ 2008, In: Wikipedia-URL:

http:// de.wikipedia.org/ wiki/ Diskussion: AttentataufJohnF.Kennedy/ Archiv/ 2008: Wikipedia, 2011)

Es ist doch der Warren-Bericht, der massiv lügt und nicht It is yet ART Warren-report RelPron massively lies and NEG seine als "Verschwörungstheoretiker" diffamierten Kritiker! his as "conspiracy-theorists" villainized critics Yet, it is the Warren report that lies massively and not his critics that have been villanized as "conspiracy theorists".

(WDD11/A42.20199: Diskussion: Attentat auf John F. Kennedy/Archiv/ 2009, In: Wikipedia-URL: http:// de.wikipedia.org/wiki/ Diskussion: AttentataufJohnF.Kennedy/ Archiv/ 2009: Wikipedia, 2011)

As in the case of clefts without particles discussed above, we also come across a small number of cases in which the exhaustivity status cannot be determined in the category of it-clefts with the additive particle also/ auch. The relevant examples are listed below:

(217) Es ist auch kein hermeneutisches Problem, das ich habe. It is also NEG hermeneutic problem RelPron I have It is also not a hermeneutic problem that I have.

(WDD11/A29.61163: Diskussion: Auferstehung/ Archiv2, In: WikipediaURL: http:// de.wikipedia.org/ wiki/ Diskussion: Auferstehung/Archiv2: Wikipedia, 2011)

(218) Es war auch nicht irgendein Handy, das den Durchbruch It was also NEG any mobile-phone RelPron ART breakthrough brachte. brought It was also not just any phone that made the breakthrough. (Z10/JUN.01944 Die Zeit (Online-Ausgabe), 03.06.2010; Für alles eine App)

(219) Es war auch nicht der DGB, der die 35-Stunden-Woche in It was also NEG ART DGB RelPron ART 35-hour-week in Frankreich eingeführt hatte. France introduced had It was also not the DGB that had introduced the 35-hour-week in France. 
(Z10/MAI.01580 Die Zeit (Online-Ausgabe), 06.05.2010; Paris macht Deutschland zum Sündenbock)

(220) Es war auch nicht die Implosion der Finanzmärkte, die It was also NEG ART implosion ART-Gen financial-markets RelPron den Romancier am Kapitalismus interessierte.

ART author about capitalism interested It was also not the implosion of the financial markets that intrigued the author about capitalism.

(Z09/JUL.00304 Die Zeit (Online-Ausgabe), 23.07.2009; Es gibt keine Sieger, nur Überlebende)

(221) Es war auch nicht die Aussicht auf Auszeichnungen - wie auf das It was also NEG ART prospect of awards - like to ART Bundesverdienstkreuz, das mittlerweile Vuckovics Lebenslauf Federal-Cross-Of-Merit RelPron meanwhile Vuckovic-GEN CV

ziert -, die die Journalistin zum Weitermachen decorates - RelPron ART journalist-FEM to carry-on

anhielt.

motivated

It was also not the prospect of awards - such as the Federal Cross of Merit which now decorates Vuckovic's $C V$ - that motivated the journalist to carry on.

(Z01/107.03166 Die Zeit (Online-Ausgabe), 04.07.2001; Die Angst lässt einen nie los [S. 67])

(222) Es ist auch nicht Dieter Bohlen, der die Berliner It is also NEG Dieter Bohlen RelPron ART Berlin Symphoniker dirigiert. Symphony-Orchestra conducts It is also not Dieter Bohlen who conducts the Berlin Sympohy Orchestra. (RHZ02/OKT.15924 Rhein-Zeitung, 21.10.2002; Kniffliges und Interessantes)

(223) Und es ist auch nicht die traditionelle Harmonik, die diesen And it is also NEG ART traditional harmony RelPron this Tanz letztendlich charakterisiert. dance in-the-end characterizes And it is also not the traditional harmony that characterizes this dance in the end.

(RHZ01/APR.07261 Rhein-Zeitung, 10.04.2001; Flamenco in die - Moderne überführt) 
(224) Es ist auch nicht der zweifellos hohe gastronomische Standard, It is also NEG ART undoubtedly high gastronomical standard der den Goldenen Adler bekannt gemacht hat.

RelPron ART Golden Eagle known made has And it is also not the undoubtedly high gastronomical standard that made the Golden Eagle well known.

(Z03/301.00255 Die Zeit (Online-Ausgabe), 02.01.2003; Endlich! Ein neuer Volksfeind [S. 50])

(225) Aber es ist auch gar nicht das Draufhauen, das man bei der But it is also even NEG ART banging-on RelPron one with the EU vermisst.

EU misses

But it is not at all the smashing that one misses with the EU.

(Z07/JUL.00325 Die Zeit (Online-Ausgabe), 12.07.2007, S. 6; Immer schön ruhig bleiben)

(226) Und es ist auch nicht die Netzhaut, die beim Blick in And it is also NEG ART retina RelPron ART-DAT look in den Schnee gefährdet ist.

ART snow endangered is And it is also not the retina that is endangered when looking into the snow.

(Z12/DEZ.00238 Die Zeit (Online- Ausgabe), 13.12.2012; Kann man vom Blick in den Schnee erblinden?)

(227) Es ist auch nicht das Spielzeug, das Militaristen oder

It is also NEG ART toy RelPron militarists or

Antimilitaristen hervorbringt.

anti-militarists creates

And it is also not the toy that produces militarists or anti-militarists.

(A09/MAR.00792 St. Galler Tagblatt, 04.03.2009, S. 33; Ikone der Popkultur)

(228) Und es ist auch nicht allein das mangelnde Geld, das

And it is also NEG only ART lacking money RelPron

richtungweisende Entwürfe verhindert.

trend-setting designs prevents

And it is also not the lack of money alone that hinders trend-setting designs.

(REI/RBR.00101 Gerhard Schröder: Rede von Bundeskanzler Gerhard Schröder anlässlich 150 Jahre Heidelberger Druckmaschinen AG und Einweihung der Print Media Academy , Hrsg: Presse- und Informationsamt 
der Bundesregierung)

Und es ist auch keine Trauerfeier, die der Grazer And it is also NEG mourning-ceremony RelPron ART Grazian Bischof Ernst Weber gemeinsam mit dem evangelischen Bischof bishop Ernst Weber together with ART protestant bishop Christian Gerhold zelebriert. Cristian Gerhold celebrates And it is also not a mourning ceremony that the Grazian bishop Ernst Weber celebrates together with the protestant bishop Christian Gerhold. (P98/SEP.35930 Die Presse, 10.09.1998, Ressort: Chronik/Wien-Journal; Glück auf - pfiat euch Gott Eine Stunde des Trostes in Lassing)

(230) Und es ist auch nicht die Stimme unseres persönlichen "Guides", And it is also NEG ART voice of-our personal "guide" die aus den Kopfhörern dringt und uns mitnimmt zum RelPron from ART headphones comes and us takes-with to-the eigentlichen Ziel unserer Reise.

actual destination of-our journey And it is also not the voice of our personal "guide" that reaches our ears through our headphones and takes us with it to the actual destination of our journey.

(HAZ09/JUN.01546 Hannoversche Allgemeine, 11.06.2009; Auf der Suche nach der verlorenen Gegenwart)

(231) Aber es ist auch nicht der Geiz, der uns zuvorderst treibt. But it is also NEG ART greed RelPron us primarily drives But is is also not greed that drives us primarily.

(HAZ08/ DEZ.02337 Hannoversche Allgemeine, 13.12.2008, S. 6;)

(232) Es ist auch nicht Jörg Haider, der kommt.

It is also NEG Jörg Haider RelPron comes It is also not Jörg Haider who is coming.

(P94/SEP.32753 Die Presse, 30.09.1994; Pretterebner mit Haider gegen den Rest der Welt)

(233) Es ist auch nicht die Stadt, die sie zum Weggang nötigt.

It is also NEG ART city RelPron her to departure urges

It is also not the city that urges her to leave.

(T01/MAI.23375 die tageszeitung, 16.05.2001, S. 23, Ressort: Kultur; Den Hass ungefiltert weitergeben)

(234) Es ist auch nicht jeder ein Ausbeuter, der

It is also NEG everyone ART exploiter RelPron 
MinijobberInnen beschäftigt.

menial-workers-FEM employs

It is also not everyone an exploiter who employs low-wage workers.

(T13/MAR.02400 die tageszeitung, 19.03.2013, S. 03; Es fühlt sich gut an - jedenfalls im Haushalt)

These sentences were excluded and treated in a special "unclear" category due to the negation in the position right in front of the pivot. Since a possible effect of negation on the exhaustivity of the cleft has not yet been conclusively investigated, it could not be determined whether the negation has an effect on the exhaustivity inference of the cleft.

\subsubsection{Contrast}

The notion of contrast was annotated regarding the preceding context. This category is interesting because there might be a dependency relation between exhaustivity and contrastivity, as it might be argued that there is no exhaustivity without contrastivity. The sentence in (206) is an example of a cleft without contrast, while the sentence in (205) is an example of an item with contrast, the contrastive element being the preceding it-cleft: Es ist die Liebe zur See, die uns alle verbindet./ It is our love for the sea that connects us.

\subsubsection{Previous mentioning of pivot}

In combination with the kind of focus particle, these data provide information on whether it is more likely to have a non-exclusive focus particle in combination with a pivot that has been mentioned in the preceding context (as in this case, the non-exhaustivity can be inferred via the context) or whether there is no correlation between the exclusive meaning component of the focus particle and the fact that the focused element in the pivot has been mentioned before. The pre-mentioning was annotated either with yes, no, partially or by related concept.

An example for a clear yes can be found in the following sentence:

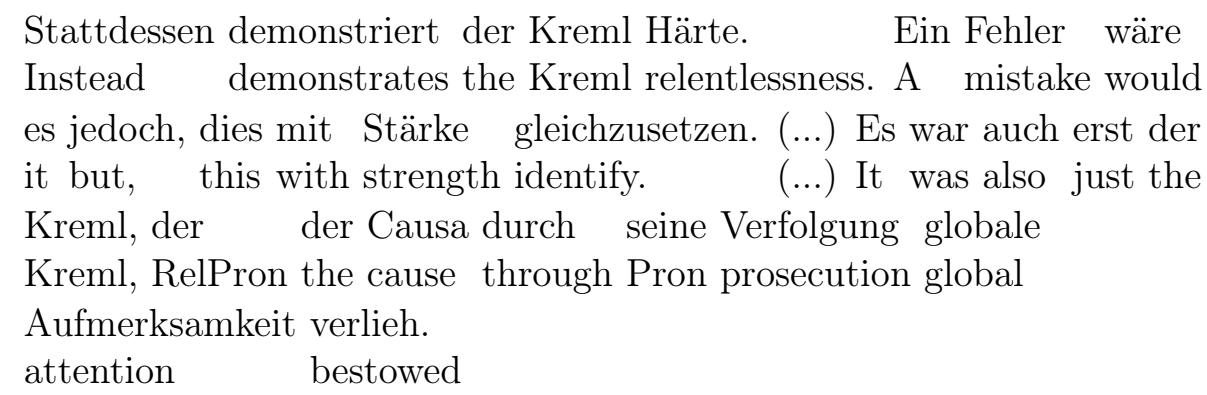


Instead, the Kreml demonstrates relentlessness. It would be a mistake to identify this with strength. It was also the Kreml that bestowed the case global attention through his prosecution in the first case. (T12/AUG.02624 die tageszeitung, 18.08.2012, S. 10; Schwäche, nicht Stärke)

The following sentence is an example of partially:

(236) Gemurmel liegt über den verschlafenen Straßen. Es ist auch der Schlaf, Murmur lies over the sleepy streets. It is also the sleep, den sich die noch nicht ganz so muntere Wanderschar aus RelPron ReflPron the yet not fully so awake group-of-hikers from den Augen wischt.

the eyes wipes

A murmur lies over the sleepy streets. It is also the sleepiness that the not yet fully awake hikers rub out of their eyes. (RHZ04/ DEZ.06090 Rhein-Zeitung, 06.12.2004; Laufen wie damals)

An example for a previous occurrence of the cleft pivot by related concept is the sentence in (205). The pivot their sense of humor can be found in the sentence right before the it-cleft where it is mentioned that the protagonists of the story are joking around with their boats.

As this category was annotated on clear evidence in the data, it is highly unlikely that there are unclear cases. However, it might be debatable whether or not some cases are partially pre-mentioned or by related concept, since these categories are very similar. It would be possible to summarize these two categories under one category for simplification.

In addition to the previous mention of the cleft pivot, it was also annotated whether and in what distance from the cleft sentence the predicate is pre-mentioned.

\subsubsection{Distance of pre-mentioned pivot/ predicate from it-cleft}

The distance of the pre-mentioned pivot and predicate is indicated by the number of sentences between the previous occurrence of the pivot element and its occurrence in the it-cleft.

\subsubsection{Grammatical role of pre-mentioned pivot in preceding sentence (subject, object, or topic)}

This category is in close relation to the question whether the exhaustivity inference that comes with it-clefts is semantic or pragmatic in nature. Previous research is pointing in the direction of a pragmatic analysis. There is the possibility of the 
exhaustivity inference being an information structural phenomenon. Therefore, it is interesting to see which grammatical role the pivot has, when it is previously mentioned in the preceding context.

The sentence in (235) in an example of a pre-mentioned pivot that occurs 5 sentence before the cleft and the grammatical role of the pre-mentioned pivot Kreml is that of a sentence subject.

The sentence in (205) is an example of a pre-mentioned cleft pivot in which the pivot occurs 1 sentence earlier (by related concept, as mentioned above) and has the grammatical role of a topic.

This category was clear to annotate and should not include a significant number of mistakes.

\subsubsection{Intonation: Pivot and/or particle stressed}

This category was annotated in order to see whether there are different ways to stress German it-clefts. While the TC structure in it-clefts has been described to have the intonational stress on the cleft relative in the case of English, there is to this point no experimental evidence that this is also the case for German. The default stress pattern for German es-clefts seems to put the main stress on the cleft pivot, with falling intonation on the relative clause. In addition to this, chapter 4 of this thesis presents an acceptability study in which it was tested whether TCclefts are acceptable as answers to overt questions that target a focus structure as their answer. Based on the results, it can be assumed that the intonation pattern in German es-clefts is not what marks them as FB or TC-clefts, respectively, but the (overt or accommodated) QUD (cf. Roberts (1996)) preceding the utterance. If the content of the cleft relative has been sufficiently activated in the context, the relative clause does not require prosodic stress.

Therefore, the pivot is annotated as stressed in all of the it-clefts. There are some it-clefts in which the focus particle is annotated as stressed and some in which it is not. The sentence in (205) is an example of both the pivot and the focus particle being stressed. The sentence in (208) is an example of an it-cleft where the pivot but not the focus particle receives prosodic stress. This category is prone to include some mistakes. The fact that the cleft pivot always receives prosodic stress can be backed up experimentally, but the annotation of the stress the focus particle receives is not that clear, which may affect the statistical analysis.

\subsubsection{Analysis}

Regarding the distinction between FB and TC-clefts, the collected corpus items show a variety of both cleft types with the following focus particles: auch/also, 
vor allem/ especially, nicht zuletzt/ not least, nur/ only ${ }^{11}$. Overall, FB-clefts are the majority: of 500 items in total (400 with focus particles plus 100 without), 387 are FB, and 113 TC-clefts. Focus particles appear in both types, albeit in different distributions. Because each particle was searched for separately, we will look at the distribution of cleft types within each particle category. This is illustrated in 3.3 below:

Figure 3.3: Distribution of focus particle per cleft type

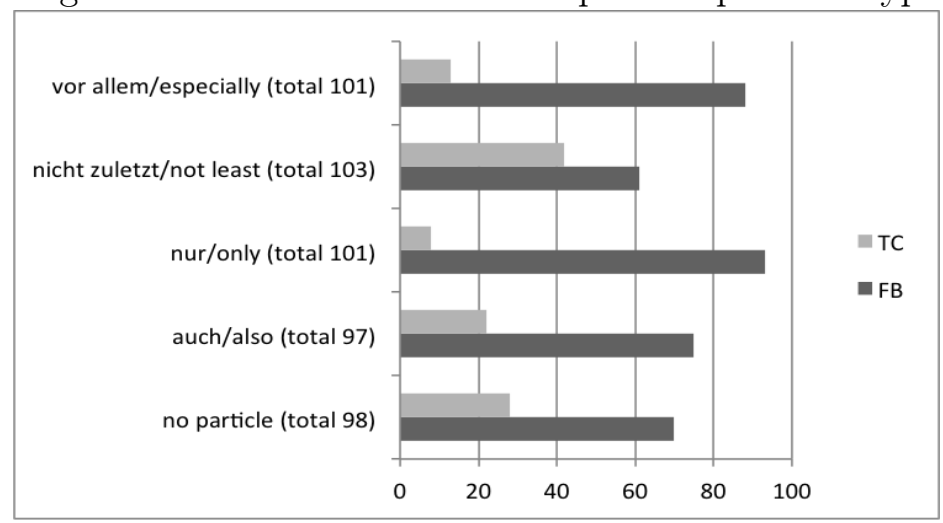

This distribution is statistically significant $\left(\chi^{2}=39.1712, \mathrm{p}=.00001, \mathrm{df}=4\right)$.

One of the key interests, illustrated in 3.4, is to see whether there is a difference in distribution of exhaustivity between the two cleft types, i.e. whether TC-clefts, in which the focused element has already been introduced in the previous context, have a higher tendency to be exhaustive than FB-clefts, in which the focused element is newly introduced via the cleft. As mentioned earlier, a small number of cases was excluded from the analysis because the exhaustivity could not be clearly annotated. This is reflected in the graph as unclear.

\footnotetext{
${ }^{11}$ As mentioned earlier, there were also it-clefts with sogar/even and beispielsweise/for example. These examples were excluded from further annotation and analysis because only a small number of examples was extracted.
} 
Figure 3.4: Distribution of exhaustivity across cleft types

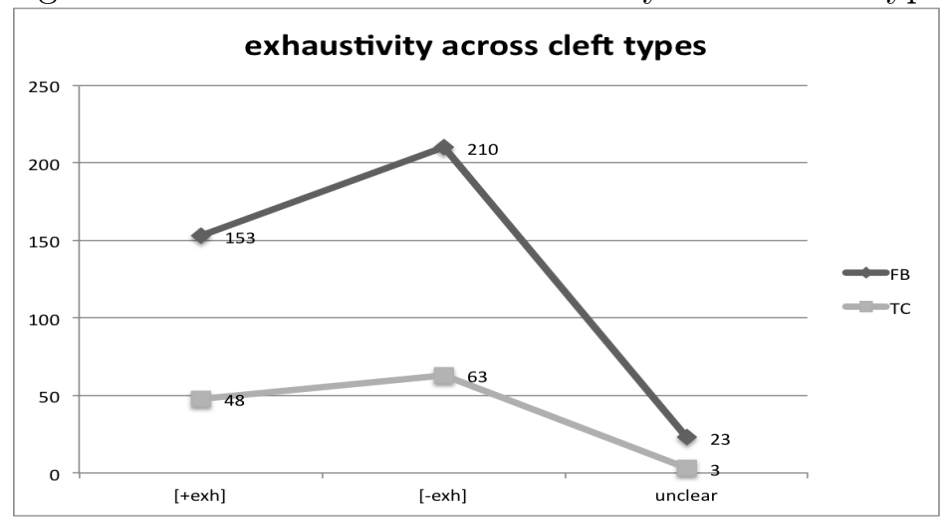

The distribution shown in 3.4 has to be taken with some care, as the majority of the clefts do come with a non-exclusive focus particle and might, therefore, include an additive presupposition. The observed effect is not statistically significant $\left(\chi^{2}\right.$ $=2.0186, \mathrm{p}=.364478, \mathrm{df}=2$ ).

To compare the distribution of exhaustivity in the two different cleft types without this unwanted effect of the possible contribution of the focus particles on the exhaustivity, we can look at the class of it-clefts without particles as shown in 3.5 below:

Figure 3.5: Distribution of exhaustivity across cleft types: clefts without particles

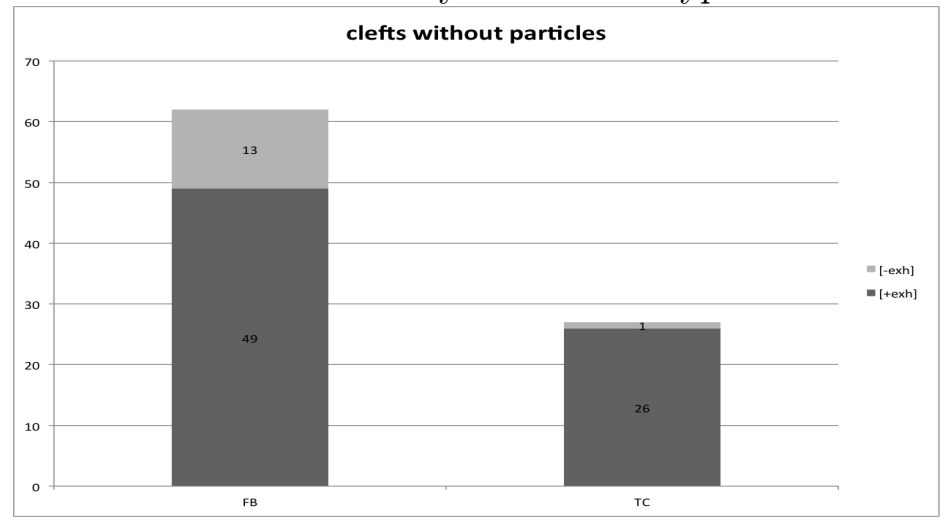

Fig. 3.5 shows that it-clefts do indeed have a significantly $\left(\chi^{2}=4.229, \mathrm{p}=.039738\right.$, $\mathrm{df}=1$ ) higher tendency to be exhaustive than non-exhaustive in both cleft types. Also, 3.5 illustrates the fact that TC-clefts are exhaustive in $96 \%$ of the cases, while FB-clefts are exhaustive in $79 \%$ of the cases. Therefore, TC-clefts have not 
only overall a high tendency to be exhaustive, but are also more exhaustive than FB-clefts ${ }^{12}$.

In the following, we take a closer look at the respective particles individually. In the case of the exclusive only and the particularizer especially, the distribution is very clear and behaves as expected: All clefts with only are exhaustive, and all it-clefts with especially are non-exhaustive. This is illustrated in Figure 3.4 and 3.5 below.

Figure 3.6: Distribution of exhaustivity among clefts with nur/only

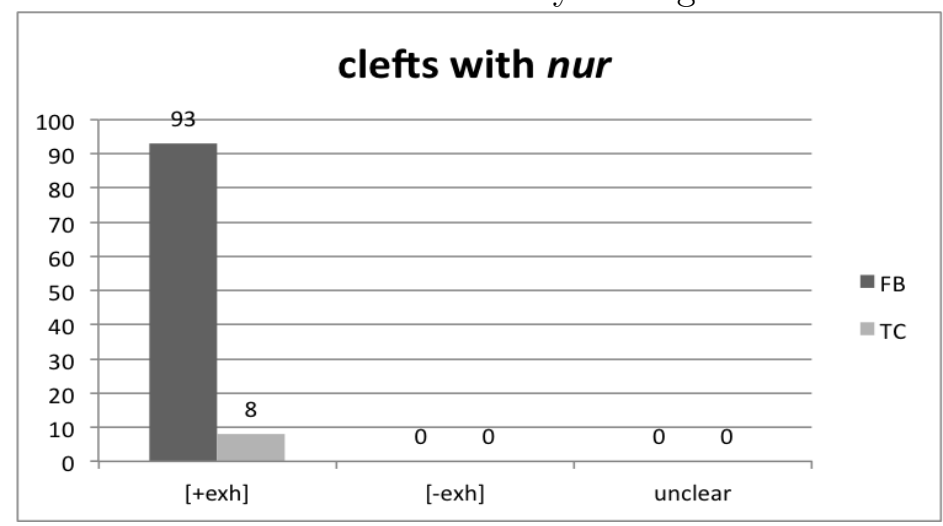

Figure 3.7: Distribution of exhaustivity among clefts with vor allem/especially

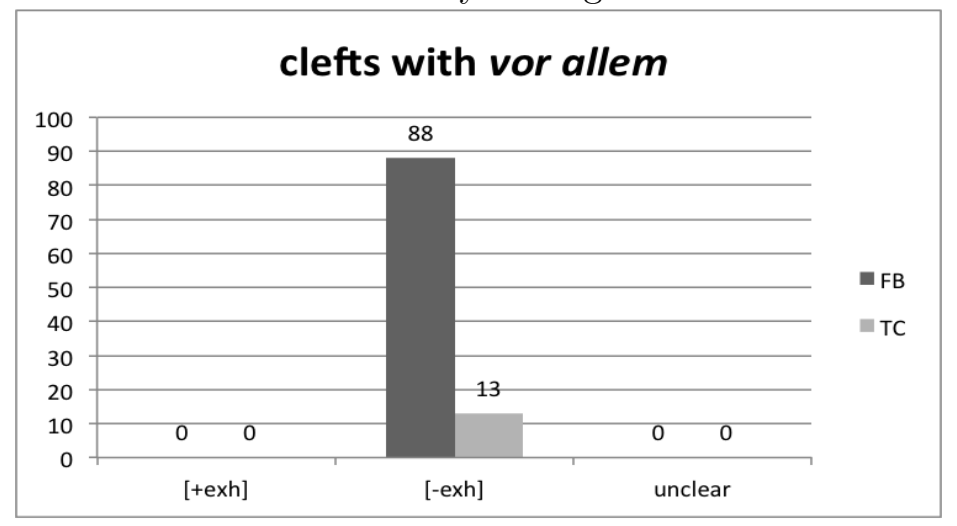

\footnotetext{
${ }^{12}$ This is particularly interesting as the results stand in opposition to previous assumptions regarding the scope of the exhaustivity. Given that TC-cleft are more exhaustive than FB-clefts, the assumption that the exhaustivity only targets the focussed element can no longer hold. Therefore, the data presented in this thesis suggest that the exhaustivity effect found in it-clefts is not a scalar implicature (see e.g. van Kuppevelt (1996), van Kuppevelt (1995), Zondervan (2010) for further discussion)
} 
When looking at the additive particle also, we do not find a clear distribution which follows the meaning of the focus particle. In general, it was to be expected that this particle would cause a clear [-exhaustive] pattern, as the presupposition of this additive particle is strongly non-exhaustive. There actually are a number of clefts with this additive particle that are either exhaustive or at least not clearly non-exhaustive (undecided) ${ }^{13}$, as shown in Fig.3.6 below. This distribution is statistically significant $\left(\chi^{2}=23.0143 . \mathrm{p}=.00001, \mathrm{df}=2\right)$.

Figure 3.8: Distribution of exhaustivity among clefts with auch/also

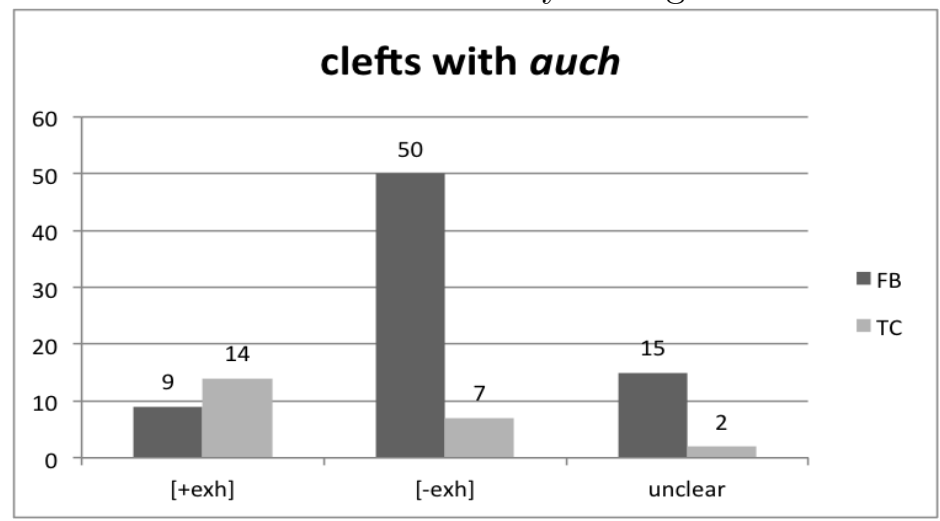

When looking at the particle not least (see Fig.3.7 below), which also comes with a non-exhaustive presupposition, the distribution of exhaustivity is much stronger than in the case of also. However, there are two distinct cases in which the clefts do come with an exhaustive interpretation. ${ }^{14}$

Figure 3.9: Distribution of exhaustivity among clefts with nicht zuletzt/not least

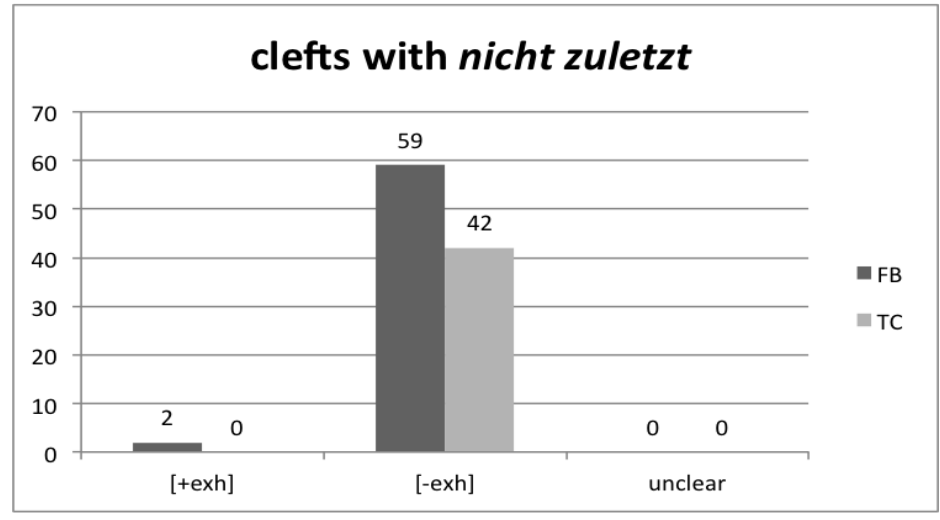

\footnotetext{
${ }^{13}$ These non-prototypical cases will be further discussed in section 3.3.5 below.

${ }^{14}$ These non-prototypical cases will be further discussed in section 3.3.5 below.
} 
The question of whether the pivot of the cleft is mentioned earlier in the context is interesting for the following reason: it might be assumed that non-exclusive focus particles in combination with a pivot that has been mentioned in the preceding context are more frequent than exclusives. In the case of non-exclusive particles, the non-exhaustivity can then be inferred via the context.

Fig. 3.8 below shows that this is in fact the case: significantly more $\left(\chi^{2}=11.4752\right.$, $\mathrm{p}=.000705, \mathrm{df}=2$ ) clefts with only do not have the pivot pre-mentioned in the preceding context as in the case of clefts with also, and more clefts with also have the pivot mentioned in the preceding context than in the case of only. This may also be explained with the

Figure 3.10: Distribution of pre-mentioned particles among one exhaustive and non-exhaustive particle

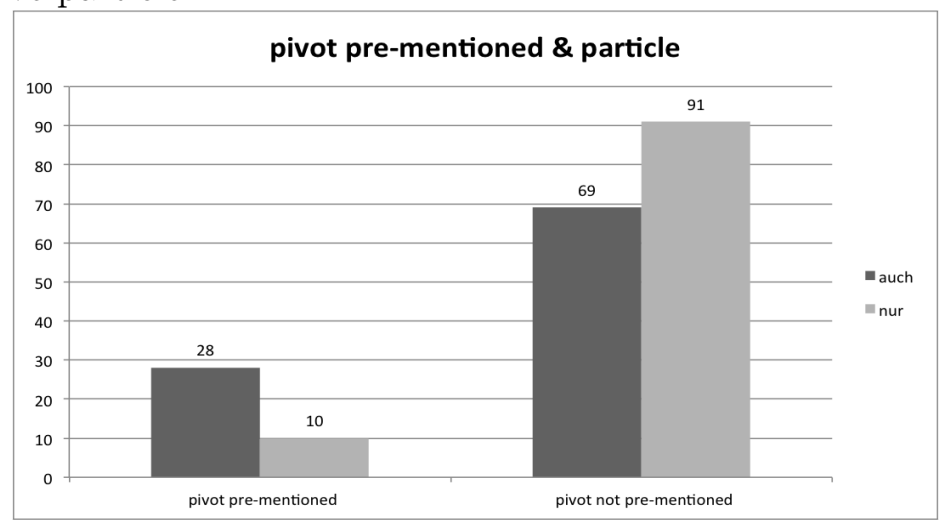

\subsubsection{Discussion}

This corpus analysis showed that a number of both exclusive and non-exclusive focus particles can and do appear in a large variety of German it-clefts. FBclefts are significantly more common than TC-clefts, which makes the FB-clefts the default case for German it-clefts and the TC-clefts non-prototypical. For clefts without focus particles, it was shown that both FB and TC-clefts are significantly more exhaustive than non-exhaustive. In addition, TC-clefts have a high tendency to be exhaustive, and are also more frequently exhaustive than FB-clefts. In the case of the focus particles only and especially, the exhaustivity of the cleft follows the presupposition of the focus particle, which makes them [+exh] with only and [exh] with especially. For the particles also and not least, this clear distribution does not hold. There are cases in which clefts that have a non-exclusive focus particle syntactically positioned directly in front of the cleft pivot are actually exhaustive. These cases can be called non-prototypical, as their exhaustivity patterns does not 
follow the predicted exhaustivity that follows the status of the focus particle (i.e. [+exhaustive] in the case of only, [-exhaustive] in the case of also, especially, not least).

In general, the results show that both $\mathrm{TC}$ and $\mathrm{FB}$-cleft types have the expected exhaustivity patterns in relation to the presupposition of the particle: nur/ only is generally exhaustive ${ }^{15}$. Vor allem/Especially is non-exhaustive in both cleft types, and in the case of nicht zuletzt/ not least, all TC and almost all FB-clefts are non-exhaustive, with few exceptions in the FB class.

These particular cases might be explained by a meaning shift of the particle, as illustrated by the following example.

Es ist nicht zuletzt (kein geringerer als) Sigmund Freud, der seinen It is not least (no less-a-figure than) Sigmund Freud who his Aufsatz «Charakter und Analerotik» (1908) prächtig um paper «Character and Anal-Eroticism» (1908) splendidly around diese Alltagsweisheit aus dem pragmatischen Volksmund this everyday-wisdom from the pragmatic vernacular herumgruppiert hat. arranged-around has.

It is not least (no less a figure than) Sigmund Freud, who arranged his paper «Character and Anal-Eroticism» (1908) splendidly around this everyday wisdom from the pragmatic vernacular.

(238) Es ist nicht zuletzt Clarín, die auflagenstärkste Zeitung spanischer It is not least Clarín, the widest-circulation paper of-Spanish Sprache, die nun der Version vom Mord an Nisman Nahrung language that now the version of-the murder of Nisman fuel liefert. delivers.

It is not least Clarin, the widest-circulated Spanish paper, that is now fueling the version of Nisman's murder.

The meaning of the particle nicht zuletzt/ not least changes in this context to no less than/kein(e) geringere(r) als, which makes it possible for the sentence to keep its exhaustivity implicature in spite of the non-exclusive focus particle.

Another non-prototypical case of an exhaustive TC-cleft with also is illustrated in the example below. ${ }^{16}$ The following examples will be listed below with their re-

\footnotetext{
${ }^{15}$ It can be exhaustive in cases when only is used as a scalar particle. However, in these cases, the cleft can still be exhaustive, which is why for the present analysis, the two cases have been analyzed together.

${ }^{16}$ In the English translation, the focus particle is placed where it would go according to the
} 
spective preceding contexts. First, the original German contexts and their English translations will be listed, followed by the it-cleft in both German and English.

Kontext: Die zentralen Studien in dieser Debatte liefert das Deutsche Institut für Wirtschaftsforschung (DIW) in Berlin. Von dort stammt die Erkenntnis, dass die reichsten 10 Prozent der Deutschen etwa zwei Drittel des gesamten Volksvermögens besitzen.

The relevant studies in this debate delivered the German Institute for Business Science (DIW) in Berlin. Here originates the insight that the richtest 10 percent of Germans own approximately two thirds of the national wealth.

Und es war auch [das DIW], das jüngst ausgerechnet hat, was And it was also the DIW that recently calculated Prf-AUX what eine einmalige Vermögensabgabe von 10 Prozent bringen würde. a one-time capital-levy of 10 percent bring would. And it was [the DIW] that also recently calculated what could be gained from a one-time capital levy of 10 percent.

The following example illustrates the case of an exhaustive FB-cleft with also:

Kontext: Nach New York mitgebracht hat Audi auch gleich den 221 kW/300 PS starken S3 mit gestuftem Gepäckabteil.

Audi brought the 221 $\mathrm{kW} / 300$ PS horsepower S3 with stepped baggage compartment to New York right away.

Es ist auch ausgerechnet ein deutscher Autobauer, der als It is also of-all-things a German car-manufacturer who as einziger auf der US-Messe noch ein paar Worte zu alternativen sole-one at the US-fair still a few words about alternative Antrieben verliert: Mercedes. engines loses: Mercedes. It is of all things a German car manufacturer, who also solitarily has some words to spare on alternative engines at the US fair: Mercedes.

In these cases, the particle seems to modify the VP (instead of, more commonly, the NP), which may explain their exhaustivity despite the presupposition of the additive particle.

To determine whether the focus particle in these non-prototypical cases stated above actually scopes over the focused element in the cleft pivot, one option is to

most natural reading. Please note that in all German cases, the focus particle is placed in front of the cleft pivot. 
check whether the two form a constituent. If they do, the focus particle modifies the DP or NP in the pivot. ${ }^{17}$ To see whether examples of this sort receive a straight-forward reading, two questionnaire studies were run, which are discussed in section 3.5 below.

\subsection{Judgment Experiment}

We have learned from the corpus study that here are various examples of it-clefts in combination with different focus particles. What is not visible in the corpus is whether the different focus particles differ in terms of acceptability, i.e. whether certain particles (e.g. exclusives such as only) are more acceptable in it-clefts than others (i.e. additives such as also). On the basis of the corpus data, a judgment experiment was conducted to gain systematic insights into the combinability of different focus particles and it-clefts in German. The aim was to collect data that allow for a comparison of different focus particles in different sentence environments. To achieve this, five different focus particles were tested in the same sentence environments to determine whether some particles were more acceptable in clefts than others.

\subsubsection{Method and Design}

12 sentences were taken from the naturally occurring examples found in the corpus and combined with 5 focus particles: nur/only, auch/also, vor allem/ especially, nicht zuletzt/ not least, sogar/ even, which are all described as belonging to the same class of particles by Beaver and Clark (2008), who analyze these focus particles as conventionally associating with focus and bearing a lexically encoded dependency on focus. Each of the sentences was paired with each of the particles (including a condition with no particle) both in the clefted (241) and in the canonical version (242).

(241) Es ist die Einsamkeit, die die Menschen immer wieder an den Spieltisch treibt.

It is the loneliness that keeps bringing people to the gambling table.

Die Einsamkeit treibt die Menschen immer wieder an den Spieltisch.

The loneliness keeps bringing people to the gambling table.

40 Participants (native German speakers, with an average age of 35 years) were

\footnotetext{
${ }^{17}$ If it is not the case that the focused element and the particle form a constituent, then it is not a given that the particle modifies the VP. In this case, on a related notion, the particle might also have various scopes, and thereby also modify the whole sentence.
} 
asked to rate the sentences on a 7-point scale for acceptability (7 being fully acceptable, 1 being not acceptable). 4 participants were excluded from the results as they did not complete the questionnaire. During a warm-up prior to the experiment phase, participants were presented with examples of poorly acceptable sentences which would be judged from 1 to 3 , as well as examples of highly acceptable sentences which would be judged 5 to 7 . A part of the filler items were designed to be rather unacceptable, in order to enable participants to make use of the whole range of the scale.

During the experiment, each sentence was only presented to each participant in one condition, ensuring that each participant only saw each sentence paired with one (or no) particle in order to avoid unwanted repetition effects. Participants saw a total of 24 sentences each, 50\% critical items and 50\% unrelated filler items. The experiment was conducted online using the free web-platform OnExp (https://onexp.textstrukturen.uni-goettingen.de/). The sentences were presented in written form individually on screen $^{18}$ and judged by checking a box with the matching number $(1-7)$.

Below is a complete list of the clefted versions without focus particles that were taken from the corpus and presented to the participants in the different conditions. All these sentences were found in the corpus in combination with a focus particle and were then only marginally edited by replacing names with more recognizable ones.

(243) Es ist die Einsamkeit, die die Menschen immer wieder an den Spieltisch treibt.

It is the loneliness that keeps bringing people to the gambling table.

(244) Es ist Stephen Spielberg, der als Regisseur den Film vorantreibt. It is Stephen Spielberg that presses the movie forward as the director.

(245) Es ist die Tiefe des Kraters, die die Wissenschaftler fasziniert. It is the depth of the crater that fascinates the scientists.

(246) Es ist Michael Ballack, der es oft schafft, einen Ball in bedrängter Position anzunehmen.

It is Michael Ballack that often manages to receive a ball in a hard-pressed position.

(247) Es ist der Wiedererkennungswert, der die Ausstellung so reizvoll macht. It is the recognition value that makes the exhibition so appealing.

\footnotetext{
${ }^{18}$ Since the stimuli were presented to participants in written form, the present study did not control for the way participants interpreted the sentences, namely as focus-background or topiccomment clefts.
} 
(248) Es ist Seneca, der den zögernden Kaiser drängt, die Mutter zu beseitigen. It is Seneca that urges the hesitant emperor to get rid of the mother.

(249) Es ist der medizinische Fortschritt, der die Kosten in die Höhe treibt. It is the medical progress that increases the costs.

(250) Es ist Qaradawi, der auf Anfrage eines islamischen Armee-Seelsorgers mit anderen Gelehrten ein Fatwa für Muslime im amerikanischen Militär verfasste.

It is Qaradawi that issued a fatwa for muslims in the American army on demand from an islamic army counsellor together with other scholars.

(251) Es ist das Nahrungsangebot, das die Halden für Möwen attraktiv macht. It is the range of food that makes the dumps attractive for seagulls.

(252) Es ist Jennifer Lawrence, die den Film zu einem Höhepunkt des Abends macht.

It is Jennifer Lawrence that turns the movie into a highlight of the evening.

(253) Es ist die Uniform der Feuerwehrleute, die die kleinen Kinder beeindruckt.

It is the firefighters' uniform that impresses the little kids.

(254) Es ist Werner Langen, der die Sache im Europäischen Parlament als Berichterstatter massiv angeschoben hat.

It is Werner Langen that pushed the matter forward massively in the European Partliament as a messenger.

\subsubsection{Results and Discussion}

The table and chart below present the mean acceptability ratings for all conditions. In general, this experiment has shown that German it-cleft sentences are overall a little less acceptable than the canonical versions. This can possibly be explained by the fact that cleft sentences are not very frequent in (spoken) German and might seem less natural to speakers when presented to them in isolation. 


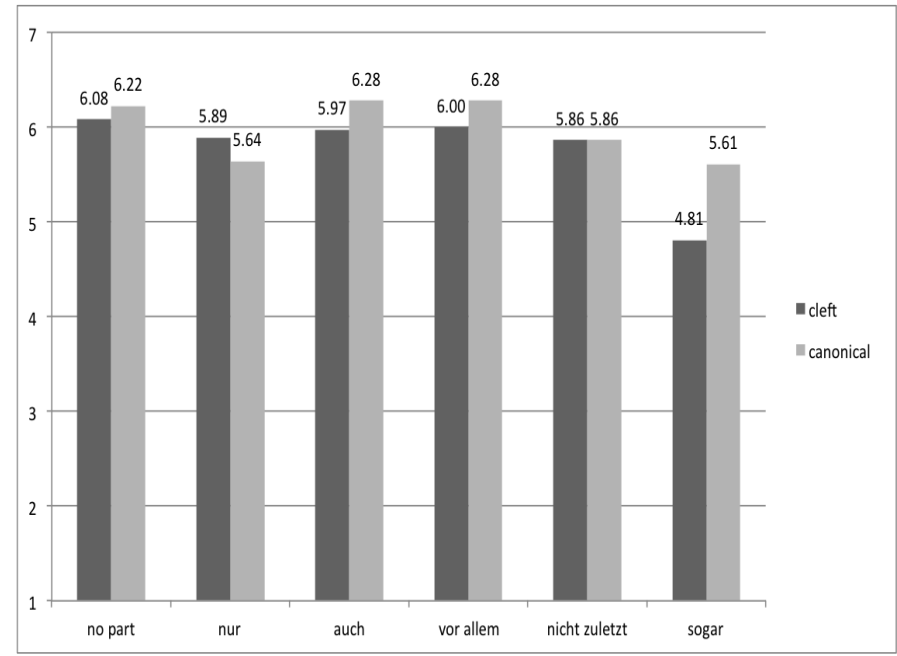

Figure 3.11: Mean results per focus particle and sentence type (cleft/canonical)

Figure 3.12: Mean acceptability ratings of target sentences (all conditions, rounded)

\begin{tabular}{|c|c|c|}
\hline & canonical & cleft \\
\hline no particle & 6,22 & 6,08 \\
\hline nur/only & 5,64 & 5,89 \\
\hline auch/also & 6,28 & 5,97 \\
\hline vor allem/especially & 6,28 & 6 \\
\hline nicht zuletzt/not least & 5,86 & 5,86 \\
\hline sogar/even & 5,61 & 4,81 \\
\hline
\end{tabular}

In a two-tailed model, there is no significant effect in the following conditions: canonicals vs. it-clefts without particles $(\mathrm{t}=0.45199, \mathrm{p}=.652673)$, canonicals vs. it-clefts with only $(\mathrm{t}=-0.68905, \mathrm{p}=.493067)$, canonicals vs. it-clefts with especially $(\mathrm{t}=0.96123, \mathrm{p}=.339743)$, and canonicals vs. it-clefts with not least ( $\mathrm{t}$ $=0, \mathrm{p}=1)$.

When looking at the visibly larger differences in the canonicals vs. it-clefts with even, we are actually looking at a significant result $(\mathrm{t}=2.04144, \mathrm{p}=.044978)$.

The difference between even and also in clefts is also significant ( $\mathrm{t}=-3.11618, \mathrm{p}$ $=.002657)$. We observe this effect when comparing the results of judgments of any other particle in it-clefts with the judgments of even in it-clefts. (even cleft 
vs. especially cleft: $\mathrm{t}=-3.16338, \mathrm{p}=.002307$. The result is significant., even cleft vs. not least cleft: $\mathrm{t}=-2.64979, \mathrm{p}=.009949$. The result is significant., even cleft vs. only cleft: $\mathrm{t}=-2.93902, \mathrm{p}=.004457$. The result is significant., even cleft vs. no particle cleft: $\mathrm{t}=3.4953, \mathrm{p}=.000826$. The result is significant.)

For the case of even, the effect might be due to the specific meaning of the particle and the mode of presentation of the items in this experiment. When reading or hearing even, speakers have certain expectations on the context, e.g. that the element in the scope of the particle is compared to something in the discourse. When presented out of context, this expectation is not met, which might help explain the low judgment for this particle. To test this hypothesis, it would be possible to rerun this experiment with some preceding context sentences, and see whether this can increase the acceptability of it-clefts with even. However, since the low ratings appear for both the clefted and canonical version in the case if sogar/ even, it might be due to the fact that this particle is in general hard to process, as it is both an additive and a scalar particle (cf. König (1991)).

However, this does not hold for the case of nur/ only, where the rating is marginally better in the clefted condition. This might allow the conclusion that an exclusive focus particle in fact strengthens the exhaustivity inference and, therefore, the general acceptability of the cleft sentence, thereby supporting Horn (1981) in his analysis, arguing that the insertion of exclusives into a cleft has a truth-functional effect, while this is not the case for clefts without an exclusive particle which explicitly states exhaustivity.

The underlying hypothesis of this study, following the prior theoretical approaches of Altmann (1976) and Percus (1997), was that it-clefts including non-exclusive focus particles would not be acceptable to German speakers, therefore leading to judgments between 1 and 3 on a 7 -point scale. This assumption was falsified, as the sentences are overall highly acceptable to native speakers. Also, since participants judged those unrelated filler items that were expected to be rated between 1 and 3 as unacceptable, the statistical analysis is strengthened as participants understood the task correctly.

In general, the results show that German it-clefts are rated as acceptable by native speakers (above 5 on a 7 -point scale). When combined with a non-exclusive focus particle, the acceptability ratings of the cleft sentences remain high and stable.

\subsubsection{Conclusion}

In contrast to previous theoretical approaches, and in line with previous corpus studies (e.g. Wedgwood et al. (2006), Hedberg (1988)), this study shows that 
German it-clefts can in fact occur in combination with a variety of (non-exclusive) focus particles, and native speakers judge them just as acceptable as cleft sentences without focus particles.

Additionally, German it-clefts combined with particles that carry a non-exclusive meaning (auch/also, vor allem/ especially, nicht zuletzt/ not least) were overall rated acceptable (above 5 on a 7 -point scale). These findings show that it-clefts can be exhaustive or not exhaustive and they can be combined with exclusive and non-exclusive focus particles. In the light of previous theoretical approaches that describe it-clefts as being semantically exhaustive, these findings are somewhat surprising. This does, however, not mean that it-clefts are generally non-exhaustive, as there are also examples of it-clefts that receive an exhaustive interpretation.

\subsection{The Scope of Focus Particles: Two Experi- ments}

In light of the surprisingly large number of non-prototypical cases regarding exhaustivity that were found in the corpus (as discussed above), a questionnaire study was designed. The aim of the pilot study and experiment that are described in the following section was to gain a better understanding of how native speakers interpret the scope of the additive particle also/auch in it-clefts.

\subsubsection{Objectives}

Since there are it-clefts with the additive particle also/ auch that receive an exhaustive interpretation in the corpus, the next question is whether these cases are interpreted consistently. The following predictions were formulated:

- Hypothesis 1: The additive focus particle that is positioned directly in front of the focus in the cleft pivot associates with the focus and not with any other element in the sentence (e.g. the VP in the cleft relative). This would mean that the it-clefts are not exhaustive.

- Hypothesis 2: (a) It-clefts are not intrinsically exhaustive. Therefore, an additive focus particle is generally acceptable in an it-cleft. (b) When combined with a superlative (and, therefore, exhaustive) predicate in the cleft relative, the sentences are rejected in cases where the focus particle is interpreted as associating with the focused element in the pivot, making it non-exhaustive. This clash of the same sentence expressing both exhaustivity (via the superlative predicate) and non-exhaustivity leads to unacceptable sentences. When the focus particle is interpreted as associating with the predicate in the cleft relative, the sentences are accepted. 
- Hypothesis 3: There are two types of it-clefts, Focus-Background-clefts (FB) and Topic-Comment-clefts (TC). (a) FB-clefts are expected to be interpreted as being about the focused element, while TC-clefts are expected to be interpreted as being about the cleft relative. (b) The two types of it-clefts differ in terms of exhaustivity. Since the pivot is what the FB-cleft is about, FB-clefts are interpreted as being exhaustive regarding the focused element. In TC-clefts, the exhaustivity targets the cleft relative.

\subsubsection{Pilot-Study}

\subsubsection{Method and Design}

Participants were addressed via email and received a Google Forms questionnaire that presented them with the cleft in the original context in which it was found in the corpus. The context was presented initially, followed by the cleft sentence. The cleft sentences ( $5 \mathrm{FB}$ and $5 \mathrm{TC}$-clefts) were manipulated only in a way that made them intrinsically exhaustive, i.e. via a semantically exhaustive predicate such as a superlative. There were no items in this experiment that did not include superlatives. The sentences were manipulated in this way to rule out exhaustivity inferences that might be derivable from the context. This way, if participants judge the cleft sentences as exhaustive, they cannot infer exhaustivity from the context. For the pilot, 9 participants with an average age of 28.5 were tested. Since it was a pilot study, no fillers were used and no randomization took place.

The items were of the form illustrated in the example below:

(255) a. Hintergrund: Die zentralen Studien in dieser Debatte liefert das Deutsche Institut für Wirtschaftsforschung (DIW) in Berlin. Von dort stammt die Erkenntnis, dass die reichsten 10 Prozent der Deutschen etwa zwei Drittel des gesamten Volksvermögens besitzen. (Background: The key studies for this debate were presented by the Institute for economical research (DIW) in Berlin. From there stems the insight that the richest 10 percent of Germans own approximately two thirds of the entire countries wealth.)

b. Cleft Sentence: Und es war auch das DIW, das jüngst als einziges ausgerechnet hat, was eine einmalige Vermögensabgabe von 10 Prozent bringen würde. (And it was /the DIW] that also recently calculated what could be gained from a one-time capital levy of 10 percent.)

c. Binary forced-choice questions (see below)

After reading the context and the target sentence, the participants were asked to answer three multiple choice questions about the target clause: 
1. Is the sentence acceptable? (Answer options: Yes/ No) (Hypotheses 1 and 2)

2. What is the sentence about? (Answer options: the pivot/ the cleft relative) (Hypothesis 3a)

3. What follows from the sentence? (Answer options: the focused element has done something else/ Someone else has done the activity denoted in the relative clause) (Hypothesis $3 \mathrm{~b}$ )

The answer options were designed in a way that each targeted the exhaustivity inference of the cleft sentence.

\subsubsection{Predictions}

\section{Question 1:}

If participants judged the first question Is the sentence acceptable with yes, then the hypothesis is that they are of the opinion that also and a superlative predicate are acceptable together in a sentence. This is illustrated below:

It was also John who drank the most last night.

a. John drank the most last night, and also did something else (e.g. dance on the table)

$\rightarrow$ judgment: acceptable

$\rightarrow$ exhaustivity on the cleft relative

b. John, along with somebody else, drank the most last night.

$\rightarrow$ judgment: not acceptable

$\rightarrow$ exhaustivity on the cleft pivot

If both the additive particle and the exhaustive (as a result of the superlative) cleft predicate are accepted together in one sentence (judgment: yes), these judgments are taken to mean that the focus particle refers to the cleft relative.

If participants judged the first question with no, then they think that also and a superlative predicate are not acceptable together in a sentence. In this case, these judgments are taken to mean that the focus particle refers to the cleft pivot.

\section{Question 2:}

FB-clefts are expected to be interpreted as being about the focused element, while TC-clefts are expected to be interpreted as being about the cleft relative. When asked what the sentence is about, speakers are expected to answer that it is about the cleft pivot for FB-clefts and about the cleft relative for TC-clefts. 
(257) It was also John who drank the most last night.

a. The sentence is about John.

$\rightarrow$ judgment: cleft pivot

b. The sentence is about who drank most last night.

$\rightarrow$ judgment: cleft relative

\section{Question 3:}

The third question What follows from the sentence?, is aimed at checking for inferences regarding the exhaustivity. Here, participants judge the scope of the focus particle.

(258) It was also John who drank the most last night.

a. It follows that John did something else besides drinking the most

$\rightarrow$ judgment: cleft pivot

b. It follows that someone besides John drank the most last night.

$\rightarrow$ judgment: cleft relative

\subsubsection{Experimental stimulus}

What follows is a list of all target items used in both the pilot and follow-up study:

(259) Hintergrund: Es ist ein runder Geburtstag, der 100. der Strecke zwischen Gau-Algesheim und Bad Münster.

(FB-cleft) Und es ist auch ein besonderer Zug, der hier als einziger erwartet wird: einer mit alter Dampflok vorne dran.

Background: It is a anniversary birthday, the 100. of the track between Gau-Algesheim und Bad Münster. (FB-cleft) And it is also a special train that is being awaited here as the only one: one with an old steam engine at the front.

(260) Hintergrund: Die Tatsache, dass sie nun nicht stärkste Partei im politischen Leben Marokkos geworden ist, dürfte dem jungen König Mohammad VI. nicht unbedingt ungelegen kommen. Zwar erlaubt das komplexe marokkanische Wahlsystem keine klare Mehrheit für eine Partei.

(FB-cleft) Und es ist auch der König, der ganz allein den Premierminister, unabhängig vom Wahlausgang, bestimmt.

Background: The fact that they have not become the strongest party in the political life of Morocco should not be completely displeasing to the young kind Mohammad VI. The complex Moroccan elective system does not allow an absolute majority for one party. (FB-cleft) And it is also the king who nominates the prime minister alone, independent of the election results. 
(261) Hintergrund: Der Jugendbetreuer sagt: „Ich habe aber gelernt, die Flinte nicht ins Korn zu werfen." Immer wieder sei er motiviert worden, weiterzumachen.

(FB-cleft) Es ist auch dieser positive Blick auf die Jugendlichen und ihre Perspektiven, der ihm als einziges Mut macht.

Background: The social worker says: "I have learned not to give up. "He was motivated repeatedly to keep going. (FB-cleft) It is also this positive perspective on the teenagers and their perspectives that is the only thing that gives him strength.

(262) Hintergrund: Der Rechtsextremist Vojislav Seselj hatte bereits vor den Wahlen angedeutet, sein Hemd sei ihm näher als der Krönungsmantel Milosevics.

(FB-cleft) Und es ist auch Seseljs Partei gewesen, die gestern als einzige die selben Zahlen zum Wahlergebnis veröffentlichte wie die Opposition.

Background: The right wing extremist Vojislav Seselj had already suggest prior to the elections that his own interests are more important to him than those of Milosevics. (FB-cleft) And it was also Seseljs party that published as the only one yesterday the same numbers on the election as the opposition.

(263) Hintergrund: Es gibt im Film keinen ermittelnden Kommissar. Dagegen spricht schon, dass der Quasi-Schwiegervater Dr. Olson bei der Polizei erst noch eine (Durchsuchungs) Genehmigung erwirken muss.

(FB-cleft) Es ist auch Francis, der nachts allein vor dem Wohnwagen von Caligari steht.

Background: There is no investigating detective in the movie. What speaks against that is already the fact that the quasi-father-in-law Dr. Olson has to get a search warrant from the police first. (FB-cleft) It is also Francis who stands alone in front of Caligaris camper van at night.

(264) Hintergrund: Stattdessen demonstriert der Kreml Härte. Ein Fehler wäre es jedoch, dies mit Stärke gleichzusetzen. Mit dem Prozess stellt er sich selbst ein erbärmliches Urteil aus. Ein Staat, der sich über drei junge Frauen hermacht, die in anderen Ländern bestenfalls zu einer Ordnungsstrafe verurteilt worden wären, offenbart seine Schwäche. Es ist nicht der starke Staat, den Putin nach außen suggeriert, sondern ein Papiertiger, der durch die Schallwellen der Punkerinnen ins Zittern geriet. (TC-cleft) Es war auch erst der Kreml, der als einziger der Causa durch seine Verfolgung globale Aufmerksamkeit verlieh.

Background: Instead, Kreml demonstrates hardness. It would be a mistake to equate this with strength. He presents a terrible judgment on himself with the court case. A state that attacks three young women that 
would have gotten a minor fine at most in other countries reveals its weakness. It is not the strong state, that Putin demonstrates to the outside, but a paper tiger, that has been shaken up by the shock waves of the punker girls. (TC-cleft) It was also the Kreml that was the only one who gave the case a global attention through its persecution.

(265) Hintergrund: Die zentralen Studien in dieser Debatte liefert das Deutsche Institut für Wirtschaftsforschung (DIW) in Berlin. Von dort stammt die Erkenntnis, dass die reichsten 10 Prozent der Deutschen etwa zwei Drittel des gesamten Volksvermögens besitzen.

(TC-cleft) Und es war auch das DIW, das jüngst als einziges ausgerechnet hat, was eine einmalige Vermögensabgabe von 10 Prozent bringen würde.

Background: The central studies in this debate were delivered by the German Institute for Economic Science (DIW) in Berlin. There originates the knowledge that the richest 10 percent of Germans own approximately two thirds of the entire countries wealth. (TC-cleft) And it was also the $D I W$ that was the only one to recently calculate what a one-time payment of 10percent would gain.

(266) Hintergrund: Nicht verabschiedet hat er sich von seiner Dauerkarte für den Zoo. Jahrelang ist er täglich hierher gekommen, hat täglich den gleichen Weg genommen, sich auf die gleiche Bank gesetzt, den Tieren ins Gesicht gesehen.

(TC-cleft) Es war auch die Dauerkarte, die ihm als einiziges sein literarisches Debüt beschert hat: „Der Schatten der Tiere“.

Background: He did not say goodbye to his season ticket for the zoo. For years he has been coming here, has been walking the same path, been sitting on the same bench, looking the animals into their eyes. (TC-cleft) It was also the season ticket that presented him as teh only thing his literary debut "The animals shadows.

(267) Hintergrund: Erst im letzten Jahr stieg Usbekistan aus der Eurasischen Wirtschaftsgemeinschaft wieder aus, nachdem die EU Sanktionen gegen Taschkent gelockert hatte.

(TC-cleft) Es war auch Usbekistan, das als einziges Land über eine Verstärkung russischer Militärpräsenz in Kirgisien stark verunsichert war.

Background: Usbekistan left the Eurasian Economic Union again just last year after EU loosened sanctions against Taschkent. (TC-cleft) It was also Usbekistan that was the only one to be insecure about an increase of Russian military presence in Kirgistan.

(268) Hintergrund: Alles, was Ibé im Zentrum für Straßenkinder gelernt hat, 
literarisches Schreiben, Schauspielen, Artistik, vermittelt er nun weiter an die Jüngsten.

(TC-cleft) Es ist auch Ibé, der als einziger die ganz kleinen Straßenkinder bewusst auf der Straße sucht, um sie in das Haus zu holen.

Background: Everything Ibé has learned at the center for homeless children, literary writing, acting, artistic, he now teaches to the youngest. (TC-cleft) It is also Ibé who is the only one to looks for the little ones on the street to bring them to the center.

\subsubsection{Results and Discussion}

In total, a majority $77 \%$ of participants judged the sentences as acceptable. Since the superlative predicate makes the cleft intrinsically exhaustive, the majority of speakers thinks that the additive focus particle refers to the cleft relative, as is illustrated in 3.14. 3.13 illustrates that both cleft types behave similarly regarding overt exhaustivity judgments.

Figure 3.13: Question 1 Is the sentence acceptable? Total number of judgments

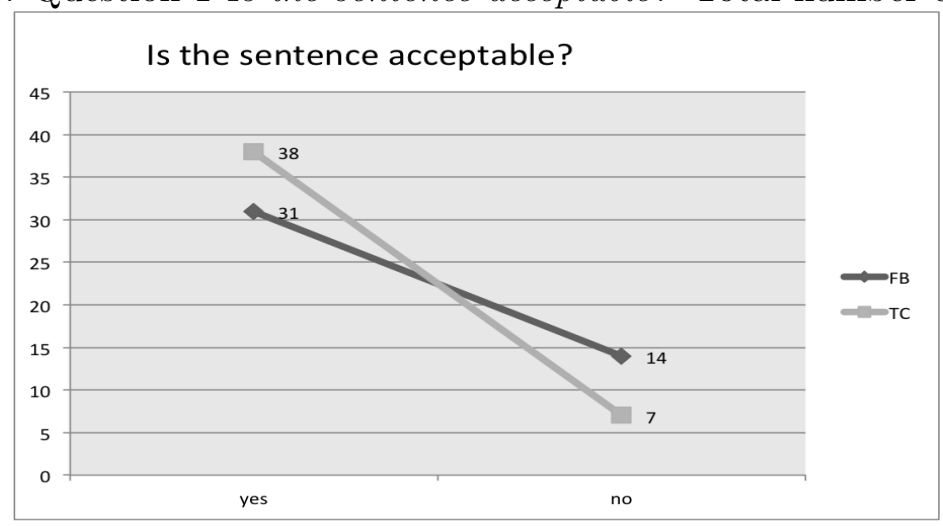


Figure 3.14: Question 1 Is the sentence acceptable? Total distribution: 77\% yes, $23 \%$ no

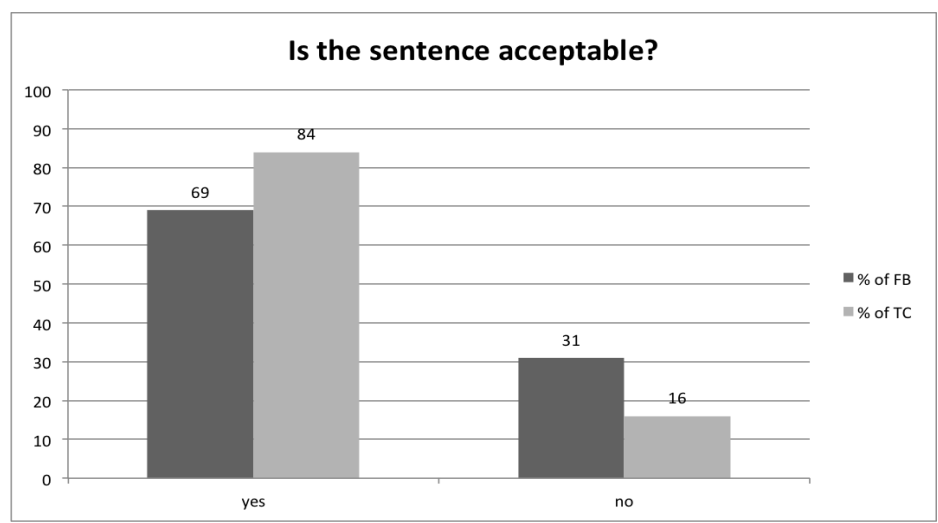

These results go against hypothesis 1 , as they show that the additive particle does not associate with the focused element in the cleft pivot, but with the cleft relative. The results do support hypothesis $2 \mathrm{a}$, as the additive focus particle is generally accepted in the cleft sentence. As the sentences are accepted, the focus particle is interpreted as associating with the predicate in the cleft relative (hypothesis $2 \mathrm{~b}$ ).

FB-clefts are less acceptable than TC-clefts. Since there were examples with also/ auch for both cleft types in the corpus, but speakers do not accept FB-clefts with superlatives and auch, this could mean that speakers may have found a nonexhaustive interpretation in the corpus examples. However, this explanation is not satisfying because there is no intuitive evidence that FB-clefts are less exhaustive than TC-clefts. Therefore, it is more likely that in FB-clefts, the focus particle associates with the cleft relative instead of the cleft pivot. This must be checked for in the answers to question 3. We expect speakers to answer $x$ did something else for the majority of FB-clefts.

The second question What is the sentence about? also targets the ways in which speakers interpret the it-clefts. As illustrated in 3.16, participants are undecided about what to take as the main topic of the sentence. In both TC and FB-clefts, a small majority of speakers (59\%) judged the cleft relative as the main topic of the sentence. This matches the judgments for question 1 in so far, as the majority of speakers decided there that John did something besides drinking the most last night. Therefore, it makes sense for the speakers to regard the cleft relative as the topic of the sentence. Hypothesis 3a is not supported, as there are no observable differences in the judgments for FB and TC-clefts. 
Figure 3.15: Question 2 What is the sentence about? Total number of judgments

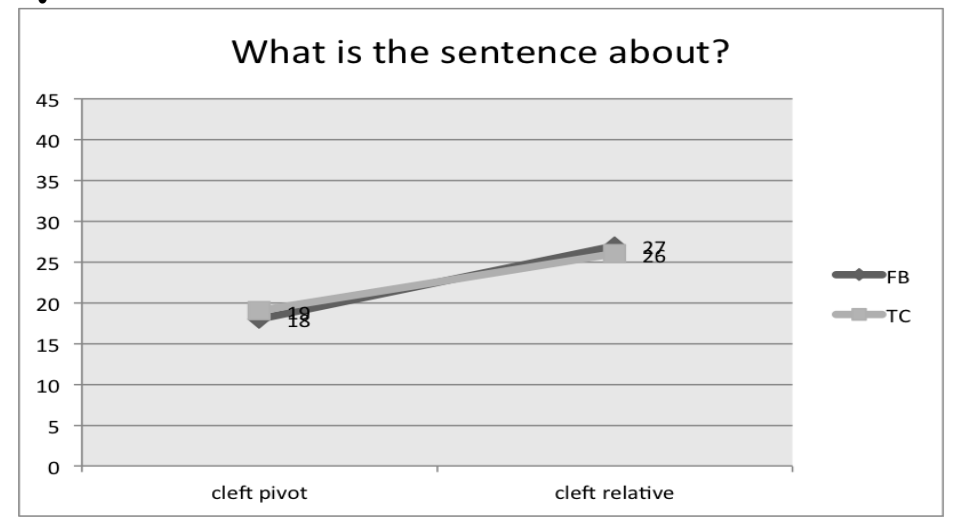

Figure 3.16: Question 2 What is the sentence about? Total distribution: $41 \%$ pivot, $59 \%$ cleft relative

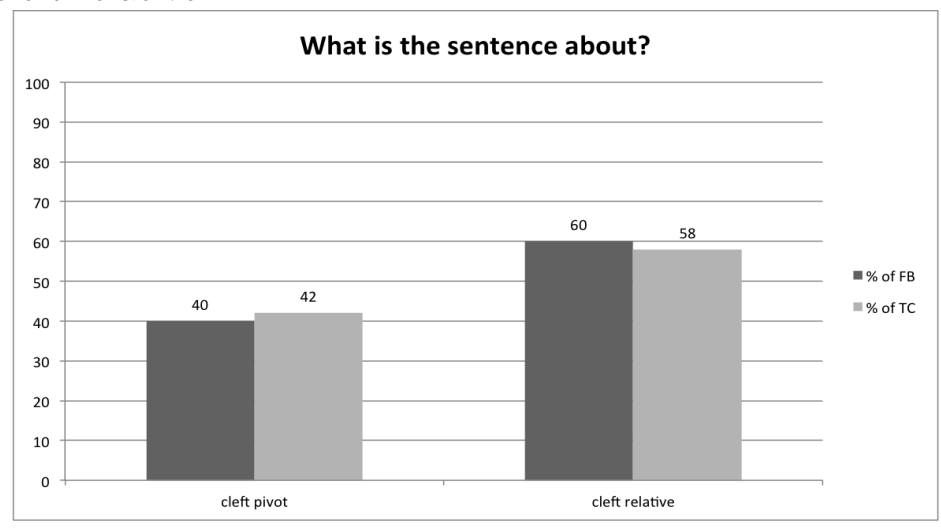

Regarding the third question What follows from the sentence?, the majority of participants $(73 \%)$ judged the cleft pivot as exhaustive (It follows that the cleft pivot did something else in addition to what is stated in the cleft relative, but no one else did the action expressed by the cleft relative). $27 \%$ of participants answered that someone other than the cleft pivot performed the action stated in the cleft relative. Therefore, the cleft relative is exhaustive. Hypothesis $3 \mathrm{~b}$ is rejected, as the judgments for the two cleft types do not differ in terms of exhaustivity. 
Figure 3.17: Question 3 What follows from the sentence? Total number of judgments

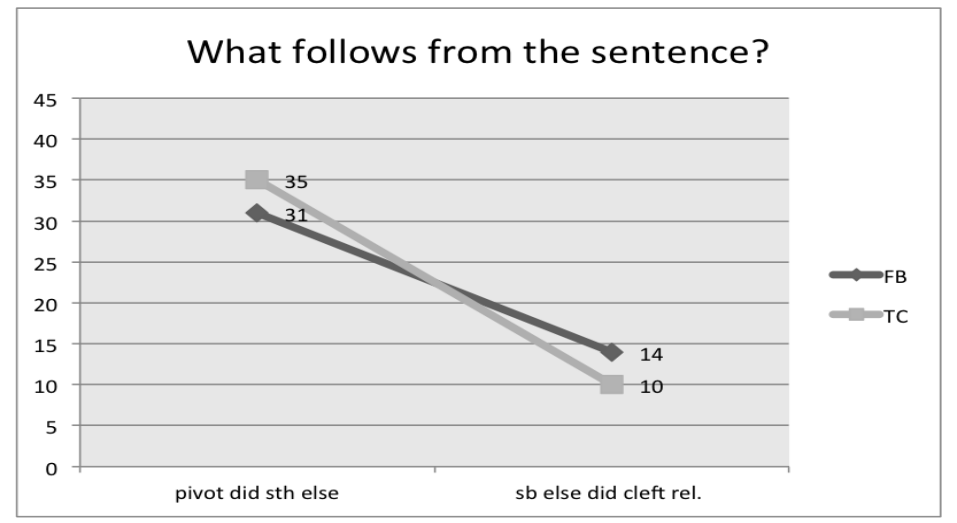

Figure 3.18: Question 3 What follows from the sentence? Total distribution: $73 \%$ pivot non-exh, $27 \%$ cleft relative non-exh

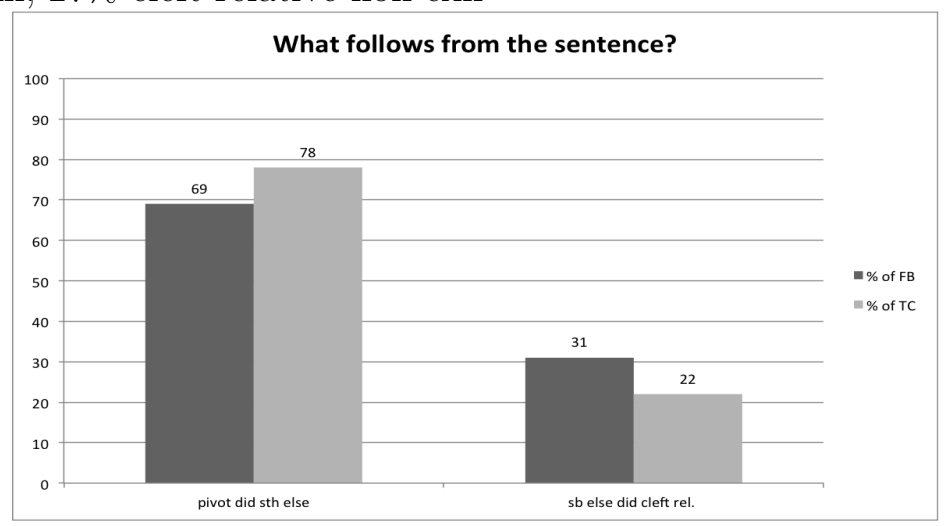

In sum, this pilot experiment showed that speakers treat TC and FB-clefts on par when interpreting their exhaustivity and aboutness/topicality.

In general, these three questions showed that it-clefts with an additive particle are mostly interpreted as being about the cleft relative by native speakers.

In the case of the cleft

(269) It was also John who drank most last night.

speakers infer that

1. the sentence is about what John did last night 
2. John did something besides drinking most last night

There are no noticeable differences between the two clefts types in speakers' ${ }^{\prime}$ judgments.

\subsubsection{Follow-Up}

\subsubsection{Methods and Design}

Based on the data from the pilot study, it was decided to take a closer look at the results and run the experiment again with some small alterations. This is due to the rather surprising results that it-clefts with additive particles are judged to be about the cleft relative rather than the cleft pivot, as would be assumed of this focus structure.

For the follow-up experiment, a total of 40 participants were tested, 9 of which had to be excluded because they did not fully complete the questionnaire. The data of 31 participants with an average age of 24 years was evaluated. All participants had at least a high school degree. 19 participants were female, 11 male.

This study again included $5 \mathrm{FB}$ and 5 TC-clefts, with an additional 10 fillers. Targets and fillers were presented in a pseudo-randomized order and randomized within each item group. The target items remained the same as in the pilot-study discussed above.

\subsubsection{Results and Discussion}

If participants judged the first sentence as non-acceptable, they do not think that also and a superlative predicate are acceptable together in a sentence. In this case, these judgments are taken to mean that the focus particle refers to the cleft pivot. In total, a majority $83 \%$ (as opposed to $77 \%$ in the pilot) of participants judged the sentences as acceptable. Since the superlative predicate makes the cleft intrinsically exhaustive, the majority of speakers thinks that the additive focus particle refers to the cleft relative. In question 1 , speakers behaved on par with the results from the pilot.

When looking at the difference between FB and TC-clefts (see 3.19), we can see that speakers do not distinguish the two cleft kinds concerning particle scope. In the case of FB-clefts, $81 \%$ of participants judged the sentence as acceptable, and in the case of TC clefts, it was a majority of $84 \%$. Speakers do seem to have a clear opinion on the acceptability of the sentence, and they think that it-clefts with an additive particle and a superlative predicate are in fact acceptable. 
Figure 3.19: Question 1 Is the sentence acceptable? Total distribution: $83 \%$ yes, $17 \%$ no

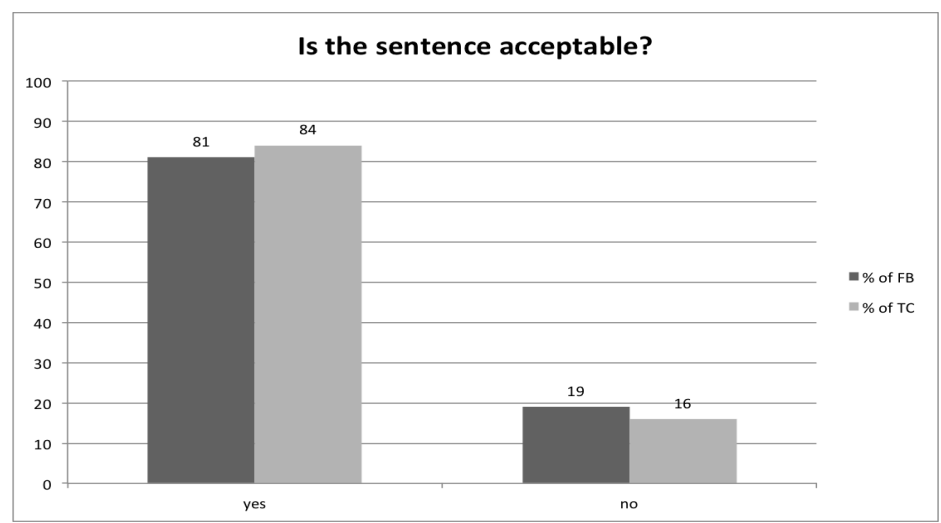

A one-tailed analysis of the difference between FB and TC-cleft acceptability showed that there is no significant effect $(\mathrm{t}=0.59741, \mathrm{p}=.275337)$. In terms of the relative distribution, the results looked like this: FB: $81 \%$ yes, $19 \%$ no, TC: $84 \%$ yes, $16 \%$ no, total: $83 \%$ yes, $17 \%$ no.

These results again reject hypothesis 1 , as they show that the additive particle is not interpreted as associating with the focused element in the cleft pivot, but with the cleft relative. Hypothesis $2 \mathrm{a}$ is again supported by these results, because the additive focus particle is generally accepted in the cleft structure. Therefore, the focus particle is interpreted as associating with the predicate in the cleft relative (hypothesis 2b).

In the second question, participants were again asked to judge what the sentence is about. Here, we see that speakers are quite undecided as to what to take as the topic of the cleft: $51 \%$ judge it to be about the cleft pivot, while $49 \%$ think the cleft is about the cleft relative (as opposed to $41 \%$ pivot, $59 \%$ relative in the pilot).

Here, we see a small difference between the two cleft kinds, at least at first glance: In the case of FB-clefts, $55 \%$ of speakers judge the pivot as being the topic of the cleft, and $45 \%$ the cleft relative. In TC-clefts, $46 \%$ think that the pivot is what the cleft is about, while $54 \%$ take the cleft relative to be the topic of the sentence. The trends seem to be reversed. However, this difference is not statistically significant. 
Figure 3.20: Question 2 What is the sentence about?: Total number of judgments per answer-option pivot/relative

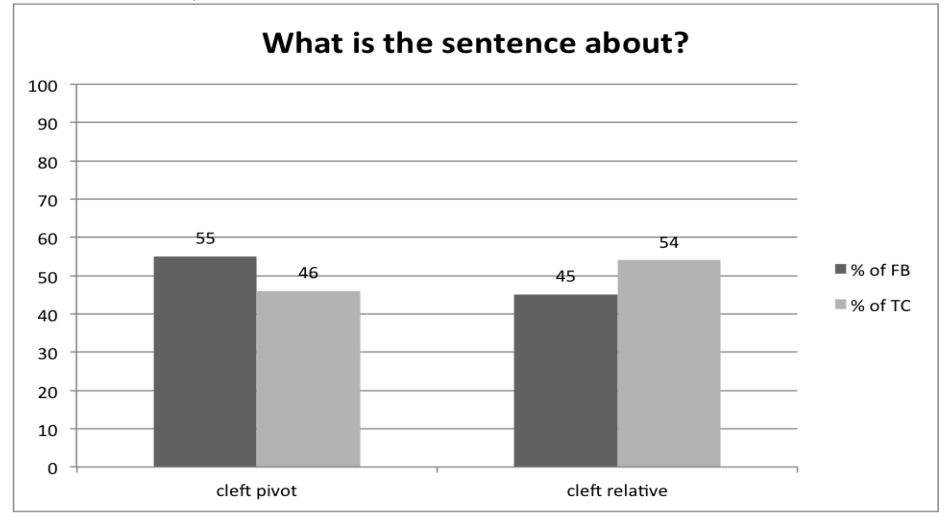

For question two, the results look quite different from what was found in the pilot study. While all three questions were patterned on par with FB and TC-clefts in the pilot study, the graph shows that they actually trend into opposite directions in the follow-up. A one-tailed analysis shows an effect $(\mathrm{t}=-1.70653, \mathrm{p}=.044458$. The result is significant.)

In terms of relative distribution of answers, this result is also visible: FB: $55 \%$ pivot, $45 \%$ cleft relative, TC: $46 \%$ pivot, $54 \%$ cleft relative, total: $51 \%$ pivot, $49 \%$ relative. These results lead to two assumptions: Firstly, speakers do not seem to be so sure as to what the topic of a cleft is. The answers are almost at a 50\% mark, meaning that roughly half of the participants think that the cleft is about the pivot, and the other half of participants think it is about the cleft relative. Secondly, when looking at the distribution of FB and TC-clefts, we see that FB-clefts are judged to be about the cleft pivot, while TC-cleft are judged to be about the cleft relative. Since this difference is statistically significant, it might lead to the conclusion that the two cleft kinds in fact do have different discourse functions, as they are interpreted differently by native speakers. This question should be addressed by further research.

Hypothesis 3a is supported by these results, as there are observable differences in the judgments for FB and TC-clefts.

In the third question, participants were again asked to judge what they think follows from the sentence. In the follow-up, $80 \%$ of participants answered that they infer that the pivot did something else (pivot is exhaustive), while $20 \%$ judged that somebody else did the action expressed by the cleft relative (predicate is exhaustive). This is in line with the findings from the pilot (73\% pivot exh, $27 \%$ relative exh). When looking at the two different cleft kinds, we see that in the 
case of FB-clefts, $80 \%$ of participants judged the pivot as exhaustive and $20 \%$ the cleft relative, while in the case of TC-clefts, $79 \%$ of speakers judged the pivot as exhaustive and $21 \%$ the cleft relative.

Figure 3.21: Question 3 What follows from the sentence?: Total number of judgments per answer-option pivot/relative

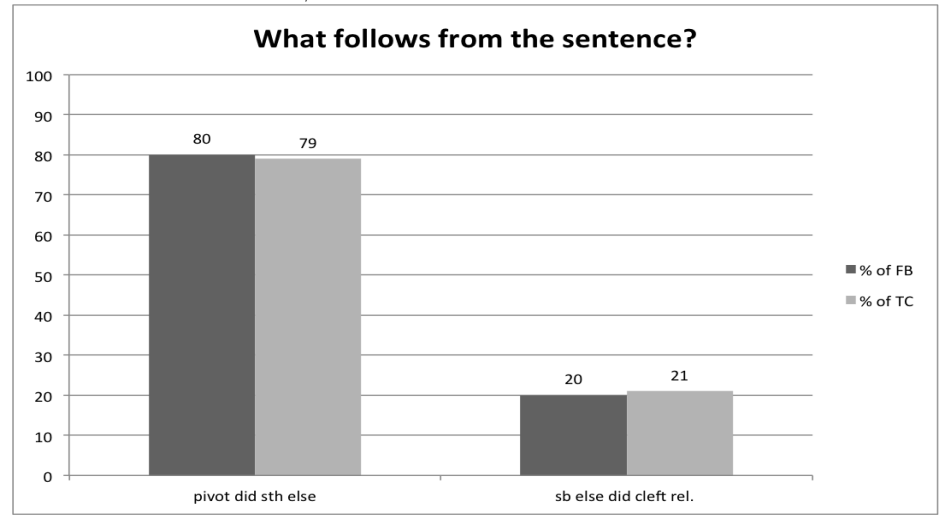

A one-tailed analysis showed no effect between cleft type $(\mathrm{t}=-0.14069, \mathrm{p}=$ .444102. The result is not significant.) The relative distribution shows a similar pattern to question 1 , and is again in line with the results of the pilot study: FB: $80 \%$ pivot exh, $20 \%$ cleft relative exh, TC: $79 \%$ pivot exh, $21 \%$ cleft relative exh, total: $80 \%$ pivot exh, $20 \%$ cleft relative exh.

Hypothesis $3 \mathrm{~b}$ is rejected, as the judgments for the two cleft types do not differ in terms of exhaustivity.

\subsubsection{Summary}

Up to this point, the present chapter has presented an extensive corpus study with a variety of both exclusive and non-exclusive focus particles that appear in German it-clefts. FB-clefts are overall significantly more common than TC-clefts. Therefore, it is concluded that the FB-clefts can be classified as the default case for German it-clefts and the TC-clefts as non-prototypical.

For clefts without focus particles, the data show that both cleft types are significantly more frequently exhaustive than non-exhaustive. TC-clefts have a very strong tendency to be exhaustive, more so than FB-clefts. This result matched the hypothesis, as the main characteristic of TC-clefts is that the cleft pivot is mentioned in the previous context.

In terms of the different particles, only and especially, makes the clefts in which they appear [+exh] with only and [-exh] for especially. For the particles also and not least, this clear distribution does not hold. 
The related pilot experiment showed that the majority of speakers think that the additive focus particle refers to the cleft relative (and not, as possibly more likely, to the focused element in the cleft pivot) (question 1).

In question 2, the majority of participants also judged the clefts as being about the cleft relative, which strengthens the results. When asked what they can infer from the clefts (question 3), speakers said that it follows that the cleft pivot also did something else in addition to what was stated in the cleft relative, thereby judging the cleft pivot as exhaustive. It follows that, when exhaustive it-clefts with the additive focus particle auch are accepted, this means that the focus particle modifies the cleft relative.

This does, however, not mean that all it-clefts are generally exhaustive, because the input material in this experiment was manipulated to create intrinsically exhaustive items via superlatives.

The results of the pilot experiment were not only strengthened in parts, but actually be extended with a follow-up of the same design. The follow up showed that speakers are unanimous about acceptability and exhaustivity of both types of it-clefts. Both FB and TC-clefts are comparatively acceptable when combined with an additive particle and a superlative cleft relative. This is interpreted in a way that speakers accept these sentences possibly because they take the additive particle to modify the cleft relative, and not the pivot (in the sense of what also happened was...).

In terms of exhaustivity of the cleft (targeted by question 3) speakers are again rather clear in their judgment that the cleft relative is non-exhaustive in both cleft types, even though the additive particle is in the syntactical position directly in front of the cleft pivot.

In terms of topicality, speakers seem rather undecided in the follow-up study.

These results indicate that in German it-clefts with an additive focus particle that appears directly in front of the cleft pivot, the focus particle can modify the VP of the cleft relative. If these clefts are exhaustive, this can then be explained by the focus particle, despite its syntactical position, actually modifying the VP.

\subsection{Focus Particles and Exhaustivity: Conclusion}

The extensive corpus study in combination with several related experiments in this chapter has presented us with interesting insights on the topic of various focus particles and it-clefts in German.

In general, it can be said that FB-clefts are more common in German than TCclefts. This is suggested by the relative distribution of the two cleft kinds in the corpus (500 items in total, $387 \mathrm{FB}, 113$ TC-clefts, significant at $\mathrm{p}<.05$ ). Therefore, it can be concluded that FB-clefts can be categorized as the prototypical it-cleft 
in German, while TC-clefts are less common and, therefore, non-prototypical. Regarding exhaustivity, the corpus data suggest that it-clefts in German are significantly more frequently exhaustive than non-exhaustive, regardless of the cleft type. When dividing TC and FB-clefts, it was shown that TC-clefts are more frequently exhaustive than FB-clefts.

When a focus particle is positioned directly in front of the cleft pivot, the effects on the exhaustivity of the it-cleft vary. In the case of only and especially, the clefts in which they appear are interpreted $[+\mathrm{exh}]$ with only and [-exh] for especially, thereby following the presupposition and/or meaning contribution of the respective particle.

For the particles also and not least, the behavior regarding exhaustivity is less clear. We do find clefts with also and not least that receive a non-exhaustive interpretation. These non-prototypical cases were resolved by showing that the additive particle and the cleft pivot no not form a (strong) constituent, which makes it possible for the particle to modify other elements than the focused NP/DP in the pivot. In the pilot and follow up experiments, where it-clefts with the additive particle also had to be interpreted by native speakers of German, it was shown that the majority of speakers think that the additive focus particle refers to the cleft relative. In terms of exhaustivity of the cleft speakers are again rather clear in their judgment that the cleft relative is non-exhaustive in both cleft types. Considering the additive particle is in the syntactical position directly in front of the cleft pivot and should, therefore, by default modify the pivot and make the clefted element non-exhaustive, these results are taken to mean that this is not the case. The additive particle actually modifies the cleft relative, which then receives a non-exhaustive interpretation.

When being asked what the sentence is about, participants are undecided. When looking at the two cleft kinds, however, we see an effect: FB-clefts are judged to be about the cleft pivot, while TC-cleft are judged to be about the cleft relative. From this it can be concluded that the two cleft kinds in fact do have different discourse functions, as they are interpreted differently by native speakers.

In the related judgment experiment, it was shown that, contrary to previous theoretical approaches, German it-clefts are highly acceptable in combination with a variety of (non-exclusive) focus particles. There were no significant differences in judgments of it-clefts and their respective canonical sentences with also and only. This allows the conclusion that it-clefts are not exhaustive in every case. They may receive an exhaustive or a non-exhaustive interpretation. 


\section{Chapter 4}

\section{Exhaustivity and the Question Under Discussion}

\subsection{Introduction}

This chapter ${ }^{1}$ first takes a general look at the information structural properties of it-clefts and the possible impact they have on the two main kinds of it-clefts that we can distinguish (for German), Topic-Comment and Focus-Background clefts. The question whether these two kinds of clefts vary in exhaustivity (as a possible result of their different information structural functions) is investigated in an experiment for German and Hungarian. The experiment presented here targets the question whether different kinds of overt context questions have an influence on the exhaustivity judgment of it-clefts and pre-verbal focus. In addition to that, this chapter also shows the results of a second experiment which investigates the possible effect that non-exclusive focus particles may have on the exhaustivity judgment of the two focus constructions. This chapter provides a direct link to the results presented in chapter 3 of this thesis on focus particles and it-clefts, while at the same time extending the discussion presented there to a cross-linguistic level.

\subsection{Background}

It has been argued (see Velleman et al. (2012) as discussed in section 2.3.2.3 of this thesis and repeated here for the reader's convenience) that the main difference between it-clefts and exclusives lies in the discourse-status of the exhaustivity

\footnotetext{
${ }^{1}$ The work in this chapter was done in cooperation with Gergő Turi from NUYTD Budapest. The author declares that the idea for and design of the experiment presented in this chapter are her own. The author also declares that the writing of the text and the interpretation and discussion of the results were done by herself. The co-author contributed the statistical analysis.
} 
inference. While only makes the exhaustiveness inference at-issue, it-clefts make the same inference not-at-issue (see, e.g. Horn (1981), Velleman et al. (2012), Büring and Križ (2013), Horn (2014), Destruel et al. (2015)). This is illustrated in the example below (Büring and Križ (2013), adapted from Horn (2014)):

a. \# Bob knew she invited Fred, but he didn't know it was Fred she invited. (not-at-issue exhaustivity)

b. Bob knew she invited Fred, but he didn't know she only invited Fred. (at-issue exhaustivity)

Velleman et al. (2012) classify it-clefts and exclusives as inquiry terminating (IT) constructions. IT constructions have the following characteristics: they are focussensitive, have closely related semantics, and have the discourse function of marking an utterance to give a complete answer to the Current Question (CQ) ${ }^{2}$. In this framework, it-clefts are treated as exhaustive. The exhaustivity is derived via two semantic operators, which are introduced into the logical form of the cleft. The crucial difference between the exclusive and the it-cleft is that in exclusives, exhaustivity is directly asserted and, therefore, at-issue, while in it-clefts, it is presupposed or conventionally implicated and, therefore, non at-issue.

Velleman et al. (2012) assume the following two semantic operators, $\mathrm{MIN}_{S}$ (presupposed, requirement: there is a true answer to the $\mathrm{CQ}$ above a certain lower bound) and $\mathrm{MAX}_{S}$ (asserted/at-issue, requirement: there is no true answer to the CQ above a certain upper bound). Exhaustivity in clefts and sentences with exclusives is treated as a pragmatic discourse function introduced via the two semantic operators $\mathrm{MIN}_{S}$ and $\mathrm{MAX}_{S}$ (S here stands for sentence). These IT-constructions thereby assign to a sentence the function of being the maximal (or: complete/ exhaustive) answer to the CQ and terminating the line of inquiry.

The different at-issueness status of exclusives and it-clefts can, according to Velleman et al. (2012), also help explain the proposed asymmetry in the two constructions regarding informativeness, as illustrated by Horn (1981) using the following examples:

(271) I know Mary ate a pizza...

a. ?? but I've just heard it was a pizza she ate.

b. but I've just heard she only ate a pizza. (Horn (1981), 130)

The sentence in (b) bears the at-issue content and is therefore informative in itself (Mary ate a pizza and ONLY a pizza). While (b) can serve as an extension of the statement, this is not the case for (a). The cleft in (a) is redundant. The $\mathrm{MIN}_{S}$ (Mary ate at least a pizza), which is made at-issue by the cleft, is already in the

\footnotetext{
${ }^{2}$ For a more detailed discussion of the notion of the Current Question, see section 2.3.3 of this thesis.
} 
Common Ground, and is therefore not informative.

While arguing that the exhaustivity in it-clefts is a discourse function, Velleman et al. (2012) still hold onto the idea that it is conventionally coded and cannot be canceled. In case speakers wish to close a line of inquiry but leave open the option of adding more information, other constructions are available (e.g. in situ focus):

\section{A: Who laughed?}

a. B: MARY laughed. So did JOHN.

b. B: \# It was MARY who laughed. And so did JOHN. (Velleman et al. (2012), 457)

Following Roberts $(1996)^{3}$, the exhaustivity inference is said to be at-issue if it addresses the Question Under Discussion (QUD). Presuppositions and Conventional Implicatures are also argued to be not-at-issue inferences (see Simons et al. (2010), Tonhauser et al. (2013), Potts (2005)). The distinction between at-issue and non-at-issue exhaustivity has been the objective of several publications on it-clefts (see e.g. Drenhaus et al. (2011), DeVeaugh-Geiss et al. (2015), Destruel (2012), Destruel et al. (2015)) and is one of the objectives in this chapter.

There have been a variety of approaches to define the notion of at-issueness. It is often analyzed in opposition or comparison to a notion of Conventional Implicature (CI) in the Gricean terms. Grice (1975) names the following conditions for CIs:

- CIs are part of the conventional (lexical) meaning of words,

- CIs are commitments, and thus give rise to entailments,

- These commitments are made by the speaker of the utterance by virtue of the meaning of the words that he chooses, and

- CIs are logically and compositionally independent of what is said, i.e. independent of the at-issue entailments.

Potts (2005) characterizes at-issue entailment as being an alternative term for regular asserted content and contrasts it with CIs. CIs are secondary entailments used rarely by cooperative speakers to express controversial propositions or carry the main themes of a discourse. CIs therefore take over only a secondary position in structuring of information in an utterance. They mainly help the hearer to gain a better understanding of why the at-issue content is particularly relevant at that moment of discourse, as illustrated below:

\footnotetext{
${ }^{3}$ For a more detailed discussion of the notion of QUD, see section 2.3.1.1 of this thesis.
} 
(273) Ed's claim, which is based on extensive research, is controversial. at-issue: Ed's claim is controversial.

not-at-issue: Ed's claim is based on extensive research. (Potts (2005), 3)

Potts (2005) formulates the generalization that no lexical item contributes both an at-issue and a CI meaning. This is taken to mean that CIs, like at-issue entailments, but unlike presuppositions and conversational implicatures, cannot be canceled.

Beaver and Clark (2008) identify at-issue content with what they call ordinary content and agree with Potts (2005) that there is an opposition of at-issue content and presupposed content.

Horn (2014) (as discussed previously in section 2.3.2.3 of this thesis and repeated here for the convenience of the reader) agrees that at-issueness plays a key role in it-cleft exhaustivity. For him, the question is whether the exhaustivity is entailed or implicated ${ }^{4}$. Horn (2014) presents three counterarguments to the view that it-clefts (and other related focus constructions) assert and entail exhaustivity:

Firstly, it-clefts do not license negative polarity items (NPIs) in cases where there is no overt exhaustivity marker like an exclusive, which is illustrated below:

a. \# It is $[\mathrm{BUSH}]_{F}$ who ever proposed any tax cuts in wartime.

b. Only $[\mathrm{BUSH}]_{F}$ ever proposed any tax cuts in wartime.

c. It is only $[\mathrm{BUSH}]_{F}$ who ever proposed any tax cuts in wartime. (Horn (2014), 14)

Note that the cleft with the NPI becomes acceptable when combined with the exclusive only. Only makes the exhaustivity at-issue, while this is not the case in the cleft in (a). The plain cleft is not combinable with NPIs, which indicates that the exhaustivity in it-clefts is non-at-issue.

Secondly, clefts are uninformative when the corresponding un-marked proposition has already been established in the Common Ground. This is not the case for sentences with only.

(275) I know Mary ate a pizza...

a. \# but I've just heard it was a pizza she ate.

b. but I've just heard she only ate a pizza.

c. but I've just heard it was only a pizza that she ate. (Horn (1981), 130)

\footnotetext{
${ }^{4}$ Presupposition is ruled out by Horn (2014) because its projection properties are not satisfied.
} 
When inserting only into the cleft construction, the exhaustivity becomes at-issue, and the statement in the cleft is no longer uninformative.

Thirdly, the exhaustivity in clefts can be canceled or overridden, such as illustrated below:

It's the ideas that count, not just the way we write them. (Horn (2014), 16)

The "Yes-but" task, introduced by Onea and Beaver (2009), is slightly altered to illustrate that it-cleft and Hungarian pre-verbal focus exhaustivity is a result of the interaction between focus and the Question Under Discussion ${ }^{5}$ and therefore a pragmatic phenomenon. Horn (2014) supports this argument further by introducing the "Bullshit-diagnostic" which is modeled after the "Yes-but" test and uses the refutation maker bullshit.

A: It's you I love.

$\mathrm{B}_{1}$ : \# Bullshit - you love Rosalin, too.

$\mathrm{B}_{2}$ : Yes, but you love Rosalin, too. (Horn (2014), 22)

A: It's only you I love.

$\mathrm{B}_{1}$ : Bullshit - you love Rosalin, too.

$\mathrm{B}_{2}$ : \# Yes, but you love Rosalin, too. (Horn (2014), 23)

As illustrated by the two different answers $B_{1}$ and $B_{2}$, the exhaustivity inference can be refused with the bullshit-marker when the exhaustivity is stated overtly via the exclusive. When only is not present in the cleft, the exhaustivity is not targeted by the refutation maker and the answer is not felicitous. Horn (2014) concludes that exhaustivity in clefts is - unlike in exclusives - not truth-functional. Citing Wedgwood (2005), Horn (2014) argues that exhaustivity is not part of the truth-functional meaning of neither identificational nor information focus. Instead, it is derived pragmatically via the discourse structure and the alternative sets present in the discourse. Overall, the conclusion is that it-cleft exhaustivity is non-at-issue and might be due to a conversational implicature. Furthermore, Horn (2014) suggests that it-cleft exhaustivity might be a matter of degree that can vary depending on the discourse function.

Karttunen and Peters (1979) state that presuppositions, i.e. contents that survive under operators like negation or modals, are propositions which the respective sentence is not primarily about. Presuppositions, therefore, are not part of the main point of an utterance and therefore not-at-issue. As the exhaustivity inference in

\footnotetext{
${ }^{5}$ For a detailed discussion on the notion of the Question Under Discussion see section 2.3.3.2 of this thesis.
} 
clefts is taken to be not-at-issue semantic, it can be presuppositional.

Tonhauser (2012) suggests (with reference to Roberts (2006)'s QUD account) that CIs, like presuppositions, are part of the not-at-issue content of a sentence. She defines at-issueness in the following way:

- A proposition $\mathrm{p}$ is at-issue iff the speaker intends to address the QUD via ?p

- An intention to address the QUD via ?p is felicitous only if:

(i) ?p is relevant to the QUD, and

(ii) the speaker can reasonably expect the addressee to recognize this intention

Therefore, a question Q1 can be seen as relevant to another question Q2 iff Q1 has an answer which contextually entails a partial or complete answer to Q2.

At-issue content can be directly agreed to or disagreed with by the addressee. It's therefore the at-issue content which opens up a set of alternatives, as can be seen in the following example:
A: Does Juan live in Maria's house?
B1: Yes, he does/lives in Maria's house. (at-issue)
B2: \# Yes, Maria has a house. (not-at-issue)

In Tonhauser (2012)'s approach, one needs to know the current QUD in order to determine the at-issue content of an utterance. In summary, at-issue content can be assented/dissented with, that it addresses the QUD and it determines the relevant set of alternatives ${ }^{6}$.

\subsubsection{Focus-Background and Topic-Comment structures in it-clefts}

Generally, as shown in chapter 3 of this thesis, German it-clefts can be divided into at least two main subgroups: Focus-Background and Topic-Comment clefts. In the case of English, Focus-Background (FB) clefts are mainly used in answers and corrective statements, with the contrast on clefted constituent. For example in this question-answer pair ${ }^{7}$ :

\footnotetext{
${ }^{6}$ For For further discussion and a re-modeling of the definition also see Beaver et al. (2017). For further discussion of the notion of at-issueness also see Xue and Onea (2011), Potts (2015), Hunter and Asher (2016).

${ }^{7}$ However, this is not necessarily the case for German.
} 
Q: Who drank most at the party?

A: It was Max who drank most at the party.

In Topic-Comment clefts (TC), on the other hand, the clefted constituent is mostly old, activated, or accessible, while the non-clefted information is new to the hearer. The main stress is on the non-clefted part, like in the example:

It was in 1879 when Edison invented the electric lightbulp.

It is important to keep these two kinds of clefts distinct, because they might have different information structural functions: It may be possible that the FB-clefts are means of focus marking (in terms of Roberts (1996)) and that is the reason why they can be introduced by an explicit question. TC-clefts, on the other hand, might rather shift the direction of discourse towards the topic of the previous sentence or discourse. TC-clefts can also appear at the very beginning of a discourse, which has not been described for FB-clefts (see Prince (1978), Hedberg (2013)). TC-clefts can therefore be described as being presuppositional in every case. The use of the cleft construction would in that case be used to add redundant information in the pivot.

Roberts (1996) argues that focal alternatives are calculated on the basis of the placement of prosodic focus in the utterance, along the lines of those developed in the theories of Rooth (1985), Rooth (1992) and von Stechow (1989). According to Roberts $(1996)^{8}$, speakers follow two types of rules, (a) language internal or conventional rules, i.e. syntactic, compositional, semantic, etc., and (b) conversational rules, following the Gricean Maxims (see Grice (1975)). Within the rules, speakers make two kinds of moves (or speech acts) when communicating: they make either set-up moves, i.e. ask questions, or payoff moves, i.e. assert answers to questions. It should be mentioned that the questions in a discourse do not always have to be uttered explicitly, while a discourse is still organized and structured by question-answer-relations. One way of stating an implicit question is prosodic focus (Roberts (1996) looks at English), which presupposes a certain Question Under Discussion (QUD) for the current discourse. This enables the speaker to reconstruct the implicit question and therefore the direction in which the discourse is being moved by the assertion. Since intonational focus in English is presuppositional, the information that interlocutors can gain from intonational focus is redundant. When an utterance has a presupposition, this presupposition is already at least entailed by the context, or explicitly part of the CG. This redundancy can be used by interlocutors to indirectly convey information. This,

\footnotetext{
${ }^{8}$ As also discussed in chapter 2.3.1.1 of this thesis and repeated here for the convenience of the reader.
} 
however, is not a semantic operation, but a pragmatic derivation of certain focus effects, and it does not assume any direct focus sensitivity for focus particles like only or even.

When defining her notion of QUD, Roberts (1996) refers to Stalnaker (1974) and the notion of The Big Question (What is the way things are?) as the goal of a discourse. A question which is uttered in the discourse sets up a partition on the context set.

The context set itself represents the ultimate set of alternatives. The context set is the selection of a unique, or actual world, which is the goal of a discourse. Assertions by speakers are choices among alternatives. If accepted by all interlocutors, they are added to the CG and thereby shrink the context set. Answers to the Big Question stand in an entailment relation to answers to a set of all sub-questions. For example, the question "What do you like?" entails "What drinks do you like?". As a result, if interlocutors can answer enough sub-questions, they have an answer to the superquestion. Another result of this entailment relation of questions and answers is that inquiries in discourse have a hierarchical structure. The set of questions that are at stake at a given point in the discourse is thought of as a push-down store, which Roberts (1996) calls the QUD-stack. When a question is accepted into the CG by all interlocutors, it is added on the top of the stack. When a question is answered (or determined to be unanswerable), it is moved from the stack, making way to the ones below it. The question on top of the stack is the (immediate) QUD at any point in discourse.

While the TC structure in it-clefts has been described to have the intonational stress on the cleft relative in the case of English, there is to this point no experimental evidence that this is also the case for German. The default stress pattern for German es-clefts seems to have the main stress on the cleft pivot, with falling intonation on the relative clause. This chapter presents the results of an acceptability study in which it was tested whether TC-clefts are acceptable as answers to overt questions that target a focus structure as their answer (like in (280) above). The results are presented in the discussion of the German data (section 4.7.3 below).

Based on those results, it can be assumed that the intonation pattern in German es-clefts is not what marks them as FB or TC-clefts, respectively, but the (overt or accommodated) QUD (cf. Roberts (1996)) preceding the utterance. The results support Lambrecht (2001), who argues that the relative clause of a cleft can remain unaccented, if its denotatum has been activated by an element in the immediately preceding context. If the content of the cleft relative has been sufficiently activated in the context, the relative clause does not require prosodic stress. 


\subsubsection{Hungarian pre-verbal Focus}

From a cross-linguistical perspective, the exhaustivity effect in it-clefts is commonly analyzed on a par with Hungarian pre-verbal focus. If a focused expression appears in the immediately pre-verbal position in Hungarian, it is interpreted exhaustively, as in the (282) below, in the same way as if it were in the scope of an exclusive like only. In cases where it appears in another position, as in example (283) below, this exhaustiveness effect is not available (cf. Szabolcsi (1981), Onea and Beaver (2009), Onea (2007), Onea (2009a)), and focus here is merely marked prosodically.

$$
\begin{aligned}
& \text { Péter MARIT csókolta meg. } \\
& \text { Peter Mary.ACC kissed PRF } \\
& \text { Peter kissed Mary (and no one else). }
\end{aligned}
$$

Péter meg-csókolta MARIT.

Peter PRF-kissed Mary.ACC

Peter kissed Mary (and possibly someone else as well). ( Onea and Beaver (2009), 342)

Following É. Kiss (1998), two main kinds of focus can be distinguished crosslinguistically: information focus and identificational focus. Information focus has the function of marking new, non-presupposed information, while identificational focus functions via semantic identificational predication. It thereby exhaustively identifies the set of individuals of which the predicate holds, with the exhaustivity being part of its meaning. Hungarian pre-verbal focus has often been described as identificational focus, with the exhaustivity being truth-conditional and semantic (see Szabolcsi (1981), É. Kiss (1987), Kenesei (1986), Szabolcsi (1994), Horváth (2005)).

The strong exhaustivity of this focus construction has led to the tentative conclusion that the pre-verbal focus in Hungarian is semantically exhaustive, which makes it an ideal mode of comparison for the exhaustivity of it-clefts.

Although the pre-verbal focus structure has traditionally be seen as a structure that is semantically exhaustive in nature (see e.g. Szabolcsi (1981), Kenesei (1986), É. Kiss (1987), Szabolcsi (1994)), this view has been under constant dispute in the past years.

In a text-completion task for Hungarian focus, Onea and Beaver (2009) show that, while Hungarian pre-verbal focus does indeed come with an exhaustivity effect, it is not as strong as the effect which can be observed with the exclusive focus particle csak/only. Their findings therefore go against the common prediction that pre- 
verbal focus is semantically exhaustive, i.e. that the exhaustivity is part of the truth-conditional content of the construction. Instead, they offer a pragmatic analysis. Their key prediction is that pre-vebal focus is grammatically constrained to be a question-answering constituent. Onea and Beaver (2009) use a task that measures the way participants contradict sentences with and without exclusives. In their design, participants match pictures to three kinds of spoken sentences: (i) pre-verbal focus on the subject, (ii) overt exclusive csak, (iii) unmarked default intonation. Three answer options are given to react to the target statements: a. Yes, and..., b. Yes, but... c. No...

As predicted, it was shown that the majority of participants gave "Yes, but" or "No" answers in the pre-verbal focus condition. This is taken to mean that the exhaustivity effect in this focus construction is pragmatic, as people often reacted with disagreement rather than with contradiction.

Pre-verbal focus is here described as functioning as an answering constituent to a QUD (cf. Roberts (1996)) that may also be implicit. It was further predicted that adding an overt wh-question would not trigger an increase in exhaustivity judgments for pre-verbal focus. This was tested in a second experiment. The original design was varied by the introduction of an overt question that was presented along with the picture stimulus. Here, the results showed again that speakers did not directly contradict the pre-verbal focus sentences when the exhaustivity was violated. For the corresponding data elicited for German, however, introducing an overt question to which the focused element is the answer had an effect: the results show that prosodic focus in German is actually more exhaustive than pre-verbal focus in Hungarian.

Onea and Beaver (2009) conclude that pre-verbal focus in Hungarian is used to answer an (implicit) wh-question which can be accommodated by the hearer. The fact that this structure often gets an exhaustive interpretation is explained via a pragmatic procedure. Speakers tend to interpret answers as being optimal in the discourse at hand. Speakers assume completeness and therefore exhaustivity of the given answer.

Onea (2009b) suggests that exhaustivity is not part of the truth-conditional content of pre-verbal focus in Hungarian. It was shown that Hungarian pre-verbal focus is more exhaustive than German prosodic focus. However, this does not lead to the conclusion that pre-verbal focus is exhaustive qua structure, as his study also shows that pre-verbal focus is less exhaustive than sentences with an overt exhaustivity marker like only. Generally, Onea (2009b) assumes that direct answers to overt wh-questions are often interpreted exhaustively. Similar to the "Yes, but"-test described for Onea and Beaver (2009) above, Onea (2009b) assumes that overt contradiction of a given statement (with a clear "No"-answer) is 
used by speakers in situations where the misscontent is rather serious. Only when a speaker is very certain that a statement is completely false, he or she would contradict it using a clear "No". If the speaker can accommodate the slightest sign of truth, he or she would choose a less strong response, like a "Yes, but" answer. Falsity of a sentence leads to contradiction, truthfulness to acceptance, and the "Yes, but" response is triggered pragmatically in situations when it it not technically false, but misleading.

The data suggest that pre-verbal focus is significantly less likely to be contradicted for not being exhaustive than sentences containing an exclusive. When comparing the Hungarian and German data, it was found that the exhaustivity inference with pre-verbal focus is stronger than the one found with German prosodic focus. In Hungarian, if an exclusive is part of the sentence, there is a strong tendency to contradict the sentence when exhaustivity is violated, while in pre-verbal focus sentences, most participants react with "Yes, but" answers. As exclusives and pre-verbal focus did not pattern alike, the conclusion can be drawn that the exhaustivity inference in these two structures is not identical.

These findings are further supported by the results of an extensive corpus study of Hungarian pre-verbal focus, in which Wedgwood et al. (2006) show that this construction does not, in fact, show the robust exhaustivity inference that has been ascribed to it (e.g. by É. Kiss (1998)). Instead, the naturally occurring examples from the Hungarian corpus show a great variety of focus adverbials with the focused element in their scope (jórészt/for the most part, legkevésbé/ least of all, elsosốrban/ primarily, többek között/ among others), which have the effect of explicitly de-exhaustifying the focused element. ${ }^{9}$

Further arguments to treat Hungarian pre-verbal focus as a pragmatic phenomenon can e.g. be found in Szendrői (2003), Wedgwood (2005), and Gerôcs et al. (2014).

Wedgwood (2005) states that it has not yet been conclusively answered whether inferential processes can or cannot influence truth-conditional meaning, and it is possible to derive exhaustivity from pragmatic factors. Instead he suggests that the exhaustivity effect should be explained using the Relevance Theory (see Sperber and Wilson (2004)): when an utterance is the result of a choice between equal alternatives (generated by focusing), the exhaustive interpretation is the optimally relevant choice (in the terminology of Relevance Theory: generating the quantity implicature is worth the cognitive effort).

\footnotetext{
${ }^{9}$ While Wedgwood et al. (2006) criticize a semantic analysis of the exhaustivity inference in Hungarian pre-verbal focus, it should be noted that they do not explicitly stress the relation between focus particles and the exhaustivity inference. This, in addition to the formal analysis of the different particles and implicatures, is left to further research.
} 
Gerôcs et al. (2014) provide empirical evidence that exhaustivity in pre-verbal focus is not entailed, but is derived pragmatically via Conventional Implicature. They present two experiments which are build on the theoretical framework of Relevance Theory (see e.g. Sperber and Wilson (2004)), which predicts that, when cognitive resources are limited, listeners are expected to process semantic content but not pragmatic implicatures. Experiment 1 is a truth-value judgment task in which participants are pressured for time. Experiment 2 is an indirect task and compares pre-verbal focus with three other types of focus (real Hungarian cleft sentences, exclusives and syntactically unmarked focus). In direct comparison between these focus types, Gerốcs et al. (2014) show that the level of exhaustivity depends on whether exhaustivity is asserted or entailed. They also raise the issue of Q-implicatures: differences in exhaustivity rates of pre-verbal focus they found in their two experiments might be due to the presence or absence of overt whquestions in the preceding context. If exhaustivity in pre-verbal focus is due to a pragmatic implicature (as their results suggest), then their results support contextualist approaches to Q-implicatures (e.g. Sperber and Wilson (2004)), according to which implicatures licensed by a sentence arise as a function of context.

In recent studies, the perspective on Hungarian pre-verbal focus has changed. Instead of primarily analyzing the structure as semantically exhaustive, the literature now explains the exhaustivity via a predication structure, in which the focus functions as an identificational or specificational predicate. What makes the pre-verbal focus exhaustive is the exhaustive listing of all the members of the set which is reached via referential identification of that set (see É. Kiss (2006), É. Kiss (2016)). The predicational subject bears an existential presupposition, as only existing things can be presupposed. The exhaustivity is in this case not overtly asserted, but rather presupposed (via existential presupposition).

É. Kiss (2016) presents examples of pre-verbal constructions that include nonexclusive focus particles, which actually cancel the exhaustivity, as illustrated in the example below:

János többek között Évát hívta fel.

John among others Eve-ACC called up.

It was Eve, among others, that John called up. (É. Kiss (2016), 681)

The proposal to analyze the exhaustivity of pre-verbal focus as a presupposition can also be found in Kenesei (1986), where the focus is described as expressing exclusion by identification. 


\subsubsection{Narrow and Semi-narrow/wide Focus Questions}

It is generally assumed that wh-question can license different kinds of foci in the answers, depending on the question:

a. A: What happened? B: [John called Mary $]_{F}$ (wide focus)

b. A: What did John do? B: John [called Mary] $]_{F}$ (semi-narrow focus)

c. A: Who did John call? B: John called [Mary $]_{F}$ (narrow focus) (Repp (2016), 13)

The distinction between FB and TC-clefts discussed above for the case of German falls into the distinction of narrow and semi-narrow/wide focus questions in the case of Hungarian.

A: Who is wearing a cape? (narrow focus)

B: It's [the $\operatorname{dog}]_{F}$ who is wearing a cape.

$\mathrm{B}^{\prime}$ : $[\text { The } \operatorname{dog}]_{F}$ is wearing a cape.

A: What do you know about the dog? (semi-narrow/wide focus)

$\mathrm{B}$ : [The $\mathrm{dog}]_{F}$ is wearing a cape.

$\mathrm{B}^{\prime}$ : ??It's [the $\left.\operatorname{dog}\right]_{F}$ who is wearing a cape.

We would expect a narrow focus question to license a pre-verbal focus or cleft answer (or make these kinds of answer more acceptable than others), while in seminarrow/wide-focus questions, we would assume that a cleft or pre-verbal focus is not generally accepted.

The questions triggering a FB-context for the clefts can therefore be interpreted as introducing a narrow focus domain, while those triggering a TC-context also introduce a semi-narrow/wide focus domain.

\subsection{Experimental Study}

\subsubsection{Method and Design}

To address the pending questions regarding the exhaustivity inference in pre-verbal focus and it-clefts, the following experiment was conducted using the online tool Inquisit (by milisecond). The items were pseudo-randomized between targets and fillers and randomized within targets and fillers. We opted for sentence-pictureverification, which has been successfully used to address exhaustivity in previous studies (e.g. Pintér (2016), Gerócs et al. (2014), Onea and Beaver (2009)). In the introduction to the experiment, participants were provided with a rich background story, presented in written form (see appendix). The story describes an animal costume party on a farm, in which the invited animals are wearing various 
items of clothing. Using animals instead of human individuals has the benefit of creating easily identifiable individuals that do not have to be characterized using names (which the participants have to memorize or that have to be written with every item, which includes written material into the audio-visual-input) or definite descriptions. The reason the material is embedded in a rich context story lies in the assumption that pre-verbal focus has been described as a type of information structural marking (cf. Onea and Beaver (2009)). When trying to target information structural properties with experiments, truth-value judgment tasks are generally not helpful, as the task of judging the truth or falsity of single (or isolated) sentences is not natural.

The target items are preceded by two kinds of questions (Focus-Background (narrow focus) or Topic-Comment (semi-narrow/VP-focus), which make the potential exhaustiveness inferences in the answers [+at issue] or [-at issue]:

(288) a. Who is wearing a cape? [narrow focus]

Answer options: The dog, the cat, the pig, the duck [+at-issue]

b. What do you know about the dog? [semi-narrow/VP-focus]

Answer options: The dog is wearing a cape. [-at-issue]

We assume that the kind of question that precede the target items introduce either a narrow or a $\mathrm{VP}$-focus focus. The answer options that participants have can then be at-issue or non-at-issue. The at-issueness status is assumed to be directly linked to the kind of focus introduced by the question. Audio stimulus is used in order to control for the status ( $+/-$ at-issue) of the exhaustivity inference through the context question. Especially in the case of Hungarian, using audio stimulus is very important, as the intonation has a direct effect on the interpretation of the sentences. Generally, Hungarian stress is leftward-oriented, with the nuclear stress assigned to the leftmost phonological phrase. Focus bears the pitch accent, while the background is de-accented (see É. Kiss (2016), Szendrói (2003)).

At-issue inferences are taken to address the current QUD and the current QUD is typically marked by prosodic focus (see Roberts (1996), Beaver and Clark (2008)) in FB-clefts, in which the prosodic stress lies on the cleft pivot.

In the case of TC-clefts (see e.g. Prince (1978), Hedberg (1990), Delin (1992), Delin and Oberlander (1995), Huber (2006)), the cleft relative (and not the pivot) provide the at-issue information. Since a clefted (or, in the case of Hungarian, a pre-verbal focus) answer to a question of the kind presented in (288)(b) above has the non-at-issue information in the pivot (and vice versa for FB-clefts), we can test whether there is an effect on the exhaustivity judgments depending on the 
kind of cleft and therefore the status of the exhaustivity inference.

In each trial, participants are first presented with a picture showing 4 individuals (a dog, a cat, a duck, and a pig) which have been introduced to them as the party guests in the background story. The picture is followed by the audio-stimulus (the question-answer pair, recorded with distinctively different voices for the two interlocutors), which is played twice to make sure that participants pay attention to the context-questions, as the questions trigger either the narrow or $\mathrm{VP}$-focus. Pictures are present during the entire trials. The sentences are in the following conditions:

1. - Cleft/preVFoc,--part: The dog is wearing a cape. Der Hund trägt einen Umhang. Felvett a kutya egy köpenyt.

2. - Clelft/preVfoc, + part: Also the dog is wearing a cape. Auch der Hund trägt einen Umhang. Felvett többek között a kutya egy köpenyt.

3. + Clelft/preVfoc,--part: It is the dog that is wearing a cape. Es ist der Hund, der einen Umhang trägt. A KUTYA vett fel egy köpenyt.

4. + Clelft/preVfoc, + part: It is also the dog that is wearing a cape. Es ist auch der Hund, der einen Umhang trägt. Többek között A KUTYA vett fel egy köpenyt.

The pictures verify or falsify the exhaustivity implicature in the following conditions (see also example images below):

1. Exhaustive: Only the dog wears a scarf, the other animals wear nothing,

2. Non-exhaustive: the dog and two others wear a scarf

3. False: one of the other animals (not the dog) wears a scarf, the other animals wear nothing.

The false picture condition is only used for the controls (with only), while the exhaustive and non-exhaustive picture condition is used for all targets.

The design includes two experiments. Experiment Context, which targets to answer the question whether the kind of context question (FB or TC) has an influence on the exhaustivity, and Experiment Particle, which aims at the possible influence 
of an additive particle in the cleft/pre-verbal focus structure. The experimental conditions for both experiments are illustrated in the figures below:

$\left.\begin{array}{c|c|c}\text { focus type } & \text { particle } & \text { question type } \\ \hline \text { clelft/preV } & \text { excl } & \mathrm{FB} / \text { narrow } \\ \text { clelft/preV } & \text { excl } & \mathrm{FB} / \text { narrow } \\ \text { clelft/preV } & \text { excl } & \text { TC/wide } \\ \text { clelft/preV } & \text { excl } & \text { TC/wide }\end{array}\right\}$ control conditions

Figure 4.1: Experiment Context

$\left.\begin{array}{c|c|c}\text { focus type } & \text { particle } & \text { picture } \\ \hline \text { clelft/preV } & \text { excl } & \text { exh } \\ \text { clelft/preV } & \text { excl } & \text { false }\end{array}\right\}$ control conditions

Figure 4.2: Experiment Particle 
Figure 4.3: Exhaustive picture condition

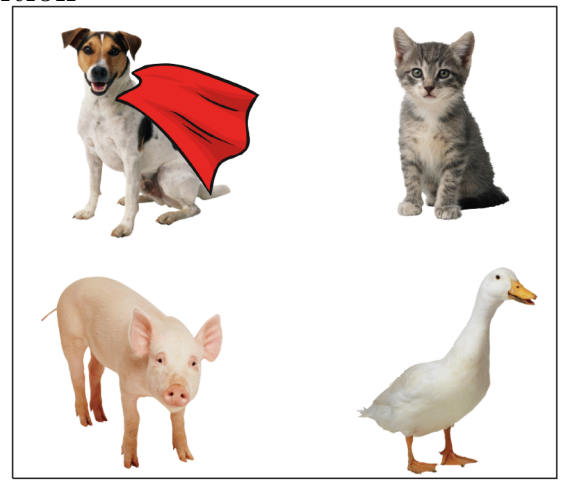

Figure 4.4: Non-exhaustive picture condition

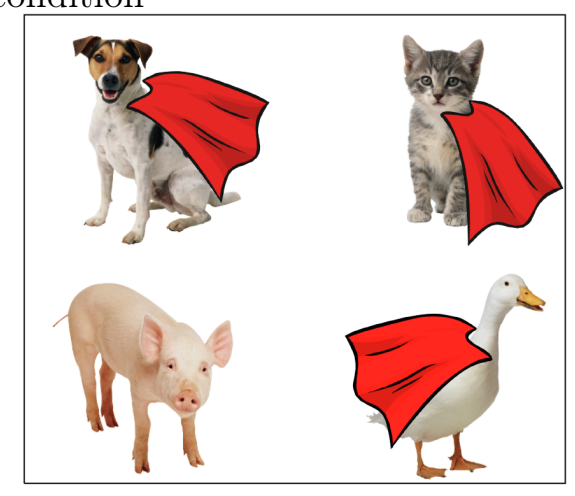

The additives többek között/ among others for Hungarian and auch/also for German are used in the target items. The exclusives nur for German and csak for Hungarian are used as controls. Participants are asked to judge how well the answers match the questions regarding the picture, using a 7-point Likert scale.

To make the question-answer pairs consistent, a vivid context story is provided in written form. The context story also accounts for the possibility that the picture and the target clause do not match, provides enough information to make every question-answer-pair consistent and introduces the character who answers the questions as trustworthy. Before the critical trials, participants had the chance to practice the task and received feedback for their responses. A total of 64 test items (with 4 lexicalizations per condition), and 64 filler items are used. All participants see all items.

\subsection{Participants}

33 Hungarian and 30 German participants took part in this experiment. They were all native speakers of their respective language. The Hungarian participants were University students in Budapest who received a small monetary compensation, the German participants were from the lower Rhine region of West Germany and participated on a voluntary basis. All participants were supervised during the preparatory, practice, and experimental phase.

\subsection{Predictions}

To account for the the two different experiments that are part of this experimental design, we work with the following hypotheses: 
- H1 (general): Hungarian pre-verbal focus and German it-clefts are exhaustive in some way. Therefore, if the exhaustivity inference denoted in the target sentence is violated, e.g. via a picture that shows a violation of the exhaustivity (non-exhaustive picture condition), participants are expected to judge the sentences low.

- H2 (context-question): Hungarian pre-verbal focus and German it-clefts are not semantically exhaustive. The patterns for both FB/narrow-focus and $\mathrm{TC} /$ wide-focus question types should not be parallel in this case. If the structures were semantically exhaustive, the exhaustivity should not depend on the cleft type, but is expected to appear across cleft types. Therefore, if the two cleft types differ regarding exhaustivity, it can be concluded that the structures are not semantically exhaustive.

- H3 (focus particle): In cases where the exhaustivity inference is weakened or overridden via an additive (or other non-exclusive) focus particle (for German auch/also, for Hungarian többek kösött/among others), there is no exhaustivity inference and participants are expected to judge the sentence better in the non-exhaustive picture condition than in the exhaustive picture condition. If the judgments for the same conditions ( $+/$-exh pictures) are different for sentences with and without additive particles, it can be concluded that the particles have an effect on the exhaustivity of the sentences.

\subsection{Results}

The experiment was divided into four sub-experiments, which each target one of the two aspects we investigate. The experiment Context in the first two subexperiments (called ExpC Hungarian and ExpC German hereafter) address the role of the context question (FB or TC) on the exhaustivity judgment. The experiment Particle in the second and third sub-experiments (called ExpP Hungarian and ExpP German hereafter) investigate the role of the non-exclusive particle in the exhaustivity interpretation.

The results are presented and discussed sorted by language in the following section, starting with Hungarian.

\subsubsection{ExpC Hungarian: The Role of Context on Exhaustiv- ity}

The graphs below illustrate the results for the post-verbal and pre-verbal sentences with narrow and wide focus questions in the non-exhaustive picture condition. 


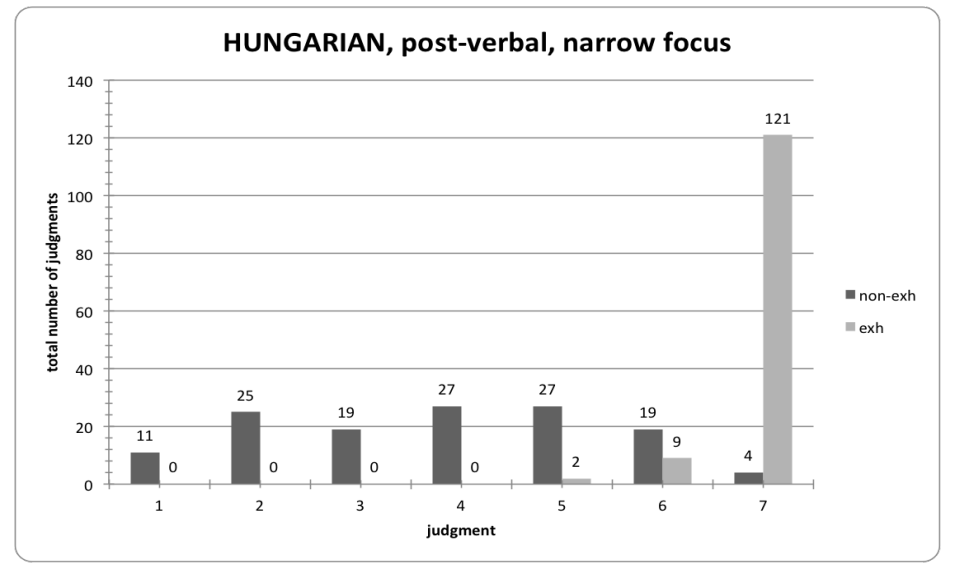

Figure 4.5: Q-A-pair: Who is wearing a cape? - The dog is wearing a cape.

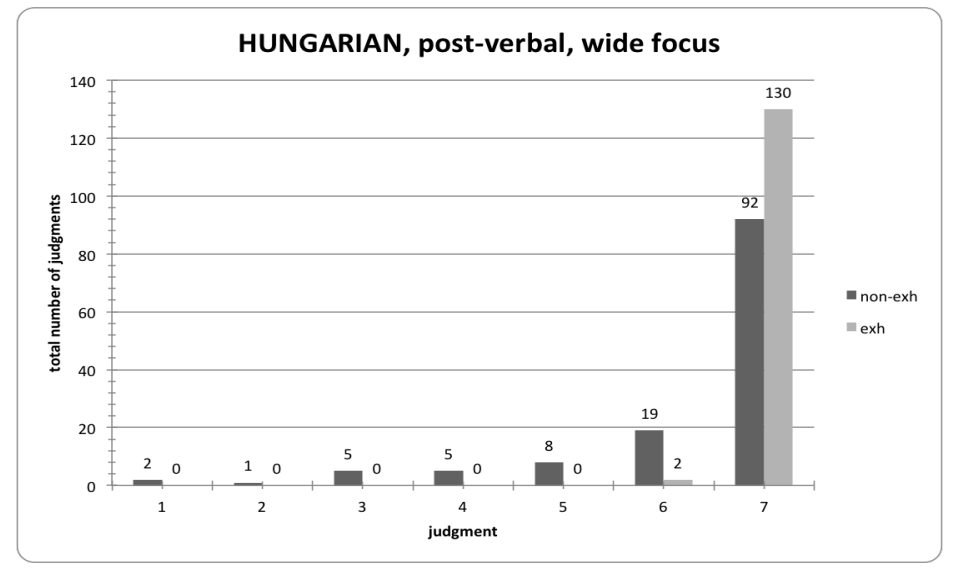

Figure 4.6: Q-A-pair: What do you know about the dog? - The dog is wearing a cape.

The distribution of judgments in the graph in 4.6 is close to a normal distribution pattern, which means that the judgments are more or less random. Participants do not appear to be sure what to do in this case. When comparing this case to the distribution in the graph in 4.5 it is evident that the distributions are completely different. In the latter, participants appear to have a strong tendency towards giving a high judgment and are much more unified than in the former. 


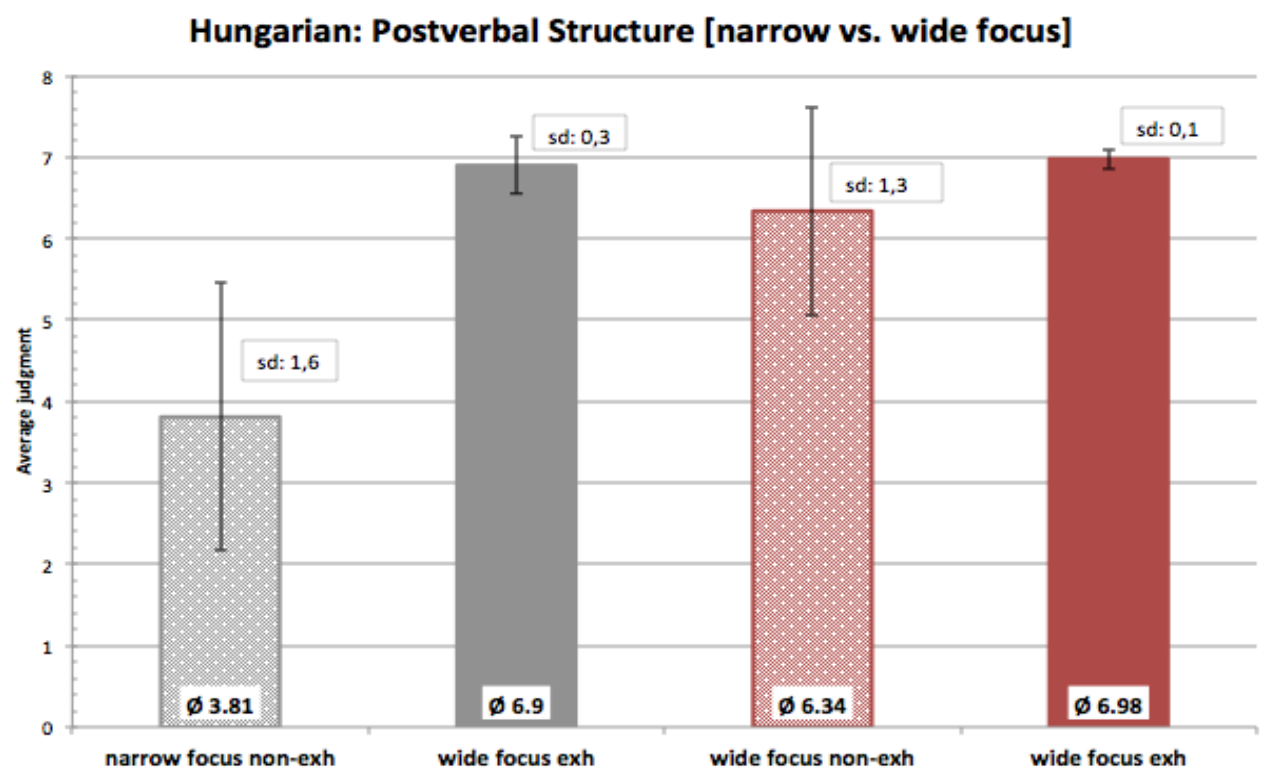

Figure 4.7: Average results postverbal structure

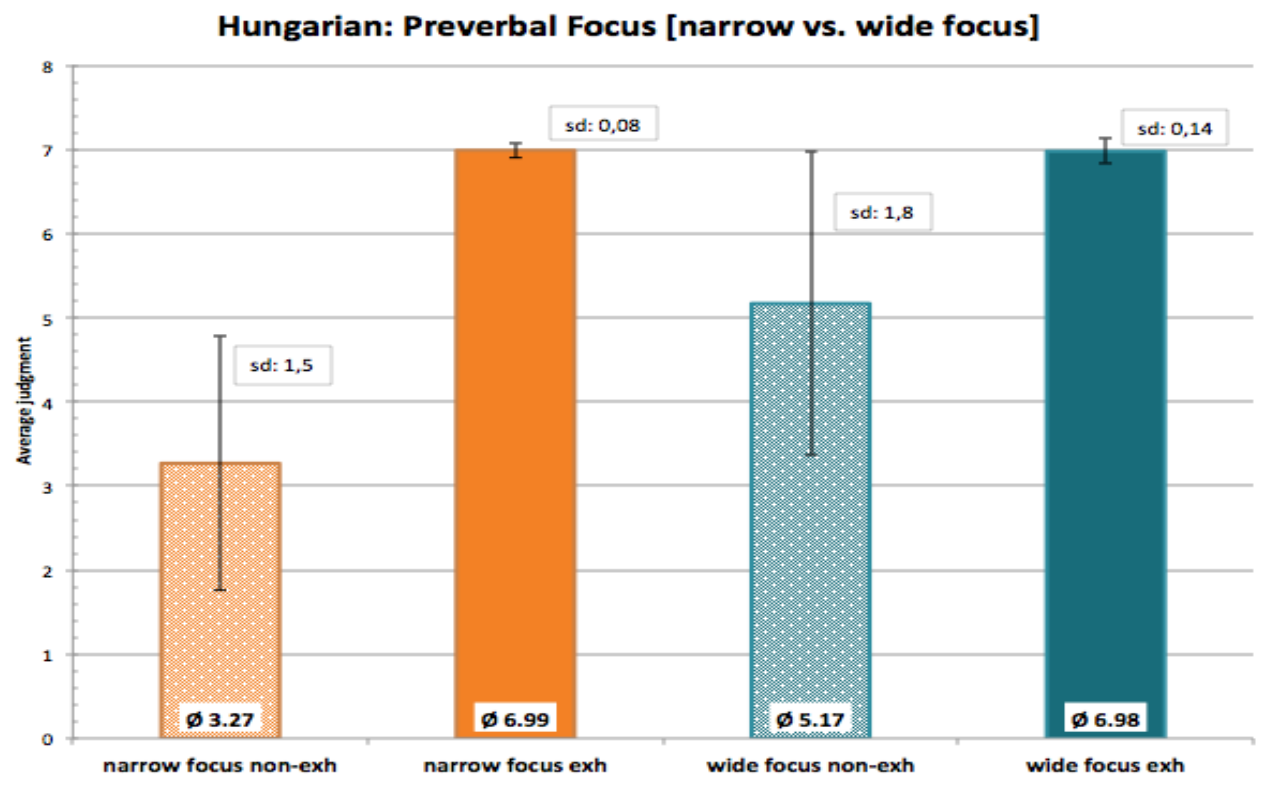

Figure 4.8: Average results preverbal focus

Statistically significant difference between the two context questions in post-verbal 
sentences (wide vs. narrow in postV) in the non-exh condition (z-ratio $=-13.468$, $\mathrm{p}<.0001)$.

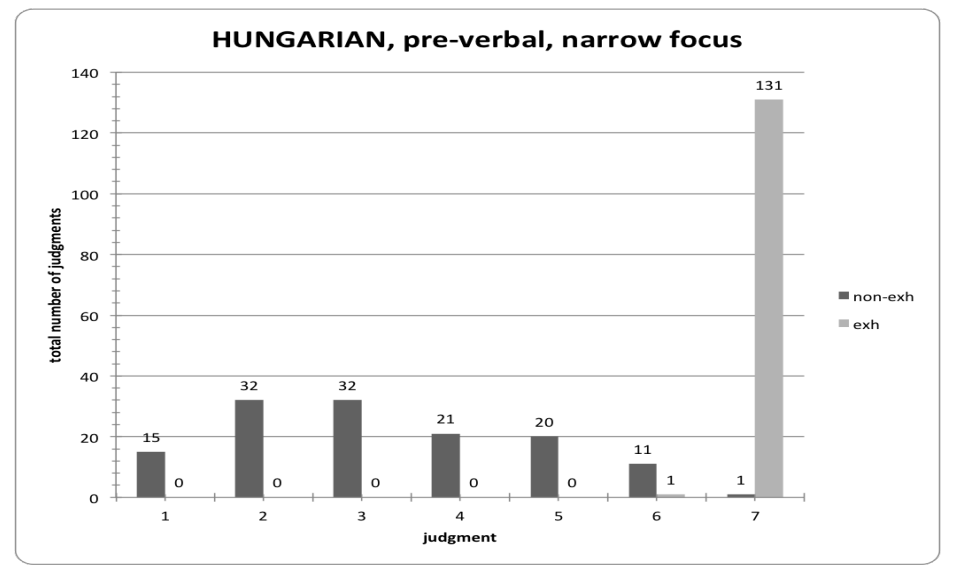

Figure 4.9: Q-A-pair: Who is wearing a cape? - It is the dog who is wearing a cape.

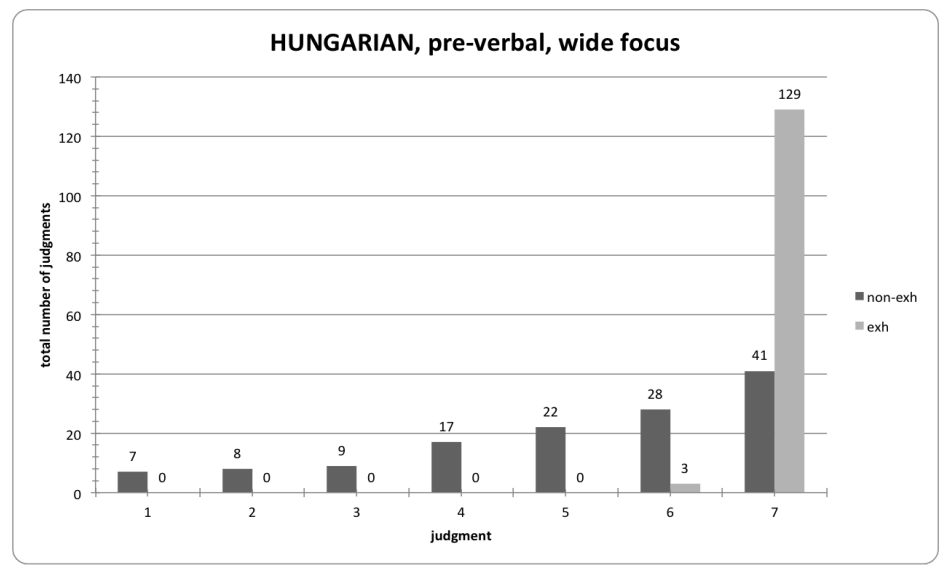

Figure 4.10: Q-A-pair: What do you know about the dog? - It is the dog who is wearing a cape.

When comparing the graphs in 4.9 and 4.10 with each other it becomes clear that the judgments for the non-exhaustive items increase when the pre-verbal focus is paired with a TC-question.

Statistically significant difference between the two context questions in pre-verbal sentences (wide vs. narrow in preV) in the non-exh condition (z-ratio $=-9.617$, $\mathrm{p}<.0001)$ There is a weak interaction between the factors in the narrow focus 
(postV narrow, non-exh and preV narrow non-exh): z-ratio 2.726, $\mathrm{p}=0.0325$, and a strong interaction in the VP-focus (postV wide, non-exh and preV wide, non-exh): z-ratio 8.140, $\mathrm{p}<.0001$.

In the graphs above it can be seen that the judgments in the $\mathrm{FB} /$ narrow-focus condition are higher when the picture verifies the answer. This is consistent over all conditions. In the $\mathrm{TC} /$ wide-focus condition the judgments are always high when the picture verifies the sentence. However, there are also lower judgments in the TC/wide-focus condition. This goes against the prediction that in a TopicComment environment, pre-verbal focus constructions are always exhaustive in Hungarian. What is also interesting is that there seems to be no difference between post-and pre-verbal focus in the TC/wide-focus condition. The graphs illustrate that the judgments in pre-verbal and post-verbal pattern similarly.

\subsubsection{ExpP Hungarian: The Role of Focus Particles on Ex- haustivity}

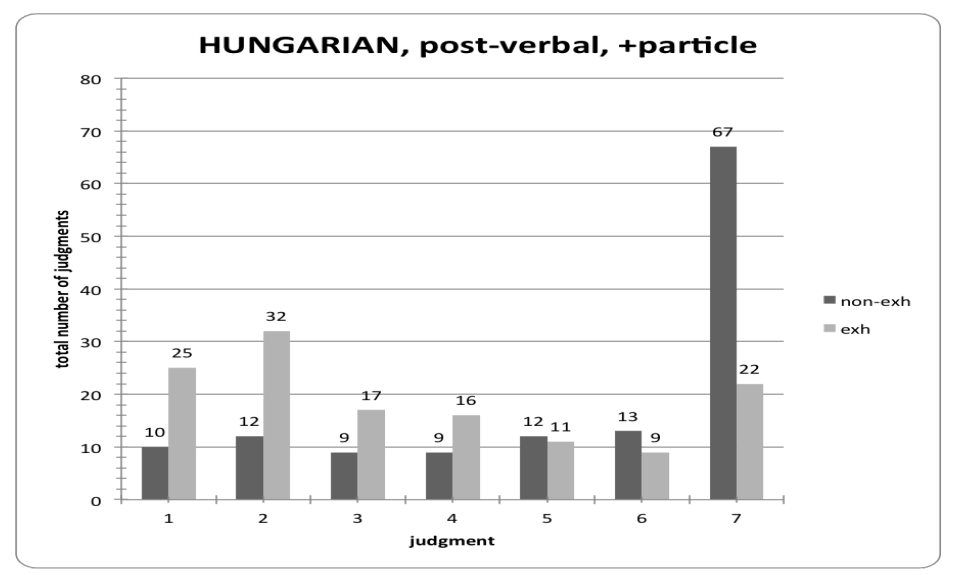

Figure 4.11: Also the dog is wearing a cape. 


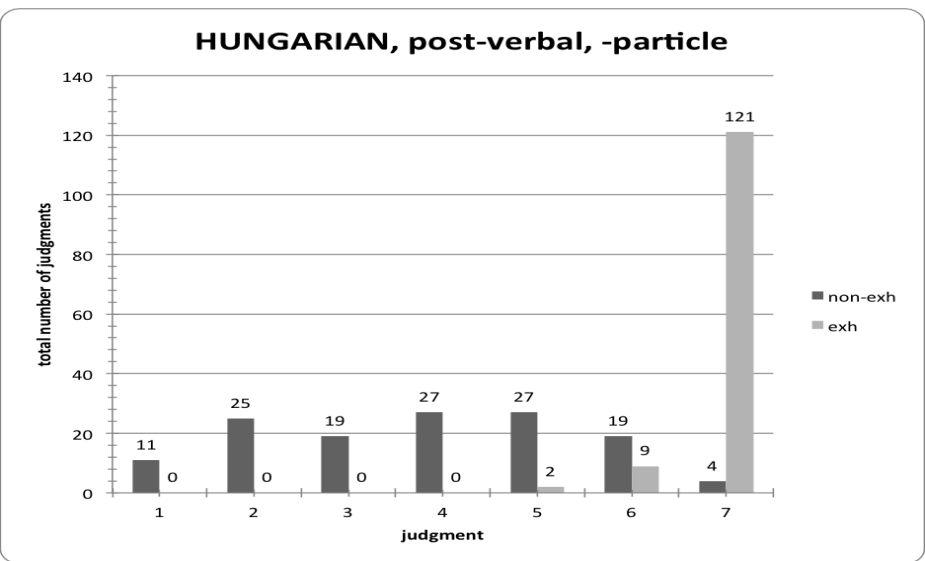

Figure 4.12: The dog is wearing a cape.

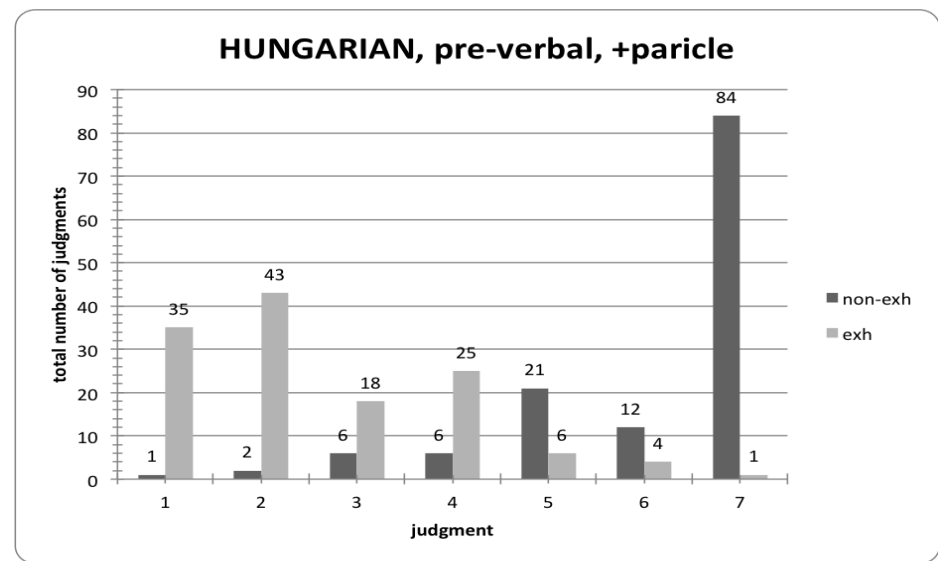

Figure 4.13: It is also the dog who is wearing a cape. 


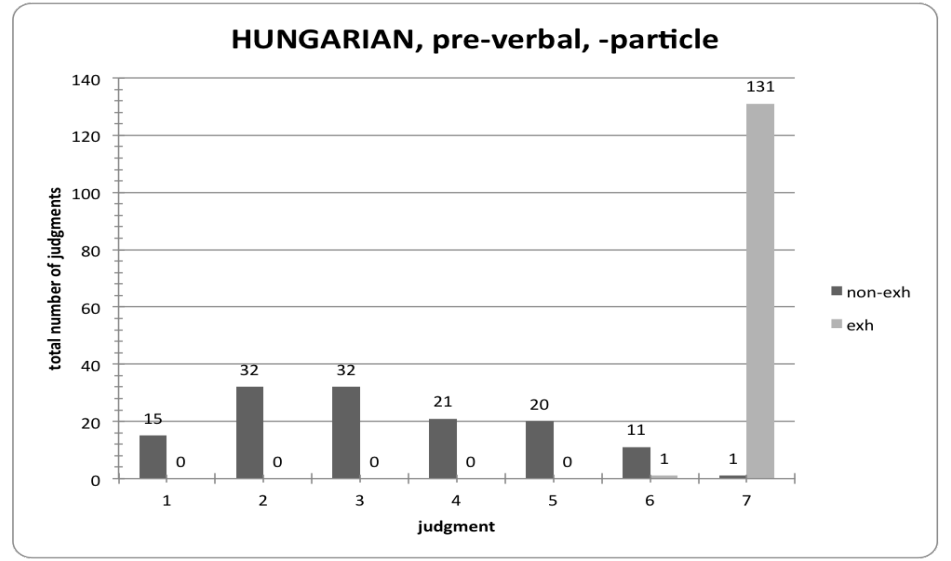

Figure 4.14: It is the dog who is wearing a cape.

Hungarian: Preverbal Focus [+/- Particle]

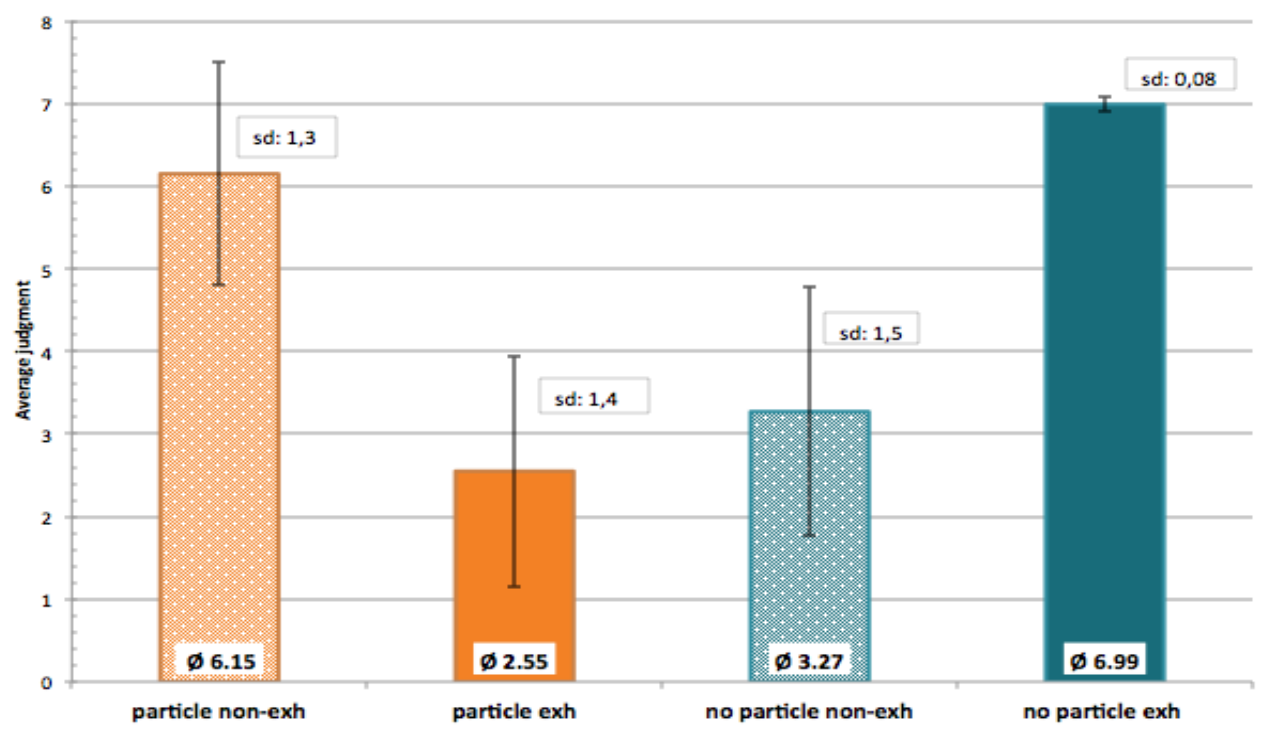

Figure 4.15: Average judgments pre-verbal focus 
Hungarian: Postverbal Structure [+/- Particle]

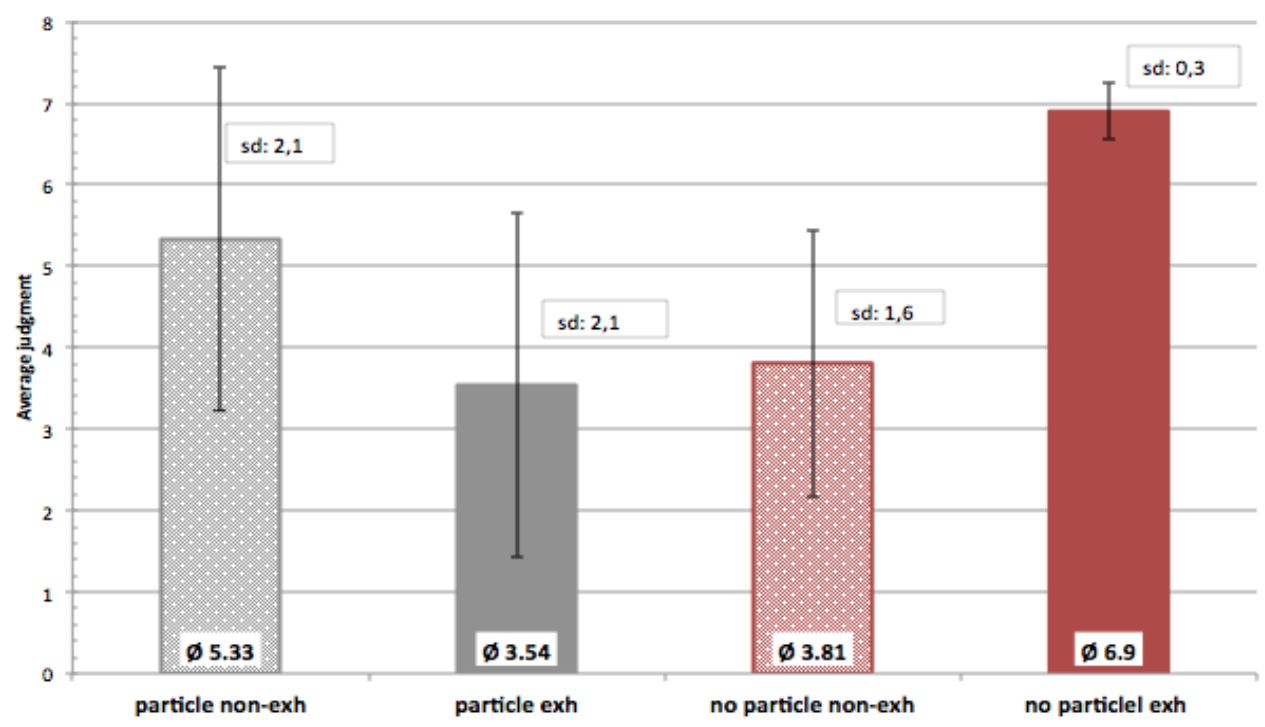

Figure 4.16: Average judgments postverbal structure

There is a significant difference between pre-verbal focus with and without particle (z-ratio $=2.904, \mathrm{p}=0.0193)$.

In the pre-verbal focus sentence with the additive particle, the ratings are higher in the non-exhaustive picture condition. In the case of the pre-verbal focus without the particle, the ratings in the exhaustive picture condition are higher. It can be concluded that the additive focus particle does have an effect on the exhaustivity judgment of the pre-verbal focus.

Overall, it is interesting that for Hungarian, the pre-verbal and post-verbal constructions trigger similar response patterns, and the difference in overall judgments lies in the existence of an additive particle in the respective constructions. 


\subsubsection{ExpC German: The Role of Context on Exhaustivity}

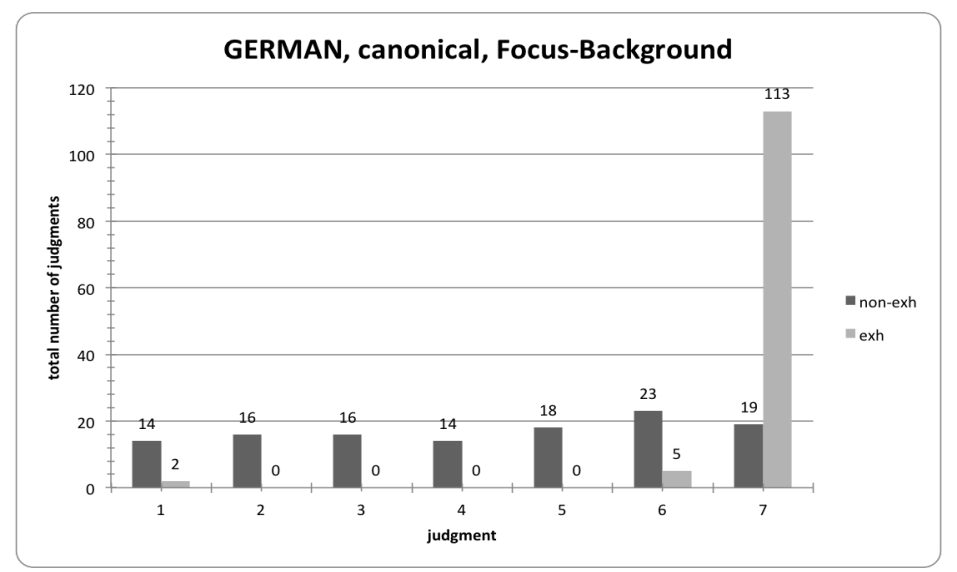

Figure 4.17: Q-A-pair: Who is wearing a cape? - The dog is wearing a cape.

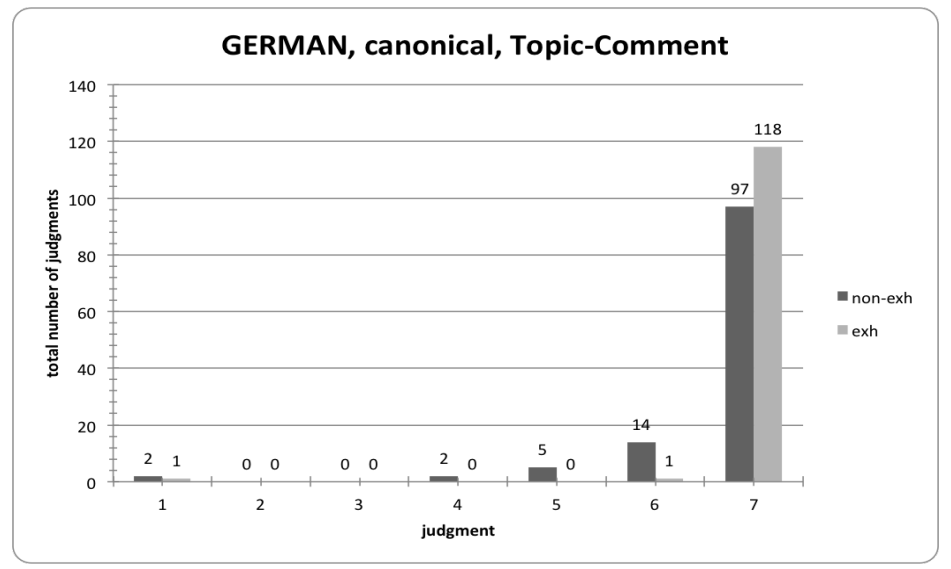

Figure 4.18: Q-A-pair: What do you know about the dog? - The dog is wearing a cape.

Statistically significant difference between the two context questions (wide vs. narrow in canonical) in the non-exh condition (z-ratio $=-11.812, \mathrm{p}<.0001)$. 


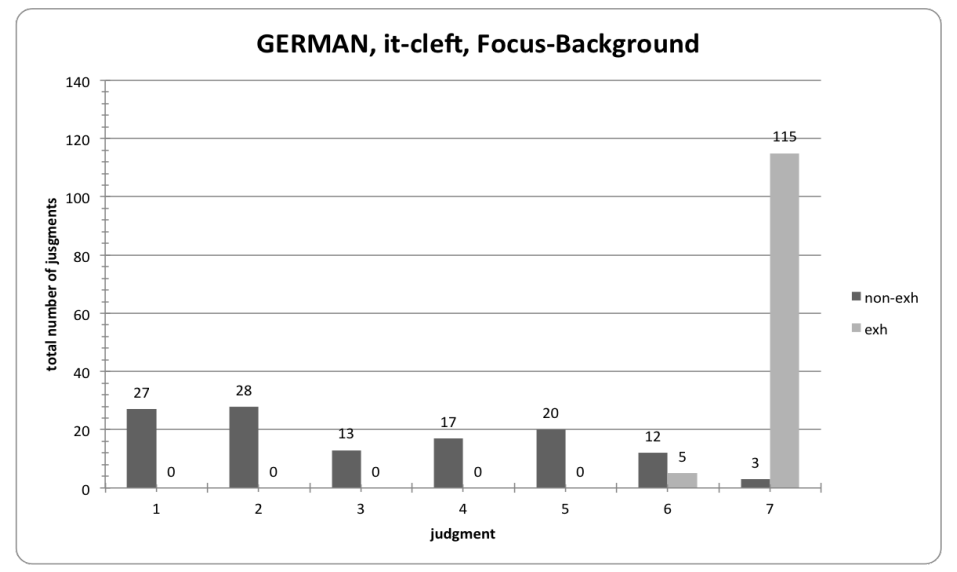

Figure 4.19: Q-A-pair: Who is wearing a cape? - It is the dog who is wearing a cape.

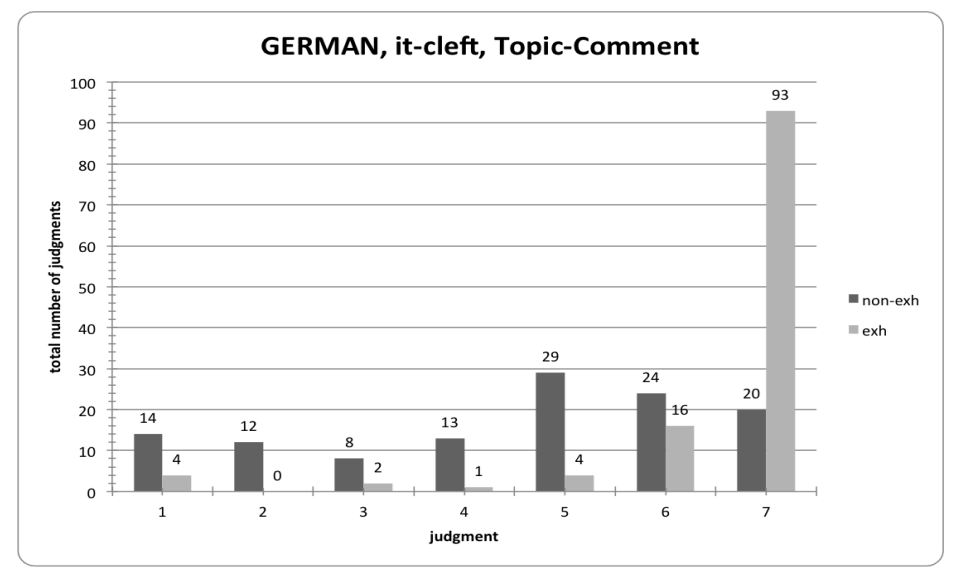

Figure 4.20: Q-A-pair: What do you know about the dog? - It is the dog who is wearing a cape. 
German: Es-cleft [narrow vs. wide focus]

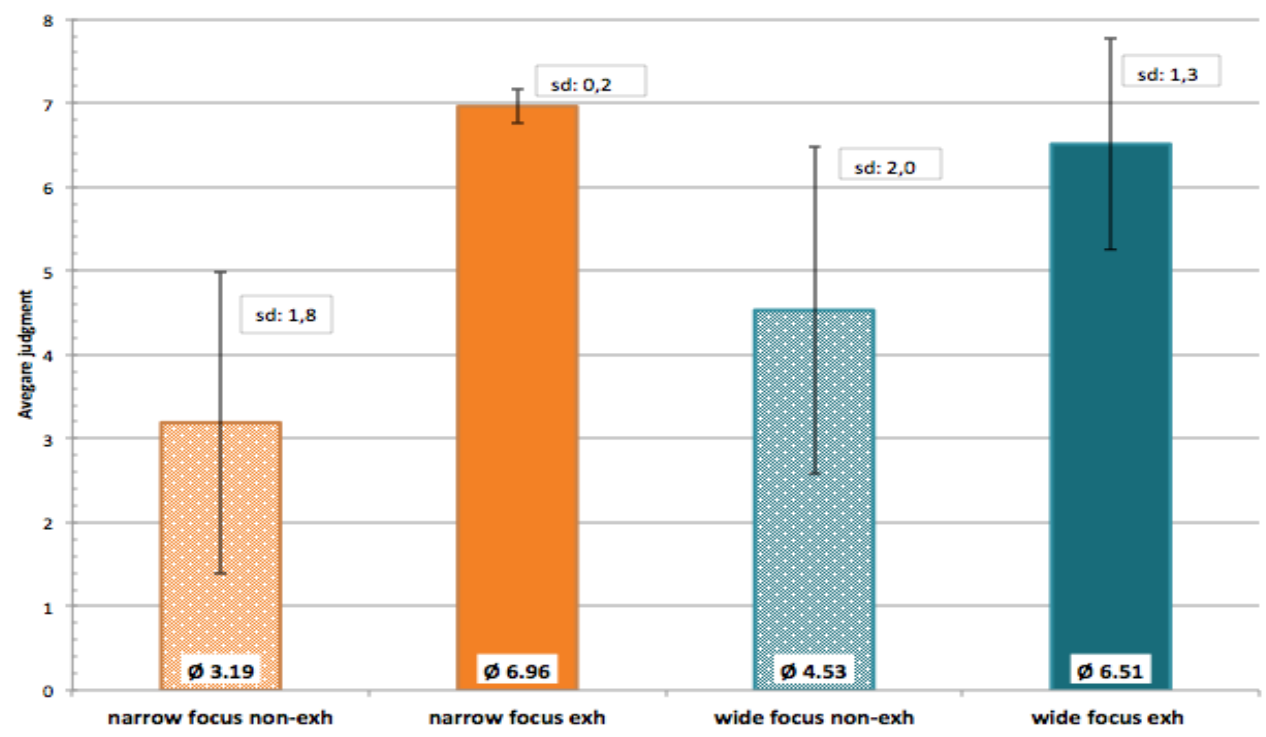

Figure 4.21: Average judgments cleft structure

German: Canonical Structure [narrow vs. wide focus]

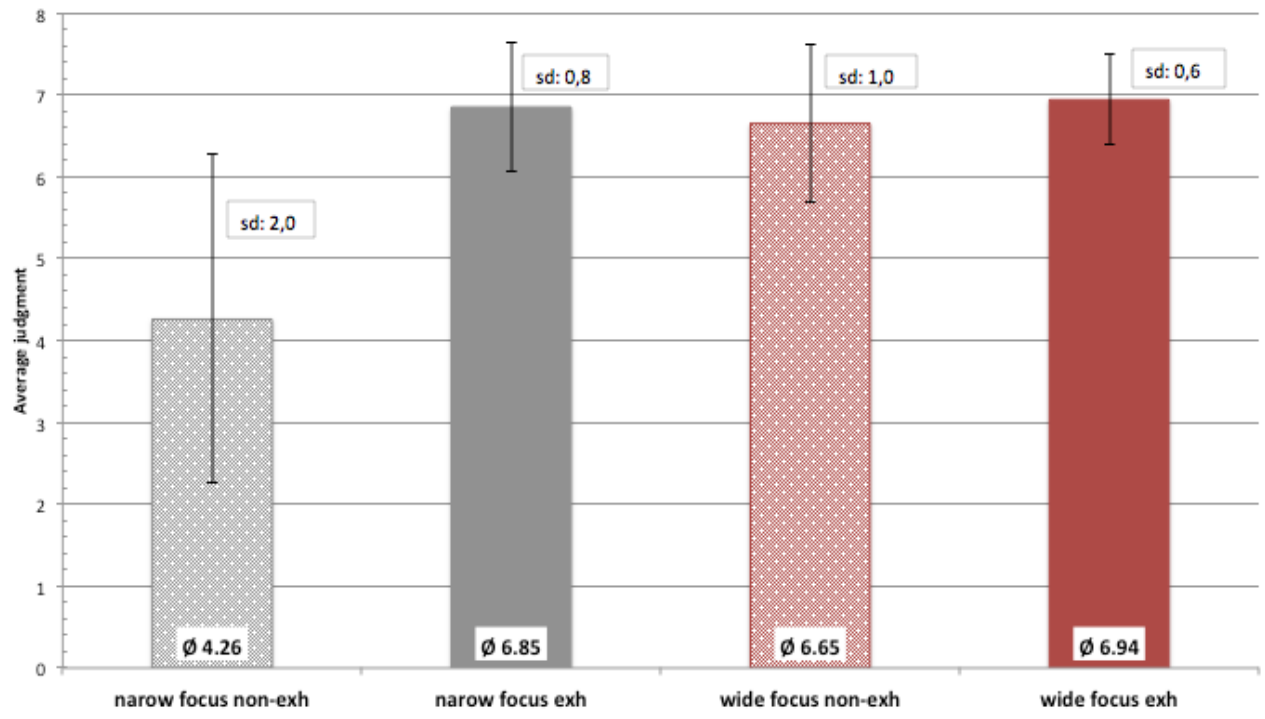

Figure 4.22: Average judgments canonical structure

German: Statistically significant difference between the two context questions 
(wide vs. narrow in clefts) in the non-exh condition (z-ratio $=-11.812, \mathrm{p}<.0001$ ). Strong interaction between factors in narrow Foc (CL - exh and CAN -exh): zratio 4.738, $\mathrm{p}<.0001$, and wide focus (CL - exh and CAN -exh): z-ratio 11.191, p $<.0001$.

The TC/wide-focus condition is rated higher when the picture is exhaustive.

These results are parallel to the behavior in the Hungarian experiment. In the $\mathrm{FB} /$ narrow-focus condition, the answers are judged higher when the picture is exhaustive.

\subsubsection{ExpP German: The Role of Focus Particles on Ex- haustivity}

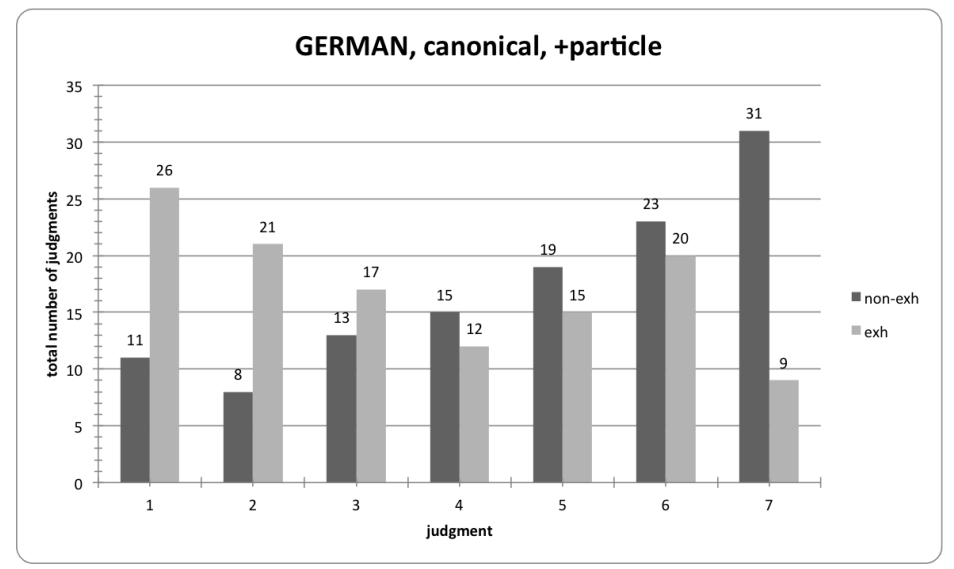

Figure 4.23: Also the dog is wearing a cape. 


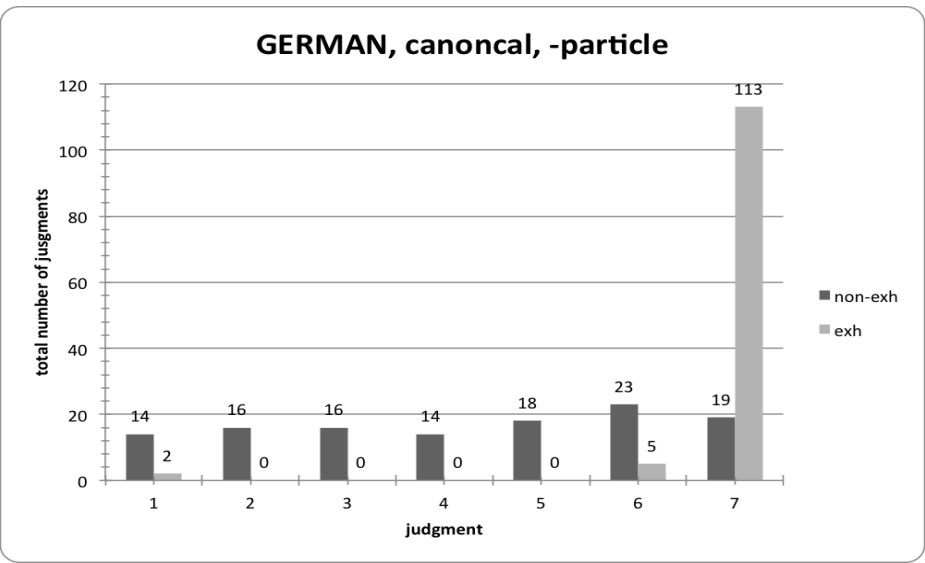

Figure 4.24: The dog is wearing a cape.

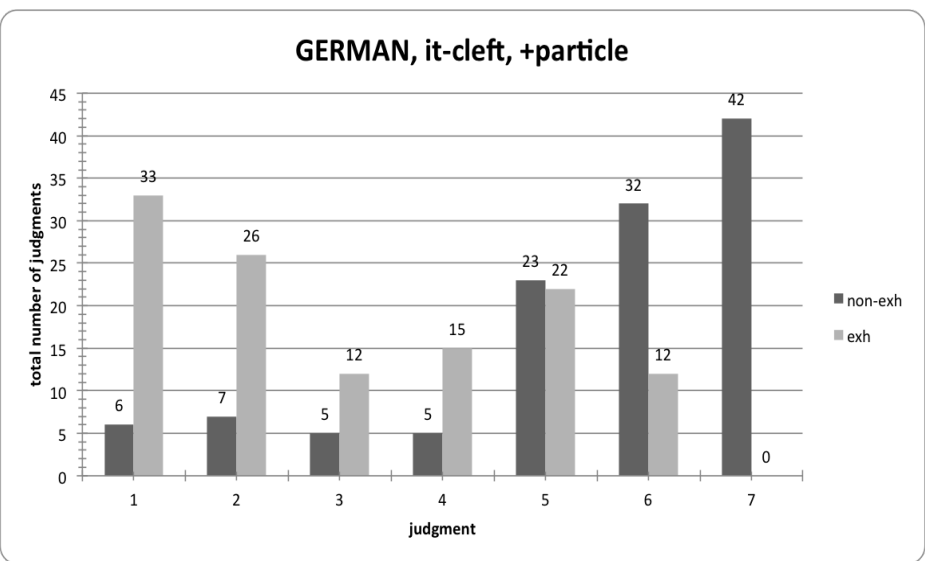

Figure 4.25: It is also the dog who is wearing a cape. 


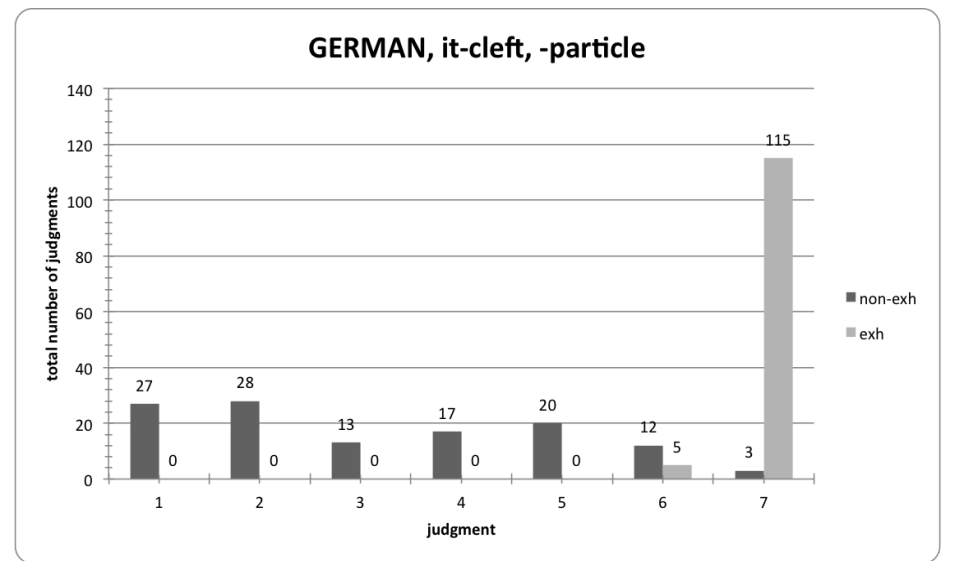

Figure 4.26: It is the dog who is wearing a cape.

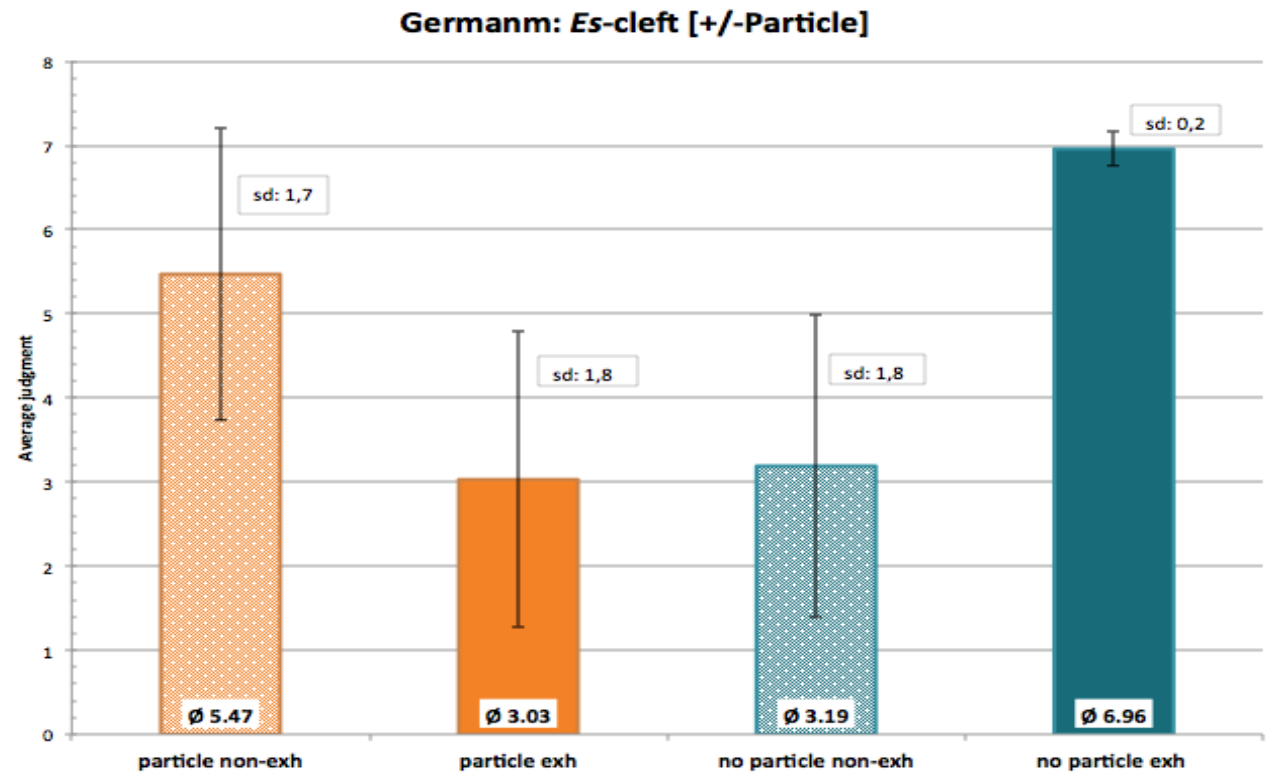

Figure 4.27: Average judgments cleft structure 


\section{German: Canonical Structure [+/- Particle]}

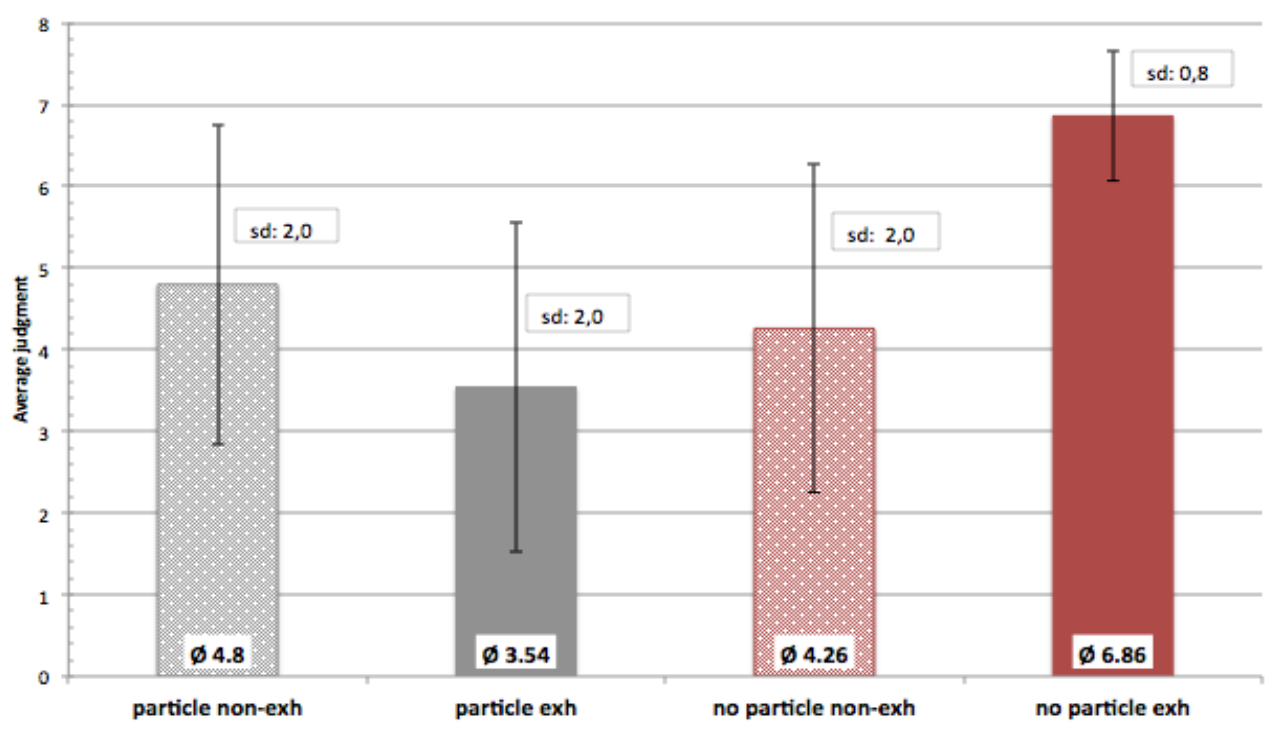

Figure 4.28: Average judgments canonical structure

In the case of it-clefts with auch, the sentences are more acceptable in the nonexhaustive condition, as we predicted. In the case of clefts without the particle, the sentences are judged higher when the picture is exhaustive. The difference between exhaustive and non-exhaustive picture in clefts with the additive particle is significant (z-ratio $=5.167, \mathrm{p}<.0001$ ). The difference between judgments of it-cleft with particle and without particle in the exhaustive condition is significant (z.ratio $=-9.709$, p-value $=<.0001)$.

It can be concluded that the particle does have an effect on the exhaustivity judgments in the German sentences, just as in the case of Hungarian pre-verbal focus.

\subsection{Discussion}

For statistical analysis, a Cumulative Link Mixed Model fitted with the Laplace approximation was used. The control condition including a picture which correctly depicted the auditively given stimulus worked in both languages, as participants judged this condition consistently highly, as depicted in the table below: 
Figure 4.29: Means (median) of judgments for control condition (Hungarian)

\begin{tabular}{|c|c|c|}
\hline & narrow focus & wide focus \\
\hline pre-verbal & $6.99(7)$ & $6.98(7)$ \\
\hline post-verbal & $6.9(7)$ & $6.98(7)$ \\
\hline
\end{tabular}

Figure 4.30: Means (median) of judgments for control condition (German)

\begin{tabular}{|c|c|c|}
\hline & narrow focus & wide focus \\
\hline pre-verbal & $6.96(7)$ & $6.5(7)$ \\
\hline post-verbal & $6.86(7)$ & $6.94(7)$ \\
\hline
\end{tabular}

\subsubsection{Hungarian}

Regarding H1 (pre-verbal focus is exhaustive in some way), we look at the results for pre-verbal focus without particle and compare the exhaustive and nonexhaustive picture condition.

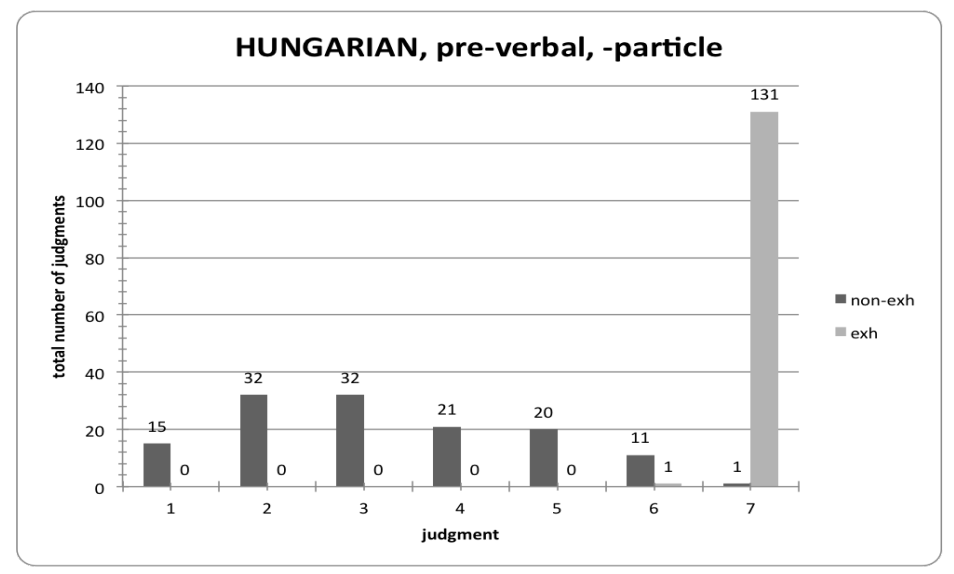

Figure 4.31: It is the dog who is wearing a cape.

Nearly $100 \%$ of cases for pre-verbal focus where the picture is exhaustive are judged with 7 . When the picture is non-exhaustive, judgments are widespread, with the majority in the $2-3$ area. From this significant result $(\mathrm{z}$-ratio $=5.673, \mathrm{p}<.0001)$ we can conclude that Hungarian pre-verbal focus is exhaustive in some way, as non-exhaustive pictures are rejected in combination with the pre-verbal focus.

Regarding H2 (Hungarian pre-verbal focus is not semantically exhaustive), we look at the pre-verbal focus condition and compare the narrow and $\mathrm{VP}$-focus conditions. 
If the patterns for both narrow and $\mathrm{VP}$-focus question types are not parallel, Hungarian pre-verbal focus is not semantically exhaustive.

As illustrated in the graph in 4.32 below, pre-verbal narrow focus is always judged 7 when the picture is exhaustive, so narrow focus is strongly exhaustive. When the picture is non-exhaustive, the narrow focus is judged low, with most judgments between 2 and 3. However, it is not necessarily exhaustive, as there are judgments of 5 and 6 as well.

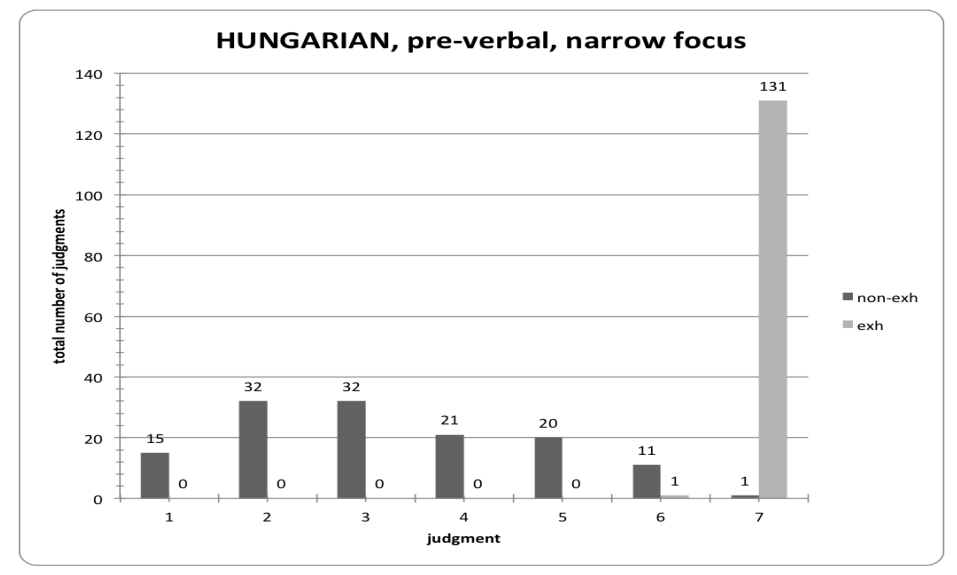

Figure 4.32: Q-A-pair: Who is wearing a cape? - It is the dog who is wearing a cape.

As illustrated in the graph in 4.33, pre-verbal VP-focus is nearly always judged 7 when the picture is exhaustive, so $\mathrm{VP}$-focus is also strongly exhaustive. In the non-exhaustive picture condition however, most judgments are 6 and 7 ; the least judgments are in the 1-3 range. A pre-verbal focus as a direct answer to a $\mathrm{VP}$-focus question, therefore, is not necessarily exhaustive. 


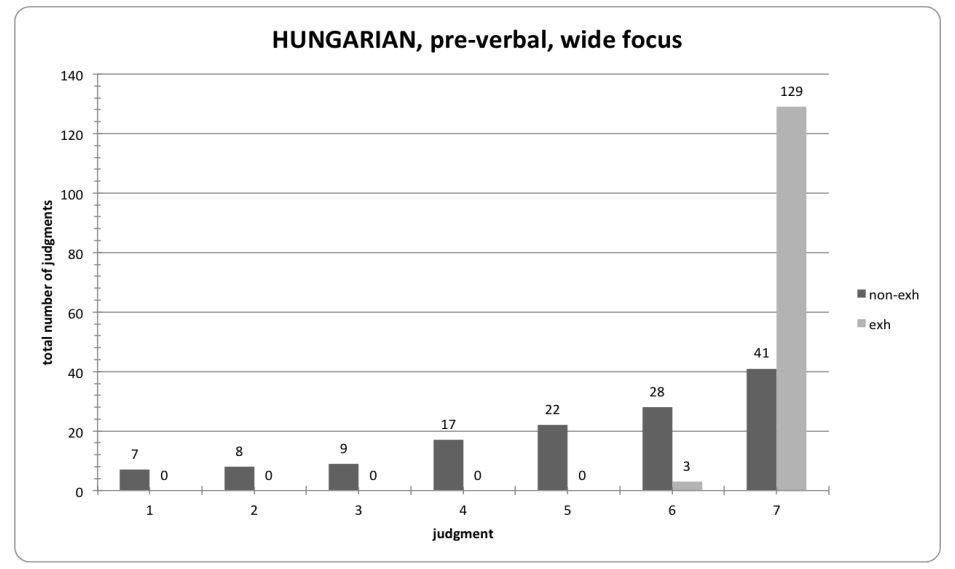

Figure 4.33: Q-A-pair: What do you know about the dog? - It is the dog who is wearing a cape.

These results (significant: $\mathrm{z}$-ratio $=-8.811, \mathrm{p}<.0001$ ) suggest that in Hungarian, pre-verbal focus constructions can be used in more contexts than previously assumed by the literature. As answers to questions that suggest a VP-focus, preverbal focus is accepted in exhaustive as well as non-exhaustive scenarios, while this is not the case in narrow focus question environments. When assumed to be answering a narrow focus question, speakers reject pre-verbal focus in nonexhaustive situations, while in situations when the pre-verbal focus is assumed to answer a VP-focus questions, it is accepted in non-exhaustive contexts.

A non-focused answer to an overt wh-question is generally assumed to be nonexhaustive (see e.g. É. Kiss (2016)). Our results show that, when the new information is not in the pivot of the cleft/ in the focus position (What do you know about the dog? - It is [the dog] $]_{G I V E N}$ [who is wearing a cape. $]_{N E W}$ ) the sentence is accepted in the non-exhaustive picture environment. It is still judged higher when exhaustive, although it does not have to be exhaustive to be judged as acceptable. Therefore, just like non-focused answers to wh-questions, a focused answer to an overt wh-question is also not exhaustive, as it is accepted in a non-exhaustive picture environment.

As the patterns for both narrow and semi-narrow/wide question types are not parallel, it can be said that Hungarian pre-verbal focus is not semantically exhaustive. These results support Onea and Beaver (2009), as they propose that pre-verbal focus in Hungarian is used to answer wh-questions. Regarding Q-implicatures (see Gerócs et al. (2014)), the results presented above suggest that two kinds of question types provide contexts in which preV focus are felicitous answers. Gerôcs et al. (2014) observe that differences in exhaustivity rates of pre-verbal focus could 
be due to the presence or absence of overt wh-questions. The data elicited in the present experiment suggest that the issue might not (only) be whether or not there are overt wh-questions in the context, but what kind of focus domain the respective questions address: In VP-focus, exhaustivity is weak (preV focus is not rejected in non-exh condition), while it is very string on narrow-focus (preV focus is rejected in non-exh condition).

Regarding H3 (When combined with a focus particle, participants are expected to judge the sentence better (above 5 on a 7 -point scale) in the non-exhaustive picture condition than in the exhaustive picture condition), we look at the preverbal condition and compare the judgments with and without the particle. If the judgments for the same conditions ( $+/$-exh pictures) are different for sentences with and without additive particles, it can be concluded that the particles have an effect on the exhaustivity of the sentences.

As illustrated in the graph in 4.34 for Hungarian, when a pre-verbal focus is combined with the additive particle többek között/among others, in combination with the exhaustive picture, judgments are widespread (ranging from 1-6), with the majority in the 1-2 range. This means that speakers reject pre-verbal focus with an additive in an exhaustive picture environment. Hence the focus particle makes the sentence non-exhaustive. In the non-exhaustive picture condition, the majority of judgments is 7 , so this combination is highly acceptable.

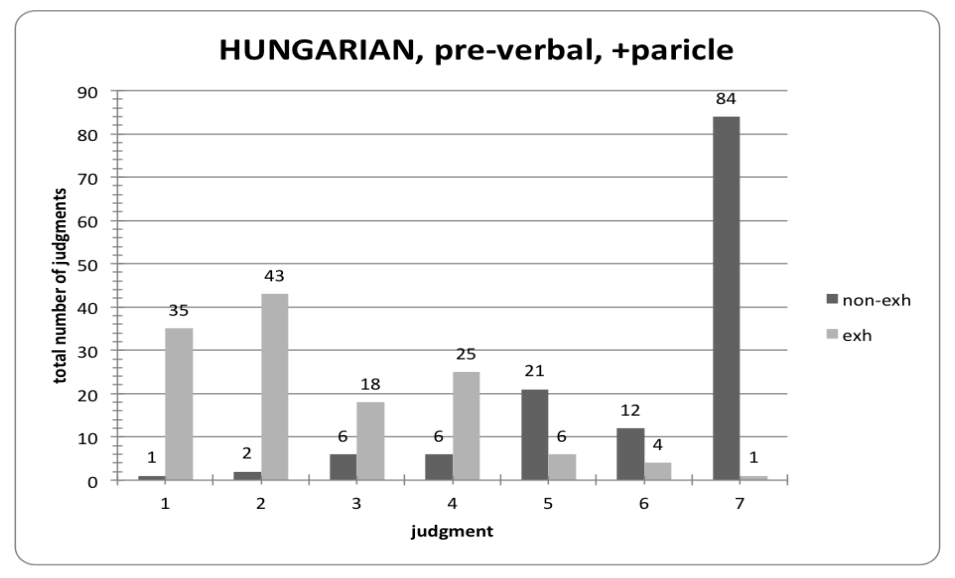

Figure 4.34: It is also the dog who is wearing a cape. 


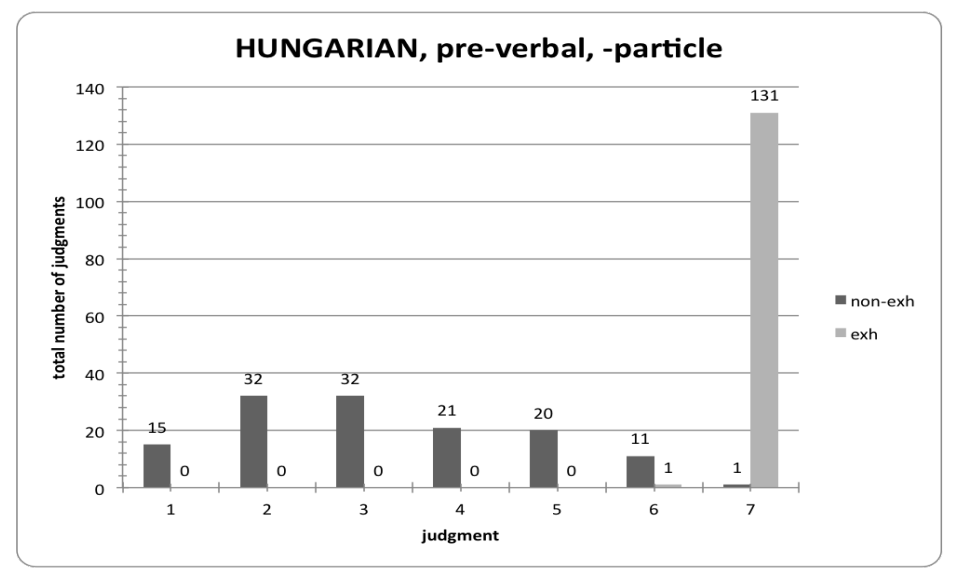

Figure 4.35: It is the dog who is wearing a cape.

As illustrated in the graph in 4.35 for Hungarian, in the pre-verbal condition without the focus particle, all sentences in the exhaustive picture condition are judged 7 , so pre-verbal focus is always accepted in an exhaustive environment. In the non-exhaustive picture condition, it is rather rejected, with the majority of judgments being between 2 and 3 .

Therefore, it can be concluded that the particle does have an effect on the exhaustivity of the pre-verbal focus (significant difference between pre-verbal focus with and without particle $\mathrm{z}$-ratio $=2.904, \mathrm{p}=0.0193)$.

These results support É. Kiss (2016) in stating that the additive particle többek között/among others is combinable with pre-verbal focus under an alternative analysis.

\subsubsection{German}

Regarding H1 (it-clefts are exhaustive in some way) we look at the results for it-clefts without particle and compare the exhaustive and non-exhaustive picture condition without any particle. As illustrated in Fig. 5.20 for German, the vast majority of it-clefts with an exhaustive picture are judged 7 , and some 6 . When the picture is non-exhaustive, judgments are widespread, with the majority being 1 and 2. From these significant results $(\mathrm{z}$-ratio $=5.167, \mathrm{p}<.0001)$ we can conclude that German it-clefts are exhaustive in some way, as non-exhaustive pictures are rejected in combination with it-clefts.

Regarding H2 (German it-clefts are not semantically exhaustive), we look at the cleft condition and compare the FB and TC-focus condition. 


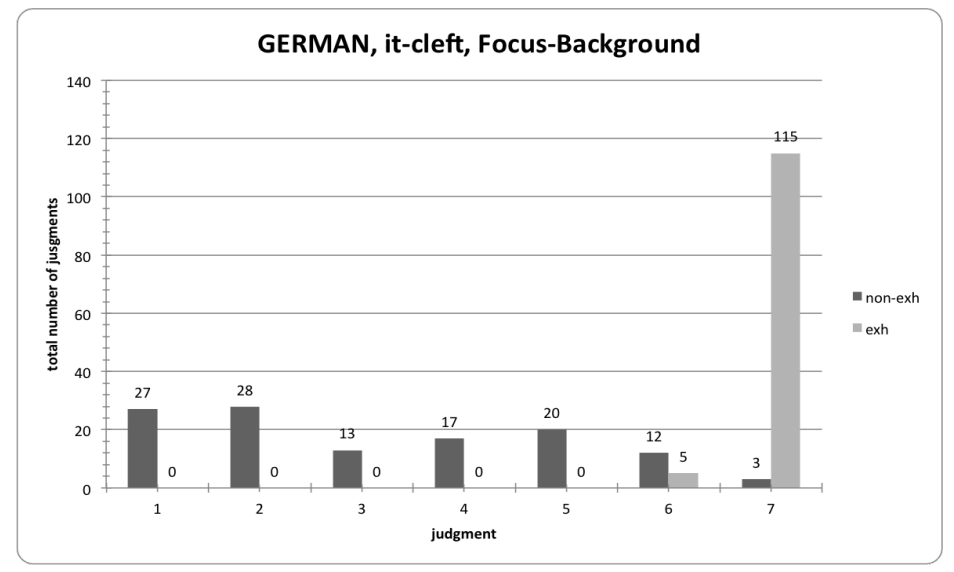

Figure 4.36: Q-A-pair: Who is wearing a cape? - It is the dog who is wearing a cape.

As illustrated in the graph in 4.36 above, FB-clefts are almost always judged exhaustive in the exhaustive picture condition (most judgments 7 , some 6). In the non-exhaustive picture condition, the judgments are widespread, with the majority very low (1-3). The difference between exhaustive and non-exhaustive picture condition in the FB-condition is significant $(\mathrm{z}$-ratio $=-11.584, \mathrm{p}<.0001$ )

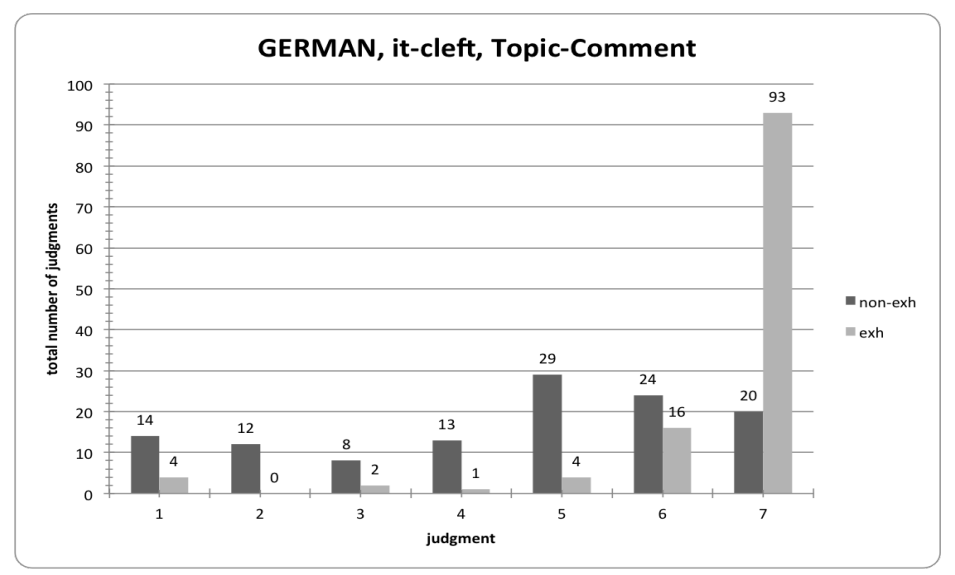

Figure 4.37: Q-A-pair: What do you know about the dog? - It is the dog who is wearing a cape.

As illustrated in the graph in 4.37, in the exhaustive picture condition for TCclefts, judgments are spread between 5 and 7, with most judgments on 7. TCclefts seem to be a little less exhaustive than FB-clefts, as in the non-exhaustive 
picture condition, the judgments are also rather high (5-7). (There are some 1 judgments in the exhaustive picture condition, however, these might be outliers.) These results are significant ( $\mathrm{z}$-ratio $=-3.799, \mathrm{p}=0.0008$ ).

In the non-exhaustive condition, the difference in judgments between FB and TCquestions is significant ( $\mathrm{z}$-ratio $=-11.812, \mathrm{p}<.0001$ ). In the exhaustive condition, the difference in judgments between FB and TC-questions is also significant when applying a $\mathrm{P}$ value adjustment using the Tukey method for comparing a family of 4 estimates $(\mathrm{z}$-ratio $=4.286, \mathrm{p}=0.0001)$.

As the patterns for both FB and TC-question types are not parallel, German itclefts are not semantically exhaustive.

Regarding H3 (When combined with a focus particle, participants are expected to judge the sentence better (above 5 on a 7 -point scale) in the non-exhaustive picture condition than in the exhaustive picture condition), we look at the cleft condition and compare the judgments with and without the particle. If the judgments for the same conditions ( $+/$-exh pictures) are different for sentences with and without additive particles, it can be concluded that the particles have an effect on the exhaustivity of the sentences.

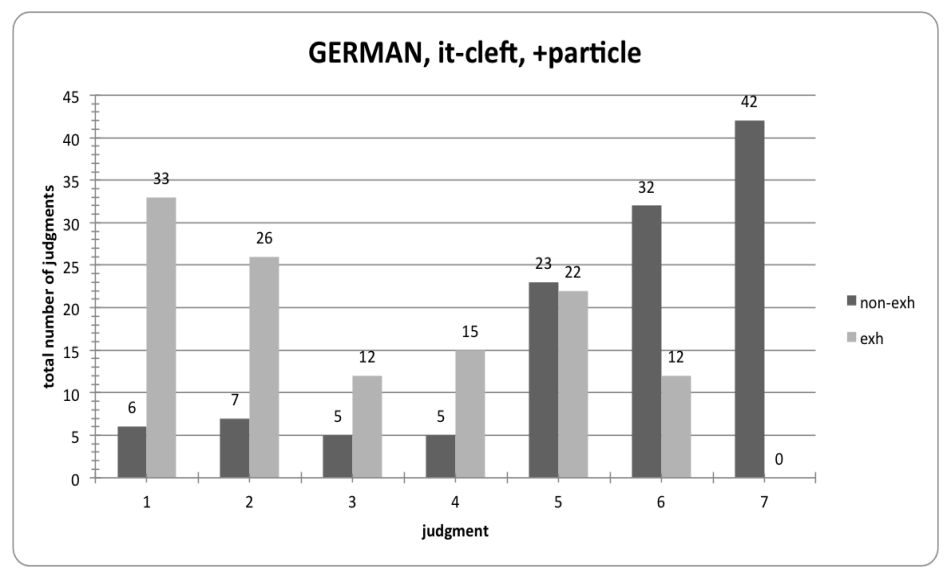

Figure 4.38: It is also the dog who is wearing a cape.

As illustrated in 4.38, a cleft in combination with the additive particle auch/also in the exhaustive picture condition is judged very widespread, with a lot of judgments between 1 and 2, but a fair amount also between 4 and 5 . Speakers seem to be rather undecided as to how to interpret cleft sentences with an additive particle. The structure seems to be not perfect, since there are no 7 judgments, but also not completely rejected, as in the case of Hungarian. In combination with 
a non-exhaustive picture, ratings are higher (mostly 6 and 7 ), so this combination is highly acceptable. The difference between exhaustive and non-exhaustive picture in clefts with the additive particle is significant (z-ratio $=5.167, \mathrm{p}<.0001)$.

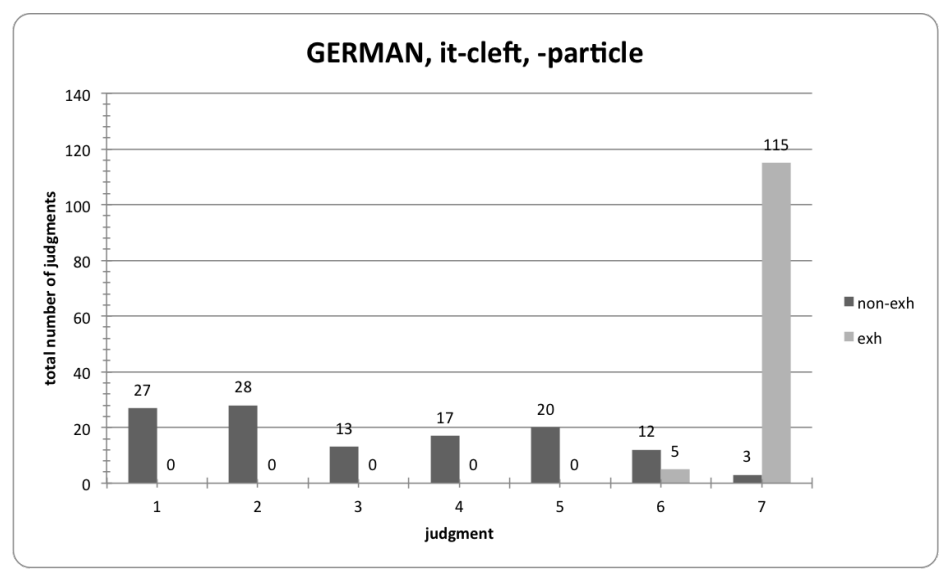

Figure 4.39: It is the dog who is wearing a cape.

As illustrated in 4.39 for German, when the it-cleft is combined with the exhaustive picture, judgments are high ( 6 and 7 , with a clear majority on 7 ), and rather widespread in the lower numbers (majority 1-2) in the non-exhaustive picture condition. The difference between the exhaustive and non-exhaustive picture condition in it-clefts without any particle is significant (z-ratio $=-8.638, \mathrm{p}<.0001$ ). The difference between judgments of it-cleft with particle and without particle in the exhaustive condition is significant (z.ratio $=-9.709$, p-value $=<.0001$ ). The difference between judgments of it-clefts with particle and without particle in the non-exhaustive condition is significant when applying a $\mathrm{P}$ value adjustment using the Tukey method for comparing a family of 4 estimates $(\mathrm{z}$-ratio $=4.773, \mathrm{p}$ $<.0001)$.

It can be concluded that, in the case of German it-clefts, the insertion of an additive focus particle does have an effect on the exhaustivity inference that can come with the cleft structure.

We can conclude that the exhaustivity inference in Hungarian pe-verbal focus and it-clefts is not part of the truth conditions, as previously concluded by other experimental studies (e.g. Drenhaus et al. (2011)).

Therefore, these results support those studies who have argued in favor of a pragmatic account of Hungarian pre-verbal focus and it-cleft exhaustivity.

It can also be observed in the data that the judgments in both Hungarian and Ger- 
man are high in both the $\mathrm{FB}$ /narrow-focus and $\mathrm{TC}$ /wide-focus conditions. Onea and Beaver (2009) and Onea (2009b) argue that the immediately pre-verbal position in Hungarian grammatically marks a question-answering constituent. The present study shows that speakers judge both focus constructions highly as answers to two different kinds of overt wh-questions. Our results thereby support those studies in which these constructions have been described as question-answering constructions, and disputing the view that clefts are not good answers to overt wh-questions (e.g. Destruel and Velleman (2014)).

\subsubsection{Acceptability Study of German Items}

For the case of English, it has been pointed out that TC-clefts have the intonational stress on the cleft relative. If that was also the case for German, this would pose a slight constraint on the experimental design presented in this chapter, as it would make TC-answers to FB-questions unacceptable. This would mean that some of the stimuli used in the German experiment are in themselves not acceptable sentences of German, which could shed out the results. To this point, there has not yet been conclusive experimental evidence that the intonation patterns that are described for English also hold for the case of German. On the contrary, the default stress pattern for German es-clefts has the main stress on the cleft pivot, while leaving the cleft relative unaccented. To ensure the validity of the data, an acceptability study was conducted, which tested whether TC-clefts are acceptable as answers to overt questions which target a focus structure as their answer.

\subsubsection{Predictions}

- Hypothesis 1: The default intonation pattern for German it-clefts places the pitch accent on the cleft pivot. This holds for both FB and TC-clefts. We assume this mainly because there has not yet been conclusive experimental evidence that the intonation patterns that are described for English also hold for the case of German. When asked if they had any comments after finishing their trial of the experiment, none of the participants commented on any strange or grammatically non-matching combinations of question-answer pairs.

- Hypothesis 2: If there are differences in the intonation patterns for FB and TC-clefts, speakers will not accept TC-clefts as direct answers to overt questions that require a focus in their answer.

- Hypothesis 3: If there is only one default intonation, speakers will not reject TC-clefts as direct answers to overt questions that require a focus in their 
answer.

\subsubsection{Method and Design}

A total of 23 participants with an average age of 27 took part in this online study, which was conducted using the free online tool OnExp ${ }^{10}$. Participants were acquired using various online platforms.

The participants were first presented with a background story in written form very similar to the one used in the main experiment, introducing a costume party on a farm, to which one guest could not attend. This guest would still like to know what costumes the other guests are wearing, so he keeps calling his friend who is attending the party, inquiring about the other guests. This background motivates the telephone conversations that the audio-input of the experiment consists of.

32 target items and 16 fillers were used, which were pseudo-randomized across and randomized within their groups. To make sure to test all items used in the original experiment, the targets were distributed across two lists.

Participants could go forward through the audio-items in a self-paced manner. Each audio-item consists of a short dialog of one question and one answer. The questions and answers were recorded using two different speakers (one male, one female), to ensure the naturalness of the created dialog situation as well as consistency within the experiment.

Participants were asked to decide whether each individual dialog was an example of a natural piece of conversation in German, using a binary scale of yes or no buttons in their browser. They had the option of re-playing each dialog before making their decision.

To make sure that participants would use both ends of the binary scale, the fillers included a number of unnatural dialogs, in which the answer did not match the question.

To ensure that participants could actually hear the audio-stimulus properly, a test sentence was given to them before the start of the experiment, which they had to type into a text field in the browser.

\subsubsection{Results}

Since all items from the original design were to be tested for acceptability, both es-clefts with and without focus particles are used.

The average distribution of acceptable and non-acceptable ratings across all possible question-answer-combinations are presented in the table below:

\footnotetext{
${ }^{10}$ https://onexp.textstrukturen.uni-goettingen.de/.
} 
Figure 4.40: Average ratings over all conditions

\begin{tabular}{|c|c|c|}
\hline & acceptable & not acceptable \\
\hline question FB, answer FB & $57 \%$ & $43 \%$ \\
\hline question FB, answer TC & $57 \%$ & $43 \%$ \\
\hline question TC, answer FB & $32 \%$ & $68 \%$ \\
\hline question TC, answer TC & $57 \%$ & $43 \%$ \\
\hline \hline question FB, answer FB+particle & $36 \%$ & $64 \%$ \\
\hline question FB, answer TC + particle & $27 \%$ & $73 \%$ \\
\hline question TC, answer FB + particle & $36 \%$ & $64 \%$ \\
\hline question TC, answer TC + particle & $39 \%$ & $61 \%$ \\
\hline
\end{tabular}

The following examples each list one of the items that were used in the experiment for each condition.

\section{question FB, answer FB}

Wer trägt einen Umhang? Es ist DER HUND, der einen Umhang trägt. Who is wearing a cape? It is THE DOG who is wearing a cape.

\section{question FB, answer TC}

Wer trägt einen Umhang? Es ist der Hund, der EINEM UMHANG TRÄGT.

Who is wearing a cape? It is the dog who IS WEARING A CAPE.

The two question-answer pairs in the examples (289) and (290) above are of main interest in this experiment. The objective of this experiment is to determine whether TC-clefts are acceptable as answers to overt questions which target a focus structure as their answer. If this is the case, the two question-answer-pairs in (289) and (290) should receive similar judgments.

(291) question TC, answer FB

Was weißt du über den Hund? Es ist DER HUND, der einen Umhang trägt.

What do you know about the dog? It is THE DOG who is wearing a cape.

question TC, answer TC

Was weißt du über den Hund? Es ist der Hund, der EINEM UMHANG TRÄGT.

What do you know about the dog? It is the dog who IS WEARING A CAPE.

$$
\text { question FB, answer FB + particle }
$$


Wer trägt einen Umhang? Es ist auch DER HUND, der einen Umhang trägt.

Who is wearing a cape? It is also THE DOG who is wearing a cape.

(294)

question FB, answer TC + particle

Wer trägt einen Umhang? Es ist auch der Hund, der EINEM UMHANG TRÄGT.

Who is wearing a cape? It is also the dog who IS WEARING A CAPE.

(295) question TC, answer FB + particle

Was weißt du über den Hund? Es ist auch DER HUND, der einen Umhang trägt.

What do you know about the dog? It is also THE DOG who is wearing a cape.

question TC, answer TC + particle

Was weißt du über den Hund? Es ist auch der Hund, der EINEM UMHANG TRÄGT.

What do you know about the dog? It is also the dog who IS WEARING A CAPE.

The first two conditions are of main interest here, as the question to answer with this acceptability study is whether a TC-structure is a felicitous answer to a overt FB-question. When looking at the conditions of FB-question with FB-answer and FB-question with TC-answer, we can see that they received identical ratings. This is further illustrated in the graph below:

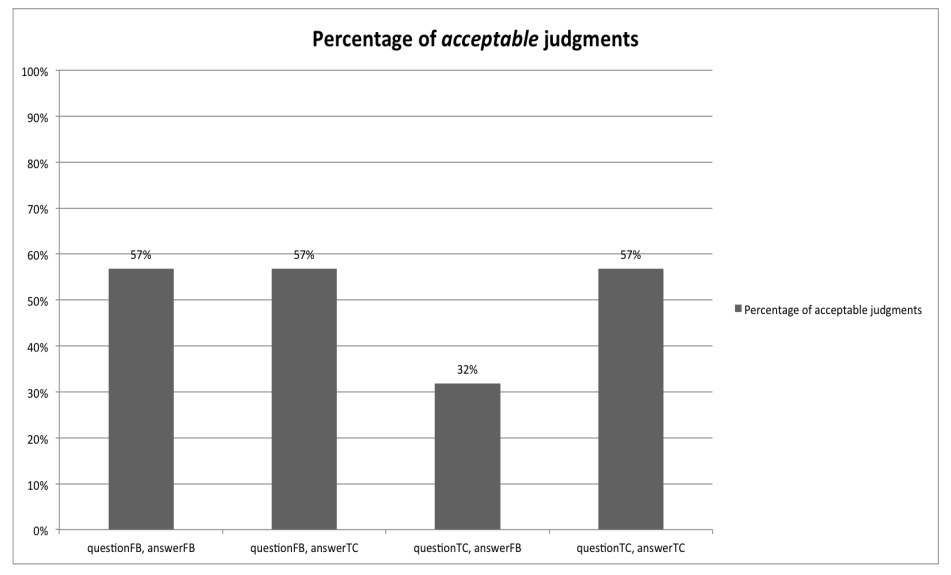

Figure 4.41: Average acceptability across conditions.

In a two-tailed analysis, the difference between the two conditions is not significant $(\mathrm{t}=0, \mathrm{p}=1)$. 
When looking at the counterpart of TC-questions, the acceptability ratings look fairly different, as can also be seen in the graph above. These question-answercombinations do not seem to be equally acceptable to speakers. Here, we can observe an effect $(\mathrm{t}=-2.4111, \mathrm{p}=.018033$. The result is significant.).

The next pair of conditions to look at is the combination of the two different questions types with TC-answers. Again, as in the case of FB-questions, the acceptability is distributed evenly across the two conditions, leading to no significant effect $(\mathrm{t}=0, \mathrm{p}=1)$.

When taking a look at the two question types with FB answers, we can observe a different behavior. Here, we can see an effect $(\mathrm{t}=2.4111, \mathrm{p}=.018033$. The result is significant.), and observe another hint pointing to the conclusion that FB-questions are acceptable with both kinds of answers, while this is not the case for TC-questions, which are not acceptable with FB-answers.

Since the original experiment did include items with focus particles, which might also have an effect on acceptability, those items should also be evaluated for acceptability to determine whether the focus particles in the answers might affect the acceptability of the question-answer-pairs. The results are illustrated in the following graph: 


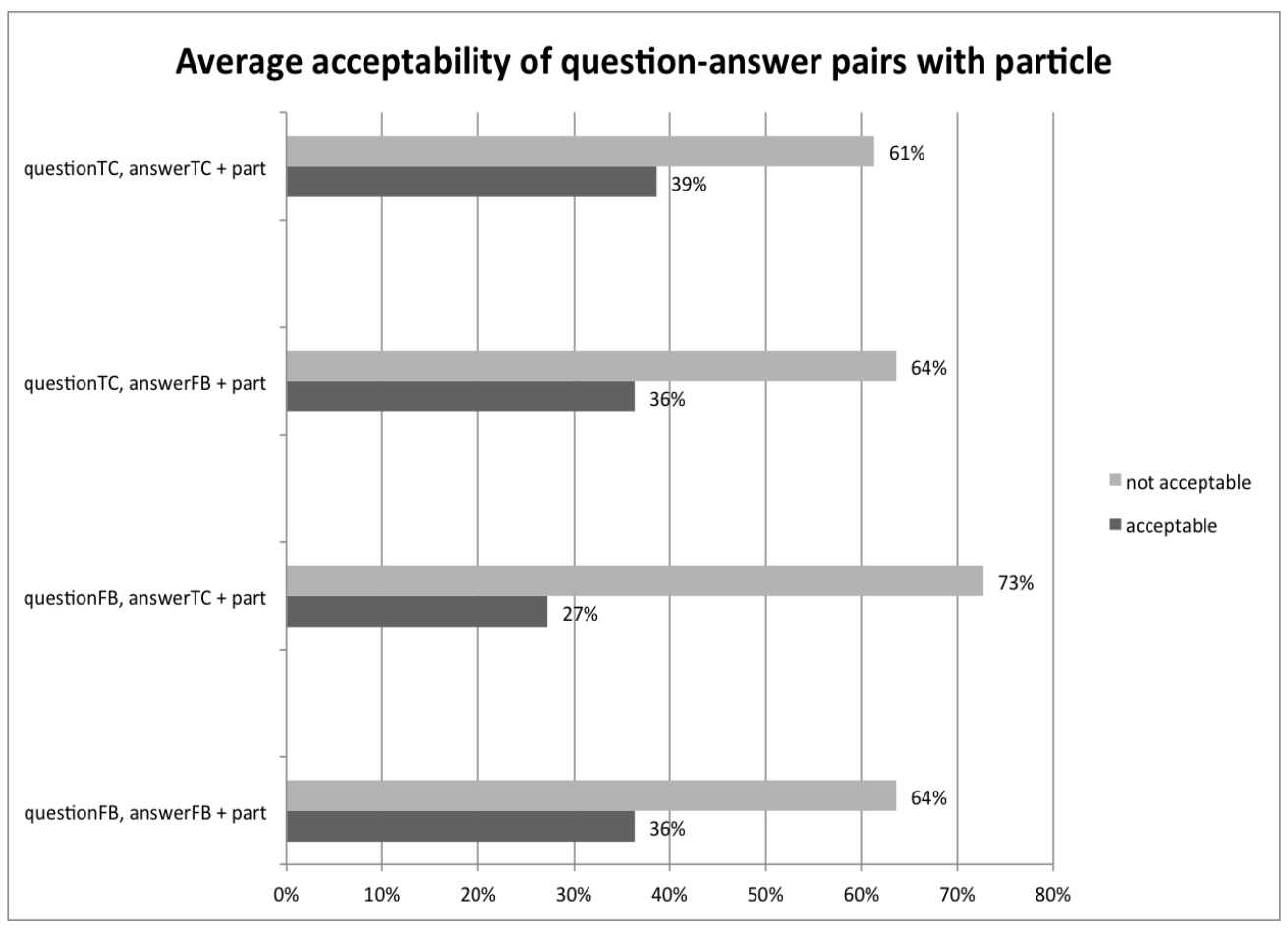

Figure 4.42: Average acceptability of question-answer-pairs with both answer types including also

Here again, we need to consider the comparison of the following conditions: FBquestion and $\mathrm{FB}+$ particle-answer vs. FB-question and $\mathrm{TC}+$ particle-answer $(\mathrm{t}=$ $0.90935, \mathrm{p}=.365705$. The result is not significant.), as well as TC-question and $\mathrm{FB}+$ particle-answer vs. TC-question and $\mathrm{TC}+$ particle-answer $(\mathrm{t}=-0.21774, \mathrm{p}=$ .82815. The result is not significant.) There is no effect observable with answers that include a particle.

\subsubsection{Discussion}

The results of this acceptability study show that the material that is provided in the original design is acceptable and the data are valid based on the input material. A question-answer-pair in German in which the question targets a focus and the answer provides that focus is just as acceptable as a question-answer-pair in which the question targets a focus while the answer provides a different stress pattern (hypothesis 1 and 3 are supported). The two question-answer-pairs below illustrate the two different cases:

$$
\text { A: Wer trägt einen Umhang? (FB) }
$$


B: Es ist DER HUND, der einen Umhang trägt. (FB)

A: Who is wearing a cape? - B: It is THE DOG that is wearing a cape.

A: Wer trägt einen Umhang? (FB)

B: Es ist der Hund, der EINEM UMHANG TRÄGT. (TC)

$A$ : Who is wearing a cape? - B: It is the dog that IS WEARING A $C A P E$.

In addition to validating the input material used in the original design, this acceptability study allows further conclusions. As these findings are parallel but not directly combinable with the results of the original design, we will use a different terminology to keep the results distinct. It can be concluded that the intonational pattern in German es-clefts is not what marks them as FB or TC-clefts, respectively, but the (overt or accommodated) QUD (cf. Roberts (1996)) preceding the utterance. We will call these clefts QUD-clefts.

When looking at the ratings for the question-answer-pairs with TC-questions, it can be seen that speakers do not accept them equally.

A: Was weißt du über den Hund? (TC)

B: Es ist DER HUND, der einen Umhang trägt. (FB)

A: What do you know about the dog? - B: It is THE DOG that is wearing a cape.

(300) A: Was weißt du über den Hund? (TC)

B: Es ist der Hund, der EINEM UMHANG TRÄGT. (TC)

A. What do you know about the dog? - B: It is the dog that IS WEARING A CAPE.

This is not surprising, as the TC-question structure makes a focus on the cleft pivot in the answer redundant.

These observations are strengthened by comparing the respective acceptability of the two different answer types with the two question types that are illustrated above.

Since we cannot observe an effect with answers that include the focus particle also either, it is save to assume that the entirety of the input material is valid for German, and that German es-clefts do not have the same intonational patterns as English it-clefts (hypothesis 1). 


\subsection{Conclusion}

The experimental data presented in this chapter contribute to the empirical evidence that supports a pragmatic approach to the exhaustivity inference in Hungarian pre-verbal focus and it-clefts. This thesis does not provide a detailed formal analysis of the exhaustivity, however, the approaches presented by Horn (1981), Horn (2014), or Onea and Beaver (2009) seem to best fit the results presented in this thesis.

The results show that in both pre-verbal and post-verbal focus, sentences are judged higher when preceded by a wide-focus question. Post-verbal and preverbal focus behave similarly, which means that the kind of question (narrow/wide) has more influence on the exhaustivity than the syntactical construction (preverbal/post-verbal focus). As an answer to questions with VP-focus, pre-verbal focus is accepted in $[+$ exh] as well as [-exh] scenarios, while this is not the case with narrow focus. When assumed to be answering a narrow focus question, speakers reject preV focus in [-exh] contexts, while it is accepted when it answers a widefocus questions.

A non-focused answer to an overt wh-question is generally assumed to be nonexhaustive (see e.g. É. Kiss 2016). The results presented in this chapter show that, when the new information is not focused, (What do you know about the dog? - It is [the dog $]_{G I V E N}$ [who is wearing a cape. $]_{N E W}$ ) pre-verbal focus is accepted in [-exh] contexts. Therefore, just like non-focused answers to wh-questions, a focused answer to an overt wh-question is also not exhaustive, as it is accepted in [-exh] picture environments. As the patterns for both questions are not parallel, the results suggest that Hungarian pre-verbal focus is not semantically exhaustive.

The data suggest that pre-verbal focus is not at-issue exhaustive. Therefore, the exhaustivity inference is not semantic. Additionally, we show that the insertion of an additive particle leads to higher ratings in non-exhaustive environments, which experimentally supports the theoretical assumptions by É. Kiss (2016) and Kenesei (1986).

Regarding the issue of Q-implicatures, the experiment suggests that two different kinds of question types provide contexts in which pre-verbal foci are felicitous answers to these overt questions. There are, however, differences when it comes to the exhaustivity inference. In FB/narrow-focus environments, pre-verbal focus is rejected in non-exhaustive contexts, while in $\mathrm{TC} /$ wide-focus environments, this is not the case. Gerôcs et al. (2014) observed that differences in exhaustivity rates of pre-verbal focus they found in their two experiments could be due to the presence or absence of overt wh-questions in the preceding context. Our data suggest that the issue might not only be whether or not there are overt wh-questions in the immediate context, but also (and very strongly so) what kind of focus domain the 
respective questions address: In VP-focus, exhaustivity is weak, while it is very string on narrow-focus.

For the case of German it-clefts, the results presented in this chapter show that it-clefts are exhaustive in some way, because non-exhaustive pictures are rejected in combination with it-clefts. However, German it-clefts are not semantically exhaustive, as the exhaustivity judgments for the two cleft types are not parallel. Speakers judge FB-clefts as strongly exhaustive, while this is not the case for TCclefts. The insertion of the additive focus particle auch/also does have an effect on the exhaustivity inference that can come with the cleft structure.

Additionally, it was shown that there is one default intonation pattern for German it-clefts, which puts the nuclear stress on the cleft pivot. This intonation is then acceptable as a direct answer to overt questions that require a focus or a topic structure as their answer.

In this way, this experiment sheds new light on the semantic-pragmatic debate on it-clefts and Hungarian focus as it includes systematic controls for context and overt questions as a factor. 


\section{Chapter 5}

\section{It-Cleft Exhaustivity and Contrast}

\subsection{Introduction}

This chapter ${ }^{1}$ aims at investigating whether there are certain context environments that can trigger the production of it-clefts, and whether exhaustivity and contrast play a part in it-cleft production.

The notion of contrast was first mentioned in relation to it-clefts by Jespersen (1927), who proposed the following:

(301) A cleaving of a sentence by means of it is (often followed by a relative pronoun or connective) serves to single out one particular element of the sentence and very often, by directing attention to it and bringing it, as it were, into focus, to mark a contrast. (Jespersen (1927), 147f.)

Since then, the role of contrast has played a rather secondary role in the discourse regarding it-cleft semantics. As described in some detail above (see section 2.3.2.2 of this thesis), it-clefts have been said to be identificational focus (see É. Kiss (1998)). This classification leads to two distinct semantic features of it-clefts, which are illustrated below:

(302) It was John who cooked the beans.

a. Nobody other than John cooked the beans. (exhaustivity inference)

b. The fact that John cooked the beans contrasts with something in the discourse context. (contrast) (Destruel and Velleman (2014), 197)

\footnotetext{
${ }^{1}$ Parts of the work in this chapter was done in cooperation with Liu Ying, Lilla Pintér and Yang Yu'an. The author declares that the design of the pilot study presented in this chapter was done in cooperation with the aforementioned authors. The design of the follow-up experiment, as well as the analysis of the results of both experiments were done by the author herself. The author further declares that the writing of the text and the interpretation and discussion of the results were done by herself.
} 
To test whether certain context environments, more specifically contexts that include exhaustivity and/or contrast, trigger the production of it-cleft sentences, production experiments can be used. Destruel and Velleman (2014) present a pilot production experiment for English in which they show that speakers are not likely to use it-clefts as direct answers to explicit wh-questions. They are more likely to use a cleft structure when they are correcting a previous statement. When they just give an informative answer, speakers of English are more likely to use a simple canonical sentence structure rather than an it-cleft. Destruel and Velleman (2014) conclude that the use of it-clefts in English is restricted to certain pragmatic uses of focus, namely to offer a correction to a presupposition made in the previous context. In addition to that, Byram-Washburn et al. (2013) found in a psycholinguistic experiment that speakers find it-clefts more acceptable in confrontational situations.

This chapter aims at extending their study and investigate further for the case of German whether a contrastive context is more likely to trigger the production of cleft sentences than an exhaustive or a mere informational context environment.

For the experiment presented in this chapter, the design used by Destruel and Velleman (2014) is altered slightly. The current study compares informational, contrastive, and exhaustive contexts and thereby investigates the relation between contrastivity and exhaustivity in more detail. This chapter will present the results of a pilot study and a follow-up production task, after introducing the main theoretical work on contrast in relation to it-clefts.

\subsection{Background}

The notion of contrast and its role in grammar are still not conclusively answered. On a pre-theoretical basis, contrast can be defined as a relation between sentences, where $\mathrm{s}_{1}$ contains an element $\alpha$ that can be construed as an alternative to an element $\beta$ in $\mathrm{s}_{2}$, as illustrated in (303) below (see Repp (2016). In this thesis I follow Repp (2016) in using a rather weak notion of contrast.):

$$
\left.[\text { Pete }]_{\text {contr } 1} \text { went to }[\text { Rome }]_{\text {contr } 2} \text {. [Marc }\right]_{\text {contr } 1} \text { went to }[\text { London }]_{\text {contr } 2} \text { (Repp }
$$
(2016), 2)

The example above shows a prototypical case of contrast. However, contrast can be expressed in less straight forward ways, such as in the two following examples:

(304) [Pete $]_{\text {contrast }}$ slept for an hour. Then it was $[\text { Marcs }]_{\text {contrast }}$ turn. (Repp (2016), 2)

An $[\text { American }]_{\text {contrast }}$ farmer was talking to a [Canadian $]_{\text {contrast }}$ farmer. 
(Repp (2016), 2)

Note that the sentences are still contrastive even when there is no overt parallelism in the sentences, such as in the case of the two farmers. One relevant notion for contrastivity is the existence of an alternativeness of the elements. The second is the role of discourse relations between two sentences, which includes the concept that contrast is not either present or absent, but can vary in degrees.

Repp (2016) notes that, since there is such a large variety of definitions of contrast used across the literature, there are some theories that are better suited to be applied to how contrast is linguistically expressed in a certain language than others. As a result, what is described theoretically as contrast in those languages might not at all be comparable cross-linguistically, if not the same definition of what has to be understood as contrastivity is used cross-linguistically. This chapter aims at investigating contrast and exhaustivity in German, while Destruel and Velleman (2014) draw their conclusions for the case of English.

\subsubsection{Alternatives and Contrast}

The constituents that can be taken as alternatives for each other to create contrast have been described in the literature in two different ways, which can both either be overt or covert:

1. symmetrical in terms of grammatical roles

2. non-symmetrical in terms of grammatical roles

Two examples that are repeated below show symmetrical-overt cases, in which the alternatives are overtly stated within the sentences used to state the contrast, and ordered symmetrical within these sentences. Usually the contrast is expressed via parallelism and/ or lexically or overtly given alternatives in the context, as is the case in the two following sentences:

$$
\begin{aligned}
& {[\text { Pete }]_{\text {contr } 1} \text { went to }[\text { Rome }]_{\text {contr } 2} \text {. }[\text { Marc }]_{\text {contr } 1} \text { went to }[\text { London }]_{\text {contr } 2 \text {. }}} \\
& \text { An }[\text { American }]_{\text {contrast }} \text { farmer was talking to a }[\text { Canadian }]_{\text {contrast }} \text { farmer. }
\end{aligned}
$$

A sentence can also be contrastive if the alternatives are not overtly given, but rather have to be deducted from the discourse. The contrastive element is then often marked by prosodic stress, indicating that there is an implied alternative to it:

(308) [PETE] went to Rome. 
The example (309) below illustrates a non-symmetrical case, in the way that the second sentence contains an element for which an alternative can be found in the first sentence. The first sentence creates the context for the contrastive sentence.

$$
\text { John, Pete and Josie all offered help. I asked John. (Repp (2016), 3) }
$$

In this case, there is a restricted set of clearly identifiable alternatives given in the context (see e.g. É. Kiss (1998)) which consists of Pete and Josie. In this framework, the alternatives are clearly marked by discourse and always available to the interlocutors. This framework can be referred to as the Restricted Set View (see Repp (2016)).

Another view that defines the notion of contrast around alternatives is described by Repp (2016) as being identical to the notion of focus in Alternative Semantics (Rooth (1985), Rooth (1992), Krifka (2008)). In this framework, alternatives are always in contrast to each other because they are not identical. Since symmetry has shown not to be a necessary condition for a sentence to be contrastive, Repp (2016) argues that it is not crucial for the definition of contrast.

\subsubsection{Contrastive Discourse Relations}

Corrective statements have been described as contrastive. The argument is that a contrast appears because there is an alternative to the contrastive element which makes the original statement false:

$$
[\mathrm{Max}]_{\text {contrast }} \text { didn't cook the best pasta dish, }[\text { Peter }]_{\text {contrast }} \text { did. }
$$

This view has been referred to as the Exclusion of alternatives- view (Repp (2016)). This framework (see also Kenesei (2006)) also brings the notion of exhaustivity into the picture, as excluding all alternatives to the focused element makes a sentences exhaustive.

Consider again the example from above and the same example including but:

$$
\begin{aligned}
& {[\text { Pete }]_{\text {contr } 1} \text { went to }[\text { Rome }]_{\text {contr } 2} \text {. }[\mathrm{Marc}]_{\text {contr } 1} \text { went to }[\text { London }]_{\text {contr } 2 \text {. }}} \\
& {[\text { Pete }]_{\text {contr } 1} \text { went to }[\text { Rome }]_{\text {contr } 2} \text { but }[\text { Marc }]_{\text {contr } 1} \text { went to }[\text { London }]_{\text {contr } 2}}
\end{aligned}
$$

The sentence in (311) can be continued with And Pete also went to London., as there is no overt statement of an exclusion of all alternatives. This sentence can even be seen as not expressing contrast at all according to the Exclusion of alternatives- view. For the sentence in (312) this is not as easily available ${ }^{2}$.

\footnotetext{
${ }^{2}$ For a more detailed discussion on the topic of but, and coordination in general, also see Umbach (2005), Haspelmath (2004).
} 
According to Repp (2016), if we were to grade the degree of contrast, the example without but would be least contrastive, the same with but would be more contrastive, and the corrective statement in the pasta-example in (310) above most contrastive.

For a parallel statement like (311), Repp (2016) introduces the term similar. The conjunction but is used as a discourse marker to express a violation of expectation that the interlocutors had on the discourse. The insertion of but indicates that the two conjuncts make opposing contributions to the current QUD (Repp (2016), 10). For statements like (312), Repp (2016) uses the term oppose, while corrections like in (310) are labeled antithesis.

In a variety of languages, contrast is reflected morphosyntactically. One example are clefts, in which the contrastive constituent moves to the left periphery of the sentence into the cleft pivot. In the case of Hungarian, left-peripheral movement is particularly well described. É. Kiss (1998) defines contrastiveness of an element to be present if every member in its alternative set is clearly identifiable.

As previously discussed (see section 2.3.2.2 of this thesis), following É. Kiss (1998), two main kinds of focus can be distinguished cross-linguistically: information focus and identificational focus. Information focus has the function of marking new, non-presupposed information, while identificational focus functions via semantic identificational predication. It thereby exhaustively identifies the set of individuals of which the predicate holds, with the exhaustivity being part of its meaning. Hungarian pre-verbal focus has often been described as identificational focus, with the exhaustivity being truth-conditional and semantic (see also Szabolcsi (1981), É. Kiss (1998), Kenesei (1986), Szabolcsi (1994)).

Identificational focus in Hungarian is exhaustive and can be [+/- contrastive]. A sentence bearing an identificational focus is rendered [+ contrastive], according to É. Kiss (1998), if it operates on a closed set of entities whose members are known to the interlocutors (É. Kiss (1998), 267). When the set of alternatives is open, an identificational focus can be [-contrastive], as illustrated below:

a. Ki írta a Háború és békét?

Who wrote War and Peace?

b. A Háború és békét [Tolsztoj] $]_{F}$ írta.

It was [Tolstoi] $]_{F}$ who wrote War and Peace. (É. Kiss (1998), 268)

Thus, exhaustivity plays an important role in the interpretation of pre-verbal focus in Hungarian, while contrastivity has not been prominently discussed in relation to this sentence structure. Repp (2010) points out that it has not yet been conclusively answered whether pre-verbal focus constructions that are exhaustive are 
also contrastive in every case. However, Repp (2010) does not discuss the most recent literature in which the assumption that the assumed exhaustivity inference necessarily comes with Hungarian pre-verbal focus has been challenged by experimental work (e.g. Onea and Beaver (2009), Wedgwood et al. (2006), Szendrói (2003), Wedgwood (2005), and Gerôcs et al. (2014)) and been reconsidered from a theoretical standpoint (É. Kiss (2016)).

Following É. Kiss (1998), Destruel and Velleman (2014) also distinguish information focus and identificational focus as their two main kinds of focus. Information focus has the function of marking new, non-presupposed information, while identificational focus functions via semantic identificational predication. It thereby exhaustively identifies the set of individuals of which the predicate holds, with the exhaustivity being part of its meaning. Destruel and Velleman (2014) adopt the position that identificational focus is (always) exhaustive and (sometimes) contrastive.

To illustrate what it takes for a discourse to be contrastive, consider the examples below (from Destruel and Velleman (2014), 200-201). Both B and B' are answers that include a focus, which is elicited by the wh-question. $\mathrm{B}^{\prime}$ however, is contrastive, as it focuses an element to which there are overt alternatives available in the discourse (here, the question $\mathrm{A}^{\prime}$ ). In the case of $\mathrm{B}^{\prime \prime}$, which can be a felicitous answer to both questions, it is assumed that this is a case of a contrastive and exhaustive answer ${ }^{3}$.

A: Who cooked the beans?

B: $[\text { John }]_{F}$ cooked the beans. (not contrastive)

A': Who cooked the beans, John or his brother Fred?

$\mathrm{B}^{\prime}$ : $[\mathrm{John}]_{F}$ cooked the beans. (contrastive)

Destruel and Velleman (2014) develop a gradient understanding of contrast (see also Repp (2016)), as opposed to a categorical constraint. They build their definition of contrast as a conflict of expectations on the Contrastive focus hypothesis by Zimmermann (2011), where contrastive focus is used in situations in which the speaker can reasonably suspect that the hearer does not expect the assertion of the focused constituent as likely to be included into the Common Ground. Contrast is understood anaphorically, which in this framework means that clefts are only felicitous in contexts in which there is an antecedent available in the previous discourse which is an alternative to the focused element. Clefts, according to their approach,

\footnotetext{
${ }^{3}$ Please note that the notion of contrast described here is a little stronger than the one described by ?
} 
are more felicitous the more they conflict with the expectations expressed by the interlocutors. In cases in which there is no antecedent available, the cleft is not felicitous. Clefts are assumed to mark contrastive focus, which operates from a closed set of alternatives and stands in opposition to informational focus (É. Kiss (1998)).

Destruel and Velleman (2014) test how strong the conflict of expectations needs to be for an it-cleft to be chosen as the preferred structure, as opposed to e.g. canonical sentences with in situ focus marking. Destruel and Velleman (2014) present the results of a production task pilot study (which is re-iterarted in a slightly extended way in this chapter below) in which they test how frequently native speakers of English produce it-clefts. The semi-spontaneous design consisted of stimuli of the form illustrated below (taken from Destruel and Velleman (2014), 203):

a. Your friend says: I can't believe that Mark bought that ugly car. It looks like it's about to fall apart. Who convinced him to buy it?

b. Answer: Leah

c. You say:

a. Your friend says: I can't believe Mark bought that ugly car. It looks like it's about to fall apart, too. I have no idea how Leah convinced him to buy it.

b. Correction: John

c. You say:

The Your friend says part constitutes the context and always ends with either a wh-question or a sentence containing a piece of information in bold. This is illustrated above in (317) for an answer-case and in (318) for a correction-case. The Answer or Correction part provides participants with the information to use to formulate their answer in the third part. The information was labeled Answer in the condition where it is used to formulate an answer to a wh-question, and Correction in the condition where it must be used to offer a corrective statement to the false assumption made by the "friend" in the preceding context. The You say part which included a blank line for participants to write out their response. The task was to read the context carefully and then give a reply (either an answer or a correction) while using the provided information. The design tests for two contexts: informative and counter-presuppositional, the latter of which is taken to be contrastive. The results showed that in informational contexts, participants chose a canonical sentence as their answer. There is a significant increase of itclefts as responses in the counter-presuppositional contexts, as the odds of using a cleft are 13.1 times higher when the speech act involves a correction than when 
it involves a simple answer (Destruel and Velleman (2014), 204). Destruel and Velleman (2014) conclude that the production of it-clefts is restricted to certain pragmatic uses of focus, namely to offer a correction to a presupposition. As is pointed out, these results match the current state of research as well as the predictions provided by Gricean maxims: unmarked contexts evoke simple sentence structures, while highly marked contexts require more complex means of focus marking such as it-clefts ${ }^{4}$.

Building on the results presented by Destruel and Velleman (2014), Destruel et al. (2016) propose a slightly different notion of contrast, while also building their framework around Zimmermann (2011)'s notion of hearer expectation (also see Zimmermann (2008)). However, they define the notion of contrast in a more narrow way as being used mostly in corrective statements. According to their assumptions, however, correction is not what it-clefts mark. To keep the two notions of contrast in a wide and narrow sense distinct, they introduce the term contrariness for doxastic contrast, which is build on hearer expectations (see Zimmermann (2011)). Contrariness is measured in their experimental design as the product of commitment (of the speaker to his or her own utterance) and contradiction (whether or not the information in a second speaker's sentence contradicts the information stated in the last sentence uttered by the first speaker). Their experimental design tests the naturalness of it-clefts as direct reactions to statements of other speakers using written input material in an online questionnaire.

They found that clefts are overall rated as more natural when the context contains a stronger degree of contrariness than when the context does not include a contrast at all. When a context contains an explicit alternative (or, in other words, a contrast), then it-clefts are judged as more natural by native speakers.

Destruel et al. (2016) conclude that the felicity of clefts stands in close relation to the presence of doxastic contrast/contrariness (as defined in terms of Zimmermann (2011)). Simply finding an antecedent in the discourse to form a contrast is not enough to raise the felicity of clefts in English. The notion of contrast needs to be stronger and more refined, and include the notion of speaker's expectations. While the presence of an explicitly stated alternative to the focused element makes clefts more felicitous, this is a necessary, but not a sufficient condition. When there is a metalinguistic contrast (i.e. when the antecedent is not expected by the interlocutor) in the discourse, clefts are more natural.

\footnotetext{
${ }^{4}$ However, this is not a necessary condition of it-cleft production. As Destruel and Velleman (2014) point out, their results show that canonical sentences can also be produced to express contrast.
} 


\subsection{Pilot study on free production}

To test whether there are noticeable differences in the production of it-clefts between contexts that are contrastive or contain some (weak) level of exhaustivity, a semi-spontaneous production task is conducted. The design is based on the experimental design presented by Destruel and Velleman (2014).

\subsubsection{Method and Design}

This experiment has a $2 \mathrm{x} 2$ within-subject design, controlling for two factors: exhaustivity and contrast. The term exhaustivity is used here to refer to speakers expectations. When a context is called exhaustive in this experiment, this means that participants are expected to give an exhaustive answer. When a context is called non-exhaustive, this means that participants are expected to give a nonexhaustive answer.

The design used here combines the notion of contrast used in the experiments by Destruel and Velleman (2014), and the notion of contrariness used by Destruel et al. (2016), who found that clefts are overall rated as more natural when the context contains a strong degree of contrast, e.g. in the form of an explicit alternative. Since there are overt wh-questions in all conditions, this design is not able to show whether the production of clefts is influenced in any way by the presence of overt wh-questions compared to statements ${ }^{5}$.

4 scenarios with 4 critical conditions plus 2 filler items in each scenario were tested. The items were randomized. We use a within-subject design.

The experiment was conduced online using Google Forms and delivered to the participants via email. The call for participants was published on a linguistics email-list at the University of Göttingen.

All participants were ignorant as to the purpose of the experiment. First, participants read instructions, in which they are told that during the following experiment, they are presented with various conversation contexts. They are asked to imagine that they were themselves part of the situation and taking an active part in the conversation. In the dialogs that are part of each individual conversation, their conversational partner always asks them a question. Below the question, they receive a hint (presented clearly marked in brackets) as to what the correct answer to the question is. Below that, they find an empty text field in which they can then type the answer, using a full sentence. They are instructed to answer as if

\footnotetext{
${ }^{5}$ However, at least for the case of German and Hungarian, previous studies (see chapter 4 of this thesis for discussion) have shown that clefts are rated highly as direct answers to a variety of overt wh-questions. While Destruel and Velleman (2014) present data that argue for the contrary prediction, the present thesis focuses on the difference between contrast and exhaustivity in itcleft production in this chapter.
} 
they were speaking normally in everyday conversation. The scenarios are designed in a way that reflects everyday conversational exchange between different kinds of conversational partners (a close friend, a police officer, a work colleague). Before the experiment starts, participants are presented with an example to familiarize themselves with the task.

The experiment consists of the following parts:

a. A short description of the situation the participants are to imagine themselves in, introducing a specific conversational partner for the following dialogs.

b. A question that the conversational partner introduced in the situation asks about the situation.

c. A hint as to what the correct answer to the question is.

d. A "you say"-part in which the participants can write freely into an empty text field their answer to the question, using the information given in the hint while saying it in their own words.

It is chosen not to overtly mark that there is a difference between a plain answer to the question and a correction, as in the case of Destruel and Velleman (2014), to control for a possible bias. Instead, the design presented here opts for every short discourse as a question-answer pair, some of them being corrections.

One of the scenarios and one of the dialogs is listed below as an example:

(320) Situation: A very important project of the company you are working for failed this year and the company lost a lot of money because of it. Jake from HR and you are talking about the consequences.

Dialoge 1: Jake: I heard that someone from your team did most of the work on this project. Who was that?

(Hint: Bill)

Your answer: empty text field for free production

\subsubsection{Predictions}

Participants are presented with questions in the following conditions:

\section{Informational Context [-contrastive] [-exhaustive]:}

Informational contexts are triggered by an overt wh-question with the given target being the direct answer to the question. The question includes nonexhaustive plurals ("Can you name one or two" members of an unspecified set) and the answer includes two names. 
Example: Jake: Who worked on this project? Can you list one or two of them?

(Hint: Sam and Tracy)

Prediction: most likely to produce plain/ unmarked sentence structures.

2. Contrastive Context [+contrastive] [-exhaustive]:

Contexts are triggered by an overt Is that correct?-question with a statement that includes nobody. Corrections are highly contrastive, which is why they are used to trigger contrastive contexts. In this context, participants are expected to give non-exhaustive answers, as the hint is a plural of one specific person and more, non-specified individuals.

Example: Jake: I heard that nobody was fired. Is that correct?

(Hint: Paul and his team)

Prediction: most likely to produce a focus construction, not necessarily an it-cleft.

3. Exhaustive Contrastive Context [+contrastive] [+exhaustive]:

Contexts are triggered by an overt Is that correct?-question with a statement that includes one corrective element that is not identical to the one given in the context sentence. In this context, participants are expected to give an exhaustive answer. The hint is a single, clearly identified person which highly suggests exhaustivity.

Example: Jake: I heard that the regional manager made the final decision. Is that correct?

(Hint: the CEO)

Prediction: most likely to produce a negated statement, probably an itcleft.

\section{Exhaustive Context [-contrastive] [+exhaustive]:}

Contexts are triggered by overt wh-questions with statements that include no specific name in the context sentence, and the answer in the hint being a single name. These contexts are again expected to produce exhaustive answers from participants, as the hint only lists one clearly identifiable individual and thereby suggests certainty of the answer that participants will give.

Example: Jake: I heard that someone from your team did most of the work on this project. Who was that?

(Hint: Bill)

Prediction: it-cleft. 


\subsubsection{Results}

23 participants with an average age of 31 years took part in the pilot study. All participants were native speakers of German.

The following table shows the produced clefts per condition, including the filler items:

Figure 5.1: Total numbers of produced it-clefts per condition in the pilot study

\begin{tabular}{|c|c|}
\hline$[+$ exh, + cont $]$ & 11 \\
\hline$[+$ exh, -cont $]$ & 3 \\
\hline$[$-exh, +cont $]$ & 0 \\
\hline$[$-exh, -cont $]$ & 0 \\
\hline filler & 12 \\
\hline total & 26 \\
\hline
\end{tabular}

Figure 5.2: Raw data counts: it-clefts produced in the pilot study

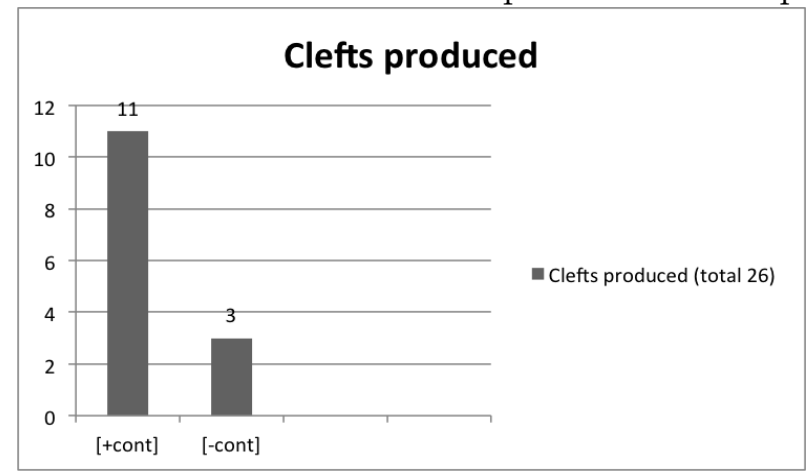

In the table and graph above, the raw data for the pilot experiment are visible. The following examples illustrate the sentences that were produced in the various conditions ${ }^{6}$ :

[+exhaustive, + contrastive]

(321) Es war Max, der das beste indische Gericht gekocht hat. It was Max RelPron the best Indian dish cooked has It was Max who cooked the best Indian dish.

\footnotetext{
${ }^{6}$ For a complete list of the results, please see Appendix 2 of this thesis.
} 
Es war Michael, der als Letzter mit Maria gesprochen hat. It was Michael RelPron as last with Mary talked has It was Michael who was the last person to talk to Mary.

[+exhaustive, -contrastive]

Es war Peter, der als letztes das Haus verlassen hat. It was Peter RelPron as last the house left has It was Peter who was last to leave the house.

(324) Es war Manuela, die die meiste Arbeit geleistet hat. It was Manuela RelPron the most work achieved has It was Manuela who did most of the work.

\section{Filler}

The it-clefts that were produced in the filler conditions are presented with their respective contexts in order to make the exhaustive and contrastive properties of the contexts transparent.

[+exhaustive, + contrastive]

Es waren nur weniger als die Hälfte der Teilnehmer, die It were only less than ART half of the participants RelPron sehr hohe Punktzahlen erreicht haben. very high points reached have It was only less than half of all participants that received very high points.

Es waren weniger als fünf Mitarbeiter, die wussten, dass es It were less than five employees RelPron knew that it scheitern würde.

fail would

It was less than five employees who knew that it would fail.

[+exhaustive,-contrastive]

Es waren drei Teilnehmer die thailändisch gekocht haben. It were three participants RelPron Thai cooked have It was three participants that cooked a Thai dish.

When taking a closer look at the specific filler items that elicited a cleft production, it becomes apparent that they, just like in the case of the targets, are also [+exh] 
and $[+/-$ cont $]$. The reason that the fillers are also designed following these two variables is to keep the fillers as close to the targets as possible to avoid that participants could find out the purpose of the experiment. Only one change was made regarding the items from targets to filler: the use of numbers or quantifiers instead of proper names.

Figure 5.3: Raw data counts: it-clefts produced in all conditions pilot study

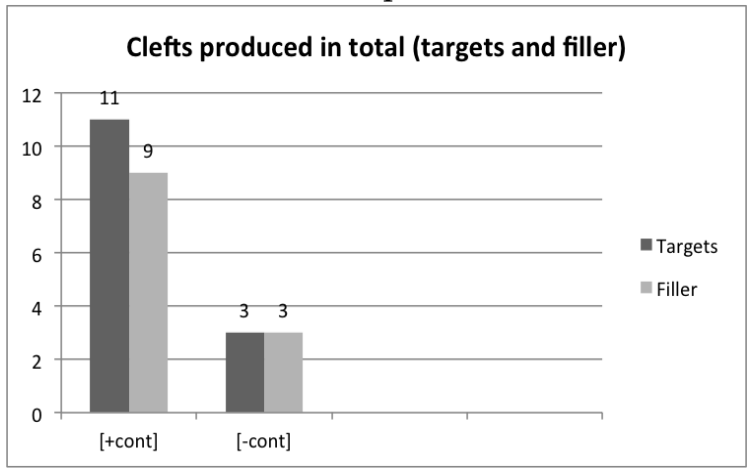

\subsubsection{Discussion}

The results of this pilot study suggest that there may be an interaction between contrast and it-cleft production in the case of German. When contexts are manipulated for the factors of exhaustivity and contrast, it may have an effect on the production of cleft structures. However, since the sample size is very small due to the overall low number of produced clefts, no clear conclusion can be drawn from the results.

The data presented above seem to suggest that the production of clefts in German is limited to contexts that show some level contrast, as the highest number of clefts were produced in exhaustive and contrastive contexts. In contexts that are exhaustive, but not contrastive, there are also clefts, but fewer.

However, since there only was a small number of participants for this pilot, our sample is not big enough to draw more general conclusions. We also found some problems with our design, which is addressed in the following section.

\subsection{Follow-Up Production Study}

During the pilot experiment some weaknesses in the design were detected:

- informational context [-cont] [-exh]: The way the questions were framed so far, the existence presupposition cannot be satisfied. Therefore, in the follow- 
up, at least one or two will be used instead of one or two in the questions "Can you name one or two"?

- contrastive context [+cont] [-exh]: the non-exhaustivity of this context cannot be safely assumed in the first form, as the phrase "and his friends" could also trigger a sum-exhaustivity. Therefore, it was changed by inserting among others in the question: I heard that Max, among others, made a pizza. Hint: Max

It may also be the case that it-clefts are a dialectal phenomenon and are much more frequent in some regions than others, or a social phenomenon. To answer these questions, the collection of more information about the participants is necessary. Therefore, the following set of questions is included in the preamble:

1. Age (also included previously): free production in text field

2. Gender (also included previously): male/female multiple choice

3. Where are you from (Federal State, Region, City)?: free production in text field

4. What is your highest (academic) degree (High School, Bachelor, Master, $\mathrm{PhD})$ ?: free production in text field

\subsubsection{Method and Design}

To take the points mentioned above into consideration, and also collect data from a larger number of participants, the design of the pilot study was altered accordingly. Participants were recruited using various online notice boards and accessed a Google Forms questionnaire online.

47 native speakers of German took part in the experiment. Participants had an average age of 25 years. 8 participants were male, 39 female. The lowest degree was middle-level high-school degree (Realschulabschluss), which amounts to 10 years of schooling. The highest degree was a Masters degree.

\subsubsection{Results}

The following table shows the produced clefts per condition, including the filler items: 
Figure 5.4: Total numbers of produced it-clefts per condition in the follow-up study

\begin{tabular}{|c|c|}
\hline$[+$ exh, +cont $]$ & 1 \\
\hline$[+$ exh, -cont $]$ & 0 \\
\hline$[$-exh, +cont $]$ & 2 \\
\hline$[$-exh, -cont $]$ & 0 \\
\hline filler & 11 \\
\hline total & 14 \\
\hline
\end{tabular}

Figure 5.5: Raw data counts follow-up study

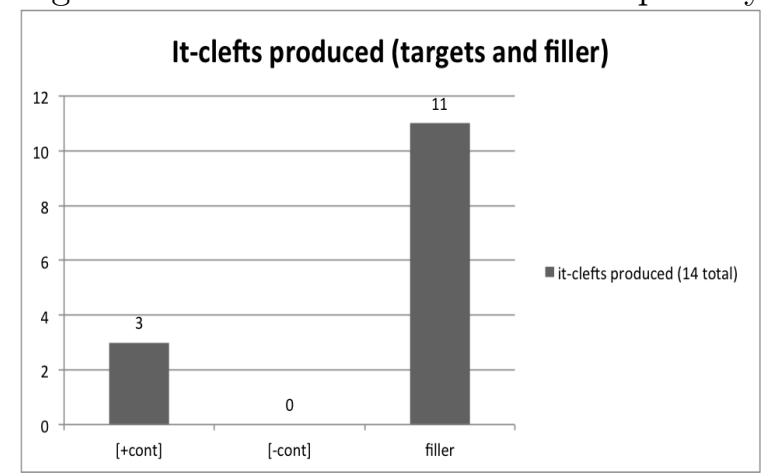

The table and graph above present the raw data for the follow-up experiment. Even with an increased number of participants, there were still very few it-clefts produced. The following examples illustrate the sentences that were produced in the various conditions ${ }^{7}$ :

[-exhaustive, +contrastive]

(328) Nein, es war Anna, die die Schüsse gehört hat.

No it was Anna RelPron the shots heard has

No, it was Anna who heard the shots.

Nein, es war Andreas, der den verloren hat.

No it was Andreas RelPron that lost has No, it was Andreas who lost that.

[+exhaustive, + contrastive]

\footnotetext{
${ }^{7}$ For a complete list of the results, please see Appendix 2 of this thesis.
} 
so weit ich weiss war es der vorstandsvorsitzende der das letzte as far I know was it the chief executive RelPron the last wort hatte.

word had

It was the chief executive who had the last word, as far as I know.

Filler

[+exhaustive, +contrastive]

Es waren weniger als fünf Leute, die davon wussten.

It were less than five people RelPron about that knew

It were less than five people who knew about that.

\section{[+exhaustive,-contrastive]}

$$
\begin{aligned}
& \text { Es waren drei Teilnehmer, die thailändisch gekocht haben. } \\
& \text { It were three participants RelPron Thai cooked have } \\
& \text { It were three participants who cooked a That dish. }
\end{aligned}
$$

Es sind ein Pärchen und zwei Familien, die neu eingezogen sind.

It are a couple and two families RelPron new moved in are It is a couple and two families who moved in recently.

\subsubsection{Discussion}

The changes that were made in two categories between the pilot and the follow-up seemed to have no visible effect on the production of it-clefts. It is the case that there were clefts produced in the [-exhaustive, +contrastive] condition, but since the overall production of it-clefts is so low, one can hardly speak of a significant difference here. However, in both the pilot and the follow-up study, there is production of it-clefts in German. More so, clefts are exclusively produced in contexts that were either exhaustive or contrastive. To make the small samples a little more accessible, one can look at the relative distribution of it-clefts that were produced in the various conditions and overall in the two experiments. This is illustrated in the two figures below: 
Figure 5.6: Relative Distribution of it-clefts and other sentence types produced in the pilot study

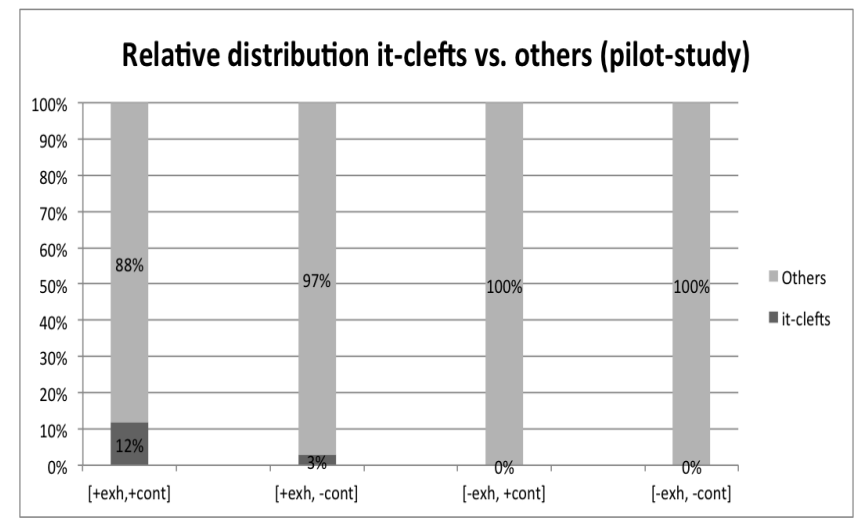

Figure 5.7: Relative Distribution of it-clefts and other sentence types produced in the follow-up

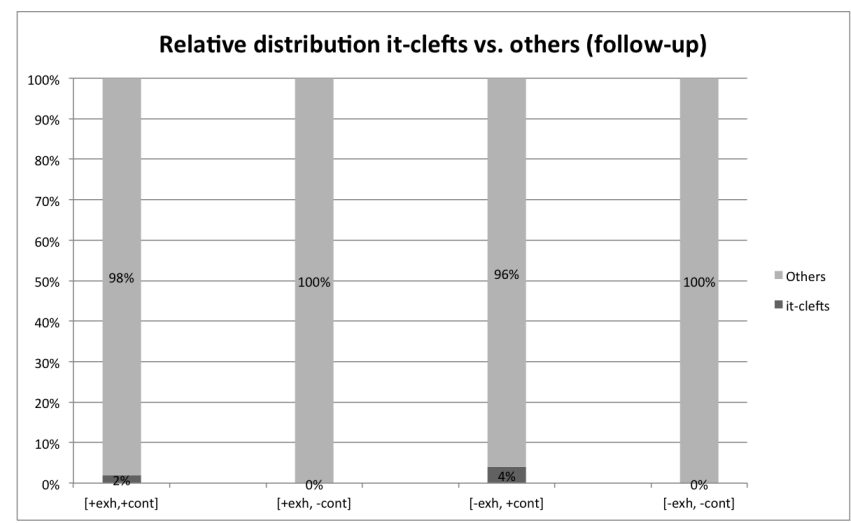

As expected, there were no it-clefts produced in the [-exhaustive, -contrastive] condition. Clefts were predicted to be produced in both the $[+$ exhaustive, + contrastive] and [+exhaustive, -contrastive] conditions. In the [-exhaustive, +contrastive] condition, it was expected that focus constructions would be produced, but not necessarily it-clefts. As can be seen in the graphs above, those predictions were met. However, based on the small data sample, no strong statements are possible as to whether contrast and exhaustivity in contexts have an effect on the production of it-clefts in German.

As there were a relatively large number of it-clefts produced in the filler conditions, we now take a closer look at the contexts they were produced in. 
In the pilot study, it-clefts were produced in the following distribution:

\begin{tabular}{c|c}
{$[+\mathrm{exh},+$ cont $]$} & 7 \\
\hline$[+\mathrm{exh},-$ cont $]$ & 5
\end{tabular}

In the follow-up, it was actually the case that the majority of it-clefts were produced in the filler conditions. Here, it-clefts were produced in the following distribution:

\begin{tabular}{c|c}
{$[+\mathrm{exh},+$ cont $]$} & 6 \\
\hline$[+\mathrm{exh},-$ cont $]$ & 5
\end{tabular}

Overall, this results in the following production pattern:

\begin{tabular}{c|c}
{$[+$ exh,+ cont $]$} & 13 \\
\hline$[+$ exh, - cont $]$ & 10
\end{tabular}

As there were no changes made in the filler conditions for the follow-up, the numbers for both are added together for this post-hoc analysis of the filler items. When looking at the distribution of the two experiments combined, it can be seen that there is no large difference between contrastive and non-contrastive contexts. As demonstrated for the target conditions, it seems to be enough for a context to either have an general/weak exhaustive or contrastive element to trigger the production of an it-cleft in German at all. There is (if at all) only a marginal increase of the production of it-clefts in contexts which is both exhaustive and contrastive.

\subsection{Conclusion}

The objective of this chapter was to see whether certain properties of a given context, i.e. exhaustivity and contrast, can trigger the production of it-clefts in German. As has been mentioned before, it-clefts are not a very frequent structure in spoken German. While it-clefts do appear rather frequently in written German (as shown in chapter 3 of this thesis), there have not yet been any studies that answer conclusively whether they are equally frequent and, therefore, equally accessible to speakers as a viable option to express contrast or exhaustivity in spoken German. Therefore, the expectation was to be faced with a very low number of itclefts in the overall experiment, which is why the low percentage of it-clefts overall is not surprising or should be interpreted negatively related to our design.

A possible reason why the pilot study had a larger amount of it-clefts than the follow-up could be that participants for the pilot were recruited using a linguistics email-list at the university of Göttingen. It is highly likely that most of the 
participants in the pilot study have a background in linguistics, and, therefore, possibly a higher awareness of it-clefts as a possible construction. But since there was no question for the highest academic degree in the pilot study, this is just a hypothetical explanation.

We did receive the predicted production pattern for our experimental conditions in both the pilot and follow-up study. However, as the sample is so small, we can not conclusively answer whether it-cleft production in German can be influenced by exhaustivity and/or contrast of the context. Based on the data presented in this chapter, it can be concluded that there is a tendency for a higher production of it-clefts in exhaustive and/or contrastive contexts as opposed to contexts that have neither of those two characteristics. However, this is only a suggestion and not a definite conclusion.

This question is left for further research, ideally with production experiments with a very large number of participants and in a way that participants can speak rather than write to make the design more natural. It would further be of interest to see whether the production of it-clefts in German can be influenced through priming of it-clefts, e.g. via a text that participants have to read prior to the production task in which one group is presented with a text that includes a large number of it-clefts, while a control group does not.

It has previously been argued that contrast might play a role in it-clefts (see e.g. Jespersen (1949)). Recalling the study the experiment presented in this chapter was designed after, Destruel and Velleman (2014) found that in English, it-clefts make bad answers to explicit wh-questions. As will be discussed in chapter 4 of this thesis, this does not hold for the case of German. Therefore, this explanation does not serve to explain the low relative production of it-clefts in this experiment. It is important to keep in mind that it-clefts are a fairly frequent structure in - written as well as spoken - English, while they are rare in spoken German. Destruel and Velleman (2014) furthermore found that speakers are more likely to use a cleft structure when they are correcting a previous statement. As the results of the two experiments presented here are not representative, it cannot be conclusively answered whether this is the case for German as well. However, since certain tendencies were observed and no it-clefts were produced in the [exhaustive, -contrastive] condition in either experiment, it can be concluded that in this respect, German and English are similar: in German as in the case of English, contrast does seem to play a role in the production of it-clefts. The results presented in this chapter suggest that the conclusion Destruel and Velleman (2014) offer might also hold for the case of German, and the use of it-clefts in (spoken) German is (while not restricted, as in the case of English, though possibly) favored 
by particular pragmatic uses of focus, i.e. to either correct a presupposition of the statement made in the previous context, or to provide an exhaustive listing of the members named in previous context that satisfy the property denoted by the cleft relative.

The results presented in this chapter are also in line with the predictions made by Destruel et al. (2016), who argue that the mere presence of an antecedent in the discourse that can form a contrast is not enough to raise the felicity of clefts in the case of English. They build their framework on speaker's expectations and conclude that, while the presence of an explicitly stated alternative to the focused element does increase the felicity of an it-cleft, this is a necessary, but not a sufficient condition. Because in the experimental design presented above, the alternative element that served as the cleft pivot in those it-clefts that were produced, was given to the participants as part of their own knowledge, but not part of their addressees knowledge, the results do not stand in opposition to this analysis.

To sum up, we can say that the results presented in this chapter support the assumption that it-clefts are not a very common structure in German. The theoretical relevance of the data is marginal due to the overall small number of it-clefts produced. However, what is interesting about the results is that there were no it-clefts at all among those items that were neither exhaustive nor contrastive. The findings presented in this chapter support the prediction that it-clefts are not a case of informational focus, but are used to mark exhaustive and/or contrastive focus. 


\section{Chapter 6}

\section{Conclusion}

\subsection{The main questions}

This dissertation has taken a close look into a number of questions that have been the topic of much theoretical and experimental debate regarding it-clefts. This dissertation set out to answer the following research questions:

1. Are it-clefts exhaustive, and if yes, how should the exhaustivity be analyzed?

2. Are it-clefts combinable with focus particles and if yes, can these particles have an influence on the exhaustivity?

3. Does the cleft type (Focus-Background or Topic-Comment cleft) have an effect on the exhaustivity?

4. Does contrastivity play a role in the production of it-clefts?

To answer these research questions, different methods were necessary. Regarding exhaustivity, a corpus-based approach was chosen, in addition to experiments that were designed based on the corpus data. Using corpus data is useful to investigate it-cleft exhaustivity, as it includes the context of the it-cleft. Being able to take the context of a naturally occurring example of a cleft into consideration may influence the judgment on exhaustivity and/or acceptability that subjects will assign to the sentences in experimental environments.

The question of how and when certain focus particles are combinable with it-clefts is closely connected to exhaustivity. The combination of non-exclusive (e.g. additive, scalar, etc.) focus particles with it-clefts has been described as problematic (see e.g. Altmann (1976), Büring and Križ (2013), Percus (1997)), as the semantics of these particles appear to clash with the exhaustivity of the cleft structure. The corpus search, however, resulted in a high number of it-clefts with non-exclusive 
focus particles, which were then tested in an experimental study which showed that it-clefts with non-exclusive particles are accepted by speakers of German.

A cross-linguistic study for German and Hungarian used overt context questions to frame two different kinds of it-clefts (that were already distinguished in the corpus research): Focus-Background and Topic-Comment clefts. The experiment shows that neither Hungarian pre-verbal focus nor German it-clefts are semantically exhaustive, as the kind of context question (TC or FB) preceding an it-cleft or pre-verbal focus has an influence on the exhaustivity of the answer. In the second part of the experiment, the two focus structures were combined with additive focus particles to test whether these particles could influence exhaustivity. The results show that for both constructions, additive particles have an effect on the exhaustivity of the sentence.

Regarding the role of contrast and exhaustivity in the production of it-clefts, it was asked whether it-clefts are more likely to be produced in certain contexts rather than others. The semi-spontaneous written production experiment which was used comes with certain problems. First, a written form of everyday communication is not as natural as spoken language production. Second, there was an overall low outcome of it-clefts within the experiment. However, it could be observed that there are certain tendencies for it-clefts to be produced in specific environments, which could lead to more developed and very interesting future research.

\subsection{It-Cleft Exhaustivity and Focus Particles}

The question of whether and in which way it-clefts can or have to be rendered exhaustive has been a well-debated topic for many years from both theoretical and experimental perspectives. This thesis has taken a corpus-based and experimental approach.

The extensive corpus study, combined with the experimental evidence presented in chapter 3 showed novel insights into the semantics of it-clefts: first of all, it-clefts in written German are not as infrequent as expected. In newspaper articles, it-clefts are used fairly frequently and in a variety of ways. Secondly, the assumption (see e.g. Altmann (1976), Büring and Križ (2013), Percus (1997)) that it-clefts are not combinable with certain (non-exclusive) focus particles could not be verified for the case of German. Instead, and in contrast to previous theoretical assumptions, German it-clefts are used frequently in combination with various focus particles. Two types of it-clefts were found in the corpus search: Focus-Background (FB) and Topic-Comment (TC)-clefts. Both clefts types have been the topic of previous linguistic discussions. For the case of German, the corpus analysis presented in this thesis shows that FB-clefts are overall significantly more common than TCclefts, which leads to the conclusion that the FB-clefts can be classified as the 
default case for German it-clefts and the TC-clefts as non-prototypical. Thirdly, regarding exhaustivity, the corpus data also allow important insights: both cleft types are significantly more frequently exhaustive than non-exhaustive. However, it could also be observed that TC-clefts have a very strong tendency to be exhaustive, even more so than FB-clefts. In contrast to previous theoretical approaches (e.g. Altmann (1976), Büring and Križ (2013), Percus (1997)), and in line with previous corpus studies (e.g. Wedgwood et al. (2006), Hedberg (1988)), this study shows that German it-clefts can in fact occur in combination with a variety of (non-exclusive) focus particles. What the data clearly show is that it-clefts - no matter whether FB or TC - are not exhaustive in every case. This leads to the conclusion that the context always needs to be taken into consideration when discussing exhaustivity. The context plays an especially important role when the it-cleft includes a focus particle positioned directly in front of the cleft pivot. German it-clefts combined with particles that carry a non-exclusive meaning (auch, vor allem, nicht zuletzt) appear frequently in the corpus. These findings show that it-clefts can be exhaustive or not exhaustive and they can be combined with exclusive and non-exclusive focus particles. Future approaches to it-cleft exhaustivity have to take these findings into account and take the context into consideration when analyzing the meaning of it-clefts.

For those examples of it-clefts found in the corpus where a focus particle is positioned directly in front of the cleft pivot, the observed effects on the exhaustivity are not uniform across particles. In combination with only the clefts receive an exhaustive reading. In combination with especially, they are non-exhaustive. Thereby they following the presupposition and/or meaning contribution of the respective particle.

In the cases of the particles auch/also and nicht zuletzt/ not least, the picture is not as clear. There are it-clefts with auch/also and nicht zuletzt/ not least that receive an exhaustive interpretation, which is rather unexpected given the semantics of the particle. These non-prototypical cases were addressed by showing that the additive particle and the cleft pivot do not form a constituent, which is a way to explain why these sentences can carry an exhaustivity implicature in spite of the presupposition of the non-exclusive particle. This makes it possible for the particle to modify other elements than the focused NP/DP in the pivot. A questionnaire experiment was conducted to see how native speakers judge constituency.

The results of the two experiments show that the majority of speakers agree that the additive focus particle refers to the cleft relative. As an additional factor, the two cleft kinds (FB and TC-clefts) were both included in the design, to control for possible effects of cleft types. Importantly, especially in light of previous designs and also regarding the distinction between the two cleft types, the original contexts 
of the naturally occurring corpus examples were included into the design. When asked what the cleft is about (i.e. whether the topic of the cleft is the cleft pivot or the cleft relative), the majority of speakers answer that the it-cleft is about the cleft relative. When asked what they can infer from the clefts, speakers infer that the cleft pivot also did something else in addition to what was stated in the cleft relative.

Regarding exhaustivity, speakers judge the sentences as non-exhaustive. Considering that the additive particle is in the syntactical position directly in front of the cleft pivot and should, therefore, by default modify the pivot and make the clefted element non-exhaustive, these results can be interpreted to mean that the additive particle in fact modifies the cleft relative, which then receives a non-exhaustive interpretation.

The results of the pilot experiment were strengthened and extended by the followup, which also allowed for a statistical analysis. In the pilot experiment, a slight variety was observed: FB-clefts are judged to be about the cleft pivot, while TCcleft are judged to be about the cleft relative, as illustrated in the example below:

It was also John who drank the most last night.

a. The sentence is about John.

$\rightarrow$ judgment: cleft pivot

b. The sentence is about who drank most last night.

$\rightarrow$ judgment: cleft relative

From this it can be concluded that the two cleft types do in fact have different discourse functions, as they are interpreted differently by native speakers. In the follow up, however, it was observed that both FB and TC-clefts are comparatively acceptable when combined with an additive particle and a superlative cleft relative. I suggest that speakers accept these sentences possibly because they take the additive particle to modify the cleft relative, and not the pivot. For the case of German it-clefts with an additive focus particle that appears directly in front of the cleft pivot, I conclude that the focus particle can modify the VP of the cleft relative. If these clefts are exhaustive, this can then be explained by the focus particle, despite its syntactical position, actually modifying the VP.

As observed in the related judgment experiment, German it-clefts combined with particles that carry a non-exclusive meaning (auch/also, vor allem/ especially, nicht zuletzt/ not least) were overall rated acceptable. The results of this experiment stand in contrast to the theoretical assumption that it-clefts carry an exhaustivity inference that is hard-wired into the semantics of the structure, as it should not be possible to cancel a semantic inference by the insertion of a particle which takes scope over the focused element. 


\subsection{Exhaustivity and the QUD: Hungarian pre- verbal Focus}

The experimental data for Hungarian provided by this thesis support a pragmatic approach to the exhaustivity inference in Hungarian pre-verbal focus and it-clefts. Pre-verbal and post-verbal focus were tested against each other for exhaustivity judgments, both with and without a non-exhaustive particle. It was observed that both sentence structures show similar exhaustivity judgments, which suggests that the kind of focus question (narrow/wide) preceding the sentence has more influence on the exhaustivity than the syntactical construction (pre-verbal/post-verbal focus). As an answer to questions conveying wide focus, pre-verbal focus is accepted in exhaustive as well as non-exhaustive contexts. When assumed to be answering a narrow focus question, speakers reject pre-verbal focus in non-exhaustive contexts.

Generally, the experiment shows that Hungarian pre-verbal focus is exhaustive in some way, as non-exhaustive pictures are rejected in combination with the preverbal focus. When looking more closely at the two different context questions that were used to trigger narrow and wide focus respectively, it becomes apparent that pre-verbal wide focus is nearly always judged highest when the picture is exhaustive, so wide focus is strongly exhaustive. Pre-verbal narrow focus is always judged highest when the visual context is exhaustive, meaning that narrow focus is also strongly exhaustive. In a non-exhaustive context, the narrow focus is judged mostly low. However, it is not necessarily exhaustive, as there are lower judgments as well.

Based on the results it can be suggested that in Hungarian, pre-verbal focus constructions can be used in more contexts than previously assumed by the literature. As answers to wide focus questions, pre-verbal focus is accepted in exhaustive as well as non-exhaustive scenarios, while this is not the case in narrow focus question environments. When assumed to be answering a narrow focus question, speakers reject pre-verbal focus in non-exhaustive situations. In situations when the pre-verbal focus is assumed to answer a wide-focus question, it is accepted in non-exhaustive contexts. As the patterns for both narrow and wide question types are not parallel, it can be concluded that Hungarian pre-verbal focus is not semantically exhaustive.

The results that were presented for Hungarian support the alternative analysis of the exhaustivity of Hungarian pre-verbal focus in which the exhaustivity effect is analyzed as a presupposition (cf. É. Kiss (2016), Kenesei (1986)). Furthermore, the results support Onea and Beaver (2009) in their proposition that pre-verbal focus in Hungarian is used to answer wh-questions. 
Regarding the issue of Q-implicatures which is related to Relevance Theory (Sperber and Wilson (2004)), and discussed in Gerôcs et al. (2014) for the case of Hungarian pre-verbal focus, the results presented in this thesis suggest that two kinds of question types provide contexts in which pre-verbal focus are felicitous answers to overt questions. Gerő́cs et al. (2014) assume that differences in exhaustivity judgments of pre-verbal focus might be a result of the presence or absence of overt wh-questions. When looking at the experiment in chapter 4 , the issue might not (only) be whether or not there are overt wh-questions in the context, but what kind of focus domain the respective questions address: In wide-focus, exhaustivity is weak (pre-verbal focus is not rejected in non-exhaustive contexts), while it is very strong on narrow-focus (pre-verbal focus is rejected in non-exhaustive contexts).

In terms of the effect of additive focus particle on the exhaustivity of Hungarian pre-verbal focus, this thesis showed that that speakers reject pre-verbal focus with an additive in an exhaustive environment, as the focus particle makes the sentence non-exhaustive. In the non-exhaustive contexts, the majority of judgments is very high, so this combination is highly acceptable. Therefore, it can be concluded that the particle does have an effect on the exhaustivity of the pre-verbal focus. This supports É. Kiss (2016) in stating that the additive particle többek között/among others is combinable with pre-verbal focus.

I conclude that the exhaustivity inference in Hungarian pe-verbal focus and it-clefts is not part of the truth conditions, as previously concluded by other experimental studies (e.g. Drenhaus et al. (2011)). Therefore, these results support those studies that have argued in favor of a pragmatic account of Hungarian pre-verbal focus and it-cleft exhaustivity.

\subsection{Exhaustivity and the QUD: German it-clefts}

For the case of English, TC-clefts have been described to have stress on the cleft relative. However, there is to this point no real experimental evidence that this is also holds for the case of German. The default stress pattern for German es-clefts has the main stress on the cleft pivot, with falling intonation on the relative clause. This thesis has assumed that the intonational pattern in German es-clefts is not the deciding factor in marking them as FB or TC-clefts. As demonstrated by the experiment in chapter 4, the context plays an important role here: the (overt or accommodated) QUD (cf. Roberts (1996)) preceding the utterance is what determines whether a cleft is TC or FB. This is further supported by Lambrecht (2001), who argues that the relative clause of a cleft can remain unaccented if the cleft relative has been activated by an element in the immediately preceding 
context. If the content of the cleft relative has been sufficiently activated in the context, the relative clause does not require prosodic stress.

As shown in chapter 4, it is actually of great importance to keep these two assumed cleft types distinct, as they have different information structural functions. In the experiment presented in chapter 4, the two cleft kinds were controlled for by two different kinds of overt wh-questions that are assumed to introduce the two different foci. Therefore, they trigger either a FB or a TC-cleft environment. The results for German show that the two cleft types actually vary slightly regarding their exhaustivity judgments: TC-clefts seem to be a little less frequently exhaustive than FB-clefts. Not only does this provide experimental evidence against a semantic approach to it-cleft exhaustivity, as in that case, both cleft types should receive the same exhaustivity judgment. But additionally, the results support the theoretical prediction that FB-clefts are means of focus marking (as introduced by Roberts (1996)), while at the same time showing that both cleft types can be used to answer overt wh-questions. FB-clefts are highly exhaustive and are rejected in non-exhaustive contexts. However, this is not the case for TC-clefts. They are also judged higher in exhaustive contexts, but nevertheless also acceptable in non-exhaustive environments. It can, therefore, be concluded that these two clefts types are not to be treated completely equally, even though they can actually both serve as answers to overt wh-questions. TC-clefts, however, seem to have a wider range of use, as they are acceptable in both exhaustive and non-exhaustive contexts. FB-clefts can be described to be used to mark focus in a more narrow sense, while TC-clefts can also be used for other information structural purposes, e.g. shift of discourse direction or introduction of a new topic (see Prince (1978), Hedberg (2013)).

\subsection{It-Cleft Exhaustivity and Contrast}

It-clefts are said to be a way to mark contrast morphosyntactically: The contrastive constituent moves to the left periphery of the sentence into the cleft pivot. This thesis took a closer look into the question if certain contextual properties can trigger the production of it-clefts in German. The results of the two production experiments showed that, while speakers do produce it-clefts in semi-spontaneous written dialogues, there were only very few it-clefts being produced overall. However, even given the low overall amount of it-clefts produced, the predicted production pattern for the experimental conditions in both the pilot and follow-up study were achieved. The data suggest that there is a tendency for a higher production of it-clefts in exhaustive and/or contrastive contexts as opposed to contexts that have neither of those two characteristics. In this respect, then, the results of De-

struel and Velleman (2014) for English can be assumed to also hold for the case of 
German, as contrast does seem to play a role in the production of it-clefts. Given this parallelism, it is reasonable to follow the conclusions of Destruel and Velleman (2014), meaning that the use of it-clefts in (spoken) German is (while not restricted, as in the case of English, though possibly) favored by particular pragmatic uses of focus, i.e. to either correct a presupposition of the statement made in the previous context, or to provide an exhaustive listing of the members named in previous context that satisfy the property denoted by the cleft relative. Combined with the observed tendency to produce German es-clefts more frequently in contrastive contexts, it-clefts can be said to possibly serve a corrective function in discourse, as well as means to provide the addressee with the right information according to the speaker.

\subsection{What did we learn about it-clefts?}

This thesis has provided the following novel insights on it-cleft interpretation:

First of all, German it-clefts can be exhaustive, but they are not exhaustive in every case. When used in written German, like in newspaper articles or Wikipedia forum discussions, speakers frequently make use of it-clefts, which may, but do not have to be exhaustive. Whether or not these it-clefts receive an exhaustive reading depends largely on the context. Speakers show tendencies to produce it-clefts in certain restricted context environments, namely in contexts that are exhaustive and/or contrastive for it-clefts. Speakers do not reject it-clefts in non-exhaustive environments, even though they are clearly very acceptable in exhaustive contexts. It therefore seems that it-clefts are likely to be used and interpreted to express some kind of exhaustivity. However, the data do not support a semantic analysis of this exhaustivity inference.

Additionally, it-clefts are not a unified class of sentences. There are (at least) two different kinds of it-clefts, Focus-Background and Topic-Comment clefts. These cleft types serve different information structural purposes. I suggest a pragmatic approach to it-cleft exhaustivity with specific contextual restrictions as a key variable for exhaustivity. It seems possible to argue in favor of a gradual analysis of the exhaustivity inference, which rises with the degree of contrast and/or exhaustivity of the context (see also Horn (2014)).

Secondly, it-clefts are combinable with a large variety of focus particles, both exclusive and non-exclusive. While it was predicted to find exclusives in combination with a structure that is said to be exhaustive, finding non-exclusive focus particles in it-clefts was unexpected, just as the fact that speakers judge them just 
as acceptable as their counterparts without the particle. Certain focus particles (the German additive auch/also and the Hungarian additive többek között/among others) do have an influence on the exhaustivity inference of it-clefts.

Thirdly, contrast seems to play a role in it-cleft production. There is a tendency for it-clefts to be produced more frequently in contexts that are exhaustive and/or contrastive as opposed to context environments that have neither one of these two characteristics. Contrast does seem to have an influence on the production of it-clefts in German, just as could be observed in previous work for the case of English (see e.g. Destruel and Velleman (2014), Byram-Washburn et al. (2013)). It-clefts seem to be produced to serve a pragmatic function of focus, namely to either correct a previous statement or to provide an exhaustive listing. However, these findings are merely suggestive and have to be addressed by further research.

On a cross-linguistic level, this thesis could also provide novel insights on Hungarian pre-verbal focus and its exhaustivity. I support the more recent presuppositional analysis of the exhaustivity inference of Hungarian pre-verbal focus (see É. Kiss (2016)), and tend to argue against a strict semantic analysis of exhaustivity in this structure. The presented data also support the prediction that pre-verbal focus is a means of answering overt wh-questions, which has been assumed previously, but not conclusively answered.

In addition to that, the presented data also show that speakers reject pre-verbal focus with an additive particle in an exhaustive environment, as the focus particle makes the sentence non-exhaustive. Therefore, non-exclusive focus particles may stand in pre-verbal focus constructions in Hungarian, but they do have an influence on the exhaustivity inference of that structure.

Overall, this dissertation contributed to our understanding of the interpretation of it-clefts. The main result seems to be that the context plays a significant role in the interpretation of it-clefts. It therefore needs to be taken into account when addressing the meaning of it-clefts in the future. 


\section{Bibliography}

Akmajian, A.

1970. On deriving cleft sentences from pseudo-cleft sentences. Linguistic Inquiry, 1(2):149-168.

Altmann, H.

1976. Die Gradpartikeln im Deutschen. Tübingen: Max Niemeyer Verlag.

Atlas, J. and S. Levinson

1981. It-clefts, informativeness and logical form: Radical pragmatics. In Radical Pragmatics., P. Cole, ed., Pp. 1-61. New York: Academic Press Inc.

Beaver, D.

1992. The kinematics of presupposition. In Proceedings of the Eighth Amsterdam Colloquium, P. Dekker and M. Stockhof, eds., Pp. 17-36. University of Amsterdam: ILLC.

Beaver, D.

1997. Presupposition. In Handbook of Logic and Language, J. van Benthem and A. ter Meulen, eds., Pp. 939-1008. Cambridge, M.A.: MIT Press.

Beaver, D.

2001. Presupposition and Assertion in Dynamic Semantics. Stanford, CA: CSLI Publications.

Beaver, D. and B. Clark

2008. Sense and Sensitivity. How Focus determines Meaning. Oxford: Blackwell.

Beaver, D., M. Simons, C. Roberts, and J. Tonhauser

2017. Questions Under Discussion: Where Information Structure meets projective content. Annual Review of Linguistics, 3:265-284. 
Boell, A.-C.

2016. Exhaustivity effect of focus-particles in German it-clefts: Empirical and corpus-based insights. In Proceedings of the ESSLLI 2016 Student Session, M. Köllner and R. Ziai, eds., Pp. 143-154.

Bolinger, D.

1985. Two views of accent. Journal of Linguistics, 21:79-123.

Bornkessel, I., M. Schlesewsky, and A. Friederici

2003. Contextual information modulates initial processes of syntactic integration: the role of inter-versus intrasentential predictions. Journal of Experimental Psychology: Learning, Memory, and Cognition, 29(5):871.

Büring, D. and K. Hartmann

2001. The syntax and semantics of focus-sensitive particles in German. Natural Language and Linguistic Theory, (19):229-281.

Büring, D. and M. Križ

2013. It's that and that's it! Exhaustivity and Homogeneity Presuppositions in Clefts (and Definites). Semantics and Pragmatics, 6(6):1-29.

Byram-Washburn, M., E. Kaiser, and M. L. Zubizarreta 2013. The english it-cleft: No need to get exhausted. In California Universities Semantics and Pragmatics Workshop 2012. LSA.

Chafe, W. L. 1976. Givenness, contrastiveness, definiteness, subjects, topics, and point of view. In Subject and Topic, C. N. Li, ed., Pp. 25-55. New York: Academic Press.

Chomsky, N.

1977. On wh-movement. In Formal Syntax, P. W. Culicover, T. Wasow, and A. Akmajian, eds., Pp. 71-132. New York: Academic Press.

Clark, H. and S. Haviland

1977. Comprehension and the Givenness Contract. In Discourse production and comprehension, R. Freedle, ed., Pp. 1-40. New Jersey: Ablex. 
Clech-Darbon, A., G. Rebuschi, and A. Rialland 1999. Are there cleft sentences in French? In The Grammar of Focus, G. Rebuschi and L. Tuller, eds., Pp. 83-118. Amsterdam: J. Benjamins.

Cowles, H., R. Kluender, M. Kutas, and M. Polinsky 2007. Violations of Information Structure: an electrophysiological study of answers to wh-questions. Brain and Language, 102(3):228-242.

Davis, W.

2014. Implicature. In The Stanford Encyclopedia of Philosophy, Edward N. Zalta, ed. https://plato.stanford.edu/archives/fall2014/entries/ implicature/: Metaphysics Research Lab, Stanford University.

Delin, J.

1989. Cleft Constructions in English Discourse. Master's thesis, University of Edinburgh.

Delin, J.

1992. Properties of it-cleft presupposition. Journal of Semantics, 9:289-306.

Delin, J. 1995. Presupposition and shared knowledge in it-clefts. Language and Cognitive Processes, 10(2):97-120.

Delin, J. and J. Oberlander 1995. Syntactic constraints on discourse structure: the case of it-clefts. Linguistics, 33:465-500.

den Dikken, M., A. Meinunger, and C. Wilder 2000. Pseudoclefts and ellipsis. Studia Linguistica, 54:41-89.

Destruel, E.

2012. The french c'est-cleft: An empirical study on its meaning and use. In Empirical Issues in Syntax and Semantics 9: Selected Papers from CSSP, C. Piñón, ed., Pp. 95-112.

Destruel, E.

2013. An empirical approach to the pragmatics of the (non)-canonical French sentences. In Proceedings from the 46th Chicago Linguistic Society Conference, Chicago, USA. 
Destruel, E.

2017. The pragmatics of (non-)prototypical French clefts: Influence of the type of question on naturalness and interpretation. Journal of Pragmatics, 121:58-75.

Destruel, E., D. Beaver, and L. Coppock

2016. Clefts: Quite the contrary! In Proceedings of Sinn und Bedeutung, volume 21.

Destruel, E., D. Velleman, E. Onea, D. Bumford, J. Xue, and D. Beaver 2015. A cross-linguistic study of the non-at-issueness of exhaustive inferences. In Experimental Perspectives on Presuppositions, F. Schwarz, ed., Pp. 135-156. New York: Springer.

Destruel, E. and L. Velleman

2014. Refining contrast: Empirical evidence from the English it-cleft. In Empirical Issus in Syntax and Semantics 10., C. Piñón, ed., Pp. 197-214.

DeVeaugh-Geiss, J., M. Zimmermann, E. Onea, and A.-C. Boell 2015. Contradicting (not-)at-issueness in exclusives and clefts: An empirical study. In Semantics And Linguistic Theory (SALT), S. D'Antonio, M. Moroney, and C. R. Little, eds., volume 25, Pp. 373-393.

Drenhaus, H., M. Zimmermann, and S. Vasishth 2011. Exhaustiveness effects in clefts are not truth-functional. Journal of Neurolinguistics, 24:320-337.

É. Kiss, K. 1987. Configurationality in Hungarian. Dordrecht: Reidel.

É. Kiss, K. 1998. Identification Focus versus Information Focus. Language, 74(2):245-273.

É. Kiss, K. 2006. Focussing as Predication. In The Architecture of Focus, V. Molnár and S. Winkler, eds., Pp. 169-196. Berlin/New York: Mouton de Gruyter.

É. Kiss, K.

2016. Discourse functions: The case of Hungarian. In The Oxford Handbook of Information Structure, C. Féry and S. Ishihara, eds., chapter 33, Pp. 663-685. Oxford: Oxford University Press. 
Gerőcs, M., A. Babarczy, and B. Surányi

2014. Exhaustivity in focus: Experimental evidence from Hungarian. In Language Use and Linguistic Structure, J. Emonds and M. Janebová, eds., Pp. 18194. Olomouc: Palacky University.

Geurts, B. and R. van der Sandt

2004. Interpreting Focus. Theoretical Linguistics, 30:1-44.

Grice, H. P.

1975. Logic and Conversation. In Syntax and Semantics, P. Cole and J. L. Morgan, eds., volume 3: Speech Acts, Pp. 41-58. San Diego, CA: Academic Press.

Groenendijk, J. and F. Roelofsen

2009. Inquisitive semantics and pragmatics. In Proceedings of the ilcli international workshop on semantics, pragmatics, and rhetoric. University of the Basque Country Press.

Gundel, J. K.

1977. Where do cleft sentences come from? Language, 53(3):543-559.

Gundel, J. K.

2006. Clefts in english and norwegian: Some implications for the grammarpragmatics interface. In Constrative Perspectives on Information Structure, V. Molnár and S. Winkler, eds. Berlin/New York: Mouton de Gruyter.

Gundel, J. K.

2008. Contrastive perspectives on cleft sentences: New directions in contrastive linguistics. In Languages and Cultures in Contrast and Comparison, M. A. Gómez-Gonzáles, L. J. Mackenzie, and E. Gonzáles-Álvarez, eds. Amsterdam: J. Benjamins.

Gundel, J. K. and T. Fretheim 2003. Topic and focus. In Handbook of Pragmatic Theory, G. L. Ward and L. Horn, eds., Pp. 175-196. Blackwell Publishing.

Halliday, M. A. K.

1966. Intonation system in English. London: Longman. 
Halvorsen, P.-K.

1978. Syntax and Semantics of Cleft Sentences. In Papers from the 12th Regional Meeting, Chicago Linguistic Society, C. W. S. Mufwene and S. Steever, eds.

Hamblin, C. L.

1973. Questions in Montague English. Foundations of Language, 10:41-53.

Hartmann, R. and F. Stork

1972. Dictionary of language and linguistics. London: Applied Science.

Haspelmath, M.

2004. Coordinating Constructions. Amsterdam: J. Benjamins.

Hedberg, N.

1988. The discourse function of cleft sentences in spoken English. In Paper presented at the Linguistics Society of America Conference, New Orleans.

Hedberg, N.

1990. Discourse Pragmatics and Cleft Sentences in English. PhD thesis, University of Minnesota.

Hedberg, N.

2000. The referential status of clefts. Language, 76:891-920.

Hedberg, N.

2013. Multiple focus and cleft sentences. In Cleft Structures, K. Hartmann and T. Veenstra, eds., Linguistik Aktuell, Pp. 227-250. Amsterdam: J. Benjamins.

Horn, L.

1969. A presuppositional analysis of only and even. In Papers from the 5th Regional Meeting, Chicago Linguistic Society, R. Binnick, ed., Pp. 98-107.

Horn, L.

1981. Exhaustiveness and the Semantics of Clefts. In Papers from the 11th Annual Meeting of NELS, V. Burke and J. Pustejovsky, eds., Pp. 124-142.

Horn, L.

2014. Information Structure and the landscape of (non-) at-issue meaning. In Handbook of Information Structure, C. Fery and S. Ishihara, eds., Pp. 108-127. Oxford: Oxford University Press. 
Horváth, J.

2005. Is 'focus movement' driven by stress? In Approaches to Hungarian: Papers from the Düsseldorf Conference, C. Piñón and P. Siptár, eds. Budapest: Akadémiai Kiadó.

Huber, S.

2006. The complex functions of (it-) clefts. In The Architecture of Focus, V. Molnár and S. Winkler, eds., Pp. 549-572. Berlin/New York: de Gruyter.

Hunter, J. and N. Asher

2016. Shapes of conversation and at-issue content. In Proceedings of Semantics and Linguistic Theory, volume 26, Pp. 1022-1042.

Jackendoff, R. S.

1972. Semantic Interpretation of Generative Grammar. Cambridge, M.A.: MIT Press.

Jespersen, O. 1927. A modern English Grammar 3. London: Allen and Unwin.

Jespersen, O. 1937. Analytic syntax. London: Allen and Unwin.

Jespersen, O. 1949. A Modern English Grammar on Historical Principles, Part VII. Syntax. Copenhagen: Ejnar Munksgaard; London: Allen and Unwin.

Karttunen and Peters 1979. Conventional Implicature. In Syntax and Semantics, C.-K. Oh and D. A. Dinneen, eds., volume 11, Pp. 1-56. New York: Academic Press.

Karttunen, P. 1977. Syntax and semantics of questions. Linguistics and Philosophy, 1:3-44.

Kenesei, I.

1986. On the Logic of Word Order in Hungarian. In Topic, Focus and Configurationality, W. Abraham and S. de Mey, eds., Pp. 143-159. Amsterdam: J. Benjamins. 
Kenesei, I.

2006. Focus as Identification. In The Architecture of Focus, V. Molnár and S. Winkler, eds., Pp. 137-168. Berlin/New York: Mouton de Gruyter.

König, E.

1991. The Meaning of Focus Particles. A Comparative Perspective. London: Routledge.

Korta, K. and J. Perry

2015. Pragmatics. In The Stanford Encyclopedia of Philosophy, Edward N. Zalta, ed. https://plato.stanford.edu/archives/win2015/entries/ pragmatics/: Metaphysics Research Lab, Stanford University.

Krifka, M.

2001. For a structured meaning account of questions and answers. In Audiatur vox sapientia. A Festschrift for Arnim von Stechow, C. Féry and W. Sternefeld, eds., volume 52, Pp. 287-319. Berlin: Akademie Verlag.

Krifka, M.

2008. Basic Notions of Information Structure. Acta Linguistica Hungarica, $55: 243-276$.

Lambrecht, O.

2001. A framework for the analysis of cleft constructions. Linguistics, 39(3):463510.

Levinson, S. C. 1983. Pragmatics. Cambridge: Cambridge University Press.

Mikkelsen, L.

2011. Copular clauses. In Semantics, K. von Heusinger, C. Maienborn, and P. Portner, eds., volume 33.2 of HSK. Berlin/New York: de Gruyter.

Onea, E.

2007. Exhaustivity, Focus and Incorporation in Hungarian. In Proceedings of the Sixteenth Amsterdam Colloquium, M. Aloni, P. Dekker, and F. Roelofsen, eds., Pp. 169-174. 
Onea, E.

2009a. Exhaustiveness of Hungarian Focus. experimental Evidence from Hungarian and German. In Proceedings of "Focus at the syntax semantics interface" Stuttgart 2008, A. Riester and E. Onea, eds.

Onea, E.

2009b. The myth of Hungarian focus. In Current Issues in Unity and Diversity of Languages: Collection of the Papers Selected from the CIL 18. Seoul: Linguistic Society of Korea.

Onea, E.

2016. Potential questions at the semantics-pragmatics interface, volume 33 of Current Research in the Semantics/Pragmatics Interface. Brill.

Onea, E. and D. Beaver

2009. Hungarian Focus is not exhausted. In Proceedings of the 19th Semantics and Linguistic Theory Conference, E. Cormany, S. Ito, and D. Lutz, eds., Pp. 342-359.

Percus, O.

1997. Prying open the Cleft. In Papers from the 27th Annual Meeting of NELS, K. Kusomoto, ed., Pp. 337-351.

Pintér, L.

2016. Preschoolers' interpretation of the focus particle csak 'only' in Hungarian. In 23rd Conference of the Student Organization of Linguistics in Europe (ConSOLE XXIII).

Potts, C.

2005. The Logic of Conventional Implicatures. Oxford: Oxford University Press.

Potts, C.

2015. Presupposition and Implicature. In The Handbook of Contemporary Semantic Theory, S. Lappin and C. Fox, eds., Pp. 168-202. Oxford: Blackwell.

Prince, E.

1978. A comparison of wh-clefts and it-clefts in discourse. Language, 54:883-906.

Quirk, R., S. Greenbaum, G. Leech, and J. Svartvik

1985. A comprehensive grammar of the English language. London: Longman. 
Reinhart, T.

1981. Pragmatics and linguistics: An analysis of sentence topics. Philosophica, 27(1):53-94.

Repp, S.

2010. Defining 'contrast'as an information-structural notion in grammar. Lingua, 120:1333-1345.

Repp, S.

2016. Contrast: Dissecting an elusive information-structural notion and its role in grammar. In The Oxford Handbook of Information Structure, C. Féry and S. Ishihara, eds., Pp. 270-289. Oxford: Oxford University Press.

Roberts, C.

1996. Information Structure: Towards an Integrated Formal Theory of Pragmatics. In OSU Working Papers in Linguistics, J. Yoon and A. Kathol, eds., volume 49, Pp. 91-136. Columbus: Ohio State University.

Roberts, C.

1998. Focus, the flow of information, and Universal Grammar. In The Limits of Syntax, P. Culicover and L. McNally, eds. New York: Academic Press.

Roberts, C.

2006. Only and Conventional Presupposition. The Ohio State University, ms.

Rooth, M.

1985. Association with Focus. University of Massachusetts at Amherst: Graduate Linguistics Student Association.

Rooth, M.

1992. A theory of focus interpretation. Natural Language Semantics, 1:75-116.

Rooth, M.

2016. Alternative Semantics. In The Oxford Handbook of Information Structure, C. Féry and S. Ishihara, eds. Oxford: Oxford University Press.

Selkirk, E. O.

1984. Phonology and Syntax: The Relation between Sound and Structure. Cambridge, M.A.: MIT Press. 
Sgall, P., E. Hajicova, and E. Benesova

1973. Topic, Focus and Generative Semantics. Skripton Verlag: Konberg Taunus.

Simons, M., D. Beaver, C. Roberts, and J. Tonhauser

2017. The Best Question: Explaining the projection behavior of factives. Discourse Processes, 54(3):187-206.

Simons, M., D. Beaver, J. Tonhauser, and C. Roberts

2010. What projects and why. In Proceedings of Semantics and Linguistic Theory, N. Li and D. Lutz, eds., volume 20, Pp. 309-327.

Speaks, J.

2017. Theories of Meaning. In The Stanford Encyclopedia of Philosophy, Edward N. Zalta, ed. https://plato.stanford.edu/archives/fal12017/entries/ meaning/: Metaphysics Research Lab, Stanford University.

Sperber, D. and D. Wilson

2004. Relevance Theory. In The Handbook of Pragmatics, L. Horn and G. L. Ward, eds., Pp. 607-632. Oxford: Blackwell.

Stalnaker, R.

1974. Pragmatic presuppositions. In Semantics and Philosophy, M. Munitz and P. Unger, eds., Pp. 197-213. New York: NYU Press.

Stalnaker, R.

2002. Common Ground. Linguistics and Philosophy, 25:701-721.

Szabolcsi, A.

1981. Compositionality in Focus. Acta Linguistica Societatis Linguistice Europaeae, XV(1-2):141-162.

Szabolcsi, A.

1994. All quantifiers are not equal: The case of focus. Acta Linguistica Hungarica, 42:171-187.

Szendrői, K.

2003. A stress-based approach to the syntax of Hungarian focus. The Linguistics Review, 20:37-78. 
Tonhauser, J.

2012. Diagnosing (not-) at-issue content. In Proceedings of Semantics of Underrepresented Languages of the Americas (SULA), volume 6, Pp. 239-254. UMass, Amherst: GLSA.

Tonhauser, J., D. Beaver, C. Roberts, and M. Simons

2013. Towards a taxonomy of projective content. Language, 89:66-109.

Umbach, C.

2005. Contrast and Information Structure: A focus-based analysis of "but". Linguistics, 43(1):207-232.

van Kuppevelt, J.

1995. Discourse structure, topicality and questioning. Journal of Linguistics, 31:109-147.

van Kuppevelt, J.

1996. Inferring from topics. Linguistics and Philosophy, 19(4):393-443.

Velleman, D. and D. Beaver

2016. Question-based models of Information Structure. In The Handbook of Information Structure, C. Féry and S. Ishihara, eds. Oxford: Oxford University Press.

Velleman, D., D. Beaver, E. Destruel, D. Bumford, E. Onea, and E. Coppock 2012. It-clefts are IT (inquiry terminating) Constructions. In Proceedings of the 22nd Semantics and Linguistic Theory Conference, A. Chereches, ed., Pp. 441460.

von Stechow, A.

1989. Distinguo - eine Antwort an Dieter Wunderlich. Linguistische Berichte, 122:330-339.

Wedgwood, D.

2005. Shifting the Focus: From Static Structures to the Dynamics of Interpretation. Amsterdam: Elsevier.

Wedgwood, D., G. Pethö, and R. Can

2006. Hungarian Focus Position and English It-Clefts: The Semantic Underspecification of Focus Readings. Ms., University of Edinburgh. 
Xue, J. and E. Onea

2011. Correlation between presupposition projection and at-issueness: An empirical study. In Proceedings of the ESSLLI 2011 Workshop on Projective Meaning, Ljubljana, Pp. 171-184.

Zimmermann, M.

2008. Contrastive focus and emphasis. Acta Linguistica Hungarica, Pp. 347360.

Zimmermann, M.

2011. The expression of focus in West Chadic: Variation and uniformity in and across languages. Linguistics, 49:1163-1213.

Zimmermann, M. and C. Féry

2010. Introduction. In Information Structure. Theoretical, Typological, and Experimental Perspectives, M. Zimmermann and C. Féry, eds., Pp. 1-11. Oxford: Oxford University Press.

Zimmermann, M. and E. Onea

2011. Focus marking and focus interpretation. Lingua, 121:1651-1670.

Zondervan, A.

2009. Experiments on QUD and focus as a contextual constraint on scalar implicature calculation. In Semantics and Pragmatics: From experiment to theory, U. Sauerland and K. Yatsushiro, eds., Pp. 94-112. Basingstoke: Palgrave Macmillan.

Zondervan, A.

2010. Scalar Implicatures or Focus: An Experimental Approach. PhD thesis, LOT Utrecht.

Zondervan, A., L. Meroni, and A. Gualmini 2008. Experiments on the role of the question under discussion for ambiguity resolution and implicature computation in adults. Semanntics and Linguistic theory, 18:765-777. 


\section{Chapter 7}

\section{Appendix: Stimulus Materials}

This appendix lists all experimental stimuli used in the experiments presented in this thesis. The stimuli are listed here in the order they are discussed within the thesis, sorted by chapter. The stimuli are only listed in the original German or Hungarian versions, without further glossing or translations. Additionally, this appendix also includes the results of the production study discussed in chapter 5 of this thesis.

\subsection{Chapter 3}

\subsubsection{Scope of Focus Particles}

\subsubsection{Focus-Background Clefts}

Hintergrund: Es ist ein runder Geburtstag, der 100. der Strecke zwischen GauAlgesheim und Bad Münster.

(1) Und es ist auch ein besonderer Zug, der hier als einziger erwartet wird: einer mit alter Dampflok vorne dran.

Satz (1) ist akzeptabel.

Satz (1) ist nicht akzeptabel.

Worum geht es Ihrer Meinung nach in Satz (1)?

Um den Zug.

Darum, was erwartet wird. 
Was folgt aus dem Satz?

Der Zug wird nicht nur erwartet.

Es werden noch weitere Züge erwartet.

Hintergrund: Die Tatsache, dass sie nun nicht stärkste Partei im politischen Leben Marokkos geworden ist, dürfte dem jungen König Mohammad VI. nicht unbedingt ungelegen kommen. Zwar erlaubt das komplexe marokkanische Wahlsystem keine klare Mehrheit für eine Partei.

(2) Und es ist auch der König, der ganz allein den Premierminister, unabhängig vom Wahlausgang, bestimmt.

Satz (2) ist akzeptabel.

Satz (2) ist nicht akzeptabel.

Worum geht es Ihrer Meinung nach in Satz (2)?

Um den König.

Darum, wer den Premierminister bestimmt.

Was folgt aus dem Satz?

Der König macht auch noch andere Dinge. Andere Leute bestimmen ebenfalls den Premierminister.

Hintergrund: Der Jugendbetreuer sagt: „Ich habe aber gelernt, die Flinte nicht ins Korn zu werfen." Immer wieder sei er motiviert worden, weiterzumachen.

(3) Es ist auch dieser positive Blick auf die Jugendlichen und ihre Perspektiven, der ihm als einziges Mut macht.

Satz (3) ist akzeptabel.

Satz (3) ist nicht akzeptabel.

Worum geht es Ihrer Meinung nach in Satz (3)?

Um den Blick auf die Jugendlichen.

Darum, was ihm Mut macht.

Was folgt aus dem Satz?

Der positive Blick auf die Jugendlichen hat noch weitere Effekte. 
Andere Dinge machen ihm ebenfalls Mut.

Hintergrund: Der Rechtsextremist Vojislav Seselj hatte bereits vor den Wahlen angedeutet, sein Hemd sei ihm näher als der Krönungsmantel Milosevics.

(4) Und es ist auch Seseljs Partei gewesen, die gestern als einzige die selben Zahlen zum Wahlergebnis veröffentlichte wie die Opposition.

Satz (4) ist akzeptabel.

Satz (4) ist nicht akzeptabel.

Worum geht es Ihrer Meinung nach in Satz (4)?

Darum, was Seseljs Partei gemacht hat.

Darum, wer Zahlen zum Wahlergebnis veröffentlicht hat.

Was folgt aus dem Satz?

Seseljs Partei hat noch weitere Dinge gemacht.

Andere Parteien haben auch Zahlen zum Wahlergebnis veröffentlicht.

Hintergrund: Es gibt im Film keinen ermittelnden Kommissar. Dagegen spricht schon, dass der Quasi-Schwiegervater Dr. Olson bei der Polizei erst noch eine (Durchsuchungs) Genehmigung erwirken muss.

(5) Es ist auch Francis, der nachts allein vor dem Wohnwagen von Caligari steht. Satz (5) ist akzeptabel.

Satz (5) ist nicht akzeptabel.

Worum geht es Ihrer Meinung nach in Satz (5)?

Um Francis.

Darum, wer nachts vor dem Wohnwagen steht.

Was folgt aus dem Satz?

Francis hat noch andere Dinge gemacht.

Andere Leute haben auch vor dem Wohnwagen gestanden. 


\subsubsection{Topic-Comment Clefts}

Hintergrund: Stattdessen demonstriert der Kreml Härte. Ein Fehler wäre es jedoch, dies mit Stärke gleichzusetzen. Mit dem Prozess stellt er sich selbst ein erbärmliches Urteil aus. Ein Staat, der sich über drei junge Frauen hermacht, die in anderen Ländern bestenfalls zu einer Ordnungsstrafe verurteilt worden wären, offenbart seine Schwäche. Es ist nicht der starke Staat, den Putin nach außen suggeriert, sondern ein Papiertiger, der durch die Schallwellen der Punkerinnen ins Zittern geriet.

(6) Es war auch erst der Kreml, der als einziger der Causa durch seine Verfolgung globale Aufmerksamkeit verlieh.

Satz (6) ist akzeptabel.

Satz (6) ist nicht akzeptabel.

Worum geht es Ihrer Meinung nach in Satz (6)?

Um den Kreml.

Darum, wer der Causa Aufmerksamkeit verlieh.

Was folgt aus dem Satz?

Der Kreml hat noch andere Dinge gemacht.

Andere Parteien haben ebenfalls dafür gesorgt, dass die Causa beachtet wurde.

Hintergrund: Die zentralen Studien in dieser Debatte liefert das Deutsche Institut für Wirtschaftsforschung (DIW) in Berlin. Von dort stammt die Erkenntnis, dass die reichsten 10 Prozent der Deutschen etwa zwei Drittel des gesamten Volksvermögens besitzen.

(7) Und es war auch das DIW, das jüngst als einziges ausgerechnet hat, was eine einmalige Vermögensabgabe von 10 Prozent bringen würde.

Satz (7) ist akzeptabel.

Satz (7) ist nicht akzeptabel.

Worum geht es Ihrer Meinung nach in Satz (7)?

Um das DIW.

Darum, wer etwas ausgerechnet hat. 
Was folgt aus dem Satz?

Das DIW hat noch andere Dinge gemacht.

Andere Institute haben auch Ergebnisse zur Frage der Vermögensabgabe ausgerechnet.

Hintergrund: Nicht verabschiedet hat er sich von seiner Dauerkarte für den Zoo. Jahrelang ist er täglich hierher gekommen, hat täglich den gleichen Weg genommen, sich auf die gleiche Bank gesetzt, den Tieren ins Gesicht gesehen.

(8) Es war auch die Dauerkarte, die ihm als einiziges sein literarisches Debüt beschert hat: „Der Schatten der Tiere“.

Satz (8) ist akzeptabel.

Satz (8) ist nicht akzeptabel.

Worum geht es Ihrer Meinung nach in Satz (8)?

Um die Dauerkarte.

Darum, was ihm zu seinem literarisches Debüt verholfen hat.

Was folgt aus dem Satz?

Die Dauerkarte hat noch zu weiteren Dingen geführt.

Neben der Dauerkarte haben ihm noch weitere Dinge dabei geholfen, sein erstes Buch zu schreiben.

Hintergrund: Erst im letzten Jahr stieg Usbekistan aus der Eurasischen Wirtschaftsgemeinschaft wieder aus, nachdem die EU Sanktionen gegen Taschkent gelockert hatte.

(9) Es war auch Usbekistan, das als einziges Land über eine Verstärkung russischer Militärpräsenz in Kirgisien stark verunsichert war.

Satz (9) ist akzeptabel.

Satz (9) ist nicht akzeptabel.

Worum geht es Ihrer Meinung nach in Satz (9)?

Um Usbekistan.

Darum, wer über das russische Militär verunsichert war. 
Was folgt aus dem Satz?

Usbekistan haben noch weitere Dinge verunsichert.

Andere waren auch unsicher über die russiche Militärpräsenz.

Hintergrund: Alles, was Ibé im Zentrum für Straßenkinder gelernt hat, literarisches Schreiben, Schauspielen, Artistik, vermittelt er nun weiter an die Jüngsten.

(10) Es ist auch Ibé, der als einziger die ganz kleinen Straßenkinder bewusst auf der Straße sucht, um sie in das Haus zu holen.

Satz (10) ist akzeptabel.

Satz (10) ist nicht akzeptabel.

Worum geht es Ihrer Meinung nach in Satz (10)?

Um Ibé.

Darum, wer die Straßenkinder ins Zentrum bringt.

Was folgt aus dem Satz?

Ibé macht auch noch andere Dinge.

Auch andere Leute holen die Straßenkinder ins Haus.

\subsubsection{Filler}

Hintergrund: Nach New York mitgebracht hat Audi auch gleich den 221 kW/300 PS starken S3 mit gestuftem Gepäckabteil.

(11) Derjenige, der als einziger auf der US-Messe noch ein paar Worte zu alternativen Antrieben verliert, ist ein deutscher Autobauer: Mercedes.

Satz (11) ist akzeptabel.

Satz (11) ist nicht akzeptabel.

Worum geht es Ihrer Meinung nach in Satz (11)?

Um alternative Antriebe.

Um deutsche Autobauer.

Was folgt aus dem Satz?

Mercedes hat auch noch weitere Dinge gemacht. 
Andere Autohersteller haben ebenfalls etwas zu alternativen Antrieben gesagt.

Hintergrund: Gleich am ersten Wochenende nahm "The Lost World" in den USA nahezu 100 Millionen Dollar ein. Die Spannung von "The Lost World" hat nichts mehr mit der Sympathie und Anteilnahme zu tun, die das Kinopublikum den Charakteren entgegenbringt, sondern mit reinem Kult.

(12) Derjenige, der alle paar Jahre wieder am besten der Branche, wie das Metier beherrscht wird, ist Steven Spielberg.

Satz (12) ist akzeptabel.

Satz (12) ist nicht akzeptabel.

Worum geht es Ihrer Meinung nach in Satz (12)?

Um Steven Spielberg.

Um den besten der Branche.

Was folgt aus dem Satz?

Steven Spielberg hat noch weitere Dinge gemacht.

Noch andere Regisseure sind sehr gut.

Hintergrund: Im Forf Bütschwiel herrscht noch eine große Heimatverbundenheit. Für das Fest am Nationalfeiertag in Bütschwil werden alle Bewohner des Dorfes aktiv. Ein Verein aus dem Dorf organisiert die Feierlichkeiten jedes Jahr. Seit einigen Jahren wechselt er mit dem Fussballclub ab.

(13) Das, was allen immer am meisten Spaß macht, ist die Parade aller Vereine. Satz (13) ist akzeptabel.

Satz (13) ist nicht akzeptabel.

Worum geht es Ihrer Meinung nach in Satz (13)?

Um die Parade.

Um die Frage, was den Dorfbewohnern am besten gefällt.

Was folgt aus dem Satz?

Die Vereine machen noch etwas anderes als die Parade.

Den Dorfbewohnern gefallen noch andere Dinge außer der Parade. 
Hintergrund: Auf dem Rundgang durch den Baumarkt sagte Andreas Schatzmann, Direktor: "Sogar wenn einer eine Holzhütte bauen will, findet er bei uns alles, vom Holzbalken bis hin zur Solareinheit."

(14) Diejenigen, die hier am schnellsten finden, was sie suchen, sind Heimwerker. Satz (14) ist akzeptabel.

Satz (14) ist nicht akzeptabel.

Worum geht es Ihrer Meinung nach in Satz (14)?

Um Heimwerker.

Darum, was man in einem Baumarkt finden kann.

Was folgt aus dem Satz?

Heimwerker können woanders nicht gut einkaufen. Andere Kunden können auch im Baumarkt fündig werden.

Hintergrund: Aus den Debatten vom Regierungsrat entnehmen wir aber, dass echtes Sparen - nicht Umlagern - nicht so einfach ist. Trotzdem sind ein paar Millionen gespart oder zumindest gestrichen worden. Für ganz grosse Einsparungen müssten wir unser Sozialgefüge auseinanderbrechen und unsere Sicherheit vernachlässigen.

(15) Das, was die allerbeste Lösung wäre, ist die Suche nach Mehreinnahmen.

Satz (15) ist akzeptabel.

Satz (15) ist nicht akzeptabel.

Worum geht es Ihrer Meinung nach in Satz (15)?

Um mögliche Lösungen.

Um Mehreinnahmen.

Was folgt aus dem Satz?

Es gibt noch andere Lösungen.

Mehreinnahmen sollten auch in anderen Bereichen eingesetzt werden. 
Hintergrund: Das Komitee für einen autofreien Sonntag wünscht allen Mitbürgerinnen und Mitbürgern am kommenden Sonntag einen fröhlichen, gemütlichen, autofreien Sonntag. Möge er beweisen, dass wir wenigstens für einmal aufs Auto verzichten können.

(16) Das, was dieser autofreie Sonntag auch bietet, ist die einzige Gelegenheit, wieder einmal einen ruhigen Tag mit der Familie zu verbringen.

Satz (16) ist akzeptabel.

Satz (16) ist nicht akzeptabel.

Worum geht es Ihrer Meinung nach in Satz (16)?

Um den autofreien Sonntag.

Um Familien.

Was folgt aus dem Satz?

Der Sonntag ist aus anderen Gründen auch noch besonders.

Man kann den Sonntag auch mit Freunden verbringen.

Hintergrund: Im Spätherbst ist vorgesehen, das Genehmigungsverfahren einzuleiten und bei der Gemeinde den Antrag auf eine Konzession zu stellen. Vorgängig wurden bereits Pfähle in das Hafenbecken gerammt. Diese Massnahme dient dazu, die Geologie zu ergründen und die Tragfähigkeit der Bodenschichten abzuklären.

(17) Diejenigen, die später ausschließlich von den Holzpfählen profitieren können, sind die Touristen.

Satz (17) ist akzeptabel.

Satz (17) ist nicht akzeptabel.

Worum geht es Ihrer Meinung nach in Satz (17)?

Um die Pfähle.

Um Touristen.

Was folgt aus dem Satz?

Es werden auch noch andere Menschen von den Pfählen profitieren.

Touristen können auch negative Erfahrungen mit den Pfählen machen. 
Hintergrund: Zurück nach Europa wollte der Banker nicht mehr, und so machte er sich mit einer ungewöhnlichen Idee selbständig: "Die Stadt hat soviel an Natur und Geschichte zu bieten, dass sich der Gedanke, hier zu wandern, geradezu aufdrängt."

(18) Was er Banker nun macht ist, die spektakulärsten Wanderungen für Gruppen anzubieten.

Satz (18) ist akzeptabel.

Satz (18) ist nicht akzeptabel.

Worum geht es Ihrer Meinung nach in Satz (18)?

Um Wanderungen.

Um die Art der Gruppe.

Was folgt aus dem Satz?

Es gibt auch noch weniger gute Wanderungen, die angeboten werden.

Die Wanderungen werden auch für Einzelpersonen angeboten.

Hintergrund: Anzeigenblätter verfügen im Gegensatz zu Tageszeitungen zwar über keine Vollredaktionen. Längst haben sich jedoch viele Titel zu wichtigen, manche sogar zu den wichtigsten regionalen oder lokalen Medien überhaupt entwickelt. Die redaktionelle Qualität ist in den vergangenen Jahren in vielen Regionen deutlich gestiegen.

(19) Das, woraus die Redanktionen ausschließlich bestehen, sind All-Rounder die häufig die Titel nicht nur redaktionell bestücken sondern auch gestalten.

Satz (19) ist akzeptabel.

Satz (19) ist nicht akzeptabel.

Worum geht es Ihrer Meinung nach in Satz (19)?

Um Zeitungen.

Um Mitarbeiter der Zeitungen.

Was folgt aus dem Satz?

Die Redanktionen bestehen auch noch aus anderen Mitarbeitern.

All-Rounder arbeiten auch noch in anderen Branchen. 
Hintergrund: Wenn über 4200 Personen mitten in der Nacht bei Stromausfall von einem sich steil zur Seite neigenden, fast 70 Meter hohen Schiff evakuiert werden müssen, sind chaotische Szenen unvermeidlich. Damit soll nichts entschuldigt werden - doch dass es bei der Havarie nicht mehr Tote gab, grenzt an ein Wunder.

(20) Derjenige, der der Costa Concordia allein zum Verhängnis wurde, war der Kapitän.

Satz (20) ist akzeptabel.

Satz (20) ist nicht akzeptabel.

Worum geht es Ihrer Meinung nach in Satz (20)?

Um die Costa Concordia.

Um den Kapitän.

Was folgt aus dem Satz?

Andere Dinge sind der CC auch noch zum Verhängnis geworden.

Der Kapitän hat auch noch andere Dinge getan.

\subsubsection{Judgment Experiment}

\subsubsection{Clefts}

1. Es ist die Einsamkeit, die die Menschen immer wieder an den Spieltisch treibt.

2. Es ist nur die Einsamkeit, die die Menschen immer wieder an den Spieltisch treibt.

3. Es ist auch die Einsamkeit, die die Menschen immer wieder an den Spieltisch treibt.

4. Es ist vor allem die Einsamkeit, die die Menschen immer wieder an den Spieltisch treibt.

5. Es ist nicht zuletzt die Einsamkeit, die die Menschen immer wieder an den Spieltisch treibt.

6. Es ist sogar die Einsamkeit, die die Menschen immer wieder an den Spieltisch treibt.

7. Es ist Stephen Spielberg, der als Regisseur den Film vorantreibt. 
8. Es ist nur Stephen Spielberg, der als Regisseur den Film vorantreibt.

9. Es ist auch Stephen Spielberg, der als Regisseur den Film vorantreibt.

10. Es ist vor allem Stephen Spielberg, der als Regisseur den Film vorantreibt.

11. Es ist nicht zuletzt Stephen Spielberg, der als Regisseur den Film vorantreibt.

12. Es ist sogar Stephen Spielberg, der als Regisseur den Film vorantreibt.

13. Es ist die Tiefe des Kraters, die die Wissenschaftler fasziniert.

14. Es ist nur die Tiefe des Kraters, die die Wissenschaftler fasziniert.

15. Es ist auch die Tiefe des Kraters, die die Wissenschaftler fasziniert.

16. Es ist vor allem die Tiefe des Kraters, die die Wissenschaftler fasziniert.

17. Es ist nicht zuletzt die Tiefe des Kraters, die die Wissenschaftler fasziniert.

18. Es ist sogar die Tiefe des Kraters, die die Wissenschaftler fasziniert.

19. Es ist Michael Ballack, der es oft schafft, einen Ball in bedrängter Position anzunehmen.

20. Es ist nur Michael Ballack, der es oft schafft, einen Ball in bedrängter Position anzunehmen.

21. Es ist auch Michael Ballack, der es oft schafft, einen Ball in bedrängter Position anzunehmen.

22. Es ist vor allem Michael Ballack, der es oft schafft, einen Ball in bedrängter Position anzunehmen.

23. Es ist nicht zuletzt Michael Ballack, der es oft schafft, einen Ball in bedrängter Position anzunehmen.

24. Es ist sogar Michael Ballack, der es oft schafft, einen Ball in bedrängter Position anzunehmen.

25. Es ist der Wiedererkennungswert, der diese Ausstellung so reizvoll macht.

26. Es ist nur der Wiedererkennungswert, der diese Ausstellung so reizvoll macht.

27. Es ist auch der Wiedererkennungswert, der diese Ausstellung so reizvoll macht. 
28. Es ist vor allem der Wiedererkennungswert, der diese Ausstellung so reizvoll macht.

29. Es ist nicht zuletzt der Wiedererkennungswert, der diese Ausstellung so reizvoll macht.

30. Es ist sogar der Wiedererkennungswert, der die Ausstellung so reizvoll macht.

31. Es ist Seneca, der den zögernden Kaiser drängt, die Mutter zu beseitigen.

32. Es ist nur Seneca, der den zögernden Kaiser drängt, die Mutter zu beseitigen.

33. Es ist auch Seneca, der den zögernden Kaiser drängt, die Mutter zu beseitigen.

34. Es ist vor allem Seneca, der den zögernden Kaiser drängt, die Mutter zu beseitigen.

35. Es ist nicht zuletzt Seneca, der den zögernden Kaiser drängt, die Mutter zu beseitigen.

36. Es ist sogar Seneca, der den zögernden Kaiser drängt, die Mutter zu beseitigen.

37. Es ist der medizinische Fortschritt, der die Kosten in die Höhe treibt.

38. Es ist nur der medizinische Fortschritt, der die Kosten in die Höhe treibt.

39. Es ist auch der medizinische Fortschritt, der die Kosten in die Höhe treibt.

40. Es ist vor allem der medizinische Fortschritt, der die Kosten in die Höhe treibt.

41. Es ist nicht zuletzt der medizinische Fortschritt, der die Kosten in die Höhe treibt.

42. Es ist sogar der medizinische Fortschritt, der die Kosten in die Höhe treibt.

43. Es ist Qaradawi, der auf Anfrage eines islamischen Armee-Seelsorgers mit anderen Gelehrten ein Fatwa für Muslime im amerikanischen Militär verfasste.

44. Es ist nur Qaradawi, der auf Anfrage eines islamischen Armee-Seelsorgers mit anderen Gelehrten ein Fatwa für Muslime im amerikanischen Militär verfasste. 
45. Es ist auch Qaradawi, der auf Anfrage eines islamischen Armee-Seelsorgers mit anderen Gelehrten ein Fatwa für Muslime im amerikanischen Militär verfasste.

46. Es ist vor allem Qaradawi, der auf Anfrage eines islamischen Armee-Seelsorgers mit anderen Gelehrten ein Fatwa für Muslime im amerikanischen Militär verfasste.

47. Es ist nicht zuletzt Qaradawi, der auf Anfrage eines islamischen ArmeeSeelsorgers mit anderen Gelehrten ein Fatwa für Muslime im amerikanischen Militär verfasste.

48. Es ist sogar Qaradawi, der auf Anfrage eines islamischen Armee-Seelsorgers mit anderen Gelehrten ein Fatwa für Muslime im amerikanischen Militär verfasste.

49. Es ist das Nahrungsangebot, das die Halden für Möwen attraktiv macht.

50. Es ist nur das Nahrungsangebot, das die Halden für Möwen attraktiv macht.

51. Es ist auch das Nahrungsangebot, das die Halden für Möwen attraktiv macht.

52. Es ist vor allem das Nahrungsangebot, das die Halden für Möwen attraktiv macht.

53. Es ist nicht zuletzt das Nahrungsangebot, das die Halden für Möwen attraktiv macht.

54. Es ist sogar das Nahrungsangebot, das die Halden für Möwen attraktiv macht.

55. Es ist Jennifer Lawrence, die den Film zu einem Höhepunkt des Abends macht.

56. Es ist nur Jennifer Lawrence, die den Film zu einem Höhepunkt des Abends macht.

57. Es ist auch Jennifer Lawrence, die den Film zu einem Höhepunkt des Abends macht.

58. Es ist vor allem Jennifer Lawrence, die den Film zu einem Höhepunkt des Abends macht.

59. Es ist nicht zuletzt Jennifer Lawrence, die den Film zu einem Höhepunkt des Abends macht. 
60. Es ist sogar Jennifer Lawrence, die den Film zu einem Höhepunkt des Abends macht.

61. Es ist die Uniform der Feuerwehrleute, die die kleinen Kinder beeindruckt.

62. Es ist nur die Uniform der Feuerwehrleute, die die kleinen Kinder beeindruckt.

63. Es ist auch die Uniform der Feuerwehrleute, die die kleinen Kinder beeindruckt.

64. Es ist vor allem die Uniform der Feuerwehrleute, die die kleinen Kinder beeindruckt.

65. Es ist nicht zuletzt die Uniform der Feuerwehrleute, die die kleinen Kinder beeindruckt.

66. Es ist sogar die Uniform der Feuerwehrleute, die die kleinen Kinder beeindruckt.

67. Es ist Werner Langen, der die Sache im Europäischen Parlament als Berichterstatter massiv angeschoben hat.

68. Es ist nur Werner Langen, der die Sache im Europäischen Parlament als Berichterstatter massiv angeschoben hat.

69. Es ist auch Werner Langen, der die Sache im Europäischen Parlament als Berichterstatter massiv angeschoben hat.

70. Es ist vor allem Werner Langen, der die Sache im Europäischen Parlament als Berichterstatter massiv angeschoben hat.

71. Es ist nicht zuletzt Werner Langen, der die Sache im Europäischen Parlament als Berichterstatter massiv angeschoben hat.

72. Es ist sogar Werner Langen, der die Sache im Europäischen Parlament als Berichterstatter massiv angeschoben hat.

\subsubsection{Non-clefted version}

1. Die Einsamkeit treibt die Menschen immer wieder an den Spieltisch.

2. Nur die Einsamkeit treibt die Menschen immer wieder an den Spieltisch.

3. Auch die Einsamkeit treibt die Menschen immer wieder an den Spieltisch. 
4. Vor allem die Einsamkeit treibt die Menschen immer wieder an den Spieltisch.

5. Nicht zuletzt die Einsamkeit treibt die Menschen immer wieder an den Spieltisch.

6. Sogar die Einsamkeit treibt die Menschen immer wieder an den Spieltisch.

7. Stephen Spielberg treibt als Regisseur den Film voran.

8. Nur Stephen Spielberg treibt als Regisseur den Film voran.

9. Auch Stephen Spielberg treibt als Regisseur den Film voran.

10. Vor allem Stephen Spielberg treibt als Regisseur den Film voran.

11. Nicht zuletzt Stephen Spielberg treibt als Regisseur den Film voran.

12. Sogar Stephen Spielberg treibt als Regisseur den Film voran.

13. Die Tiefe des Kraters fasziniert die Wissenschaftler.

14. Nur die Tiefe des Kraters fasziniert die Wissenschaftler.

15. Auch die Tiefe des Kraters fasziniert die Wissenschaftler.

16. Vor allem die Tiefe des Kraters fasziniert die Wissenschaftler.

17. Nicht zuletzt die Tiefe des Kraters fasziniert die Wissenschaftler.

18. Sogar die Tiefe des Kraters fasziniert die Wissenschaftler.

19. Michael Ballack schafft es oft, einen Ball in bedrängter Position anzunehmen.

20. Nur Michael Ballack schafft es oft, einen Ball in bedrängter Position anzunehmen.

21. Auch Michael Ballack schafft es oft, einen Ball in bedrängter Position anzunehmen.

22. Vor allem Michael Ballack schafft es oft, einen Ball in bedrängter Position anzunehmen.

23. Nicht zuletzt Michael Ballack schafft es oft, einen Ball in bedrängter Position anzunehmen.

24. Sogar Michael Ballack schafft es oft, einen Ball in bedrängter Position anzunehmen.

25. Der Wiedererkennungswert macht die Ausstellung so reizvoll.

26. Nur der Wiedererkennungswert macht die Ausstellung so reizvoll. 
27. Auch der Wiedererkennungswert macht die Ausstellung so reizvoll.

28. Vor allem der Wiedererkennungswert macht die Ausstellung so reizvoll.

29. Nicht zuletzt der Wiedererkennungswert macht die Ausstellung so reizvoll.

30. Sogar der Wiedererkennungswert macht die Ausstellung so reizvoll.

31. Seneca drängt den zögernden Kaiser, die Mutter zu beseitigen.

32. Nur Seneca drängt den zögernden Kaiser, die Mutter zu beseitigen.

33. Auch Seneca drängt den zögernden Kaiser, die Mutter zu beseitigen.

34. Vor allem Seneca drängt den zögernden Kaiser, die Mutter zu beseitigen.

35. Nicht zuletzt Seneca drängt den zögernden Kaiser, die Mutter zu beseitigen.

36. Sogar Seneca drängt den zögernden Kaiser, die Mutter zu beseitigen.

37. Der medizinische Fortschritt treibt die Kosten in die Höhe.

38. Nur der medizinische Fortschritt treibt die Kosten in die Höhe.

39. Auch der medizinische Fortschritt treibt die Kosten in die Höhe.

40. Vor allem der medizinische Fortschritt treibt die Kosten in die Höhe.

41. Nicht zuletzt der medizinische Fortschritt treibt die Kosten in die Höhe.

42. Sogar der medizinische Fortschritt treibt die Kosten in die Höhe.

43. Qaradawi verfasste auf Anfrage eines islamischen Armee-Seelsorgers mit anderen Gelehrten ein Fatwa für Muslime im amerikanischen Militär.

44. Nur Qaradawi verfasste auf Anfrage eines islamischen Armee-Seelsorgers mit anderen Gelehrten ein Fatwa für Muslime im amerikanischen Militär.

45. Auch Qaradawi verfasste auf Anfrage eines islamischen Armee-Seelsorgers mit anderen Gelehrten ein Fatwa für Muslime im amerikanischen Militär.

46. Vor allem Qaradawi verfasste auf Anfrage eines islamischen Armee-Seelsorgers mit anderen Gelehrten ein Fatwa für Muslime im amerikanischen Militär.

47. Nicht zuletzt Qaradawi verfasste auf Anfrage eines islamischen Armee-Seelsorgers mit anderen Gelehrten ein Fatwa für Muslime im amerikanischen Militär. 
48. Sogar Qaradawi verfasste auf Anfrage eines islamischen Armee-Seelsorgers mit anderen Gelehrten ein Fatwa für Muslime im amerikanischen Militär.

49. Das Nahrungsangebot macht die Halden für Möwen attraktiv.

50. Nur das Nahrungsangebot macht die Halden für Möwen attraktiv.

51. Auch das Nahrungsangebot macht die Halden für Möwen attraktiv.

52. Vor allem das Nahrungsangebot macht die Halden für Möwen attraktiv.

53. Nicht zuletzt das Nahrungsangebot macht die Halden für Möwen attraktiv.

54. Sogar das Nahrungsangebot macht die Halden für Möwen attraktiv.

55. Jennifer Lawrence macht den Film zu einem Höhepunkt des Abends.

56. Nur Jennifer Lawrence macht den Film zu einem Höhepunkt des Abends.

57. Auch Jennifer Lawrence macht den Film zu einem Höhepunkt des Abends.

58. Vor allem Jennifer Lawrence macht den Film zu einem Höhepunkt des Abends.

59. Nicht zuletzt Jennifer Lawrence macht den Film zu einem Höhepunkt des Abends.

60. Sogar Jennifer Lawrence macht den Film zu einem Höhepunkt des Abends.

61. Die Uniform der Feuerwehrleute beeindruckt die kleinen Kinder.

62. Nur die Uniform der Feuerwehrleute beeindruckt die kleinen Kinder.

63. Auch die Uniform der Feuerwehrleute beeindruckt die kleinen Kinder.

64. Vor allem die Uniform der Feuerwehrleute beeindruckt die kleinen Kinder.

65. Nicht zuletzt die Uniform der Feuerwehrleute beeindruckt die kleinen Kinder.

66. Sogar die Uniform der Feuerwehrleute beeindruckt die kleinen Kinder.

67. Werner Langen hat die Sache im Europäischen Parlament als Berichterstatter massiv angeschoben.

68. Nur Werner Langen hat die Sache im Europäischen Parlament als Berichterstatter massiv angeschoben.

69. Auch Werner Langen hat die Sache im Europäischen Parlament als Berichterstatter massiv angeschoben. 
70. Vor allem Werner Langen hat die Sache im Europäischen Parlament als Berichterstatter massiv angeschoben.

71. Nicht zuletzt Werner Langen hat die Sache im Europäischen Parlament als Berichterstatter massiv angeschoben.

72. Sogar Werner Langen hat die Sache im Europäischen Parlament als Berichterstatter massiv angeschoben.

\subsection{Chapter 4}

Since the stimuli for the experiments in this chapter were presented in spoken form, the intonation pattern is made visible in the following stimuli lists. Capitalized words are spoken with a pitch accent.

\subsubsection{Experiment 1}

\subsubsection{Context Story German}

Hintergrundgeschichte:

Heute findet auf dem Bauernhof eine große Kostümparty statt. Viele Tiere sind zu der Party gekommen, unter anderem der Hund, die Katze, das Schwein und die Ente.

Da es ein besonderer Anlass ist, haben die Tiere sich etwas Besonderes angezogen oder lustige Accessoires dabei.

Der Marder wurde nicht eingeladen und ist deswegen sauer. Er will aber genau wissen, was passiert, und deshalb schreibt er mit seinem Freund dem Pony, das auf der Party ist, Nachrichten hin und her.

Der Marder liebt nichts mehr als exakte Informationen. Er will ganz genau wissen, was auf der Party passiert und welche Kleidung und Accessoires die Tiere jeweils tragen. Er interessiert sich dabei ausschließlich für den Hund, die Katze, das Schwein und die Ente.

Dazu stellt der Marder verschiedene Fragen und das Pony versucht diese so genau wie möglich zu beantworten. Die anderen Tiere auf der Party haben vom Plan des Marder erfahren und wechseln ständig die Kostüme und Accessoires, um den Marder zu ärgern. Das Pony versucht zwar, so schnell wie möglich Bericht zu erstatten, hat aber zwischendurch Schwierigkeiten, mit den schnellen Kostümwechseln Schritt zu halten.

\subsubsection{Context Story Hungarian}

Háttértörténet: 
A tanyán ma nagy jelmezbált tartanak. Sok állat érkezett a buliba, többek között a kutya, a macska, a malac és a kacsa. Mivel ez egy különleges alkalom, az állatok külön beöltöztek, vagy vicces kiegészítóket viselnek. M.-et a menyétet nem hívták meg, aki ezért meg is haragudott. Ennek ellenére pontosan tudni akarja, hogy mi történik, ezért a bulin lévő barátjával P.-vel, a pónival üzengetnek egymásnak. M. mindennél jobban szereti a pontos információkat. Pontosan tudni akarja, mi történik a bulin, milyen ruhákat és kiegészítőket viselnek az egyes állatok. Azonban csak a kutyára, a macskára, a malaca és a kacsára kíváncsi. Ezért M. különbözô kérdeseket tesz fel és P. megpróbálja ezeket a leghető legpontosabban megválaszolni. A többi állat a buliban értesült M. tervéról, ezért állandóan más jelmezbe bújnak és más kiegészítóket vesznek fel, hogy M.-et idegesítsék. P. megpróbál, olyan gyorsan beszámolni, ahogy csak lehet, de egy idő után nehezen tudja tartani a lépést a jelmezcserékkel.

\subsubsection{German Stimuli}

\subsubsection{Target Items}

$[$ FB, +StrFoc, +FocPart, + TRUE $] /[$ FB, +StrFoc, +FocPart, +MORE $]$ :

1. Wer trägt einen Umhang? Es ist auch der Hund der einen Umhang trägt.

2. Wer trägt eine Brille? Es ist auch die Ente, die eine Brille trägt.

3. Wer trägt einen Schal? Es ist auch das Schwein, das einen Schal trägt.

4. Wer trägt einen Hut? Es ist auch die Katze, die einen Hut trägt.

[FB, +StrFoc,-FocPart, +TRUE]/ [FB, +StrFoc,-FocPart, +FALSE $] /$ [FB, +StrFoc,-FocPart, +MORE]:

1. Wer trägt einen Umhang? Es ist DER HUND, der einen Umhang trägt.

2. Wer trägt eine Brille? Es ist DIE ENTE, die eine Brille trägt.

3. Wer trägt einen Schal? Es ist DAS SCHWEIN, das einen Schal trägt.

4. Wer trägt einen Hut? Es ist DIE KATZE, die einen Hut trägt.

[FB, -StrFoc, +FocPart, +TRUE] / [FB, -StrFoc,+FocPart, +MORE]:

1. Wer trägt einen Umhang? Auch der Hund trägt einen Umhang.

2. Wer trägt eine Brille? Auch die Ente trägt eine Brille. 
3. Wer trägt einen Schal? Auch das Schwein trägt einen Schal.

4. Wer trägt einen Hut? Auch die Katze trägt einen Hut.

[FB, -StrFoc,-FocPart, +TRUE] / [FB, -StrFoc,-FocPart, +FALSE] / [FB, -StrFoc,-FocPart, +MORE]:

1. Wer trägt einen Umhang? DER HUND trägt einen Umhang.

2. Wer trägt eine Brille? DIE ENTE trägt eine Brille.

3. Wer trägt einen Schal? DAS SCHWEIN trägt einen Schal.

4. Wer trägt einen Hut? DIE KATZE trägt einen Hut.

[TC, +StrFoc,-FocPart, +TRUE] / [TC, +StrFoc,-FocPart, +FALSE] / [TC, +StrFoc,-FocPart, +MORE]:

1. Was weißt du über den Hund? Es ist DER HUND, der einen Umhang trägt.

2. Was weißt du über die Ente? Es ist DIE ENTE, die eine Brille trägt.

3. Was weißt du über das Schwein? Es ist DAS SCHWEIN, das einen Schal trägt.

4. Was weißt du über die Katze? Es ist DIE KATZE, die einen Hut trägt.

[TC, -StrFoc,-FocPart, +TRUE] / [TC, -StrFoc,-FocPart, +FALSE] / [TC, -StrFoc,-FocPart, +MORE]:

1. Was weißt du über den Hund? DER HUND trägt einen Umhang.

2. Was weißt du über die Ente? DIE ENTE trägt eine Brille.

3. Was weißt du über das Schwein? DAS SCHWEIN trägt einen Schal.

4. Was weißt du über die Katze? DIE KATZE trägt einen Hut. 


\subsubsection{Filler Items}

1. Was haben die Tiere? Die Tiere haben eine Ananas.

2. Was haben die Tiere? Die Tiere haben keine Ananas.

3. Was haben die Tiere? Einige Tiere haben eine ANANAS.

4. Was haben die Tiere? Einige Tiere haben keine ANANAS.

5. Was kannst du über die Tiere sagen? Die meisten Tiere haben ein TELEFON.

6. Was kannst du über die Tiere sagen? Die meisten Tiere haben kein Telefon.

7. Was kannst du über die Tiere sagen? Die Hälfte der Tiere hat ein Telefon.

8. Was kannst du über die Tiere sagen? Die Hälfte der Tiere hat kein Telefon.

9. Was kannst du über die Tiere sagen? Mindestens ein Tier hat einen Hammer.

10. Was kannst du über die Tiere sagen? Mindestens ein Tier hat keinen Hammer.

11. Was kannst du über die Tiere sagen? Mindestens zwei Tiere haben einen Hammer.

12. Was kannst du über die Tiere sagen? Mindestens zwei Tiere haben keinen Hammer.

13. Wie viele Tiere haben etwas bekommen? Mehr als drei Tiere haben ein Geschenk bekommen.

14. Wie viele Tiere haben etwas bekommen? Weniger als drei Tiere haben ein Geschenk bekommen.

15. Wie viele Tiere haben etwas bekommen? Mehr als die Hälfte der Tiere hat ein Geschenk bekommen.

16. Wie viele Tiere haben etwas bekommen? Weniger als die Hälfte der Tiere hat ein Geschenk bekommen. 


\subsubsection{Hungarian Stimuli}

\subsubsection{Target Items}

$[$ FB, +StrFoc, +FocPart, + TRUE $] /[$ FB, +StrFoc, +FocPart, +MORE $]$ :

1. Ki vett fel egy köpenyt? Többek között A KUTYA vett fel egy köpenyt.

2. Ki vett fel egy szemüveget? Többek között A KACSA vett fel egy szemüveget.

3. Ki vett fel egy sálat? Többek között A MALAC vett fel egy sálat.

4. Ki vett fel egy kalapot? Többek között A MACSKA vett fel egy kalapot.

[FB, +StrFoc,-FocPart, +TRUE]/ [FB, +StrFoc,-FocPart, +FALSE $] /$ $[\mathrm{FB},+$ StrFoc,-FocPart, +MORE]:

1. Ki vett fel egy köpenyt? A KUTYA vett fel egy köpenyt.

2. Ki vett fel egy szemüveget? A KACSA vett fel egy szemüveget.

3. Ki vett fel egy sálat? A MALAC vett fel egy sálat.

4. Ki vett fel egy kalapot? A MACSKA vett fel egy kalapot.

[FB, -StrFoc, +FocPart, +TRUE] / [FB, -StrFoc, +FocPart, +MORE]:

1. Ki vett fel egy köpenyt? Felvett többek között a kutya egy köpenyt.

2. Ki vett fel egy szemüveget? Felvett többek között a kacsa egy szemüveget.

3. Ki vett fel egy sálat? Felvett többek között a malac egy sálat.

4. Ki vett fel egy kalapot? Felvett többek között a macska egy kalapot.

[FB, -StrFoc,-FocPart, +TRUE] / [FB, -StrFoc,-FocPart, +FALSE] / [FB, -StrFoc,-FocPart, +MORE]:

1. Ki vett fel egy köpenyt? Felvett a kutya egy köpenyt.

2. Ki vett fel egy szemüveget? Felvett a kacsa egy szemüveget.

3. Ki vett fel egy sálat? Felvett a malac egy sálat.

4. Ki vett fel egy kalapot? Felvett a macska egy kalapot. 
[TC, +StrFoc,-FocPart, +TRUE] / [TC, +StrFoc,-FocPart, +FALSE] / [TC, +StrFoc,-FocPart, +MORE]:

1. Mit tudsz a kutyáról? A KUTYA vett fel egy köpenyt.

2. Mit tudsz a kacsáról? A KACSA vett fel egy szemüveget.

3. Mit tudsz a malacról? A MALAC vett fel egy sálat.

4. Mit tudsz a macskáról? A MACSKA vett fel egy kalapot.

[TC, -StrFoc,-FocPart, +TRUE] / [TC, -StrFoc,-FocPart, +FALSE] / [TC, -StrFoc,-FocPart, +MORE]:

1. Mit tudsz a kutyáról? Felvett a kutya egy köpenyt.

2. Mit tudsz a kacsáról? Felvett a kacsa egy szemüveget.

3. Mit tudsz a malacról? Felvett a malac egy sálat.

4. Mit tudsz a macskáról? Felvett a macska egy kalapot.

\subsubsection{Filler Items}

1. Mije van az állatoknak? Az állatoknak van egy ananásza.

2. Mije van az állatoknak? Az állatoknak nincs ananásza.

3. Mije van az állatoknak? ANANÁSZA van néhány állatnak.

4. Mije van az állatoknak? Nem ANANÁSZA van néhány állatnak.

5. Mit tudsz mondani az állatokról? TELEFONJA van a legtöbb állatnak.

6. Mit tudsz mondani az állatokról? A legtöbb állatnak nincs telefonja.

7. Mit tudsz mondani az állatokról? Az állatok felének van telefonja.

8. Mit tudsz mondani az állatokról? Az állatok felének nincs telefonja.

9. Mit tudsz mondani az állatokról? Legalább egy állatnak van egy kalapácsa.

10. Mit tudsz mondani az állatokról? Legalább egy állatnak nincs kalapácsa.

11. Mit tudsz mondani az állatokról? Legalább két állatnak van egy kalapácsa.

12. Mit tudsz mondani az állatokról? Legalább két állatnak nincs kalapácsa. 
CHAPTER 7. APPENDIX: STIMULUS MATERIALS

13. Hány állat kapott valamit? Több mint HÁROM ÁLLAT kapott ajándékot.

14. Hány állat kapott valamit? Kevesebb mint HÁROM ÁLLAT kapott ajándékot.

15. Hány állat kapott valamit? Több mint az ÁLLATOK FELE kapott ajándékot.

16. Hány állat kapott valamit? Kevesebb mint az állatok fele kapott ajándékot.

\subsubsection{Follow-Up Acceptability Study German}

\subsubsection{Target Items} question FB - answer FB

1. Wer trägt einen Umhang? Es ist DER HUND, der einen Umhang trägt.

2. Wer trägt einen Umhang? Es ist auch DER HUND, der einen Umhang trägt.

3. Wer trägt eine Brille? Es ist DIE ENTE, die eine Brille trägt.

4. Wer trägt eine Brille? Es ist auch DIE ENTE, die eine Brille trägt.

5. Wer trägt einen Schal? Es ist DAS SCHWEIN, das einen Schal trägt.

6. Wer trägt einen Schal? Es ist auch DAS SCHWEIN, das einen Schal trägt.

7. Wer trägt einen Hut? Es ist DIE KATZE, die einen Hut trägt.

8. Wer trägt einen Hut? Es ist auch DIE KATZE, die einen Hut trägt. question FB - answer TC

1. Wer trägt einen Umhang? Es ist der Hund, der EINEM UMHANG TRÄGT.

2. Wer trägt einen Umhang? Es ist auch der Hund, der EINEM UMHANG TRÄGT.

3. Wer trägt eine Brille? Es ist die Ente, die EINE BRILLE TRÄGT.

4. Wer trägt eine Brille? Es ist auch die Ente, die EINE BRILLE TRÄGT.

5. Wer trägt einen Schal? Es ist das Schwein, das EINEN SCHAL TRÄGT.

6. Wer trägt einen Schal? Es ist auch das Schwein, das EINEN SCHAL TRÄGT.

7. Wer trägt einen Hut? Es ist die Katze, die EINEN HUT TRÄGT. 
8. Wer trägt einen Hut? Es ist auch die Katze, die EINEN HUT TRÄGT. question TC - answer FB

1. Was weißt du über den Hund? Es ist DER HUND, der einen Umhang trägt.

2. Was weißt du über den Hund? Es ist auch DER HUND, der einen Umhang trägt.

3. Was weißt du über die Ente? Es ist DIE ENTE, die eine Brille trägt.

4. Was weißt du über die Ente? Es ist auch DIE ENTE, die eine Brille trägt.

5. Was weißt du über das Schwein? Es ist DAS SCHWEIN, das einen Schal trägt.

6. Was weißt du über das Schwein? Es ist auch DAS SCHWEIN, das einen Schal trägt.

7. Was weißt du über die Katze? Es ist DIE KATZE, die einen Hut trägt.

8. Was weißt du über die Katze? Es ist auch DIE KATZE, die einen Hut trägt.

question TC - answer TC

1. Was weißt du über den Hund? Es ist der Hund, der EINEM UMHANG TRÄGT.

2. Was weißt du über den Hund? Es ist auch der Hund, der EINEM UMHANG TRÄGT.

3. Was weißt du über die Ente? Es ist die Ente, die EINE BRILLE TRÄGT.

4. Was weißt du über die Ente? Es ist auch die Ente, die EINE BRILLE TRÄGT.

5. Was weißt du über das Schwein? Es ist das Schwein, das EINEN SCHAL TRÄGT.

6. Was weißt du über das Schwein? Es ist auch das Schwein, das EINEN SCHAL TRÄGT.

7. Was weißt du über die Katze? Es ist die Katze, die EINEN HUT TRÄGT.

8. Was weißt du über die Katze? Es ist auch die Katze, die EINEN HUT TRÄGT. 


\subsubsection{Filler Items}

1. Was tragen die Tiere? Alle Tiere tragen EINE MÜTZE.

2. Was tragen die Tiere? Einige Tiere tragen EINE HOSE.

3. Was tragen die Tiere? Es gibt EIN TIER das Gummistiefel trägt.

4. Was tragen die Tiere? Es gibt KEIN TIER, das Gummistiefel trägt.

5. Was tragen die Tiere? Nur ein Tier trägt HANDSCHUHE.

6. Was tragen die Tiere? ALLE TIERE tragen eine Mütze.

7. Was tragen die Tiere? EINIGE TIERE tragen eine Hose.

8. Was tragen die Tiere? NUR ZWEI Tiere tragen Schuhe.

9. Was kannst du über die Tiere sagen? Mehr als drei Tiere tragen SCHUHE.

10. Was kannst du über die Tiere sagen? Weniger als drei Tiere tragen SOCKEN.

11. Was kannst du über die Tiere sagen? ALLE TIERE tragen Socken.

12. Was kannst du über die Tiere sagen? Weniger als die Hälfte der Tiere trägt EINE UHR.

13. Was kannst du über die Tiere sagen? Es gibt EIN TIER, das eine Uhr trägt.

14. Was kannst du über die Tiere sagen? KEIN TIER trägt einen Rock.

15. Was kannst du über die Tiere sagen? Mindestens zwei Tiere tragen EINEN ROCK.

16. Was kannst du über die Tiere sagen? DREI TIERE tragen Gummistiefel.

\subsection{Chapter 5}

\subsubsection{Free Production Pilot Study}

\subsubsection{Stimulus Material}

Instructions:

Vielen Dank, dass Sie sich Zeit nehmen, an unserem Experiment teilzunehmen. 
Im Folgenden lesen Sie kurze Szenarien aus dem Alltag, aus denen sich jeweils 6 Dialoge ergeben. Versetzen Sie sich in die Szenen hinein als würden Sie daran teilnehmen.

Im Dialog stellt Ihr Dialogpartner Ihnen zunächst eine Frage. Darunter steht ein Hinweis in Klammern. Dieser Hinweis soll der Inhalt Ihrer Antwort auf die Frage Ihres Dialogpartners sein.

Unter dem Hinweis steht jeweils: "Sie antworten:" In dieses Feld schreiben Sie einfach den Satz, der Ihnen in dieser Situation als passend erscheint.

Nutzen Sie nur Ihr persönliches Sprachgefühl. Es gibt keine richtigen oder falschen Antworten, wir sind in diesem Experiment nur daran interessiert, mit welchem Satz Sie in den Dialogen reagieren würden.

Hier ein Beispiel:

Sie sind mit Ihrem Freund Thorsten in der Stadt, um einen neuen Wintermantel für sich zu kaufen. Thorsten geht sehr gerne einkaufen und hat Ihnen eine Auswahl bereit gelegt.

Thorsten: Ich finde alle Mäntel toll. Besonders den roten Mantel. Was denkst du?

(Hinweis: blauer Mantel)

Sie antworten:

Hier könnten Sie dann zum Beispiel schreiben "Mir gefällt der blaue Mantel am besten." oder "Ich mag den blauen Mantel." oder "Ich finde nur den blauen Mantel schön."

Wichtig!

Bitte antworten Sie immer in vollständigen Sätzen.

Die Hinweise in den Klammern sollen in ihrem Satz vorkommen, aber selbst in Dialogen, in denen es möglich wäre, nur mit einem Wort zu antworten, sollen Sie ganze Sätze bilden.

\section{Szenario 1}

Sie haben sich mit Ihrer Freundin Alexandra über den diesjährigen Kochwettbewerb unterhalten, an dem sie beide normalerweise teilnehmen. Jedes Jahr gewinnt der Teilnehmer, der das beste Gericht kocht. 
[-cont], [-gen] Alexandra: Wer hat dieses Jahr mitgemacht? Kannst du einen oder zwei Teilnehmer nennen?

(Hinweis: Julia und Stefan)

[+cont], [-gen] Alexandra: Ich habe gehört, dass niemand eine Pizza gemacht hat. Ist das korrekt?

(Hinweis: Felix und einige Freunde)

[-cont], [+gen] Alexandra: Ich habe gehört, dass jemand, den wir kennen, den Wettbewerb gewonnen hat. Wer war das?

(Hinweis: Sarah)

[-cont], [+gen] Alexandra: Ich habe gehört, dass Stefan das beste indische Gericht gekocht hat. Ist das korrekt?

(Hinweis: Max)

[filler] Alexandra: Ich mag die Thailändische Küche am Liebsten. Wie viele Teilnehmer haben dieses Jahr thailändisch gekocht?

(Hinweis: Drei Teilnehmer)

[filler] Alexandra: Ich habe gehört, dass die meisten Teilnehmer in diesem Jahr sehr hohe Punktzahlen erreicht haben. Ist das korrekt?

(Hinweis: Weniger als die Hälfte)

\section{Szenario 2}

Maria, die in Ihrer Nachbarwohnung wohnt, wurde gestern Nacht zwischen 21 und 23 Uhr ermordet. Der Kommissar ist an den Tatort gekommen um alle Nachbarn, Sie eingeschlossen, zu befragen.

[-cont], [-gen] Kommissar: Wer war mit Maria befreundet? Können Sie ein oder zwei Leute nennen?

(Hinweis: Anna und Johann)

[+cont], [-gen] Kommissar: Wir haben gehört, dass niemand die Schüsse gehört hat. Ist das korrekt?

(Hinweis: Anna und ihre Familie)

[-cont], [+gen] Kommissar: Jemand, den Maria kannte, hat als Letztes das Haus verlassen. Wer war das? 
(Hinweis: Peter)

[+cont], [+gen] Kommissar: Wir haben gehört, dass Georg gestern Abend als Letzter mit Maria gesprochen hat. Ist das korrekt?

(Hinweis: Michael)

[filler] Kommissar: Unseren Ermittlungen zufolge hat Maria drei Tage pro Woche als Verkäuferin gearbeitet. Ist das korrekt?

(Hinweis: Fünf Tage pro Woche)

[filler] Kommissar: Wir haben erfahren, dass einige Leute erst vor Kurzem in dieses Haus eingezogen sind. Wie viele der Mieter sind neu?

(Hinweis: Ein Pärchen und zwei Familien)

\section{Szenario 3}

Ein sehr wichtiges Projekt der Firma, in der Sie arbeiten, ist in diesem Jahr geplatzt, und die Firma hat dadurch eine Menge Geld verloren. Bianca aus der Personalabteilung und Sie diskutieren über die Konsequenzen des gescheiterten Projektes.

[-cont], [-gen] Bianca: Wer arbeitet in diesem Team? Können Sie einen oder zwei Mitarbeiter nennen?

(Hinweis: Achim und Lea)

[+cont], [-gen] Bianca: Ich habe gehört, dass niemand seinen Job verloren hat. Ist das korrekt?

(Hinweis: Andreas und sein Team)

[-cont], [+gen] Bianca: Ich habe gehört, dass eine Person im Team die meiste Arbeit geleistet hat. Wer ist das?

(Hinweis: Manuela)

[+cont], [+gen] Bianca: Ich habe gehört, dass der Abteilungsleiter das letzte Wort in der Sache hatte. Ist das korrekt?

(Hinweis: der Vorstandsvorsitzende)

[filler] Bianca: Es gibt Mitarbeiter, die wir nicht in diese Angelegenheit involvieren müssen. Was denken Sie, wen wir außen vor lassen können?

(Hinweis: Die meisten Leute aus Leslies Team) 
[filler] Bianca: I habe herum gefragt und erfahren, dass mehr als drei Mitarbeiter in diesem Projekt wussten, dass es scheitern würde. Ist das korrekt?

(Hinweis: Weniger als fünf)

\section{Szenario 4}

Letzten Samstag haben Sie eine Casting Show im Fernsehen gesehen. Ihre Freundin Tina hat die Sendung verpasst, obwohl sie ein großer Fan ist und jeden Kandidaten kennt. Sie haben sich mit ihr über die Sendung und die Auftritte, die sie gesehen haben, unterhalten.

[-cont], [-gen] Tina: Wer war letzte Woche gut? Kannst du einen oder zwei nennen?

(Hinweis: Ricardo und Larissa)

[+cont], [-gen] Tina: Ich habe gehört, dass niemand einen Rock Song aufgeführt hat. Ist das korrekt?

(Hinweis: Daniel und seine Band)

[-cont], [+gen] Tina: Jede Woche muss der Teilnehmer mit den wenigsten Stimmen die Sendung verlassen. Wer war das?

(Hinweis: Emily)

[+cont], [+gen] Tina: Ich habe gehört, dass Janine den Preis für den besten Tanzauftritt gewonnen hat. Ist das korrekt?

(Hinweis: Marlon)

[filler] Tina: Mir gefallen die Tanzauftritte am Besten. Wie viele Kandidaten haben dieses Mal getanzt?

(Hinweis: Fünf Kandidaten)

[filler] Tina: Einige der Teilnehmer haben mehr als 10\% der Stimmen bekommen. Ist das korrekt?

(Hinweis: Alle Tänzer)

\subsubsection{Results}

The following list shows the sentences that were produced in the various conditions: 
[+pervasive, + contrastive $]$

Also ich glaube es war Max der das beste gekocht hat. well I think it was Max RelPron the best cooked has Well, I think it was Max who cooked the best one.

Es war Max, der das beste indische Gericht gekocht hat. It was Max RelPron the best Indian dish cooked has It was Max who cooked the best Indian dish.

Es war Michael, der als Letzter mit Maria gesprochen hat. It was Michael RelPron as last with Mary talked has It was Michael who was the last person to talk to Mary.

Es war nicht Georg, sondern Michael, der gestern abend als It was not Georg but Michael RelPron yesterday night as letzter mit Maria gesprochen hat.

last with Maria talked has

It was not Georg but Michael who was the last person to talk to Mary last night.

(339) Ich denke, es war Michael, der als Letzter mit ihr gesprochen I think it was Michael RelPron as last with her talked hat.

has

I think it was Michael who was the last person to speak to her.

(340) Nein, es war der Vorstandsvorsitzende, der das letzte Wort hatte. No it was the chief executive RelPron the last word had No, it was the chief executive who had the last word.

(341) Es ware der Vorstandsvorsitzende, der das letzte Wort in der It was the chief executive RelPron the last word in the Sache hatte.

matter had

It was the chief executive who had the last word in the matter.

(342) Soweit ich gehört haben, war es der Vostandsvorsitzende, der As far as I heard have it was the chief executive RelPron das entschieden hat that decided has As far as I heard it was the chief executive who decided that.

(343) Nein, das war der Vorstandsvorsitzende, der zuletzt das Wort No that was the chief executive RelPron as last the word hatte.

had 
No, that was the chief executive who had the last word.

Nein, es war Marlon die den Preis für den besten

No it was Marlon RelPron the price for the best

Tanzauftritt gewonnen hat.

dance performance won has

No, it was Marlon who won the price for the best dance performance.

(345) Es war Marlon, der den Preis gewonnen hat.

It was Marlon RelPron the price won has

It was Marlon who won the price.

[+pervasive, -contrastive]

(346) Es war Peter, der als letztes das Haus verlassen hat.

It was Peter RelPron as last the house left has

It was Peter who was last to leave the house.

(347) Es war Manuela, die die meiste Arbeit geleistet hat.

It was Manuela RelPron the most work achieved has

It was Manuela who did most of the work.

(348) Es war Emily, die die Sendung verlassen musste.

It was Emily RelPron the show leave must

It was Emily who had to leave the show.

\section{Filler}

The it-clefts that were produced in the filler conditions are presented with their respective contexts in order to make the exhaustive and contrastive properties of the contexts transparent.

$[+$ pervasive, + contrastive $]$

Alexandra: Ich habe gehört, dass die meisten Teilnehmer in diesem Jahr sehr hohe Punktzahlen erreicht haben. Ist das korrekt?

(Hinweis: Weniger als die Hälfte)

Alexandra: I heard that most participants received very high points this year. Is that correct? (Hint: less than half)

Es waren nur weniger als die Hälfte der Teilnehmer, die It were only less than ART half of the participants RelPron sehr hohe Punktzahlen erreicht haben.

very high points reached have

It were only less than half of all participants that received very high points. 
Bianca: I habe herum gefragt und erfahren, dass mehr als drei Mitarbeiter in diesem Projekt wussten, dass es scheitern würde. Ist das korrekt?

(Hinweis: Weniger als fünf)

I asked around and found out that more than three people on this project knew that the project would fail. Is that correct? (Hint: less than five)

(350) Möglich, es waren aber auf jeden fall weniger als fünf die

Possible it were but in any case less than five RelPron

davon wussten.

about that knew

That's possible, but it were definitely less than five who knew about that.

(351) Das weiß ich nicht, aber es waren auf jeden Fall weniger als fünf, That know I not but it were in any case less than five die davon wussten.

RelPron about that knew

I don't know, but it were definitely less than five who knew about that.

(352) Ja, aber es waren weniger als fünf Mitarbeiter, die wußten, Yes but it were less than five employees RelPron knew dass das Projekt scheitern würde.

that the project fail would

Yes, but it were less than five employees who knew that the project would fail.

Es waren weniger als fünf Mitarbeiter, die wussten, dass es

It were less than five employees RelPron knew that it scheitern würde.

fail would

It were less than five employees who knew that it would fail.

(354) Ja, das ist zwar korrekt, aber es waren wohl weniger als fünf, Yes that is indeed correct but it were actually less than five die davon wussten.

RelPron about that knew

Yes, that is indeed correct, but it were actually less than five that knew about it.

(355) Ja, es waren insgesamt weniger als fünf Leute, die davon Yes it were in total less than five people RelPron about that wussten.

knew

Yes, it were less than five people all in all that knew about that. 
$[+$ pervasive,-contrastive $]$

Alexandra: Ich mag die Thailändische Küche am Liebsten. Wie viele Teilnehmer haben dieses Jahr thailändisch gekocht?

(Hinweis: Drei Teilnehmer)

I like Thai food the most. How many people cooked a Thai dish this year? (Hint: three candidates)

$$
\begin{aligned}
& \text { Es waren drei Teilnehmer die thailändisch gekocht haben. } \\
& \text { It were three participants RelPron Thai cooked have } \\
& \text { It were three participants that cooked a Thai dish. } \\
& \text { Ich glaube, es waren drei, die thailändisch gekocht haben. } \\
& \text { I think it were three RelPron Thai cooked have } \\
& \text { I think it were three that cooked a Thai dish. }
\end{aligned}
$$

Kommissar: Wir haben erfahren, dass einige Leute erst vor Kurzem in dieses Haus eingezogen sind. Wie viele der Mieter sind neu?

(Hinweis: Ein Pärchen und zwei Familien)

Detective: We heard that some people moved into this building recently. How many tenants are new? (Hint: one couple and two families)

$$
\begin{aligned}
& \text { Es sind ein Pärchen und zwei Familien die neu sind. } \\
& \text { It are a couple and two families RelPron new are } \\
& \text { It is one couple and two families that are new. }
\end{aligned}
$$

Ja, es stimmt, hier sind einige Leute neu eingezogen. Zuletzt war es Yes it is true here are some people new moved in. Last was it ein junges Pärchen und zwei Familien, die neu eingezogen sind. a young couple and two families RelPron new moved in are Yes, that's right, there are a few new people in the building. It was a young couple and two families that moved in last.

Tina: Mir gefallen die Tanzauftritte am Besten. Wie viele Kandidaten haben dieses Mal getanzt?

(Hinweis: Fünf Kandidaten)

My favourites are definitely the dances. How many candidates performed a dance this time? (Hint: five candidates)

Dieses Mal waren es fünf Kandidaten, die getanzt haben.

This time were it five candidates RelPron danced have

This time it were five candidates who danced.

\section{Follow-Up}


[-pervasive, + contrastive]

(361) Nein, es war Anna, die die Schüsse gehört hat.

No it was Anna RelPron the shots heard has

No, it was Anna who heard the shots.

(362) Nein, es war Andreas, der den verloren hat.

No it was Andreas RelPron that lost has

No, it was Andreas who lost that.

[+pervasive, + contrastive]

(363) so weit ich weiss war es der vorstandsvorsitzende der das letzte as far I know was it the chief executive RelPron the last wort hatte.

word had

It was the chief executive who had the last word, as far as I know.

Filler

[+pervasive, +contrastive $]$

Laut meinen Kenntnissen waren es weniger als die Hälfte, According to my knowledge were it fewer than the half

die wirklich hohe Punktzahlen erreicht haben.

RelPron really high points reached have

It were less than half who got really high points, according to my knowledge.

(365) Es waren zumindest weniger als 5 Mitarbeiter, die es wussten.

It were at least less than 5 employees RelPron it knew It were at least less than five employees that knew it.

(366) Ja schon, aber es waren weniger als fünf die davon

Yes ADJ but it were less than five RelPron about that

wussten.

knew

Yes pretty much, but it were less than five who knew about it.

(367) Es waren auf jeden Fall weniger als fünf Leute, die davon It were in any case less than five people RelPron about that wussten.

knew

It were ny any case less than five people who knew about that.

(368) Ich weiß es nicht genau, aber es sind weniger als fünf Leute, I know it not exactly but it are less than five people 
die wussten dass das Projekt scheitern würde.

RelPron knew that the project fail would

I am not sure but it were less than five people who knew that the project would fail.

(369) Es waren weniger als fünf Leute, die davon wussten.

It were less than five people RelPron about that knew

It were less than five people who knew about that.

\section{[+pervasive,-contrastive]}

(370) Drei Teilnehmer waren es, die indisch gekocht haben. Three participants were it RelPron Indian cooked have It were three participants who cooked an Indian dish.

Es waren drei Teilnehmer, die thailändisch gekocht haben.

It were three participants RelPron Thai cooked have

It were three participants who cooked a That dish.

(372) Es sind ein Pärchen und zwei Familien, die neu eingezogen sind. It are a couple and two families RelPron new moved in are It is a couple and two families who moved in recently.

(373) Dieses Mal waren es nur fünf Kandidaten, die getanzt haben. This time were it only five candidates RelPron danced have This time it were only five candidates who danced.

(374) Finde ich auch, diesmal waren es fünf Leute, die getanzt haben. Find I also this time were it five people RelPron danced have I agree, this time it were five people who danced. 


\section{Abstract German}

Die vorliegende Dissertation befasst sich mit der Interpretation von it-clefts (Deutsch: Spaltsätzen) im Deutschen, sowie der verwandten Ungarischen Fokus-Position und präsentiert Antworten zu einer Reihe von Forschungsfragen.

Als it-clefts bezeichnet man Sätze der Form Es war Susi, die einen Berg bestiegen hat.. Es wird gemeinhin angenommen, dass it-clefts bestimmte semantische Restriktionen haben. Es ist allgemein akzeptierte Forschungsmeinung, dass it-clefts eine Exhaustivitätsinferenz beinhalten: Niemand anderes als Sue hat einen Berg bestiegen.

Die vorliegende Dissertation widmet sich der Beantwortung der folgenen 4 Forschungsfragen:

1. Sind it-clefts exhaustiv, und wenn ja, wie sollte die Exhaustivität analysiert werden?

2. Sind it-clefts mit Fokuspartikeln kombinierbar, und wenn ja, können die Partikeln einen Einfluss auf die Exhaustivität haben?

3. Inwiefern unterscheiden sich verschiedene Cleft-Typen hinsichtlich ihrer informationsstrukturellen Funktion und hat dies Einfluss auf die Exhaustiviät?

4. Spielt Kontrastivität eine Rolle in der Produktion von it-clefts?

In Kapitel 2 dieser Dissertation werden zunächst die relevanten syntaktischen, semantischen, sowie pragmatischen Theorien diskutiert, die bisher zum Thema der it-clefts vorgebracht worden sind. Die Struktur dieses Einleitungskapitels wird sich an der inhaltlichen Struktur der gesamten Arbeit orientieren, und die Theorien entsprechend anhand der Themen Exhaustivität, die Rolle von Fokuspartikeln in it-clefts, Kontrastivität und Informationsstruktur.

Kapitel 3 dieser Dissertation präsentiert die Ergebnisse einer umfassenden Korpusstudie zu it-clefts im Deutschen und kommt zu dem Ergebnis, dass diese eher infrequente Satzstruktur tatsächlich recht häufig auftritt. Zur Frage der Exhaustvität wird sich in einer Kombination aus Korpusdaten und experimentellen Daten zeigen, dass it-clefts im Deutschen nicht in allen Fällen exhaustiv sind. 
Zusätzlich wird gezeigt, dass unterschiedliche Fokuspartikeln, sowohl exklusive als auch additive und skalare, in it-clefts vorkommen; ein Phänomen, das bisher in der Literatur häufig abgelehnt wurde. Anhand experimenteller Daten wird gezeigt, dass der Skopus der Fokuspartikeln nicht immer gleich ist, was das Vorkommen von exhaustiven it-clefts mit additiven Fokuspartikeln in der syntaktischen Position unmittelbar vor dem Fokus.

In einer Bewertungsstudie wird gezeigt, dass it-clefts in Kombination mit Fokuspartikeln von Muttersprachlern als akzeptabel bewertet werden.

Es wird weiterhin gezeigt, dass sich zwei unterschiedliche Arten von it-clefts im Deutschen unterscheiden lassen: Fokus-Background sowie Topic-Comment-Clefts. Diese Cleft-Typen haben unterschiedliche informationsstrukturelle Funktionen, was in einem späteren Experiment in Kapitel 4 weiter untersucht werden wird.

In Kapitel 4 dieser Dissertation werden sowohl Deutsche it-clefts als auch die Ungarische Fokusposition experimentell vergleichend untersucht. Es wird dabei zwischen den beiden Cleft-Typen FB- und TC-Clefts unterschieden. Zusätzlich werden die Satzstrukturen beider Sprachen mit einer additiven Fokuspartikel getestet. Dieses Kapitel kombiniert demnach die Ergebnisse der vorherigen Kapitel in einem sprachvergleichenden experimentellen Design.

Das vorgestellte Experiment beantwortet die Frage, ob unterschiedliche overte Kontextfragen einen Einfluss auf die Exhaustivität der Satzstrukturen haben. Zusätzlich zeigt sich, ob additive Fokuspartikeln die Exhaustivität beeinflussen können.

Für das Ungarische wird sich zeigen, dass die Fokusposition exhaustiv ist, allerdings weniger stark als bisher angenommen. Ebenfalls kann gezeigt werden, dass die Ungarische Fokusposition in einer breiteren Menge an Kontexten benutzt werden kann als bisher angenommen.

Für das Deutsche zeigt sich, dass die beiden Cleft-Typen sich in Bezug auf ihre Exhaustivität leicht unterscheiden, und Topic-Comment-Clefts etwas weniger stark exhaustiv sind and Fokus-Background-Clefts.

Zusammen genommen zeigen die erhobenen Daten, dass sowohl die Ungarische Fokusposition, als auch Deutsche it-clefts nicht in jedem Fall exhaustiv sind, und demnach eine semantische Analyse der Exhaustivität nicht beibehalten werden kann.

In Kapitel 5 dieser Dissertation wird in einer Produktionsstudie der Einfluss von Kontrastivität und Exhaustivität auf die Produktion von it-clefts im Deutschen untersucht. Die präsentierten Ergebnisse legen nahe, dass der Kontext einen Einfluss auf die Produktion von it-clefts haben kann: exhaustivie und/oder konstrative Kontexte triggern die Produktion von it-clefts. Dieses Kapitel bietet somit eine Erweiterung um die Dimension der Sprachproduktion. 
In Kapitel 6 dieser Dissertation folgt eine Zusammenfassung der Ergebnisse der vorherigen Kapitel, sowie ein Überblick über die neu gewonnenen Forschungseinsichten. Desweiteren präsentiert dieses Kapitel Ideen und Vorschläge für weitere Forschung. 